Universidade de São Paulo

Instituto de Física de São Carlos

Departamento de Física e Ciência dos Materiais

\title{
ESTUDOS ESPECTROSCÓPICOS DE MECANISMOS DE SORÇÃO E REAÇÃO DO HERBICIDA 2,4-D COM SUBSTÂNCIAS HÚMICAS
}

Maria Suzana Prataviera Francisco

Dissertação apresentada ao Instituto de Física de São Carlos, da Universidade de São Paulo, para obtenção do título de Mestre em Ciências: Física aplicada

Orientador: Dr. Ladislau Martin Neto

USP / IFOSC / SBI

8-2-001135

São Carlos

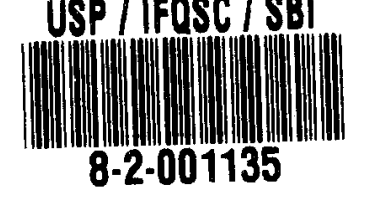

1996 
Francisco, Maria Suzana Prataviera

Estudos Espectroscópicos de mecanismos de sorção e reação

do herbicida 2,4-D com substâncias húmicas - São Carlos, 1996. $118 \mathrm{p}$.

Dissertação (Mestrado) - Instituto de Física de São Carlos, 1996.

Orientador: Ladislau Martin Neto

1. Espectroscopia. 2.Ácido húmico e herbicida.

I. Título. 


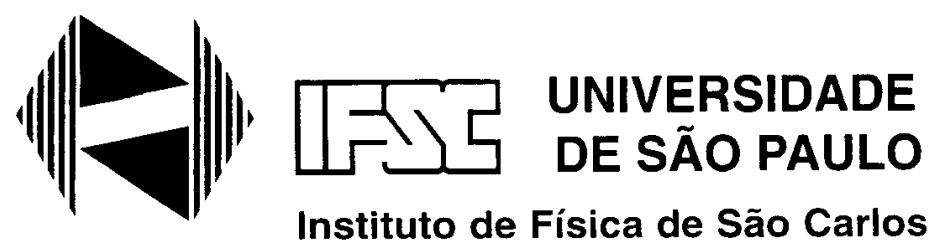

Av. Dr. Carlos Botelho, 1465 CEP 13560-250 - São Carlos - SP Brasil

Fone (016) 272-6222

Fax (016) 272-2218

MEMBROS DA COMISSÃO JULGADORA DA DISSERTAÇÃO DE MESTRADO DE MARIA SUZANA PRATAVIERA FRANCISCO APRESENTADA AO INSTITUTO DE FÍSICA DE SÃO CARLOS, DA UNIVERSIDADE DE SÃO PAULO, EM O6 DE DEZEMBRO DE 1996.

COMISSÃO JULGADORA:

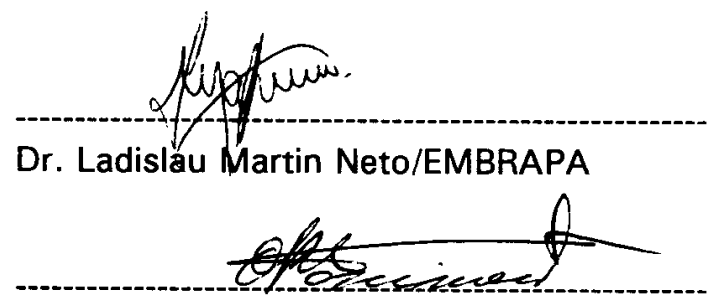

Prof. Dr. Otaciro Rangel Nascimento/IFSC-USP

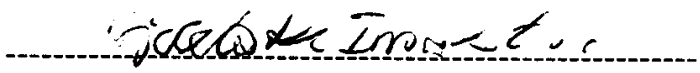

Prof.Dr. Hidetake Imasato/IQSC-USP 


\section{Dedica,}

Adilson e $\mathbb{T H}^{n}$ Eunice, a base fundamental Cláudia gosé, Me Sélvia e Me Simone, a fraternidade

Marininha, Claudinho e Rafael, a alegria 
Ao Ladislau pela idéia do projeto, pela confiança na execução, pela paciência e amizade nos meus momentos de dificuldade no dia a dia 2 ?

Ao pessoal da Embrapa/CNPDIA : Renê, Ferrazini, Valentin, Alessandra, Rubens, Marcelo, Fátima, Ricardo, Sérgio, etc. Em especial ao Dinis pelas idéias trocadas e dúvidas sanadas!

Aos amigos que ainda estão ou passaram ${ }^{\star}$ pela fisica e/ou pela USP Henrique (o amigão), Nalva (a amigona), Regina Célia (a faladeira), Cezinha, Regininha, Marcinho (o bom), Cristiane (a chorona), Maria do Rosário (a molenga), Lígia, Sergião (o vizinho), Roberto, ${ }^{\star}$ Marcinha (a japonezinha), Hosana (a maezona), Cibele e Andréa (as ex-desencanadas), Paola, Lara, Emerson (o Missão), Cátia (a Katian), e ao Ricardo Fujiwara, pela amizade, apoio e incentivo que sempre me transmitiu.

Ao pessoal do laboratório de Biofisica/USP pelo equipamento que lá utilizei,e em especial a Belzinha e ao Beto (o japinha).

Ao laboratório de Radioquímica e Química Ambiental do IQSC-USP pelas amostras de ácido húmico.

A Benê e ao Samuel pelos "scaners".

Ao meu querido gayme pelas horas de lazer

Aos meus pais queridos, Adilson e $\mathbb{E}$ Eunice "É tão imenso o amor $\boldsymbol{\nabla}$ que tenho por vocês, que não poderia descrever, é muita dedicação, confiança e carinho que vocês têm por mim, valeu!".

A minha irmã $\mathfrak{T}^{e}$ Silluia $8 \% 080$, pelas poucas conversas, mas marcantes, que temos desde tempos atrás até agora!

Ao CNPq e a Embrapa pelo respaudo financeiro. 


\section{indice}

Sista de Zigura

Sista de 7abelas

Sista de Abreviacões

Resume

Alstract viii

Capitula 1. Intraducãa

Capitula $\underline{2}$ - Substancias Hámicas da Solo $\underline{e}$ Ferbicida

2.1 O Solo

2.1.1 Substâncias Húmicas

2.1.2 A Importância do Húmus ao Meio Ambiente 11

2.1.3 Substâncias Húmicas e Espectroscopia 12

2.1.4 Os Tipos de Solos Utilizados nesse Projeto 13

- Turfa 13

- Podzólico Vermelho-Amarelo $\quad 14$

2.2 Os Herbicidas

2.2.1 Os Herbicidas - Mecanismos de Degradação dos

$\begin{array}{ll}\text { Herbicidas } & 15\end{array}$

$\Rightarrow$ Transformações abióticas e bióticas $\quad 18$

$\Leftrightarrow$ Fotodegradação $\quad 19$

$\Rightarrow$ Adsorção

2.2.2 Classificação dos Herbicidas 
$\Rightarrow$ Época de aplicação $\quad 23$

$\Rightarrow$ Seletividade $\quad 23$

$\Rightarrow$ Modo de ação

$\Rightarrow$ Grupo químico $\quad 24$

2.2.3 O Herbicida 2,4-D 24

\section{Capitala 3. Parte Teárica}

3.2 Espectroscopia por Ressonância Paramagnética Eletrônica (EPR)

3.2.1 O Fenômeno de Ressonância 33

3.2.2 O Estado das Populações de Spin 38

3.2.3 Relaxação Spin-Rede e Saturação 40

3.2.4 Interação Spin-Órbita

3.2.5 Interação Hiperfina 41

3.2.6 Interações Dipolar (ou Anisotrópica) $e$ de Contato (ou deFermi, ou Isotrópica) 43

3.2.7 Efeito do Campo Cristalino 44

3.2.8 Interação de Intercâmbio (ou de Troca) 49

3.2.9 Anisotropia dos Espectros de EPR 49

3.2.9.a Espectros em Amostras em Solução $\quad 50$

3.2.9.b Espectros de Amostras em Estado Sólido 51

3.2.10 Método do Padrão Secundário para

Deteç̧ão do Radical Livre Semiquinona 53

3.3 Espectroscopia de Absorção Eletrônica -

UV-Visivel

3.3.1 Introdução 
3.3.3 Força do Oscilador 56

3.3.4 As Bandas do Ácido Húmico e do Herbicida 2,4-D

3.4 Espectroscopia no Infravermelho por Transformada de

Fourier - (do inglês, Fourier Transform Infrared - FTIR)

3.4.1 Princípios da Espectroscopia de Infravermelho

3.4.3 O Interferômetro de Michelson

60

3.4.4 As Bandas do Ácido Húmico e do Herbicida 2,4-D

62

\section{Capítula 4. Materiais e Métodos}

4.1. Extração e Fracionamento do Ácido Húmico

4.2 .Preparação de Amostras 66

$\Leftrightarrow$ Preparação das amostras contendo herbicida

$\Leftrightarrow \quad$ Preparação das amostras de reação entre 2,4-D e ácido húmico

$\Rightarrow$ Preparação de amostras de reação entre 2,4-D e íons metálicos

\subsection{Análises Espectroscópicas}

4.3.1 Medidas de Absorção de Luz UV-Visível

$\Leftrightarrow$ Amostras contendo herbicida mais ácido húmico

$\Leftrightarrow$ Amostras contendo herbicida mais íons metais

\subsubsection{Ressonância Paramagnética Eletrônica - RPE}

$\Leftrightarrow$ Amostras contendo herbicida mais ácido húmico

$\Leftrightarrow$ Amostras contendo herbicida mais íons metais

4.3.3.Infravermelho com Transformada de Fourier - FTIR 72 4.4 Experiências de Fotodegradação

$\Rightarrow$ Amostra aquosa de 2,4-D(1mM)

$\Rightarrow \quad$ Amostras $\mathrm{AH}$ e $\mathrm{AH}+2,4-\mathrm{D}(1 \mathrm{mM})$ 


\section{Capitula 5. Resultados e Discussãa}

\subsection{Aduto 2,4-D-Ácido Húmico}

\subsubsection{Resultados}

5.1.1.a Espectros de Absorção Eletrônica $\quad 74$

5.1.1.b Espectros de EPR 81

5.1.1.c Espectros de FTIR $\quad 88$

\subsubsection{Discussões}

$\Rightarrow$ Espectros de Absorção Eletrônica $\quad 96$

$\begin{array}{ll}\Rightarrow \text { Espectros de EPR } & 97\end{array}$

$\leadsto$ Espectros de FTIR 99

5.2 Complexação 2,4-D com Cu(II)

5.2.1 Resultados

5.2.2 Discussão

5.3 Fotodegradação do 2,4-D

5.3.1 Resultados

\subsubsection{Discussão}

$$
\begin{aligned}
& \Rightarrow \text { Amostra aquosa de 2,4-D(1mM) } \\
& \Rightarrow \text { Amostras } \mathrm{AH} \text { e } \mathrm{AH}+2,4-\mathrm{D}(1 \mathrm{mM})
\end{aligned}
$$

\section{Cakitula 6 - Conclusöes}

6.1 Aduto 2,4-D-Ácido Húmico

6.2 Complexação 2,4-D+Íons Metais

6.3 Fotodegradação do 2,4-D 


\section{Sista de Ziguras}

Figura 2.1: Redução da quinona a semiquinona

Figura 2.2: Estrutura proposta para o ácido húmico

Figura 2.3: A teoria polifenol da origem das substâncias húmicas

Figura 2.4: Os tipos de solo do Estado de São

Figura 2.5: Consumo e uso de água no Brasil

Figura 2.6: Destino de defensivos agrícolas no Brasil em 1991

Figura 2.7: Processos de transferência e de degradação no meio ambiente

Figura 2.8: Ligação de hidrogênio entre substância húmica e s-triazina

Figura 2.9: Formação do complexo transferência-carga entre s-triazina

Figura 2.10: Mecanismo troca de ligante de adsorção da s-triasina

Figura 2.11: Ligação covalente entre a substância húmica e cloroanilina

Figura 2.12: Estrutura química do 2,4-D nas formas: (a) molecular

Figura 2.13: Acoplamento do 2,4-diclorofenol pela enzima lacase e

Figura 2.14: Ligação de hidrogênio entre substância húmica

Figura 2.15: Formação de um radical intermediário entre 2,4-D 
Figura 3.1: Transição envolvida em uma absorção

Figura 3.2: Espectro eletromagnético (Knowles, 1976)

Figura 3.3: Partícula de momento angular de spin igual a $|\vec{S}|=\frac{\sqrt{3} \hbar}{2}$

Figura 3.4: Condição básica para ressonância eletrônica, $h v=g \beta H$

Figura 3.5: (a) Desdobramento dos níveis de energia do spin eletrônico na

Figura 3.6: Desenho da $1^{\underline{a}}$ derivada produzido pelo campo de modulação

Figura 3.7: Esquema dos níveis de energia de um sistema $S=I=1 / 2$

Figura 3.8: Distribuição angular da densidade eletrônica das cinco funções

Figura 3.9: (a) Íon coordenado octaédricamente pelos ligantes, (b) Íon

Figura 3.10: (a) Distorções da simetria

Figura 3.11: Configurações de spin baixo e spin alto para a coordenação

Figura 3.12: Espectro de um complexo de cobre em solução a temperatura

Figura 3.13: Vaiação angular do valor de g com o campo magnético

Figura 3.14: Espectro de EPR de amostra policristalina de uma

Figura 3.15: Transição eletrônica

Figura 3.16: Espectro de absorção eletrônica de solução aquosa 
Figura 3.17: Diagrama da energia potencial de um oscilador diatômico

Figura 3.18: Esquema de um interferômetro de

Figura 3.18: Esquema de um interferômetro de Michelson

Figura 4.1: Estrutura química do 2,4-D nas formas (a) molecular

Figura 4.2: Massa de 2,4-D adsorvida pela Turfa em função de $t^{1 /}$

Figura 4.3: Curva de calibração da solução de 2,4-D

Figura 4.4: Curva de saturação do sinal do "strong pitch"

Figura 4.5: Curvas de saturação do sinal do radical livre semiquinona

Figura 5.1: Espectros de absorção eletrônica das soluções AH+2,4-D(1mM)

Figura 5.2: Espectros de absorção eletrônica das soluções $\mathrm{AH}+2,4-\mathrm{D}(1 \mathrm{mM})$

Figura 5.3: Os espectros de absorção eletrônica do herbicida 2,4-D obtidos a partir

Figura 5.4: Espectro de EPR do radical livre semiquinona do solo podzólico

Figura 5.5: Espectros de EPR do radical livre semiquinona do ácido húmico

Figura 5.6: Espectro de EPR do radical livre semiquinona da turfeira

Figura 5.7: Espectro de EPR a temperatura de nitrogênio líquido das seguintes

Figura 5.8: Espectro de FTIR de amostras do 2,4-D(1 mM) liofilizadas 
Figura 5.9: Espectros de FTIR de amostras liofilizadas contendo ácido húmico

Figura 5.10: Espectros de FTIR de amostras liofilizadas contendo ácido húmico

Figura 5.11: Espectros de FTIR do precipitado das seguintes amostras

Figura 5.12: Ligação de hidrogênio entre substância húmica e ácido

Figura 5.13: Espectro de EPR das soluções aquosas: (a) $\mathrm{CuSO}_{4} \mathrm{pH}=2,04 \mathrm{e}$

Figura 5.14: Subtração dos espectros $\mathrm{CuSO}_{4}+2,4-\mathrm{D}$ e $\mathrm{CuSO}_{4}$, com valores de

Figura 5.15: Espectro de absorção eletrônico do 2,4-D em solução aquosa para

Figura 5.16: Espectros de absorção eletrônico do 2,4-D em solução contendo 


\section{Sista de Tabelas}

Tabela 2.1: Impactos causados ao meio ambiente e a eficácia do herbicida devido a

Tabela 2.2: Processos de transferência e de degradação de herbicidas no meio ambiente

Tabela 3.1: As bandas na região do infravermelho do ácido húmico de uma turfeira

Tabela 3.2: As bandas na região do infravermelho do herbicida 2,4-D

Tabela 4.1: Análise elemenar e dos grupos funcionais dos ácidos húmico

Tabela 5.1: Intensidades da banda de absorção em $228 \mathrm{~nm}$ do herbicida 2,4-D $\left(\mathrm{A}_{228}\right)$

Tabela 5.2: Intensidades da banda de absorção em $228 \mathrm{~nm}$ do herbicida $2,4-\mathrm{D}\left(\mathrm{A}_{228}\right)$

Tabela 5.3: Intensidades da banda de absorção em 228nm do herbicida 2,4-D, obtidas

Tabela 5.4 Massa(mg) e número de moléculas de 2,4-D sorvidas pelo ácido húmico

Tabela 5.5: Média da densidade de radicais livres semiquinona $\left(\mathrm{N}_{0}\right)$, do ácido húmico

Tabela 5.6: Média da densidade de radicais livres semiquinona $\left(\mathrm{N}_{0}\right)$, do ácido húmico

Tabela 5.7: Média da densidade de radicais livres semiquinona $\left(\mathrm{N}_{\text {0prec. }}\right)$ do ácido húmico 
M.O. - Matéria Orgânica

CTC - Capacidade de Troca de Cátions

EPR - Ressonância Paramagnética Eletrônica

FTIR - do inglês: "Fourier Transform Infrared", espectroscopia no infravermelho aplicando-se transformada de Fourier 


\section{Resume}

As técnicas de absorção eletrônica no uv-visivel, ressonância paramagnética eletrônica (do inglês EPR) e infravermelho com transformada de Fourier (do inglês FTIR) foram as empregadas neste trabalho para estudar a interação do herbicida 2,4-D (ácido 2,4- diclorofenoxiacético) com ácidos húmicos provenientes de dois solos: podzólico vermelho-amarelo e de uma turfeira. Após quatro dias de reação, não foi observada alterações nos espectros de absorção eletrônica do herbicida devido a presença do ácido húmico, indicando não ter ocorrido degradação do herbicida. Com essa técnica também foi quantificada a sorção do herbicida pelo ácido húmico da turfeira, em função dos valores de $\mathrm{pH}$. Utilizando amostras liofilizadas e através de medidas de EPR, a densidade do radical livre semiquinona foi quantificada (spins/g), e não identificou-se alteração no aduto ácido húmico-2,4-D. Contrariando dados existentes na literatura internacional, segundo a qual a interação do 2,4-D com o ácido húmico ocorre via ligação covalente, com redução no nível de semiquinona. As bandas de infravermelho do aduto ácido húmico2,4-D não mostraram evidências significativas de alterações. Esse resultado é relevante pois indica que somente mecanismos de baixa energia estão envolvidos na interação do 2,4-D com os ácidos húmicos extraídos de solos brasileiros, o que sugere possibilidade de dessorção e translocação do herbicida no solo com potencial de contaminação de águas de lençol freático e suas fontes.

Foram feitos estudos da possível formação do complexo 2,4-D mais $\mathrm{Cu}(\mathrm{II})$, através da técnica de EPR. Em $\mathrm{pH}=2$, não ocorre a formação de complexo com o 2,4-D, sendo a coordenação octaédrica com simetria axial com a água a preferencial, uma vez que os grupos carboxílicos do herbicida estão protonados (pKa $=2,6$ ). Em valor de $\mathrm{pH}$ igual a 3,5 e 5,1 a coordenação com o 2,4-D é observada, gerando um complexo de simetria rômbica.

A fotodegradação com luz ultravioleta do herbicida foi observada, utilizando a técnica de absorção eletrônica, em solução aquosa, demonstrando a fotólise direta do 2,4-D. O acréscimo de ácido húmico (da turfeira) na concentração de $600 \mathrm{mg} / \mathrm{l}$ não teve o efeito fotossintetizante esperado. O material húmico agiu como um inibidor da fotodegradação do herbicida. 


\section{Alestract}

The interaction of the herbicide 2,4-D (2,4- diclorofenoxyacetic acid) with humic acids was studied by three spectroscopics methods: absorption electronic in ultraviolet-visible (Uv-vis), electron paramagnetic resonance (EPR) and Fourier transform infrared (FTIR). Humic acids used were extracted from two types of soils: podsol and peat. After four days of reaction, no change were observed in the Uv-vis spectra of the herbicide due the presence of the humic acid, in differents $\mathrm{pHs}$, indicating that the herbicide did not degradate. The herbicide sorption was quantified to peat humic acid as a function of the $\mathrm{pH}$ value using the Uv-vis spectroscopy. The EPR spectra of freeze-dried were used to determine the density of semiquinone free radicals and no change was observed in the humic acid-2,4-D sample. This results is in disagreement with literature data which showed that the 2,4-D and some humic acid interacted by covalent bond, with reduction of the semiquinone level. Vibrational bands of the humic acid-2,4-D solution also did not show significant changes. These results were significant because they indicated that only mechanisms of weak energy were involved in the interaction between 2,4-D and these two humic acids from Brazilian soils. This suggest the possibility of desorption and translocation of the herbicide in the soil, with potential contamination to groundwater and supplies.

The interaction between 2,4-D and $\mathrm{Cu}(\mathrm{II})$ was studied by the EPR spectroscopy. It was observed for $\mathrm{pH}=2$ there is no complex formation with 2,4-D, at more probably due to protonation of carboxylic groups of the herbicide $(\mathrm{pka}=2,6$ ). For $\mathrm{pH}$ values of 3,5 and 5,1, the coordination with the 2,4-D is observed, producing a complex with rhombic symmetry.

The herbicide photodegradation under ultraviolet radiation in aqueous solution was studied by uv-visible technique, demonstrating that occurred the direct photolizes of 2,4-D. The addition of peat's humic $(600 \mathrm{mg} / \mathrm{l})$ in aqueous solution did not have the expected photosensitize effect. The humic acid in this concentration acted as an inhibitor to the photodegradation of the herbicide. 


\section{Capitulo 1. Introducãa}

A ampliação de áreas de produção agropecuária, e o emprego de técnicas mais produtivas, como máquinas, tratores, fertilizantes, produtos químicos e sementes melhoradas, foram responsáveis pelo crescimento da produção mundial de grãos. O Brasil, com a revolução agrícola tornou-se um dos primeiros exportadores mundiais de alimentos.

Apesar da previsão da colheita mundial de grãos indicar o crescimento de mais de $15 \%$ até o ano 2000 , haverá cada vez menos comida para cada ser vivo. A produção de grão per capita deve cair $20 \%$ até a virada do século (Atlas do Meio Ambiente, EMBRAPA, 1994). Ou seja, o crescimento demográfico está maior que o avanço da produtividade.

Degradação acelerada dos solos, perda de sua fertilidade natural, contaminação das águas e do ambiente por agrotóxicos e fertilizantes, envenenamento dos alimentos, extinção de animais e plantas silvestres em consequência da destruição dos habitats onde vivem são alguns dos principais efeitos negativos da agricultura moderna.

$O$ fator infestação do solo pelas plantas daninhas, que oferecem concorrência as plantas cultivadas, encontrou uma solução eficaz que vem a ser o uso de herbicidas agindo contra essas plantas. De modo geral, a competição exercida pelas plantas daninhas ocorre principalmente pelos fatores relacionados diretamente com o crescimento da cultura, ou seja, água, luz e nutrientes, e assume grande importância na redução do rendimento econômico de determinada cultura.

O Brasil ocupa a quinta posição entre os países que mais empregam pesticidas, não muito distante dos Estados Unidos, Rússia, França e Japão. Esse papel de destaque do Brasil no consumo de pesticidas no entanto não tem contrapartida na pesquisa e precauções existentes nos demais países.

Em 1989 o Brasil consumiu 151,8 mil toneladas de agrotóxicos formulados (comerciais) (Funtino \& Silveira, 1991). Em 1960 as lavouras agrícolas no Brasil ocupavam uma área de 28,4 milhões ha (IBGE, 1985), e em 1991 uma área de 50,0 milhões ha (IBGE, 1993), o que mostra um aumento de 76,0\% das áreas 
cultivadas, enquanto que o consumo de agrotóxicos neste mesmo período foi de $276,2 \%$.

As regiões Sudeste e Sul do Brasil são responsáveis pelo consumo de $44,4 \%$ e $38,3 \%$, respectivamente, do total de agrotóxicos utilizados no Brasil em 1984. Os estados de São Paulo e Paraná são os que mais consomem, participam com $35,5 \%$ e $20,4 \%$, respectivamente, do total de produto formulado em 1984 , sendo que o estado do Mato Grosso do Sul foi o que menos consumiu, 4,6\%. Conforme a região, a atividade agrícola pode ser intensiva ou tradicional, sendo que esta última não emprega o uso intensivo de agrotóxicos (Spadotto et al, 1996).

O estado de São Paulo e do Paraná utilizaram 6,8 e 4,2 Kg/ha, respectivamente, de agrotóxico formulado, em 1984, sendo a média de consumo neste ano no Brasil de $2,4 \mathrm{Kg} / \mathrm{ha}$.

As culturas de laranja, soja e cana-de-açucar são as que mais consomem agrotóxico, participaram respevtivamente com 17,5\%, 15,6\% e 9,8\% do total de ingrediente-ativo do consumo anual de 1990. Esse alto consumo é devido ao fato dessas culturas ocuparem grandes extensões.

A matéria orgânica do solo tem papel fundamental na interação com pesticidas no solo, sendo para a maioria dos pesticidas apolares é o principal sítio de sorção no solo. Stevenson (1976) considera que a informação da interação matéria orgânica-herbicida, dá uma base mais racional do uso efetivo, reduzindo efeitos indesejáveis como contaminação do ambiente. Contudo um bom entendimento dessas interações é dificil devido a complexidade da matéria orgânica e as outras numerosas interações que ocorrem simultaneamente. Assim, uma alternativa é o uso de sistemas simplificados envolvendo componentes bem definidos da matéria orgânica e que possibilitam elucidar mecanismos de interação. Os méritos de usar esses compostos bem definidos como ácido húmico e ácido fúlvico, são:

$\Rightarrow$ Eles podem realmente ser extraídos da matéria orgânica dos solos em uma forma relativamente pura;

Podem ser caracterizados por várias técnicas;

São os principais constituíntes e os mais comuns da matéria orgânica.

Técnicas espectroscópicas como absorção eletrônica no uv-visível, ressonância paramagnética eletrônica, vibracional no infravermelho, e outras, têm sido 
utilizadas para caracterizar substâncias húmicas e também estudar interações com pesticidas (Martin-Neto et al 1994, Traghetta 1992, Senesi 1992). Assim as técnicas espectroscópicas acima citadas foram utilizadas neste presente projeto na investigação de mecanismos de sorção do herbicida 2,4-D por ácidos húmicos de solos tropicais: de um solo podzólico vermelho-amarelo, representativo de $60 \%$ do solo do Estado de São Paulo, e de uma turfeira, com características bem diferentes as do podzólico para comparação de reatividade com o herbicida.

Alguns experimentos também foram realizados para verificar a possível complexação do 2,4-D com o íon metálico $\mathrm{Cu}(\mathrm{II})$. Ainda realizou-se experiências de fotodegradação em solução aquosa do herbicída na presença e na ausência de ácidos húmicos, em concentração $600 \mathrm{mg} / 1$, para avaliar o seu possível papel catalítico. 


\section{Capitula 2 - Substancias Húmicas da Solo $\underline{e}$ Herbicida}

\subsection{Solo}

O solo pode ser definido como a massa natural que compõe a superficie da Terra, biologicamente ativa, entremeada por estrutura porosa. Este material desde a criação sofre a influência de fenômenos biológicos, climáticos, geológicos e topográficos. "Solos diferem largamente em suas propriedades devido a variabilidade nestes quatro fatores de um lugar para outro e com o passar do tempo. Essa variabilidade, contudo, não impede a eminência de uma característica única que distingue solos de meros materiais geológicos e serve como base para sua taxonomia: uma sistemática, sequência vertical de camadas (conhecidas como horizontes) produzidas pela ação combinada de percolação de águas e organismos vivos" (Sposito \& Reginato, 1992).

Em ecologia, o solo é definido como sendo uma rocha finamente particulada, formado por compostos inorgânicos com diferentes percentagens de substâncias orgânicas, onde plantas encontram apoio e nutrientes para se desenvolverem. A rocha particulada constituí a porção mineral do solo, cuja fragmentação ocorre por ação dos intemperismos físicos, químicos e biológicos. A matéria orgânica é adicionada a porção mineral na forma de húmus, ou seja, vegetais e animais mortos em decomposição.

Os principais minerais que compõe o solo, classificados segundo composição granulométrica, são:

\footnotetext{
$\Leftrightarrow$ Os cascalhos de mais de $2 \mathrm{~mm}$

$\Rightarrow$ As areias grossas de $0,2 \mathrm{~mm}$ a $2 \mathrm{~mm}$

$\Rightarrow$ As areias finas de $20 \mu \mathrm{m}$ a $0,2 \mathrm{~mm}$

$\Leftrightarrow$ Os limos de $2 \mu \mathrm{m}$ a $20 \mu \mathrm{m}$

$\Leftrightarrow$ As argilas (colóides minerais) de menos de $2 \mu \mathrm{m}$
} 
O solo contém aproximadamente $25 \%$ de ar, $25 \%$ de água, $46 \%$ de elementos minerais e $4 \%$ de matéria orgânica (Pinheiro and Monteiro, 1992). A quantidade de materiais orgânicos pode variar tanto entre um tipo de solo e outro, como entre horizontes de um mesmo perfil. Normalmente as maiores quantidades de material orgânico são encontradas nos horizontes mais superficiais. Entremeando os materiais sólidos encontram-se o ar e a água, que ocupam o espaço poroso. Suas proporções, ao contrário dos minerais e matéria orgânica, podem ter grandes variações em espaços de tempo relativamente curto.

Sabe-se que as plantas retiram do solo 13 componentes essenciais a vida. Destes, 6 são absorvidos em quantidades relativamente grandes, designados macronutrientes: nitrogênio, fósforo, potássio, cálcio, magnésio e enxofre. Os outros 7, igualmente essenciais, mas usados em quantidades muito pequenas são denominados micronutrientes: ferro, manganês, zinco, boro, cobre, cloro e molibdênio. Todos os elementos têm que estar presentes no solo nas concentrações e formas adequadas para que possam ser devidamente utilizados pelas plantas. Se qualquer um dos 13 elementos estiver ausente, ou presentes em proporções inadequadas, ele limitará o crescimento das plantas mesmo que os restantes estejam em quantidades adequadas e haja fornecimento apropriado de gás carbônico, oxigênio, água, luz e calor. A idéia de que o crescimento das plantas é controlado pelo nutriente existente em menor quantidade, vem desde os tempos de Justus von Liebig (1840) e é conhecida como 'Lei do Mínimo'.

\subsubsection{Substâncias Húmicas}

A matéria orgânica do solo pode ser convencionalmente classificada em dois principais grupos, substâncias não húmicas e substâncias húmicas. As substâncias não húmicas são formadas por proteínas, aminoácidos, polissacarídeos, ácidos orgânicos de baixo peso molecular, ceras e outros, têm características físicas e químicas definidas e são geralmente atacadas por microorganismos tendo, normalmente, curto tempo de vida nos solos e sedimentos.

As substância húmicas são os maiores constituíntes de solos e sedimentos ocorrendo em praticamente todos os sítios aquáticos e terrestres. Formada 
por resíduos de plantas e animais degradados e de atividades sintéticas de microorganismos e tem longo tempo de permanência no solo, com centenas ou até milhares de anos (Schnitzer \& Khan, 1978).

As substâncias húmicas representam a fração mais ativa da matéria orgânica na maioria dos solos, pode ser descrita melhor como uma série altamente ácida, de cor que vai do amarelo ao preto, massa molecular elevada, polieletrolíticos (polímeros com características de eletrólitos), com alto conteúdo de grupos funcionais contendo oxigênio, incluíndo-se ácido carboxílico, grupos fenólicos, enólicos, e alifáticos de vários tipos. As diferentes frações húmicas (ácido húmico, ácido fúlvico $\mathrm{e}$ humina) representam uma mistura complexa de moléculas distribuídos em um largo intervalo de massas moleculares (abaixo de 1000 até acima de 3000) (Stevenson, 1972).

As substâncias húmicas contêm alta concentração de radicais livres, possivelmente do tipo semiquinona, produto da redução de quinonas (figura 2.1). Fisiologicamente, o radical livre pode afetar a germinação de sementes e raízes, e o crescimento das plantas em geral. Além de mediar associações entre as substâncias húmica e enzima e a atividade enzimática residual em substâncias húmicas. Os radicais livres são muito estáveis e são relacionados com reações de polimerizaçãodespolimerização, grau de humificação da matéria orgânica e podem interagir com pesticidas e poluentes orgânicos (Schnitzer \& Khan, 1978).

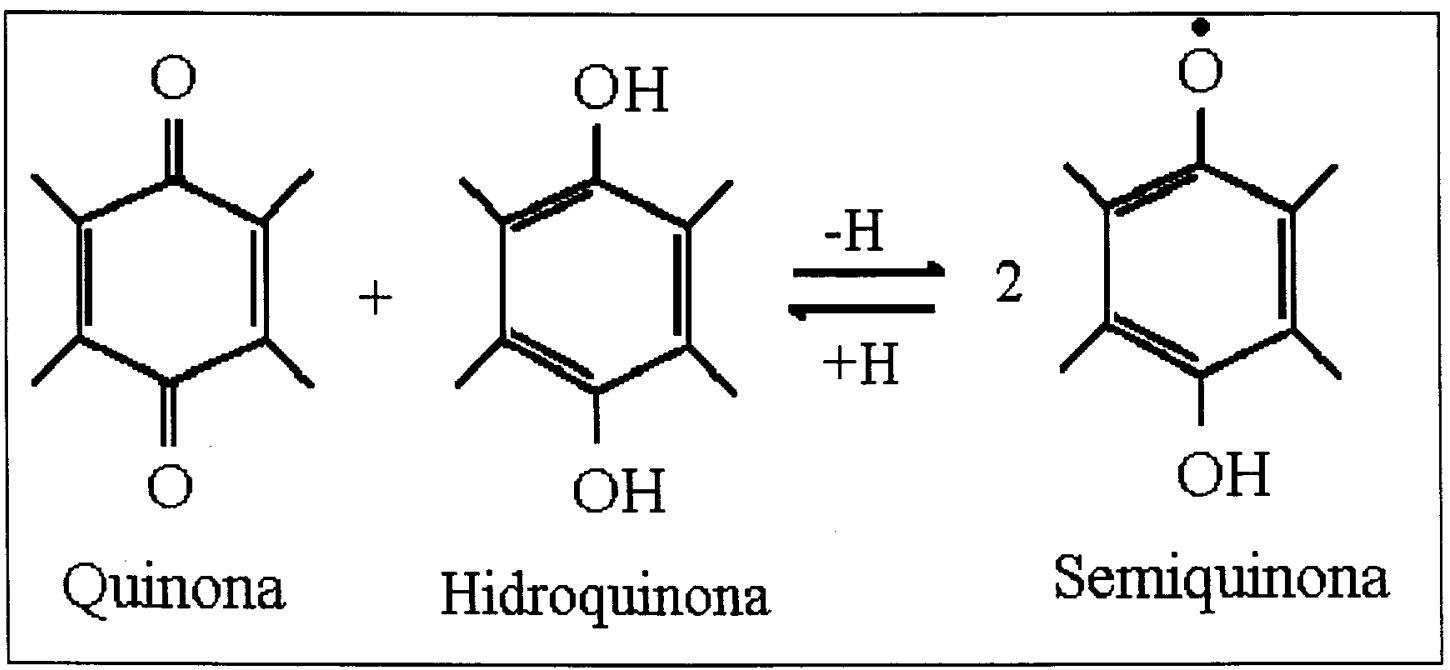

Figura 2.1: Redução da quinona a semiquinona 
Os fatores mais decisivos na formação das substâncias húmicas são (Primavesi, 1990):

\footnotetext{
$\Rightarrow$ A vegetação de cujos restos se forma;

$\Rightarrow$ o clima reinante;

$\Rightarrow$ Quantidade de mineral no solo;

$\Rightarrow \mathrm{O}$ pH do solo;

$\Rightarrow$ Os microorganimos ativos na decomposição;

$\Rightarrow$ O manejo do solo pelo homem
}

As substâncias húmicas são usualmente fracionadas, com base na sua solubilidade, em três grupos principais. As frações obtidas incluem:

$\Rightarrow$ Ácido húmico: definido como o material que é extraído do solo por solução alcalina e que é precipitado sob acidificação;

$\Rightarrow$ Ácido fúlvico: material húmico remanescente em solução quando o extrato alcalino é acidificado (solúvel em ácido e em alcali);

$\Rightarrow$ Humina: fração húmica insolúvel em extratos alcalinos e ácidos.

A estrutura química das substâncias húmicas têm sido objeto de estudos a mais de 200 anos. Apesar da abundância de dados experimentais na literatura, cientistas do solo e do meio ambiente não dispõe de uma concepção definida da estrutura química desses materiais.

Os dados obtidos por Schulten et al (1991), indicam que muito da estrutura da rede das substâncias húmicas consiste de anéis aromáticos os quais estão unidos por longas cadeias de estruturas alquil para formar uma rede flexível.

Schulten (1995) propôs a estrutura tridimensional (3-D) das substâncias húmicas e estudou a matéria orgânica do solo utilizando métodos computacionais. A construção do modelo 3-D da estrutura do ácido húmico 2-D, mostrada na figura 2.2, possui precisão quanto a distância e ângulos das ligações, ângulos de torsão, forças de van der Waals e pontes de hidrogênio. É destacada a importância das cadeias alifáticas como elos de ligação entre os sítios aromáticos e a formação de lacunas. A correspondente composição do monômero do ácido húmico é 
$\mathrm{C}_{308} \mathrm{H}_{335} \mathrm{O}_{90} \mathrm{~N}_{5}$ com uma massa molecular 5547,004g.mol ${ }^{-1}$ e uma composição elementar de $66.69 \% \mathrm{C}, 6.09 \% \mathrm{H}, 25.96 \%$ O e $1,26 \% \mathrm{~N}$. As características elementares do ácido húmico variam conforme interações com carboidratos e proteínas. Tem sido proposto que carboidratos representanta de $10 \%$ do peso do ácido húmico, assim como as proteínas.

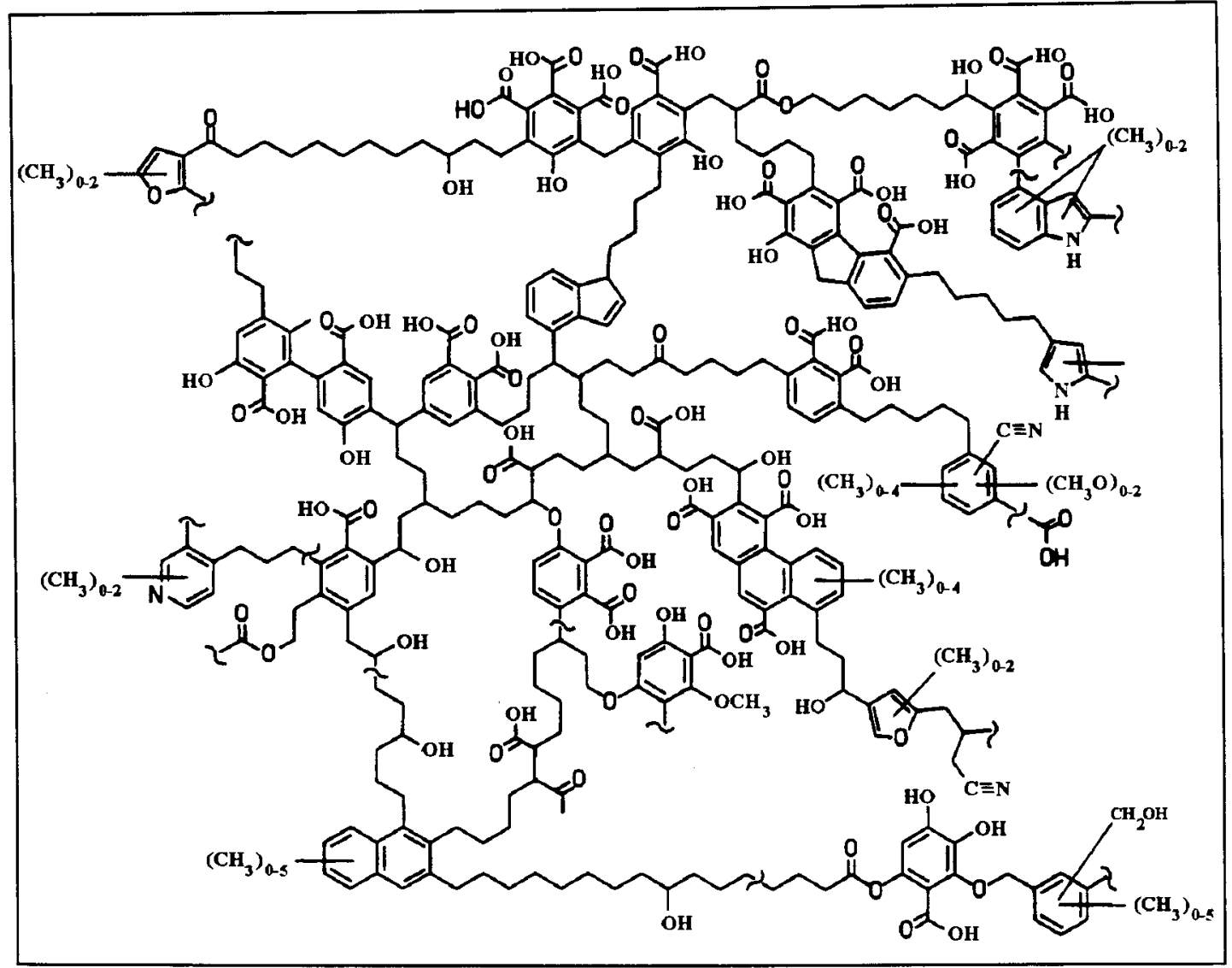

Figura 2.2: Estrutura proposta para o ácido húmico (Schulten, 1995)

De acordo com Andreux et al (1990), a principal característica das substâncias húmicas é a elevada massa molecular de estruturas poliméricas originárias principalmente de precursores polifenólicos. Estes precursores são originários da degradação de lignina, pigmentos celulares liberados a partir da decomposição de plantas, e biosíntese microbiana, os quais são oxidados em semiquinonas e quinonas, que polimerizam, ou sozinhos, ou incorporam-se a compostos aminos para formar polímeros do tipo húmico, como mostrado na figura 2.3 . 
$\mathrm{C}_{308} \mathrm{H}_{335} \mathrm{O}_{90} \mathrm{~N}_{5}$ com uma massa molecular 5547,004g.mol ${ }^{-1}$ e uma composição elementar de $66.69 \% \mathrm{C}, 6.09 \% \mathrm{H}, 25.96 \%$ O e $1,26 \% \mathrm{~N}$. As características elementares do ácido húmico variam conforme interações com carboidratos e proteínas. Tem sido proposto que carboidratos representanta de $10 \%$ do peso do ácido húmico, assim como as proteínas.

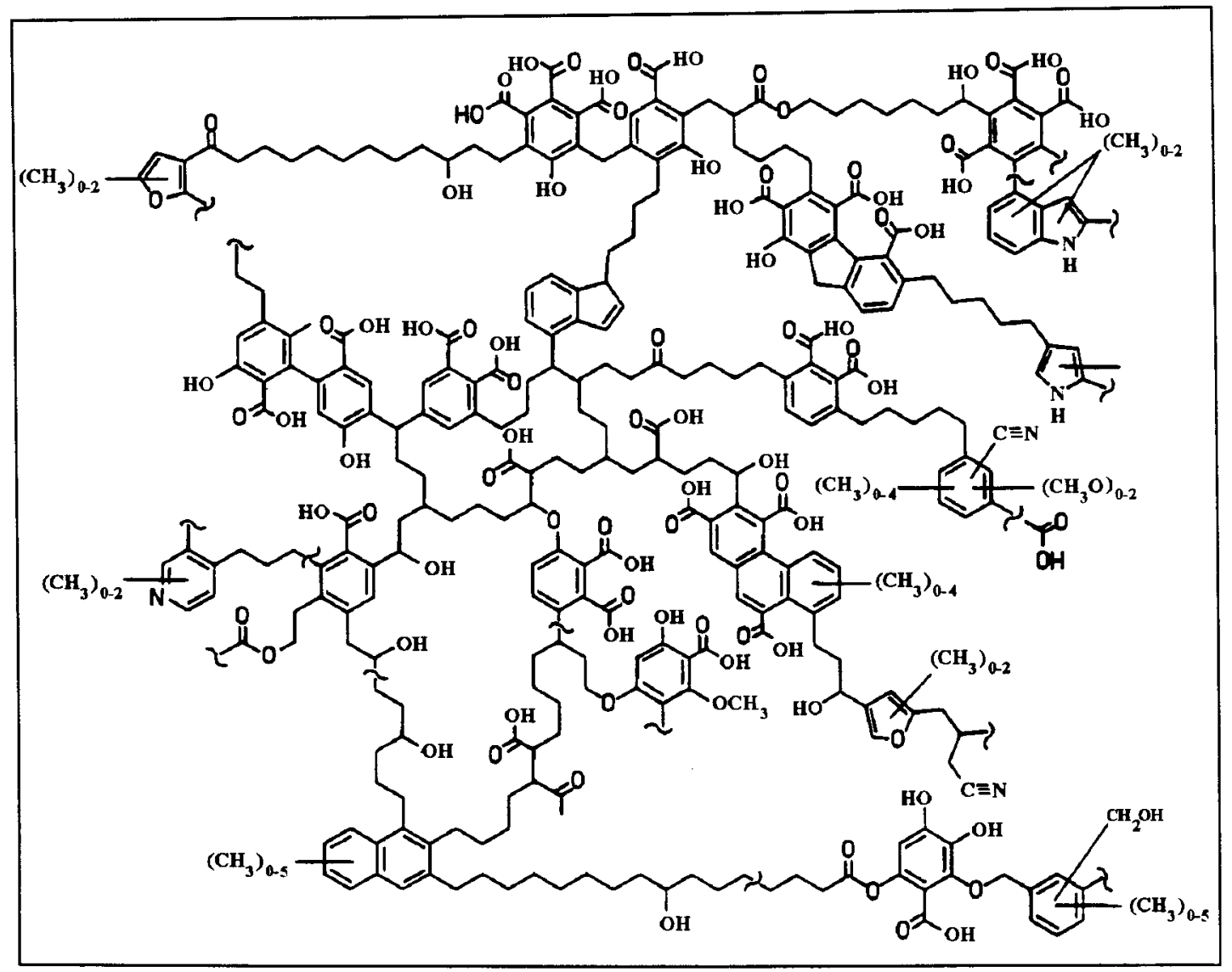

Figura 2.2: Estrutura proposta para o ácido húmico (Schulten, 1995)

De acordo com Andreux et al (1990), a principal característica das substâncias húmicas é a elevada massa molecular de estruturas poliméricas originárias principalmente de precursores polifenólicos. Estes precursores são originários da degradação de lignina, pigmentos celulares liberados a partir da decomposição de plantas, e biosíntese microbiana, os quais são oxidados em semiquinonas e quinonas, que polimerizam, ou sozinhos, ou incorporam-se a compostos aminos para formar polímeros do tipo húmico, como mostrado na figura 2.3 . 
ambiente onde são oxidados e polimerizados a substâncias húmicas. A natureza das plantas originárias não tem efeito sobre o tipo de substância húmica que é formada;

c) Autólises de células: substâncias húmicas são produzidas das autólises (auto-digestão) de células de plantas e de microrganismos depois de suas mortes. O resultado da fragmentação celular (açucar, aminoácidos, fenóis, e outros compostos aromáticos) condensa e polimeriza via radicais livres;

d) Síntese microbiana: microrganismos utilizam tecidos de plantas como fontes de carbono e energia para sintetizar intracelularmente material húmico de elevada massa molecular. Depois que os microrganismos morrem, estas substâncias são liberadas no solo. Então, as substâncias de elevada massa molecular representam os primeiros estágios de humificação, seguidos pela degradação microbiana extracelular a ácido húmico, ácido fúlvico e por último a $\mathrm{CO}_{2} \mathrm{e}_{2} \mathrm{O}$.

Todas as quatro hipóteses sugerem a formação inicialmente de um material húmico mais complexo e de alto peso molecular e que são então degradados, mais provavelmente oxidativamente, em moléculas de menor massa molecular. Então a sequência dos eventos parece ser ácido húmico $\Rightarrow$ ácido fúlvico. Possivelmente as huminas são similares aos ácidos húmicos, exceto que aparecem fortemente queladas a metais e ligadas a argilas, tornando-se insolúveis e bastante estáveis (Schulten \& Schnitzer, 1995).

Tanto o ácido húmico quanto o fúlvico possuem a mesma estrutura básica e os mesmos grupos funcionais. As análises elementar e funcional de ácido húmico e de ácido fúlvico de muitos solos mostra as seguintes diferenças entre os dois materiais:

a) Ácidos húmicos têm maior massa molecular do que os ácidos fúlvicos;

b) Ácidos húmicos contêm mais átomos de $\mathrm{C}$ mas menos átomos de $\mathrm{O}$ do que ácidos fúlvicos;

c) Ácidos húmicos contêm mais átomos de $\mathrm{H}, \mathrm{N}$ e $\mathrm{S}$ do que ácidos fúlvicos; 
d) A acidez total do ácido fúlvico (no intervalo de 890 a $1400 \mathrm{meq} / 100 \mathrm{~g}$ ) é mais alta do que em ácido húmico (no intervalo de 485 a $870 \mathrm{meq} / 100 \mathrm{~g}$ ), assim como o conteúdo de $\mathrm{CO}_{2} \mathrm{H}$;

e) Devido as propriedades a) e d), os ácidos fúlvicos são mais solúveis do que os ácidos húmicos;

f) Ácidos fúlvicos são mais ricos em grupos fenólicos e etanóicos que os ácidos húmicos, mas menor conteúdo de grupos quinóide.

Segundo Takamatsu \& Yoshida (1978), existem dois intervalos de pKa para as substâncias húmicas:

$$
\begin{gathered}
\mathrm{pKa}_{1}=4,63-5,10 \Rightarrow \text { atribuído ao grupo titulável } \mathrm{COOH} \\
\mathrm{pKa}_{2}=8.80-9.50 \Leftrightarrow \text { atribuído ao grupo fenólico- } \mathrm{OH}
\end{gathered}
$$

Segundo Stevenson (1972) tanto o grupo $\mathrm{COOH}$ quanto o grupo ácido $\mathrm{OH}$-fenólico contribuem para a natureza ácida dessas substâncias húmicas.

\subsubsection{A Importância do Húmus ao Meio Ambiente}

Neste ítem é citada a importância e o papel da substância húmica ao meio ambiente, em especial a agricultura (Russel et al, 1973,Cordeiro, 1987):

$\Rightarrow$ A coloração escura do húmus contribui para a retenção de calor no solo, o que influi na germinação de sementes e no desenvolvimento de raízes;

$\Rightarrow$ Devido a sua alta capacidade de retenção de água (até 20 vezes do seu peso), o húmus é importante na conservação do solo contra erosão, pois facilita a infiltração no solo e evita escoamento superficial;

$\Rightarrow$ A combinação com argila forma um complexo argilo-orgânico que cimenta as partículas do solo em agregados, o que permite aeração do mesmo, e aumenta sua permeabilidade;

$\Rightarrow$ Formam complexos estáveis e solúveis com vários cátions (Fe, $\mathrm{Cu}, \mathrm{Mn}, \mathrm{Zn}$, Mo e outros), a esse fenômeno dá-se o nome de adsorção iônica, o que permite a migração dos mesmos e os torna biodisponíveis, pois a retenção é temporária e sem qualquer reação química, trata-se de atração eletrostática (Baize, 1993). Essa capacidade troca de cátions (CTC) varia, em geral, de 300 a 
$1400 \mathrm{meq} / 100 \mathrm{~g}$ de húmus $\left(1 \mathrm{meq} / 100 \mathrm{~g}=1 \mathrm{mmol}^{+} / 100 \mathrm{~g}\right.$ ), o que representa de 20 a $70 \%$ da CTC do solo;

$\Leftrightarrow$ Pode combinar-se com metais tóxicos, como o chumbo $(\mathrm{Pb})$ e 0 alumínio (Al), diminuindo a concentração do metal livre e assim reduzindo a toxidez. Ao mesmo tempo pode ser um fator de contaminação de solos e águas naturais, uma vez que aumenta o tempo de permanência desses metais;

$\Leftrightarrow$ Capacidade de tamponação, isto é, resistência a mudança do $\mathrm{pH}$ que ocorre pela fixação de $\mathrm{H}^{+}$ou $\mathrm{OH}^{-}$pela substância húmica, que contribui para manter constante o $\mathrm{pH}$ do solo;

As substâncias húmicas combinam com moléculas orgânicas, o que pode afetar a bioatividade e biodegradabilidade de pesticidas.

\subsubsection{Substâncias Húmicas e Espectroscopia}

Uma das principais informações a respeito das substâncias húmicas é a medida do grau de humificação, e a identificação de um parâmetro que caracterize esse estágio de humificação é importante e tem sido objeto de muitos estudos. Um dos poucos parâmetros que reflete essa propriedade intrínseca das substâncias húmicas é o nível de radicais livres semiquinona (Riffaldi \& Schnitzer, 1972, Martin Neto et al, 1991). A técnica utilizada para detectar e quantificar os radicais livres semiquinona, e consequentemente o grau de humificação das substâncias húmicas, é a ressonância paramagnética eletrônica (EPR).

Outro parâmetro para medida do grau de humificação das substâncias é a razão $E_{4} / E_{6}$ (razão das absorbâncias em $465 \mathrm{~nm}$ e $665 \mathrm{~nm}$ ), obtido através da técnica de absorção eletrônica (Schnitzer \& Khan, 1978).

As análises no infravermelho têm sido tradicionalmente usadas para identificar grupos funcionais em substâncias húmicas, como ácidos carboxílicos, aminas, hidróxidos, polissacarídeos, grupos alifáticos e outros (Martin Neto et al, 1994, Senesi, 1992). As alterações associadas com os sinais originados por esses grupos podem indicar processos de oxidação e mineralização dos compostos húmicos. 


\subsubsection{Os Tipos de Solos Utilizados nesse Projeto}

Os ácidos húmicos utilizados nesse projeto foram extraídos de dois tipos de solo, de um podsólico vermelho-amarelo e de uma turfeira, algumas de suas características são citadas a seguir.

\section{- $\underline{\text { Turfa }}$}

A turfa é um sedimento orgânico, resultante do acúmulo de matéria orgânica em ambiente desfavorável a mineralização (Ranzani, 1969).

A turfa pode ser caracterizada como carvão geologicamente recente, formado nos últimos 10.000 anos. É uma mistura heterogênea de materiais orgânicos parcialmente decompostos (material lenhoso, arbustos, líquens, musgos) e materiais inorgânicos acumulados em ambientes saturados de água. Apresenta cor variando do amarelo ao preto, dependendo do grau de deterioração biológica e desintegração mecânica das fibras. A medida da CTC é um bom indicador do grau de decomposição.

Os diferentes tipos de turfa são distinguidos pela composição botânica, pela origem da água, ou o estado de decomposição das plantas originárias

$\mathrm{O}$ ambiente saturado de água inibe a decomposição biológica ativa de materiais vegetais e promove a retenção de carbono que normalmente seria liberado na forma de produtos gasosos decorrentes de atividades biológicas.

A turfa contém aproximadamente $90 \%$ de água, $40-50 \%$ de átomo de C, $25-35 \%$ de átomo de $0,12-20 \%$ de minerais, $3-5 \%$ de átomo hidrogênio e $2-4 \%$ de átomo de nitrogênio.

\section{- Podzólico Vermelho-Amarelo}

Entre os vários grupos de solos podzólicos, o mais comum no Brasil é o podzólico vermelho-amarelo. Da ordem dos solos zonais, os quais ocorrem em áreas relativamente grandes, limitadas por atributos geográficos. Exibem características bem desenvolvidas que refletem a ação dos fatores ativos de gênese: clima e organismos vivos. E da subordem de solos de florestas das regiões quentetemperadas e tropicais. 
O solo podzólico vermelho-amarelo é representativo de $60 \%$ do solo do Estado de São Paulo. A figura 2.4 é de um mapa mostrando os diferentes tipos de solo no Estado de São Paulo. Esse grupo frequentemente aparece associado a outros.

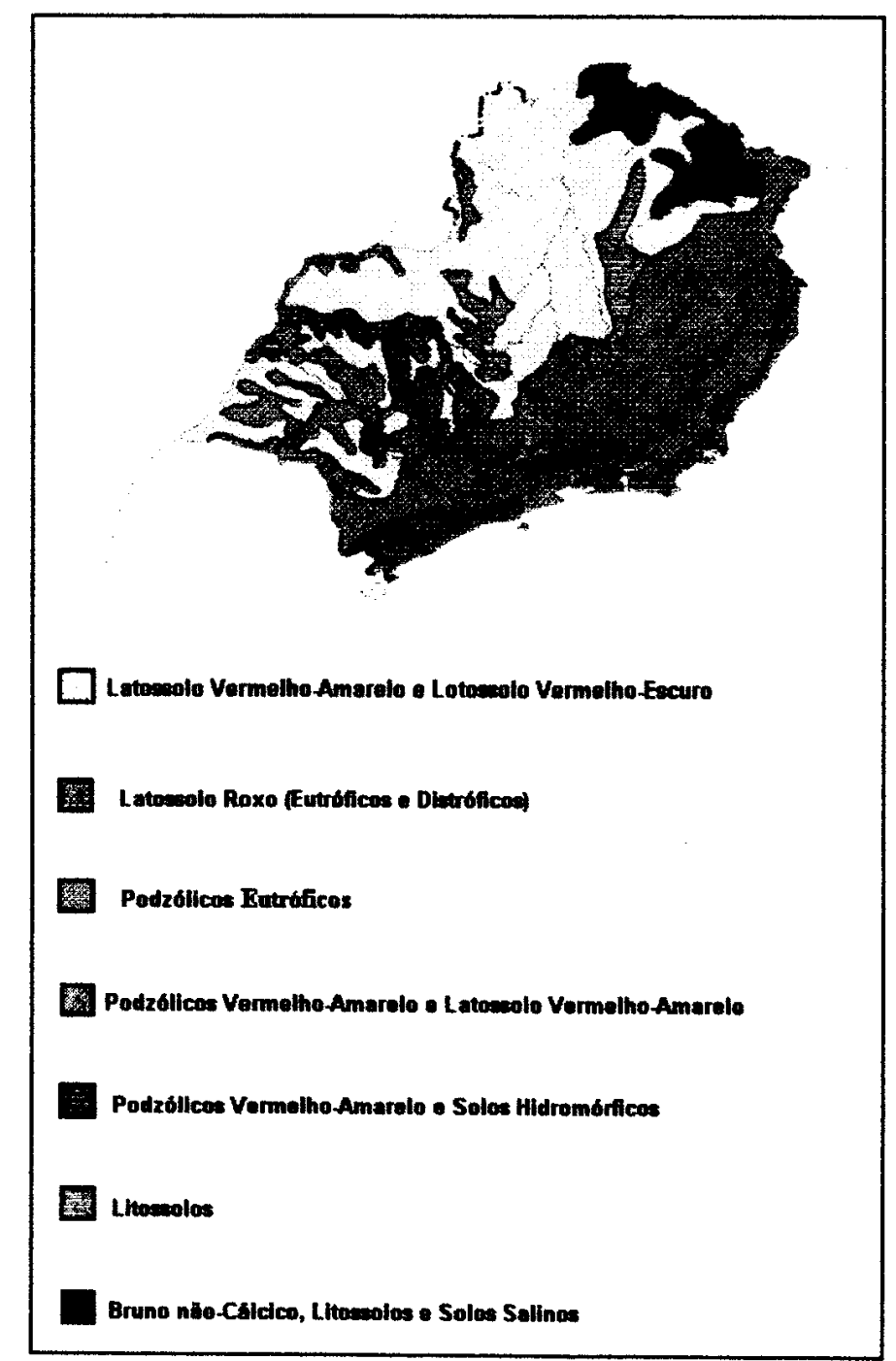

Figura 2.4: Os tipos de solo da região Sudeste Fonte: Série Prisma "Solos - formação e conservação" - 1976

Os solos de cores vermelho-amarelo decorrem de alguns fatores tais como: baixo suprimento de pigmento (ferro) fornecidos pelos minerais, boas condições de aeração e condições de clima úmido (Ranzani, 1969).

A vegetação natural mais encontrada nos solos podzólicos é a floresta de árvores de folhas largas. Normalmente são solos ácidos e de baixa fertilidade, necessitando por isso do uso adequado de corretivos e fertilizantes. 


\subsection{Os Herbicidas}

\subsubsection{Os Herbicidas - Mecanismos de Degradação dos Herbicidas}

Herbicidas aromáticos clorados são os principais responsáveis pela poluição ambiental. Eles são altamente tóxicos e resistentes a degradação, e então acumulam-se no meio ambiente. Quantidades residuais de herbicidas podem persistir por um período significativo depois da aplicação. (Donnelly et al, 1993).

Pode-se citar a contaminação por herbicidas de lencóis aquáticos como uma das preocupações crescentes de ambientalistas uma vez que as águas freáticas têm várias finalidades. Nos Estados Unidos, mais de $50 \%$ da água potável consumida pela população provém do lençol aquático, assim como aproximadamente $97 \%$ do consumo em zonas rurais, e $40 \%$ da água de irrigação na agricultura.

As figuras 2.5 e 2.6 que se seguem, ilustram em números o consumo e o uso de água, e o destino de defensivos agrícolas em 1991 no Brasil.

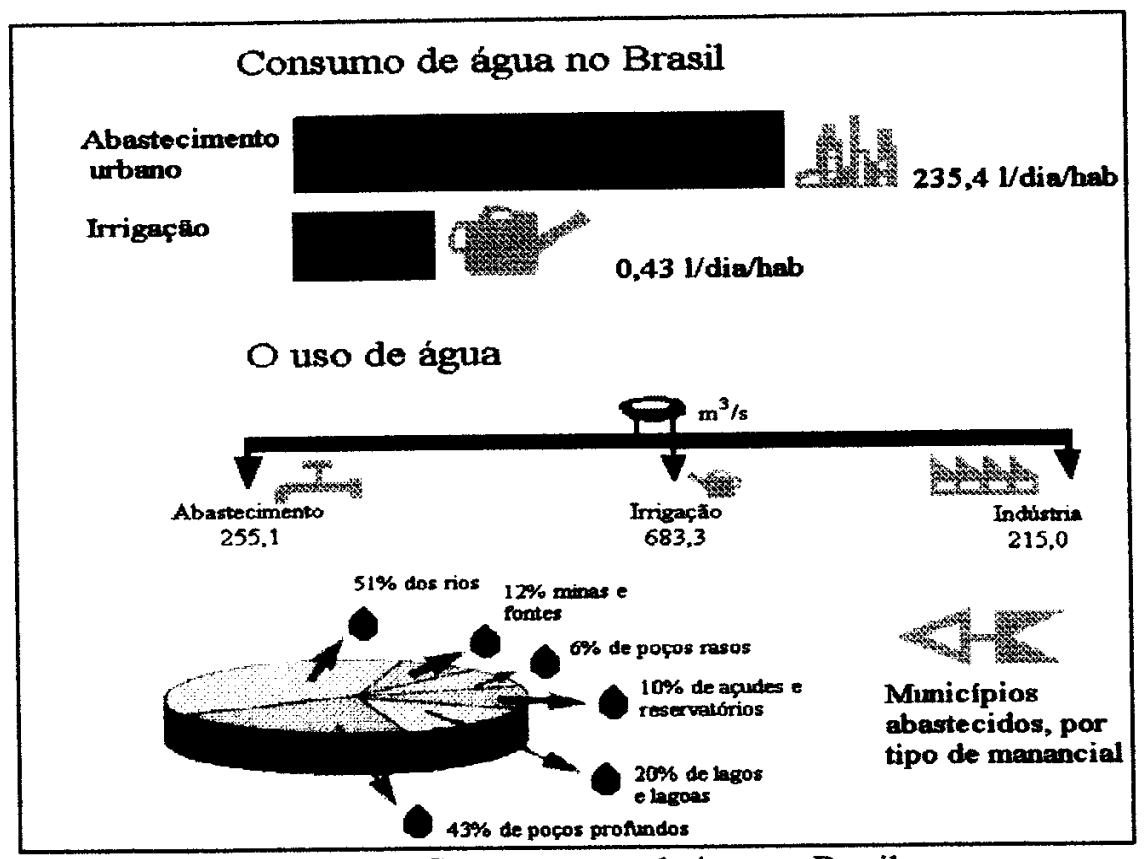

Figura 2.5: Consumo e uso de água no Brasil Fonte: Atlas do Meio Ambiente, EMBRAPA, 1994 


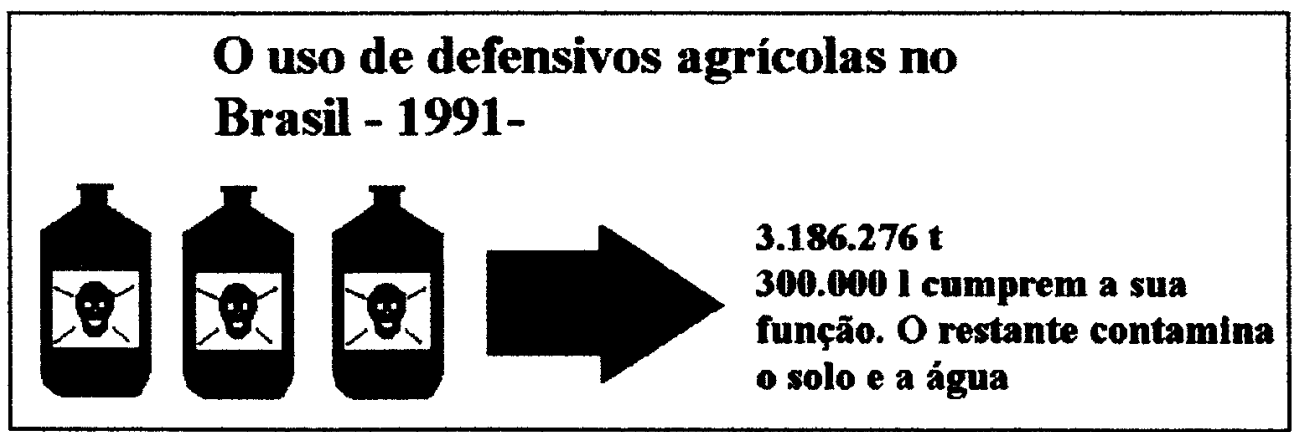

Figura 2.6: Destino de defensivos agrícolas no Brasil em 1991 Fonte: Atlas do Meio Ambiente, EMBRAPA, 1994

A tabela 2.1 lista impactos causados ao meio ambiente e a eficácia do herbicida devido a decisões de manejo.

Tabela 2.1: Impactos causados ao meio ambiente e a eficácia do herbicida devido a decisões de manejo

Fonte: Shoemaker, 1989

\begin{tabular}{|c|c|c|}
\hline Manejo & $\begin{array}{c}\text { Impactos na qualidade do meio } \\
\text { ambiente }\end{array}$ & Controle da praga \\
\hline $\begin{array}{l}\text { Tipo } \\
\text { de pesticida }\end{array}$ & $\begin{array}{l}\text { Alta sorção } \Rightarrow \text { baixa lixiviação } \\
\text { Rápida degradação } \Rightarrow \text { não } \\
\text { é transportado } \\
\text { Toxidade } \Rightarrow \text { determina a máxima } \\
\text { concentraçãa permitida em água }\end{array}$ & $\begin{array}{l}\text { Eficácia do controle depende do } \\
\text { herbicida }\end{array}$ \\
\hline $\begin{array}{l}\text { Tipo } \\
\text { de aplicação }\end{array}$ & $\begin{array}{l}\text { Incorporado ao solo } \Rightarrow \text { grande chance de } \\
\text { contaminação do lençol freático }\end{array}$ & $\begin{array}{l}\text { Toxidade a praga alvo } \\
\text { intensifica pela proximidade }\end{array}$ \\
\hline $\begin{array}{l}\text { Tecnologia } \\
\text { do 'spray' }\end{array}$ & Gotas grandes $\Rightarrow$ reduz o arrastão físico & $\begin{array}{l}\text { Grandes gotas podem decrescer } \\
\text { a eficácia }\end{array}$ \\
\hline $\begin{array}{l}\text { Época } \\
\text { de aplicação }\end{array}$ & $\begin{array}{l}\text { Próxima da estação da chuva ou irrigação } \\
\Leftrightarrow \text { aumenta a chance de contaminação do } \\
\text { lencol freático }\end{array}$ & $\begin{array}{l}\text { Eficácia do pesticida depende } \\
\text { das propriedades da época }\end{array}$ \\
\hline $\begin{array}{l}\text { Planejamento } \\
\text { temporal } \\
\text { da irrigação }\end{array}$ & $\begin{array}{l}\text { Irrigação planejada } \Rightarrow \text { reduz potencial de } \\
\text { contaminação de águas de superficies e do } \\
\text { lençol freático }\end{array}$ & $\begin{array}{l}\text { Mudanças na umidade devem } \\
\text { afetar a praga }\end{array}$ \\
\hline $\begin{array}{l}\text { Procedência } \\
\text { na aplicação }\end{array}$ & $\begin{array}{l}\text { Herbicida derramado ou de uso impróprio } \\
\text { aumenta contaminação da água e do solo }\end{array}$ & $\begin{array}{l}\text { Nunhum efeito negativo no } \\
\text { controle da praga }\end{array}$ \\
\hline
\end{tabular}

A meia-vida de um herbicida, isto é, tempo necessário para que metade da concentração do herbicida seja convertido em um sub-produto ou quando sua concentração é metade da inicial, é importante para o entendimento do potencial de impacto do herbicida ao meio ambiente. Os valores de meia-vida são controlados por volatização, fotólises, lixiviação e degradação química e microbiana.

$O$ potencial de transferência de herbicidas e sua degradação no solo são determinados por processos químicos, físicos e biológicos. A tabela 2.2 e a figura 
2.7, que se seguem, mostram osprocessos de transferência e de degradação de herbicidas no meio ambiente.

Tabela 2.2: Processos de transferência e de degradação de herbicidas no meio ambiente Fonte: Marathon-Agricultural and Environment Consultig- Fate of pesticides in the Environment, 1992.

\begin{tabular}{|c|c|c|}
\hline Processo & Consequência & Fatores \\
\hline \multicolumn{3}{|c|}{ Transferência (processo que movimenta o herbicida sem alterar sua estrutura) } \\
\hline $\begin{array}{c}\text { Arrastão } \\
\text { pelo vento }\end{array}$ & $\begin{array}{l}\text { Movimento do herbicida } \\
\text { devido a ação do vento }\end{array}$ & Velocidade do vento, tamanho da gota \\
\hline Volatização & $\begin{array}{l}\text { Perda de herbicida devida a evaporação } \\
\text { no solo, plantas ou meios aquáticos }\end{array}$ & $\begin{array}{c}\text { Pressão de vapor, velocidade do vento, } \\
\text { temperatura }\end{array}$ \\
\hline Adsorção & $\begin{array}{l}\text { Remoção do herbicida por interação com } \\
\text { plantas, solos e sedimentos }\end{array}$ & $\begin{array}{l}\text { Argila e conteúdo de matéria orgânica, } \\
\text { tipo de argila, umidade }\end{array}$ \\
\hline Absorção & $\begin{array}{l}\text { Retirada do herbicida por raízes de } \\
\text { plantas ou ingestão por animais }\end{array}$ & $\begin{array}{l}\text { Transporte via membrana celular, } \\
\text { tempo de contato e susceptilidade }\end{array}$ \\
\hline Lixiviação & $\begin{array}{c}\text { Translocação do herbicida ou } \\
\text { lateralmente ou verticalmente através do } \\
\text { solo }\end{array}$ & $\begin{array}{l}\text { Conteúdo de água, macroporos, textura } \\
\text { do solo e conteúdo de matéria orgânica }\end{array}$ \\
\hline Erosão & $\begin{array}{l}\text { Movimento do herbicida pela ação da } \\
\text { água ou do vento }\end{array}$ & $\begin{array}{c}\text { Chuva, velocidade do vento, tamanho } \\
\text { das partículas de argila e de matéria } \\
\text { orgânica compararado com o do } \\
\text { herbicida }\end{array}$ \\
\hline \multicolumn{3}{|c|}{ Degradação ( processo que altera a estrutura química) } \\
\hline Fotoquímica & $\begin{array}{l}\text { Quebra da estrutura química do } \\
\text { herbicida devida a absorção de luz solar }\end{array}$ & $\begin{array}{c}\text { Estrutura química do } \\
\text { herbicida,intensidade e duração da } \\
\text { exposição durante a luz solar }\end{array}$ \\
\hline Microbiana & $\begin{array}{l}\text { Degradação do herbicida por } \\
\text { microrganismos }\end{array}$ & $\begin{array}{l}\text { Fatores ambientais ( } \mathrm{pH} \text {, umidade, } \\
\text { temperatura), conteúdo de matéria } \\
\text { orgânica }\end{array}$ \\
\hline Química & $\begin{array}{c}\text { Alteração química do herbicida por } \\
\text { processos tais como hidrólise e reações } \\
\text { de "redox", }\end{array}$ & $\begin{array}{l}\text { pH, conteúdo de M.O., alguns fatores } \\
\text { como degradação microbiana }\end{array}$ \\
\hline Metabólica & $\begin{array}{c}\text { Transformações do herbicida depois de } \\
\text { absorvido por plantas ou animais }\end{array}$ & \\
\hline
\end{tabular}




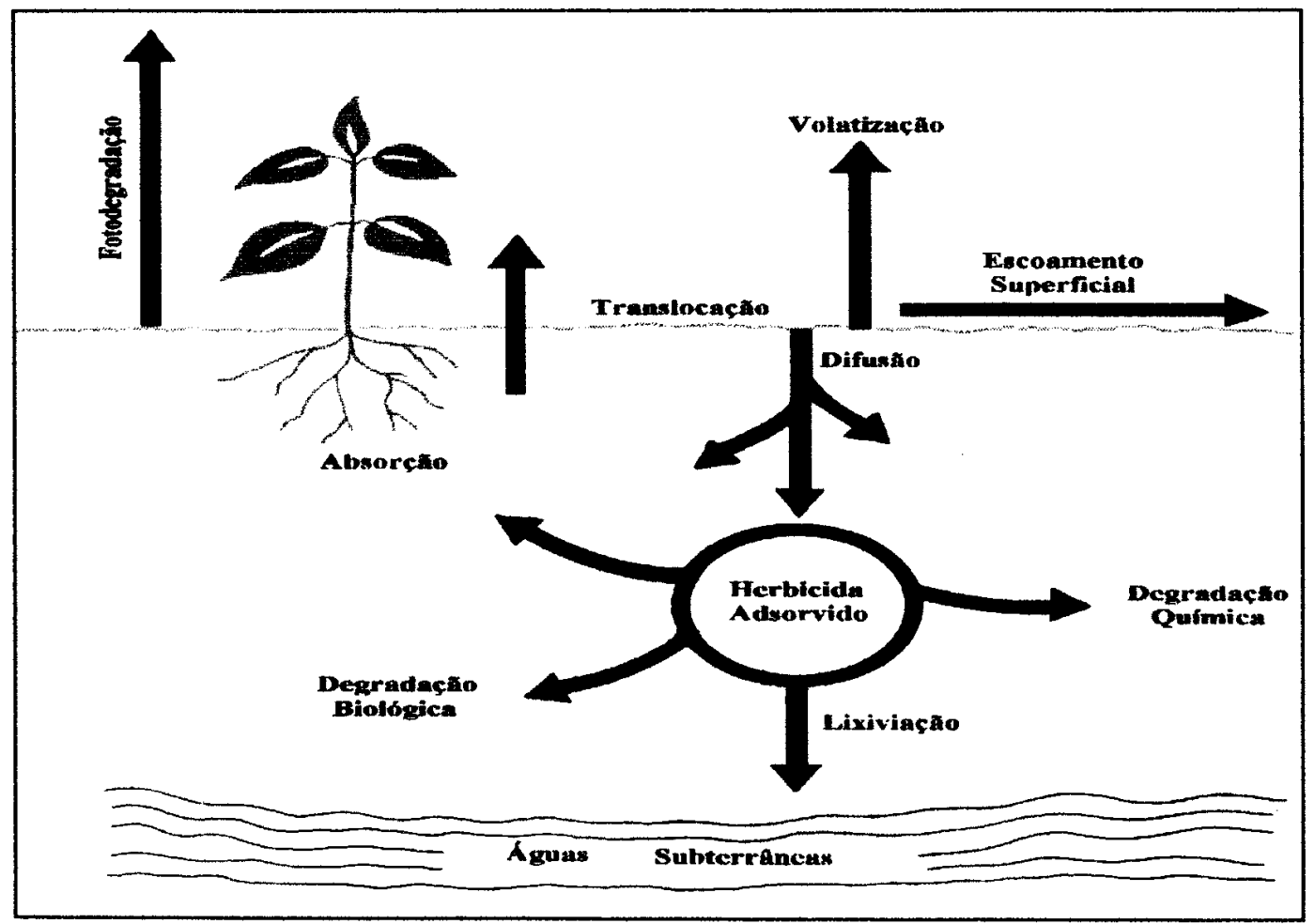

Figura 2.7: Processos de transferência e de degradação no meio ambiente

Seguem-se discussões de alguns desses processos:

Transformações abióticas e bióticas: reações abióticas e bióticas, sozinhas ou combinadas, são responsáveis por transformações de herbicidas em solo ou em meio aquático. Sob certas condições reações abióticas podem dominar, enquanto sob outras condições reações bióticas serão mais importantes. Muitas transformações de herbicida são mediadas por microrganismos, mas na realidade é um processo abiótico.

As principais reações de transformação abiótica são hidrólise, oxidação-redução ("redox") e fotólise.

Hidrólise é um processo no qual a molécula, $\mathrm{RX}$, reage com a água formando uma ligação RO e separa uma ligação $\mathrm{R}-\mathrm{X}$ na molécula original. Um possível caminho é pela direta substituição de $\mathrm{X}$ por $\mathrm{HO}^{-}$como mostrado:

$$
\mathrm{RX}+\mathrm{HO}^{-} \stackrel{\mathrm{H}_{2} \mathrm{O}}{\longrightarrow} \mathrm{ROH}+\mathrm{X}^{-}
$$


Transformações microbianas (bióticas) de herbicidas são classificadas

como:

a) Biodegradação (contaminante é usado como substrato para crescer);

b) Co-metabolismo (contaminante é transformado por reações metabólicas sem ser usado como uma fonte de energia);

c) Acumulação (contaminante é incorporado dentro do microrganismo);

d) Polimerização ou conjugação (contaminante é incorporado em outro material orgânico);

e) Efeitos secundários da atividade microbiana (contaminante é transformado devido a efeitos indiretos microbianos, isto é, $\mathrm{pH}$, redox).

Biodegradação é considerado um mecanismo primário no qual o herbicida é transformado em produtos inorgânicos tais como $\mathrm{CO}_{2}, \mathrm{H}_{2} \mathrm{O}$ e sais minerais.

Fotodegradação: a aplicação de milhões de toneladas de herbicida gera perda de produto e solo contaminado. Apenas 0,1\%-1\% do herbicida aplicado na cultura afeta a peste em questão o restante vai para o meio ambiente. Uma possível opção de tratamento desse solo contaminado é degradação química ou fotoquímica. Um método viável deve converter o composto original a um menos tóxico ou intermediários mais biodegradáveis. Idealmente poderia resultar em mineralização para compostos inorgânicos tais como $\mathrm{CO}_{2}, \mathrm{H}_{2} \mathrm{O}, \mathrm{Cl}^{-}$e $\mathrm{NH}_{3}$ (Sun et al, 1993).

Em meios aquáticos a fotólise pode ocorrer por processos diretos ou indiretos:

a) Na fotólise direta a luz solar é absorvida diretamente pelo herbicida resultando em uma transformação química. A taxa de fotólise direta depende da intensidade da luz solar e da sobreposição espectral características da radiação solar e do herbicida.

A camada de ozônio absorve radiação solar abaixo do comprimento de onda igual a $290 \mathrm{~nm}$. Então, fotólise direta por luz solar não ocorrerá se o 
herbicida em questão não absorve radiação em comprimentos de onda acima de 290 $\mathrm{nm}$, que é o caso do 2,4-D (máximo de absorção em $228 \mathrm{~nm}$ ).

b) $\mathrm{Na}$ fotólise indireta outras substâncias, como espécies inorgânicas elementares absorvem luz solar, e ou inicia uma série de reações que no final transforma o herbicida ou transfere energia ao herbicida.

As reações de fotólise em solos são dificeis para serem determinadas devida a natureza heterogênea dos solos e falta de penetração de luz solar. Fotólise é um fenômeno de superficie que é impedido se o herbicida está incorporado dentro do solo, a luz solar penetra apenas $1-2 \mathrm{~cm}$ de profundidade, mas não pode ser esquecido que a massa de solo está em movimento, o que torna possível a fotodegradação de camadas anteriormente mais internas. Existem poucos estudos realizados na superficies do solo.

$\Rightarrow$ Adsorção: é a interação do soluto na fase líquida na a superficie das partículas sólidas do solo, sendo que o tempo de retenção das camadas moleculares do herbicida que se formam depende de sua afinidade com as superficies das partículas do solo. É o processo chave no comportamento dos herbicidas, pois está diretamente relacionado com a bioatividade, persistência, biodegradabilidade no solo, além de ser um meio efetivo de diminuir a mobilidade do herbicida.

Sorção é o termo que se refere a um processo de retenção geral, no qual não se faz distinção entre os específicos processos de adsorção, absorção e difusão interna.

Adsorção-dessorção é o processo no qual moléculas são continuamente transferidas entre o volume líquido e a superfície sólida. Como os solos diferem bastante em suas características físicas, químicas e biológicas, é esperado que a natureza e a intensidade dos processos adsortivos sejam também diferentes. Logo, um modelo preditivo do destino e do transporte de herbicida requer informação sobre o comportamento da adsorção/dessorção sob condições variáveis.

As diferentes forças intramoleculares que podem atrair as moléculas do herbicida para as interfaces e retê-las podem ocorrer sozinhas ou simultaneamente. Seguem descrições de algumas delas (Senesi, 1992):

a) Forças de van der Waals: são de curto alcance (decaem rapidamente com a distância, $1 / r^{6}$ ), originadas de dipolos momentâneos de átomos e 
moléculas causados por pequenas pertubações do movimento eletrônico. Esses dipolos induzem pequeno dipolos em átomos vizinhos. Trata-se de uma atração fraca uma vez que os dipolos mudam constantemente de posição e sinal (energia envolvida entre 1-2 Kcal.mol ${ }^{-1}$ );

b) Pontes de hidrogênio: são produzidas pela atração eletrostática entre os núcleos $\mathrm{H}$ eletropositivos e pares de elétrons de átomos eletronegativos, as

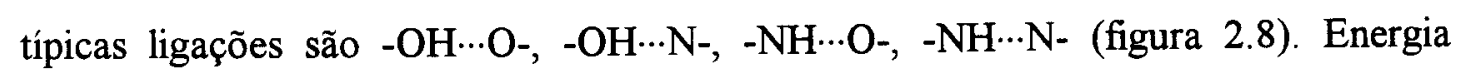
envolvida entre $2-10 \mathrm{kcal}_{\mathrm{mol}} \mathrm{m}^{-1}$

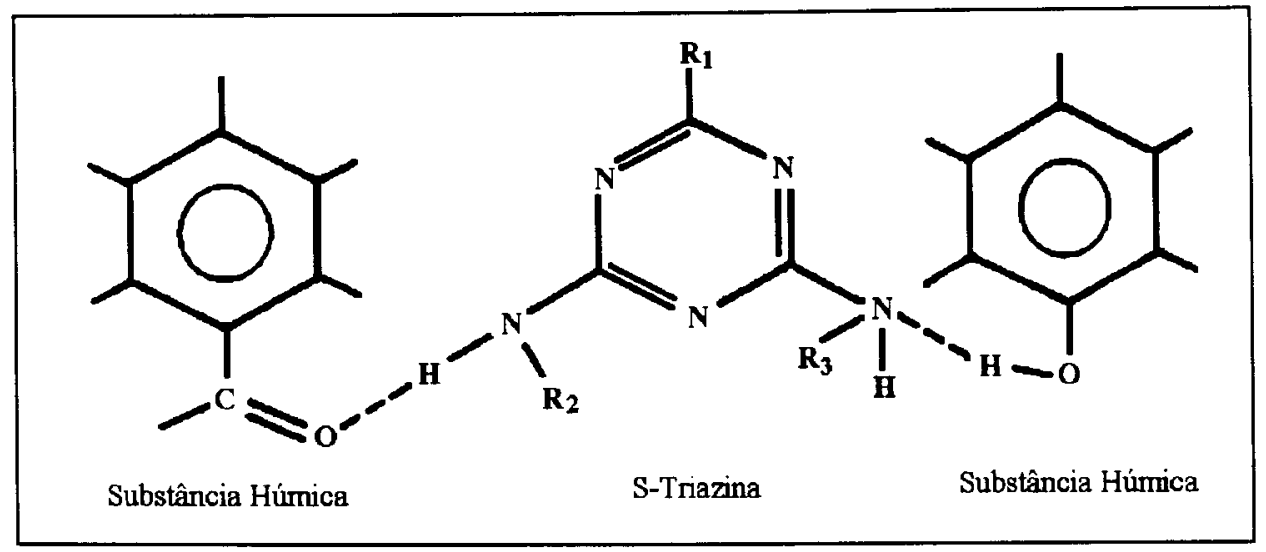

Figura 2.8: Ligação de hidrogênio entre substância húmica e s-triazina

c) Ligação hidrofóbica: para os herbicidas não polares ou compostos cujas moléculas têm regiões polares de tamanho insignificante comparadas as regiões apolares são prováveis a adsorção por regiões hidrofóbicas da matéria orgânica do solo;

d) Transferência de carga (mecanismo doador-aceitador de elétrons): consiste na formação de um complexo doador-aceitador entre uma molécula elétrondoadora e uma molécula elétron-aceitadora (figura 2.9). Envolve a sobreposição parcial dos respectivos orbitais moleculares e uma permutação parcial de densidades eletrônicas. O complexo pode ser suficientemente estável a ponto da adsorção ser praticamente irreversível; 
<smiles>COc1nc(N(C)C)nc(N(C)C)n1</smiles>

S-Triazina

(elétron-doador)<smiles>CC1=C(C)C(=O)C(C)=C(C)C1=O</smiles>

Quinona húmico

(elétron-aceptor)
Transferência de

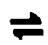

elétrons

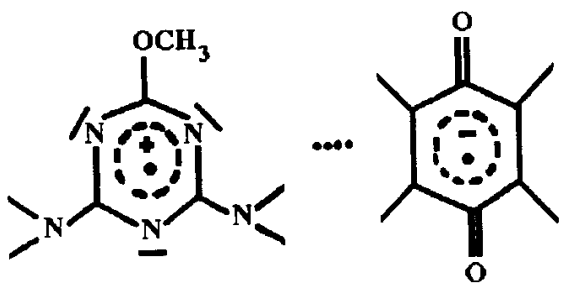

Radicais cátion e ânion

(Complexo transferência- carga)

Figura 2.9: Formação do complexo transferência-carga entre s-triazina e quinona húmico

b) Ligação iônica: ocorre naqueles herbicidas que ou existem como cátions ou que tornaram-se carregados positivamente através de protonação;

c) Troca de ligante: forma-se um complexo quando um grupo funcional orgânico, tal como um carboxilato ou hidroxíla, desaloja uma hidroxila inorgânica ou molécula de água de um íon metal (ferro ou alumínio) na superfície da parte mineral do solo (figura 2.10);

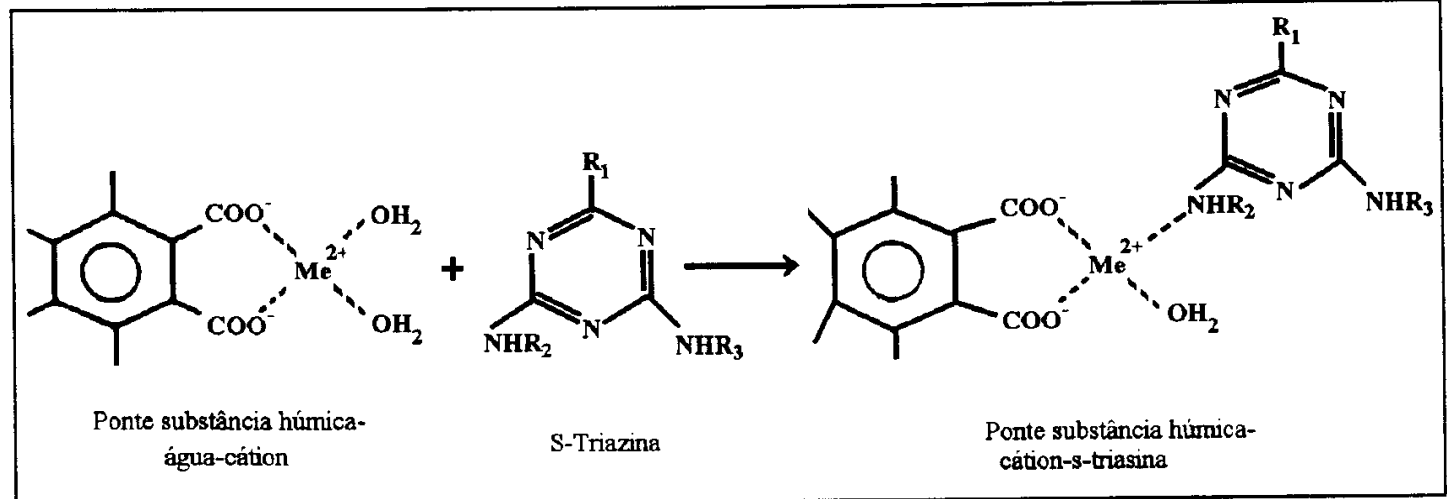

Figura 2.10: Mecanismo troca de ligante na substância húmica pela adsorção da s-triasina através de uma ponte de cátion de metal

g) Ligação covalente: a formação de ligação covalente, leva a uma incorporação estável, na maior parte irreversível entre sustâncias húmicas e herbicidas, mais provavelmente, de seus intermediários e produtos de degradação (figura 2.11). 


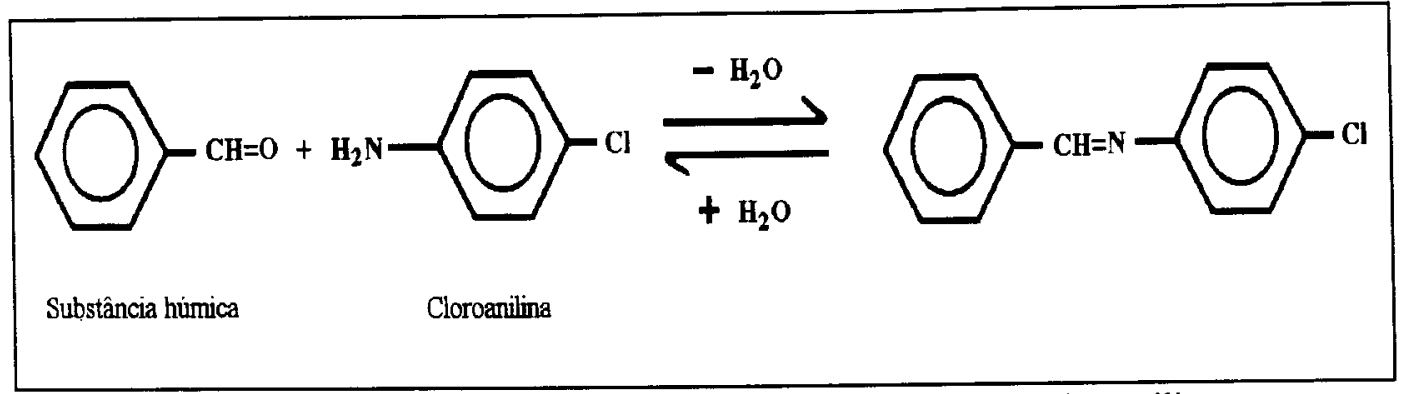

Figura 2.11: Ligação covalente entre a substância húmica e cloroanilina

\subsubsection{Classificação dos Herbicidas}

Existem diversas maneiras para classificar um herbicida, levando-se em consideração a época de aplicação, seletividade, modo de ação e grupo químico.

$\Rightarrow$ Época de aplicação:

a) Herbicida de pré-plantio: a aplicação deve ser antes do plantio da planta, facilitando o preparo do solo; para a obtenção de cobertura morta, como no manejo chamado plantio direto;

b) Herbicida de pré-plantio com incorporação ao solo: a aplicação é realizada antes do plantio, porém em função de diversos fatores relacionados com suas características tais como volatilidade, fotodecomposição e seletividade, são incorporados ao solo em época e profundidade variável de acordo com as especificações técnicas de uso de cada produto;

c) Herbicida de pré-emergência: a aplicação é realizada após o plantio antes da emergência da cultura e/ou das plantas daninhas;

d) Herbicidas de pós-emergência: a aplicação é realizada após a emergência da cultura e/ou plantas daninhas levando em consideração os estágios de desenvolvimento da planta cultivada e da planta daninha.

\section{$\Rightarrow$ Seletividade}

A seletividade de um herbicida depende tanto das propriedades físicoquímicas como também da resistência das plantas a capacidade fitotóxica do herbicida. 
Segundo a seletividade os herbicidas podem ser classificados em:

a) Seletivos quando apresentam ação fitotóxica somente sobre determinadas plantas;

b) Não seletivos ou de ação total quando conseguem exercer ação fitotóxica em qualquer planta.

\section{Modo de ação}

c) Herbicidas hormonais: provocam uma desorganização do crescimento das plantas agindo nos tecidos meristemáticos (regiões de meristemas estão presentes principalmente na extremidade das regiões das raízes e galhos, que contém células com intensa atividade mitótica responsáveis pelo crescimento nestas regiões);

d) Herbicidas inibidores de fotossíntese: pelo bloqueamento da reação de Hill é bloqueada;

e) Herbicidas inibidores do crescimento inicial: inibem o crescimento de radículos e caulículos;

f) Herbicidas inibidores da síntese proteíca: modificam a estrutura das proteínas, incluíndo enzimas;

g) Herbicidas que afetam as membranas celulares: atuam em determinados processos metabólicos nas plantas, afetando as membranas celulares.

\section{$\Rightarrow$ Grupo químico}

$\mathrm{Na}$ literatura várias classificações quanto ao grupo químico foram feitas, uma delas distribui em três classes: herbicidas acíclicos, herbicidas homocíclicos e herbicidas heterocíclicos, ou seja, são classificados segundo a função química.

\subsubsection{O Herbicida 2,4-D}

O herbicida 2,4-D (ácido 2,4-D diclorofenoxiacético) é largamente usado no Brasil e no mundo. Sua produção mundial é $2,5 \times 10^{6}$ tons/ano, sendo que nos Estados Unidos representa aproximadamente $25 \%$ da venda de herbicidas (Cloutier et al, 1985). É um herbicida pós-emergente, usado nas culturas de arroz, 
aveia, centeio, trigo, café, cana-de-açucar, milho, pastagens e manejo de plantio direto, e como pré-emergente nas culturas de café e cana-de-açucar. É um herbicida seletivo, e segundo o modo de ação é um herbicida hormonal, sendo que a absorção pode ocorrer através de raízes, caules e folhas. Pertence ao grupo químico dos herbicidas homocíclicos, sub-divisão ácidos fenóxidos.

$\mathrm{O}$ herbicida 2,4-D possui a estrutura química mostrada na figura 2.12, é um composto ácido, pois na presença de água sua tendência é de doar prótons $\left(\mathrm{H}^{+}\right)$, conforme a reação:

$$
\mathrm{HA}+\mathrm{H}_{2} \mathrm{O} \longleftrightarrow \mathrm{H}_{3} \mathrm{O}^{+}+\mathrm{A}^{-}
$$

Seu pKa é em torno de 2,6 ,valor de $\mathrm{pH}$ no qual $50 \%$ das moléculas do herbicida (representadas por $\mathrm{A}^{-}$) encontram-se na forma ionizada:

$$
\left[\mathrm{A}^{-}\right]=[\mathrm{HA}]
$$

Consequentemente, como os valores de $\mathrm{pH}$ dos solos geralmente estão no intervalo de 4,5 e 7,0, o 2,4-D quando em solução aquosa no solo, deve apresentar-se completamente ionizado.

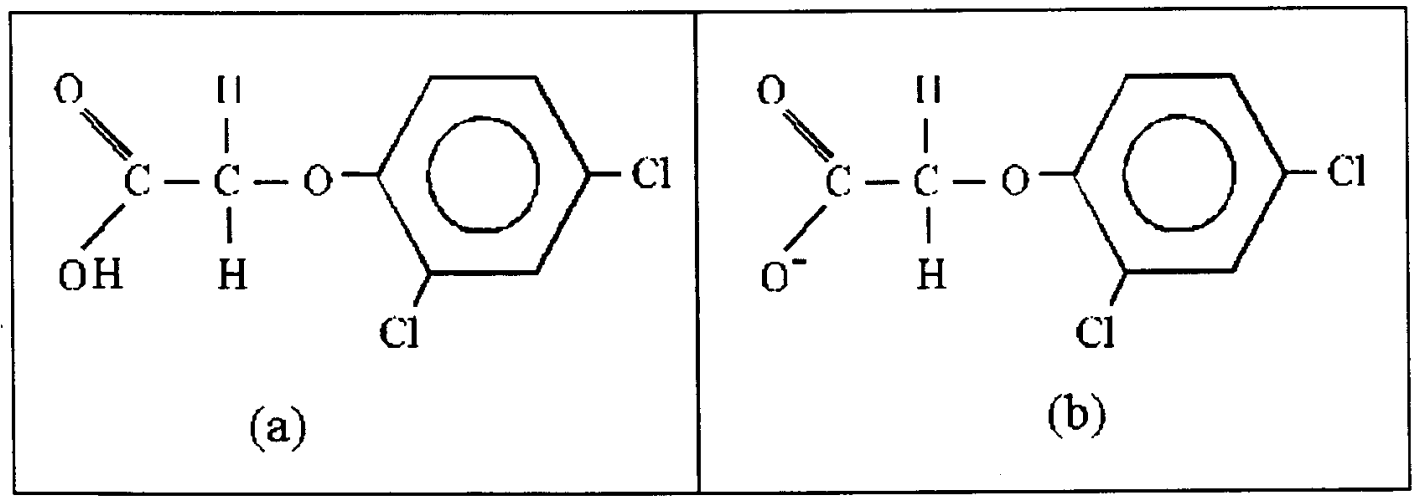

Figura 2.12: Estrutura química do 2,4-D nas formas: (a) molecular e (b) ionizada

Foi desenvolvido durante o programa da guerra química e biológica no período da Segunda Gerra Mundial (1939-1945), e continuou sendo usado na Guerra do Vietnã (1961 -1975).

Warnock et al (1982) cita que o 2,4-D causa defeitos de nascença em animais de laboratórios e danos no sistema nervoso central em humanos. Exames epidemiológicos em trabalhadores de fazendas, de florestas e pulverizadores indicam 
que o 2,4-D pode causar cancer de pele. Estudos mostraram a toxidade do herbicida a peixes.

O herbicida 2,4-D pode ser usado em meios aquáticos, como foi o caso do lago de Okanagan nos Estados Unidos, onde 2,4-D foi utilizado para deter a expansão da planta aquática asiática Milfoil. Foi um caso polêmico, no final dos anos 70 e começo dos 80, uma vez que grupos ambientalistas entraram em confronto com o programa de aplicação do governo local, tal como a liberação das águas para prática de natação dos moradores 4 dias após a aplicação do herbicida (Warnock et al, 1982).

Barriuso et al (1992) estudaram a adsorção do 2,4-D em solos de dois estados brasileiros, São Paulo e Paraná, extraídos de cobertura vegetal e solos com tempos de cultivo diferentes (12-56 anos de cultivo). A adsorção foi maior em solos do Paraná. A explicação dos autores é de que o herbicida estava aniônico sob as condições de solo por eles encontradas, e a adsorção de herbicidas aniônicos envolve interações com cargas positivas do solo, também por forças menos energéticas como as de van der Waals e transferência de carga (Stevenson, 1972). Nestes solos cargas positivas são geradas por óxidos de ferro e alumínio, os quais existem em maior concentração nos sítios do Paraná. Os mesmos autores, observaram que a adsorção do 2,4-D parece ser essencialmente dependente do $\mathrm{pH}$ e da parte mineral mas independente do conteúdo de matéria orgânica do solo.

As técnicas de FTIR e difração de Raios-X foram as utilizadas por Hermosin \& Cornejo (1993) no estudo de mecanismos de ligação do 2,4-D com duas organo-argilas. As argilas, que são hidrofilico, vermiculita e montimorilonita foram tratadas com o cátion orgânico decilamônio, formando os complexos $\mathrm{C} 10 \mathrm{~V}$ e $\mathrm{C10 \textrm {M }}$ respectivamente. A maior capacidade de adsorção do mineral C10V comparada com a do $\mathrm{C} 10 \mathrm{M}$, foi relacionada com o fato de que a $\mathrm{ClOV}$ tem maior conteúdo de $\mathrm{C}$ orgânico e a distribuição parafinada dos íons alquilamônio entre as camadas de silicato do mineral $\mathrm{C} 10 \mathrm{~V}$, formando uma inter-camada maior e mais carregada que no mineral C10M. Os espectros de FTIR do complexo herbicida-C10V mostraram a presença de uma pequena quantidade da forma molecular de 2,4-D adsorvida fracamente nas superfícies externas via ligação lifofilica (calda-anel), e algum 2,4-D adsorvido na forma aniônica produzindo as bandas de estiramento anti-simétrico e 
simétrico do íon carboxilato do 2,4-D atraído pelo grupo $\mathrm{NH}_{3}{ }^{+}$(amônia) dos cátions orgânicos. Mas a maioria das moléculas do herbicida foi adsorvida nos espaços intermoleculares, em pHs mais altos (quando o herbicida está na forma aniônica), por ligação de hidrogênio entre o grupo carbonil $\left(\sigma_{\mathrm{C}=\mathrm{O}} \mathrm{em} 1634 \mathrm{~cm}^{-1}\right)$ do 2,4-D e o grupo $\mathrm{NH}_{3}{ }^{+}$dos cátions orgânicos.

Pivetz \& Steenhuis (1995) utilizaram o herbicida 2,4-D em seus experimentos sobre impacto de macroporos do solo na biodegradação, uma vez que ele é realmente biodegradável, com tempo de meia-vida estimado em 10-50 dias ou atividade residual de 6 semanas. Comparado a outros pesticidas agrícolas, a classe de compostos contendo 2,4-D está entre as que mais facilmente biodegrada. Segundo os mesmos autores, o escoamento preferencial de pesticidas em macroporos leva ao decréscimo do tempo de "viagem" e aumento do perigo de contaminação de águas subterrâneas, contudo macroporos podem apresentar um meio favorável a biodegradação devido a maior oxigenação, nutrientes, e provém substrato, e mais alta população microbial em tocas de minhocas, comparados com a matriz do solo.

A figura 2.13 mostra o herbicida 2,4-D degradado a 2,4-diclorofenol, e posteriormente o acoplamento por ação oxidativa de enzimas fenoloxidases. A lactase do fungo Rhizoctonia praticola do solo pode polimerizar o 2,4-diclorofenol a dímero (figura 12) e produtos oligoméricos maiores (Cheng, 1990).

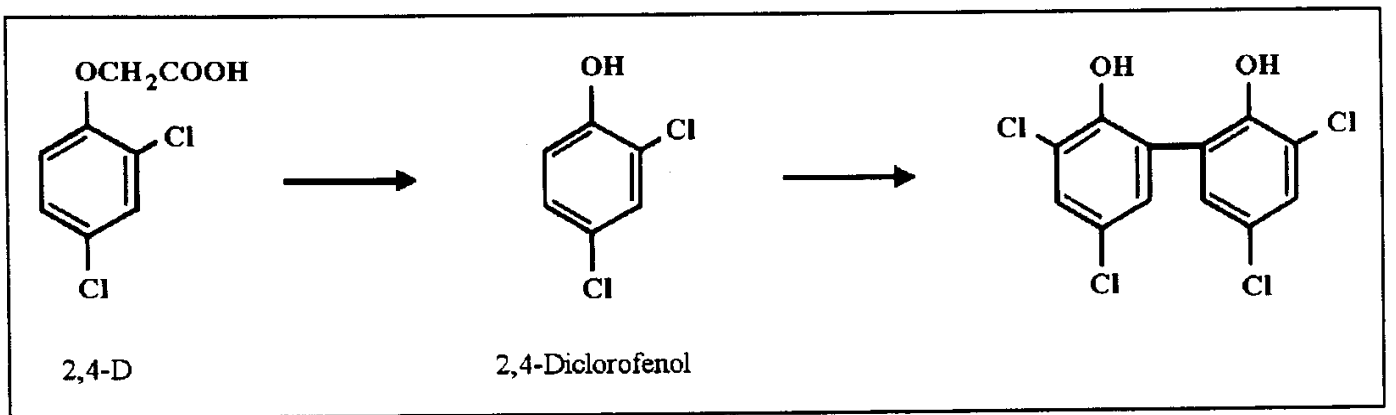

Figura 2.13: Polimerização do produto de degradação do 2,4-D, 2,4-diclorofenol catalisada pela enzima lacase do fungo Rhizoctonia praticola

A adsorção do 2,4-D em resinas trocadoras de íons foi estudada por Grover et al (1974), os quais observaram que a adsorção entre o herbicida e as resinas é insignificante, o que indica a não afinidade por superficies negativamente carregadas (nas superficies dos solos prevalecem sítios carregados negativamente, e em solução 
aquosa o 2,4-D encontra-se em geral na forma aniônica), havendo assim uma preferência para interagir com outras moléculas, como a matéria orgânica.

Wilson et al (1978) trabalhando com amostras de solos extraídas de diferentes profundidades, verificaram que a camada de $0-5 \mathrm{~cm}$ de profundidade apresentou maior adsorção de 2,4-D, havendo uma diferença significativa a partir de $20 \mathrm{~cm}$ de profundidade. Atribuiram a isto o fato de que camadas superficiais são mais ricas em matéria orgânica que as mais profundas.

Moreale et al (1980) estudaram os parâmetros físicos-químicos dos solos responsáveis pela adsorção de 2,4-D. A conclusão baseada em dados de 42 amostras de solos belgas é que a matéria orgânica, alumínio trocável e $\mathrm{pH}$ foram os parâmetros que mais correlacionaram com a adsorção do 2,4-D. Verificaram também que as altas concentrações de 2,4-D em solução a adsorção no solo diminui, sendo que a variação da concentração tem um efeito insignificante na quantidade do herbicida adsorvido.

Heeling (1971) observou a partir das análises de 13 herbicidas ( entre eles o 2,4-D) em 14 solos diferentes, que de um modo geral a mobilidade está diretamente ralacionada com o fluxo de água (sendo o 2,4-D o mais perceptível), com o conteúdo de matéria orgânica, argila e C.T.C.

Estudos realizados por Luchini (1987) obtiveram valores de coeficientes de adsorção do 2,4-D bastante baixos comparados aos coeficientes obtidos para os herbicidas paraquat e diuron, aos quais foi atribuida a alta mobilidade do 2,4-D como o provável responsável. O mesmo autor observou uma maior adsorção do 2,4-D nos solos com maior conteúdo orgânico. Segundo Stevenson (1972) as forças de Van der Waals é o mecanismo de ligação entre o 2,4-D e a matéria orgânica do solo, o que está de acordo com os baixos valores dos coeficientes encontrados por Luchini (independentemente do conteúdo de matéria orgânica), uma vez que trata-se de ligações fracas.

$\mathrm{O}$ alto grau de mobilidade do herbicida foi constatado por Wilson et al (1976) os quais verificaram o deslocamento do 2,4-D de $24 \mathrm{~cm}$ ao longo do perfil do solo estudado, após um dia de aplicação e sob um regime de chuva de $16 \mathrm{~mm}$ por um período de 3 horas. 
"Resultados de experimentos para determinação do tempo de equilíbrio de contato da sorção do 2,4-D em turfa devem ser utilizados para sugerir os mecanismos de adsorção"(Cloutier et al, 1985). Khan (1973) monitorou a massa de 2,4-D adsorvida (isto é, taxa de diminuição da concentração do herbicida por unidade de massa de ácido húmico) em função da raiz quadrada do tempo de contato $\left(t^{1 / 2}\right)$, e os dados são os mesmos mostrados no capítulo 4, figura 4.3. A não lineariedade obtida, indica que a difusão não é o único mecanismo envolvido na sorção, e que há combinação de efeitos de adsorção de superficie e difusão interna do 2,4-D através dos poros e capilares do ácido húmico. A sorção é inicialmente rápida mas torna-se linear com $t^{1 / 2}$ depois de poucos minutos. Desde que uma dependência em $t^{1 / 2}$ é típica de processos de difusão, propõe-se que a fase rápida-inicial ocorra pela adsorção superficial, enquanto a fase mais demorada ocorra pela difusão dentro da partícula de turfa.

Khan (1973) utilizou a técnica de cromatografia gasosa nos seus estudos de equilíbrio e cinética de adsorção do 2,4-D por ácidos húmicos. A análise dos dados de cinética de adsorção da parte inicial, a mais rápida, teve como resultado valores baixos para a energia de ativação e calor de ativação, levando-o a sugerir a adsorção tipo fisica, possivelmente envolvendo forças de Van der Waals e ligação hidrofóbica entre as moléculas do herbicida e a superficie do ácido húmico em um sistema aquoso.

A taxa de diminuição da concentração de um determinado herbicida devido a hidrólise biótica é frequentemente, mas não sempre, caracterizada por um período durante o qual pouco ou nenhuma mudança na concentração ocorre. Este é seguida por uma mudança rápida na concentração. Em estudos de laboratórios, alguns pesticidas, entre esses o 2,4-D, têm sido mostrado exibir este tipo de cinética.

Segundo Senesi (1992) pesticidas ácidos e aniônicos, tais como ácidos clorofenoxialcanóicos podem também ser adsorvidos por ligação de hidrogênio em substâncias húmicas, em valores de $\mathrm{pH}$ abaixo dos seus $\mathrm{pKas}$, em forma não ionizadas através de seus grupos $\mathrm{COOH}$, COOR e similar (figura 2.14). Segundo o mesmo autor estudos de ressonância paramagnética eletrônica (EPR) mostraram que uma considerável supressão da concentração original de radicais livres e um alargamento da largura de linha de ressonância ocorrem em um número de ácido húmico devido 
suas interações com ácidos clorofenoxialcanóicos em solução aquosa. Estes resultados sugerem a incorporação de radicais intermediários tipo fenóxi ao ácido húmico através de ligação covalente (figura 2.15). A presença em substâncias húmicas de catalizadores inorgânicos em quantidades residuais (isto é, íons cúprico e férrico) e atividade residual enzimática (isto é, devido as enzimas fenoloxidases e peroxidades, produzidas por fungos, bactérias e plantas), mostram que ambas são capazes de mediar quimicamente e biologicamente a degradação oxidativa envolvendo o intermediário radical fenóxi destes herbicidas. Os radicais tipo fenóxi podem ser também gerados fotoquimicamente, a partir dos compostos clorofenoxialcanóicos em solução.

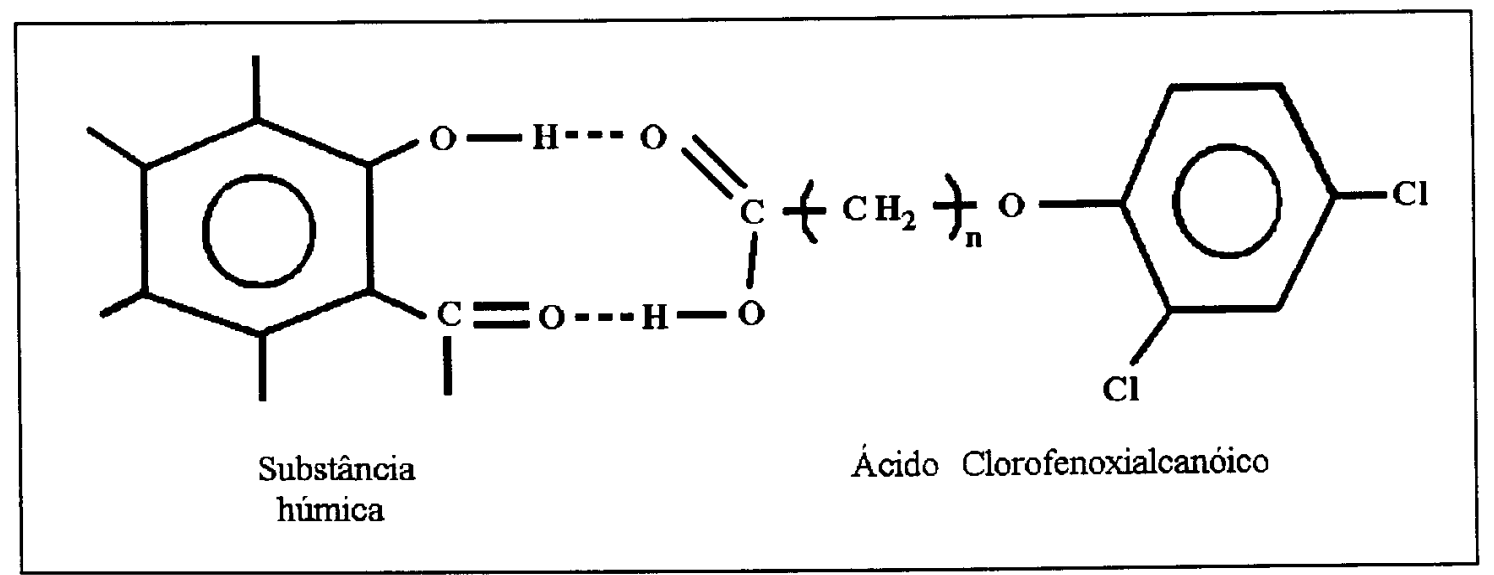

Figura 2.14: Ligação de hidrogênio entre substância húmica e ácido clorofenoxialcanóico

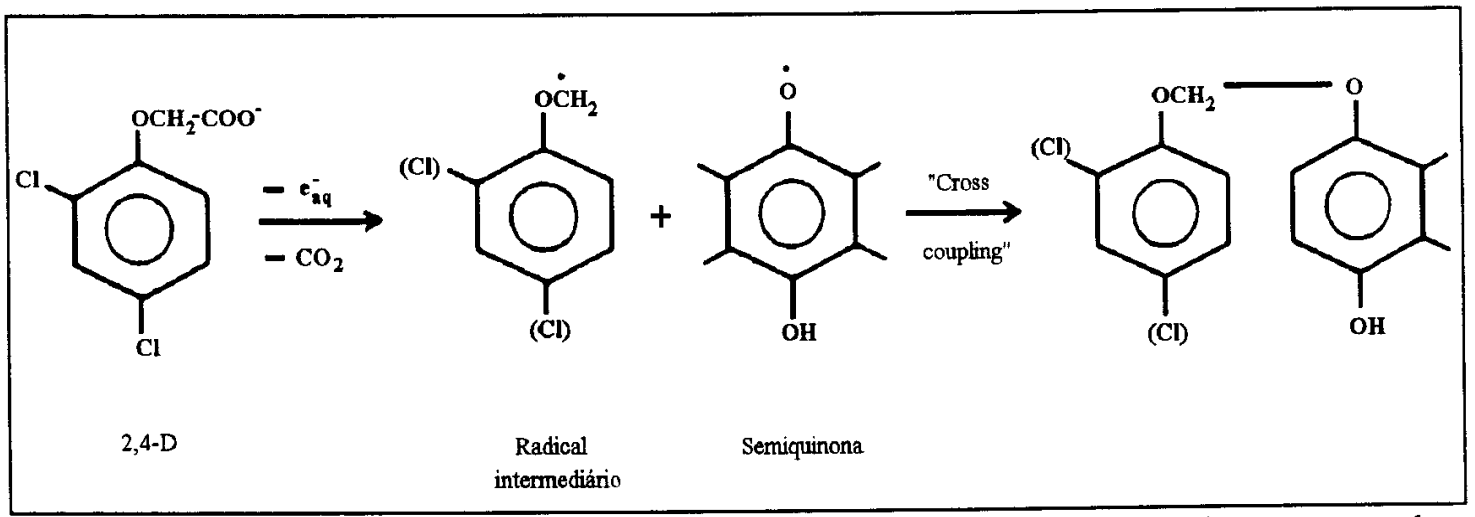

Figura 2.15: Formação de um radical intermediário entre 2,4-D e reação de acoplamento cruzado ("cross-coupling") com o radical húmico semiquinona com incorporação do resíduo a molécula húmica

Chamarro \& Esplugas (1993) realizaram estudos sobre a fotodegradação do herbicida 2,4-D em solução aquosa em função do $\mathrm{pH}$, utilizando uma lâmpada de mercúrio, de potência $360 \mathrm{~W}$, que emite radiação acima de $220 \mathrm{~nm}$. Para pequenos tempos de irradiação, os autores propuseram um mecanismo de reação 
com respeito a radiação absorvida pelo herbicida. E constataram a influência do $\mathrm{pH}$ somente para tempos maiores de irradiação: a conversão para um sub-produto do 2,4$\mathrm{D}$ era mais rápida para valores de $\mathrm{pH}$ ácidos, possivelmente devido a formação de um produto com características similares aos ácidos húmicos em meio neutro ou básico. E a decomposição do 2,4-D sem radiação ultravioleta foi considerada desprezível comparada com a decomposição obtida com fonte ultravioleta. 


\section{Capitula 3. Espectroseopia de EPR. Un-Visivel e Z79R}

\subsection{Introdução}

Toda absorção espectroscópica implica na absorção de radiação de uma molécula que transiciona para um outro nível energético mais alto como esquematizado na figura 3.1 (Knowles et al, 1976).

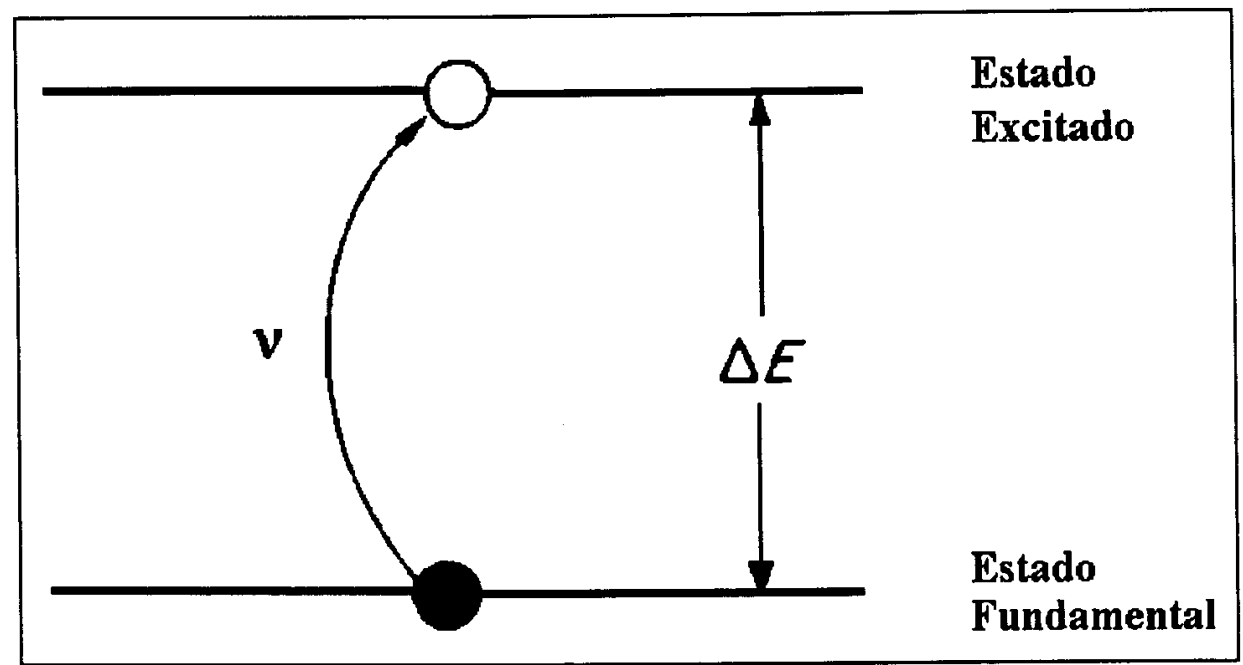

Figura 3.1: Transição envolvida em uma absorção (Knowles, 1976)

A diferença de energia entre os dois estados é dada pela equação de Planck:

$$
\Delta \mathrm{E}=\mathrm{h} v,
$$

onde hv é o quantum de energia da radiação, $v$ é a frequência da radiação e $h$ a constante de Planck.

$\mathrm{Na}$ figura 3.2 são mostradas regiões espectrais do espectro eletromagnético. Em nossos experimentos foram feitas medidas em três dessas regiões: uv-visível, infravermelho e microonda, através das técnicas de espectroscopia de UV-visível, de Infravermelho com Transformada de Fourier (do inglês FTIR) e da Ressonância Paramagnética Eletrônica (do inglês EPR). 


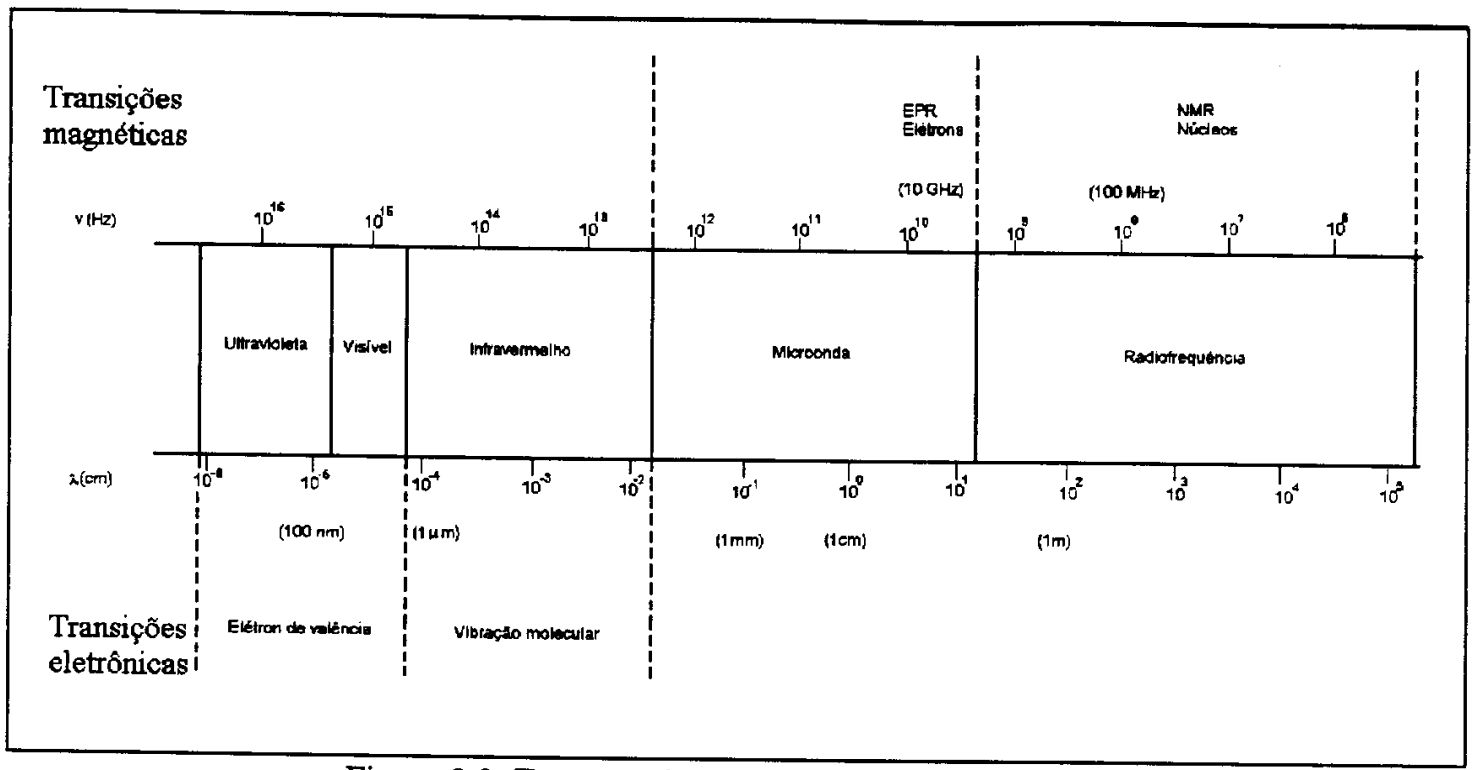

Figura 3.2: Espectro eletromagnético (Knowles, 1976)

A diferença na maneira pela qual as transições são induzidas nessas três técnicas é: nas espectroscopias de UV-Visivel e Infravermelho é o campo elétrico da radiação que interage com a carga elétrica do elétron ou com um grupo polar da molécula, e em Ressonância Paramagnética é a interação do campo magnético da radiação com o momento magnético do elétron que induz as transições (Knowles et al, 1976). Os ítens que se seguem descrevem cada uma dessas técnicas.

\subsection{Espectroscopia por Ressonância Paramagnética Eletrônica (EPR)}

\subsubsection{O Fenômeno de Ressonância}

Os espectros de EPR compreendem a seguinte região espectral: 0.04$25 \mathrm{~cm}$.

A característica básica da técnica de EPR é sua capacidade para detectar e caracterizar a presença de elétrons desemparelhados em uma substância. A propriedade essencial detectada pela técnica é a interação do momento magnético de spin do elétron $\left(\vec{\mu}_{s}\right)$ com um campo magnético externo $(\overrightarrow{\mathrm{H}})$. O momento magnético de spin do elétron é dado por:

$$
\vec{\mu}=-\mathrm{g} \frac{\mathrm{e}}{2 \mathrm{mc}} \vec{S}
$$


onde o fator g para o elétron livre é igual a 2,002319, $\mathrm{m}$ a sua massa eletrônica de repouso, c a velocidade da luz, e a carga eletrônica e $\vec{S}$ o momento angular de spin.

$\mathrm{Na}$ ausência de um campo magnético externo, os momentos magnéticos de spin do elétron estão randomicamente orientados e com mesma energia. Com a aplicação do campo magnético $\overrightarrow{\mathrm{H}}_{0}=\mathrm{H}_{0} \hat{z}$, para o caso de um único elétron desemparelhado (de spin total $S=1 / 2$ ), o momento angular de spin, $|\vec{S}|=\frac{\sqrt{3} \hbar}{2}$, precessiona e tem uma das possíveis componentes $S_{z}=1 / 2 \hbar$ ou $S_{z}=-1 / 2 \hbar$ (as possíveis componentes do spin $S$ são: $m_{s}=+S,+S-1, \ldots-S+1,-S$ ) ao longo do eixo de quantização (o eixo de aplicação do campo magnético), sendo h a constante de Planck, conforme mostrado na figura 3.3:

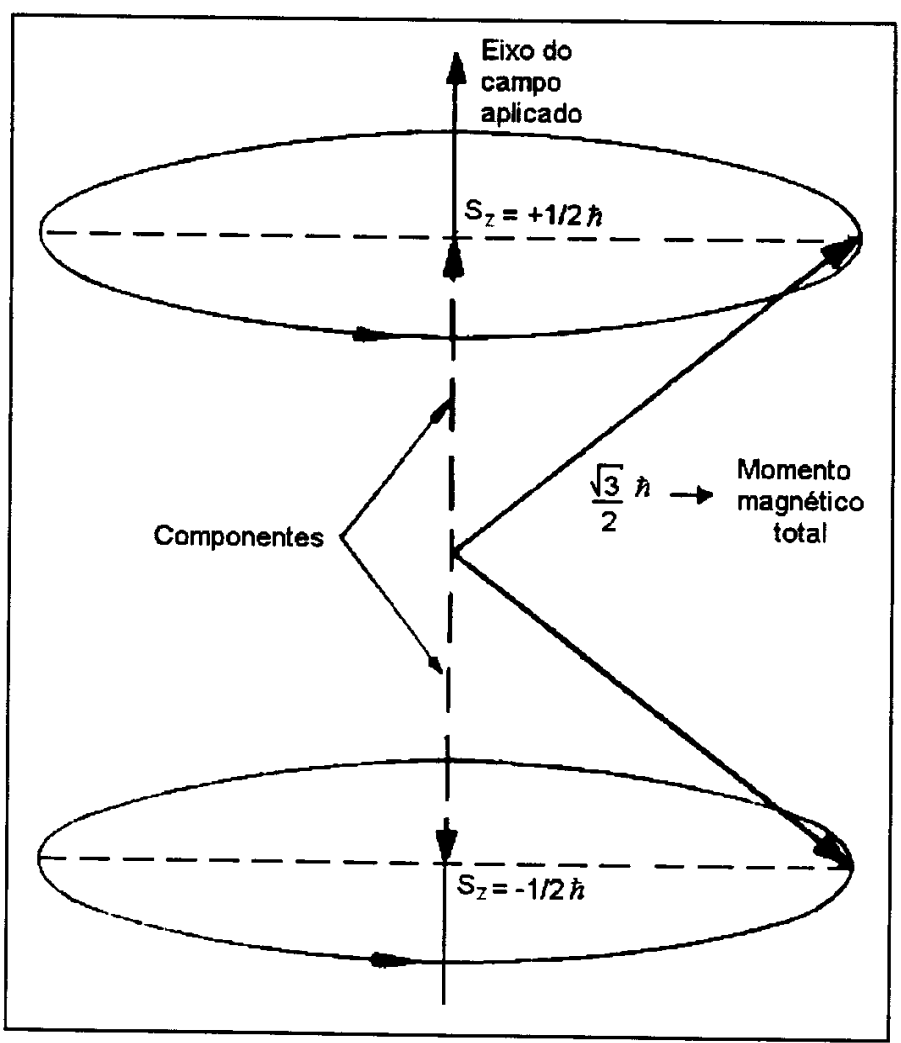

Figura 3.3: Partícula de momento angular de spin igual a $|\vec{S}|=\frac{\sqrt{3} \hbar}{2}$ (número de spin total $S=1 / 2$ ) sujeita a um campo magnético $\mathrm{H}_{0}$ aplicado na direção $\mathrm{z}$, cujas componentes $S_{\mathrm{z}}=1 / 2 \hbar \mathrm{e}$ $S_{z}=-1 / 2 \hbar$ são quantizadas em relação a esse eixo (Ingram, 1969) 
Os elétrons de spin alinhados paralelamente ao campo magnético $\left(S_{z}=-1 / 2 \hbar\right)$ têm suas energias reduzidas, enquanto que os alinhados antiparalelamente $\left(S_{z}=+1 / 2 \hbar\right)$ suas energias são incrementadas (desdobramento Zeeman). Esses valores de energia são quantizados, e podem ser descritos pela seguinte hamiltoniana (de efeito Zeeman):

$$
H=-\vec{\mu}_{s} \cdot \overrightarrow{\mathrm{H}},
$$

cujos autovalores são dados por:

$$
E=g \beta m_{s} H_{0},
$$

onde $\beta=\frac{\mathrm{e} \hbar}{2 \mathrm{mc}}=0,927332 \times 10^{-20}$ erg.gauss é o magnéton de Bohr.

No caso de campo magnético $\mathrm{H}_{0}$ aplicado na direção $\mathrm{z}$ o elétron livre apresenta dois possiveis valores de energia:

$$
\begin{gathered}
\mathrm{E}\left(\mathrm{m}_{\mathrm{s}}=1 / 2\right)=1 / 2 \mathrm{~g} \beta \mathrm{H}_{0}, \\
\mathrm{E}\left(\mathrm{m}_{\mathrm{s}}=-1 / 2\right)=-1 / 2 \mathrm{~g} \beta \mathrm{H}_{0} .
\end{gathered}
$$

A condição para que ocorra transição entre os níveis de energia é que a energia da radiação incidente corresponda a $\Delta \mathrm{E}=\mathrm{g} \beta \mathrm{H}_{0}=\mathrm{h} v\left(\right.$ ou $\Delta \mathrm{m}_{\mathrm{S}}= \pm 1$ ), a frequência da radiação deve ser na região de microondas (para campos da ordem de $3 \mathrm{KG}$ ), e a incidência perpendicular ao campo magnético (figura 3.4). 


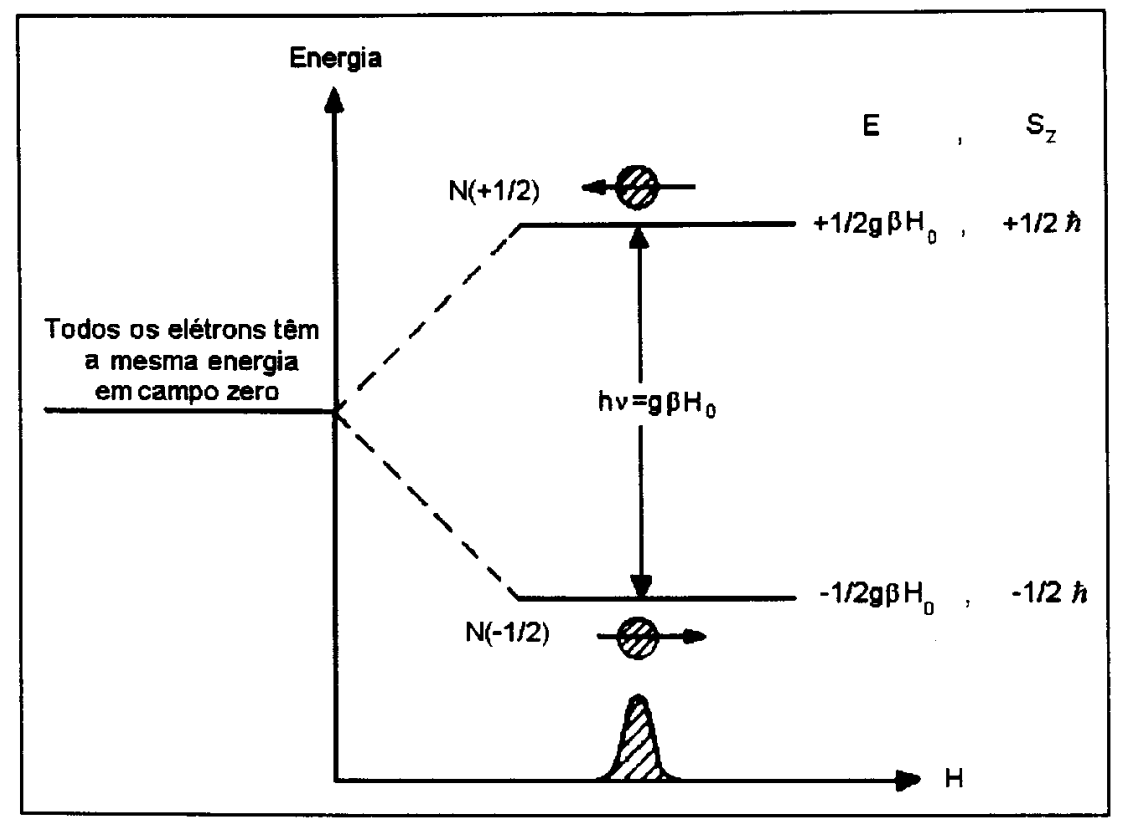

Figura 3.4: Condição básica para ressonância eletrônica, $h v=g \beta H$, onde $N(1 / 2)$ é o número de elétrons na amostra com spin $1 / 2$ e N(-1/2) é o número de elétrons com spin $-1 / 2$

Em EPR, devido a razões técnicas, o campo magnético é variado ao invés da frequência das microondas, uma vez que estas são limitadas pelas dimensões geométricas da válvula geradora chamada Klystron. As frequências mais comuns são: banda X (9,5 GHz), banda Q (35 GHz), banda S (2-4 GHz) e banda L (1-2 GHz).

O diagrama de transição é mais usualmente desenhado como na figura 3.5.a, na qual a frequência é mantida fixa e varia-se continuamente o campo magnético. A absorção de energia pelos elétrons quando "saltam" para um nível mais elevado pode ser detectada como uma redução na potência da radiação eletromagnética passando através do sistema, e esta redução é detectada por um sistema eletrônico existente nos espectrômetros de EPR (figura 3.5.b). Na maioria dos espectrômetros o que se obtém é a $1^{\mathbf{a}}$ derivada do sinal de absorção, uma vez que o campo magnético do eletroímã é modulado por outro campo magnético. 


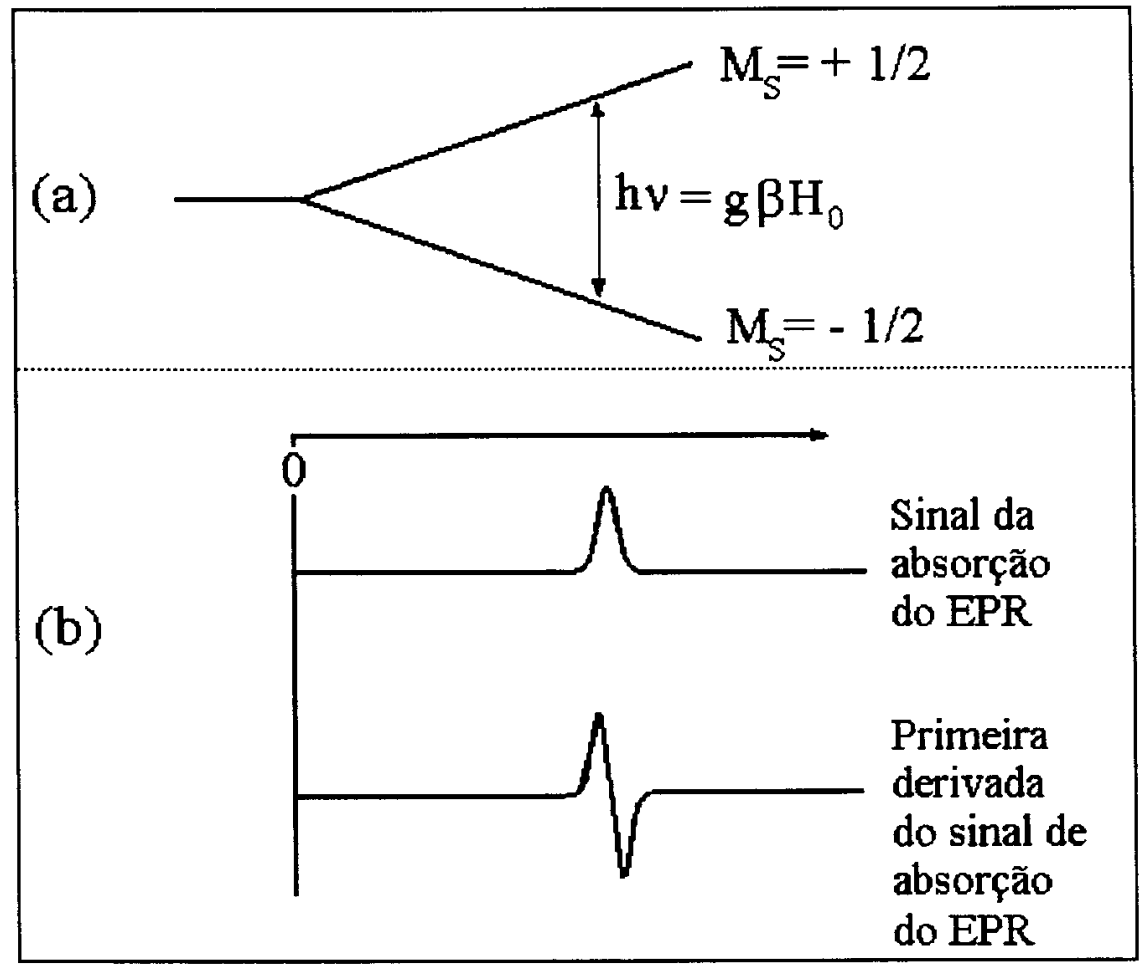

Figura 3.5: (a) Desdobramento dos níveis de energia do spin eletrônico na presença de um campo magnético ;(b) A forma da linha de absorção de enrgia do campo de microondas e (c) Derivada da linha de absorção

A técnica de modulação do campo magnético $\mathrm{H}_{0}$, gerado pelo eletroímã, chamada de "detecção sensível a fase", consiste em se superpor ao campo estático $\mathrm{H}_{0}$, um campo magnético variável de pequena amplitude $\mathrm{H}<<\mathrm{H}_{0}$. Em geral esse campo $\mathrm{H}$ tem amplitude de alguns $\mathrm{mG}$ e frequência de $100 \mathrm{KHz}$. Esse recurso é utilizado afim de ampliar o sinal de absorção, uma vez que o sinal de EPR representa uma mudança muito pequena na potência da microonda. Experimentalmente é mais conveniente amplificar correntes e voltagens alternadas e por isso deve-se converter o sinal contínuo devido aos spins, quando observado no detector de cristal, para um sinal alternado. Isso pode ser feito modulando-se $\mathrm{H}_{0}$. A curva da $1^{\mathrm{a}}$ derivada é obtida proporcionalmente a inclinação da linha de absorção, como mostrado na figura 3.6.

Outra razão de se usar o recurso da modulação do campo magnético é de obter-se tempos mais longos para a varredura do campo magnético através da ressonância (que ocorre muito rapidamente) aumentando assim a sensibilidade do aparelho. 


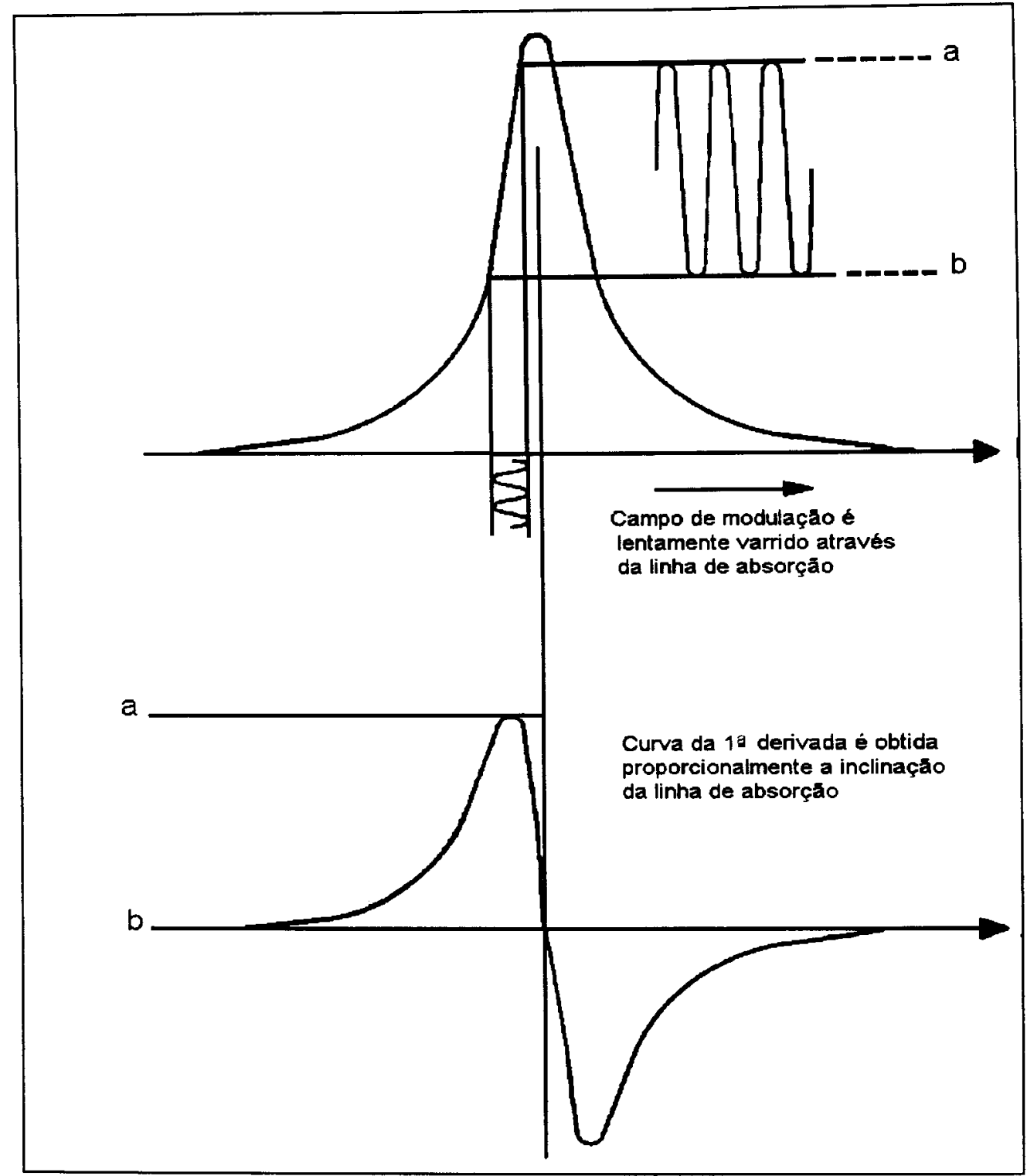

Figura 3.6: Desenho da $1^{\mathrm{a}}$ derivada produzido pelo campo de modulação de alta frequência (Ingram, 1969)

\subsubsection{Populações dos Estados de Spin}

Uma vez que Einsten mostrou que os coeficientes de absorção e emissão estimulada de luz são iguais, a única razão do porquê alguma absorção de microonda é observada é que, sob condições normais, o número de elétrons de spin paralelo ao campo $\mathrm{H}_{0}$ (população $\mathrm{N}(-1 / 2)$ ) é sempre maior que o número de elétrons de spin anti-paralelo (população $\mathrm{N}(+1 / 2)$ ), uma vez que são energeticamente mais favoráveis (pois possuem menor energia) (Ingram, 1969). No equilíbrio térmico a razão das duas populações é dada pela distribuição de Maxwell-Boltzmann (Bersohn \& Baird, 1966): 


$$
\frac{N(-1 / 2)}{N(+1 / 2)}=\exp \left(\frac{N(-1 / 2)-N(+1 / 2)}{K T}\right)=\exp \left(\frac{g \beta H_{0}}{K T}\right)
$$

onde $\mathrm{K}$ é a constante de Boltzmann e $\mathrm{T}$ a temperatura de equilíbrio do sistema de elétrons.

Quanto maior a razão $\frac{\mathrm{N}(-1 / 2)}{\mathrm{N}(+1 / 2)}$ mais forte o sinal da absorção, pois a absorção predominará sobre a emissão. Para uma temperatura de $\mathrm{T}=300 \mathrm{~K}, \mathrm{H}_{0}=$ $3400 \mathrm{G}$ e $\mathrm{g}=2,00$ tem-se que $\frac{\mathrm{N}(-1 / 2)}{\mathrm{N}(+1 / 2)}=1.0015$.

A intensidade do sinal é diretamente proporcional a diferença de população $\Delta n=N(-1 / 2)-N(+1 / 2)$. Considerando-se $N=N(-1 / 2)+N(+1 / 2)$, o número total de spins desemparelhados em ambas populações, e utilizando-se a equação (3.5) obtém-se:

$$
\Delta \mathrm{n}=\mathrm{N} \frac{\exp \left(\frac{\mathrm{g} \beta \mathrm{H}_{0}}{\mathrm{KT}}\right)-1}{\exp \left(\frac{\mathrm{g} \beta \mathrm{H}_{0}}{\mathrm{KT}}\right)+1}
$$

O denominador da expressão é aproximadamente igual a 2. Para os dados acima o denominador fica igual a 2.0002 , e obtemos:

$$
\Delta \mathrm{n}=\frac{\mathrm{N}}{2}\left[\exp \left(\frac{\mathrm{g} \beta \mathrm{H}_{0}}{\mathrm{KT}}\right)-1\right]
$$

Expandindo $\exp \left(\frac{\mathrm{g} \beta \mathrm{H}_{0}}{\mathrm{KT}}\right)$ em uma série de Taylor:

$$
\Delta \mathrm{n}=\frac{\mathrm{N}}{2}\left[\left(1+\frac{\mathrm{g} \beta \mathrm{H}_{0}}{\mathrm{KT}}+\frac{\left(\frac{\mathrm{g} \beta \mathrm{H}_{0}}{\mathrm{KT}}\right)^{2}}{2 !}+\cdots\right)-1\right]
$$


Geralmente $\frac{\mathrm{g} \beta \mathrm{H}_{0}}{\mathrm{KT}}$ é pequeno. Para os valores de $\mathrm{T}, \mathrm{H}_{0}$ e $\mathrm{g}$ anteriores, é aproximadamente igual a 0.0015 . Logo, pode-se desprezar todos os termos na expansão menos o primeiro, obtendo-se:

$$
\Delta \mathrm{n}=\frac{\mathrm{Ng} \beta \mathrm{H}_{0}}{2 \mathrm{KT}}
$$

Portanto a diferença de população varia inversamente com a temperatura absoluta. Uma linha espectral observada a temperatura de nitrogênio líquido $\left(T_{n}=77 \mathrm{~K}\right)$ é aproximadamente quatro vezes mais intensa que a mesma linha da mesma amostra a $300 \mathrm{~K}$.

\subsubsection{Relaxação Spin-Rede e Saturação}

A probabilidade de transição entre os estados do spin $\mathrm{P}_{(-1 / 2,+1 / 2)}$ é proporcional a densidade de energia da radiação $\rho(v)$. A equação da intensidade do sinal é dada por:

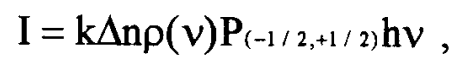

onde k é uma constante. Logo, se a potência da radiação de microonda é aumentada, o mesmo ocorre com a intensidade do sinal. Mas num dado valor de potência, a intensidade alcança um máximo, e o aumento da potência a partir desse ponto não implica no aumento do sinal, e sim no seu decréscimo e alargamento. Isto acontece porque a população de spin $+1 / 2$ torna-se aproximadamente igual a de spin $-1 / 2$, fenômeno conhecido por saturação (Bersohn \& Baird, 1966).

$O$ processo de relaxação spin-rede restabelece o equilíbrio entre a razão das populações, uma vez que o spin no estado excitado transfere energia para a rede (o meio vizinho). Esse processo de restabelecimento de equilíbrio leva um certo tempo, e é conhecido por tempo de relaxação spin-rede, o qual depende da força de acoplamento entre o spin e a rede. 


\subsubsection{Interação Spin-Órbita}

O elétron movendo-se em um orbital atômico associado a um único átomo, deve possuir um momento angular orbital considerável e mudará o valor de $\mathrm{g}$ daquele do spin livre. A razão básica dessa mudança é devido a interação do momento magnético orbital do elétron $\left(\vec{\mu}_{L}\right)$ com o momento magnético do spin do elétron $\left(\vec{\mu}_{s}\right)$ e pode ser descrita pela hamiltoniana:

$$
H=\lambda \vec{L} \cdot \vec{S}
$$

onde $L$ é o momento angular orbital e $\lambda$ a constante de acoplamento spin-órbita.

$\mathrm{O}$ estado fundamental do spin do elétron definido pelos números quânticos de spin $\mathrm{S}$ e orbital L, ao ser operado pela hamiltoniana spin-órbita têm seus momentos magnéticos $\left(\vec{\mu}_{s}\right.$ e $\left.\vec{\mu}_{L}\right)$ acoplados, formando um novo estado fundamental caracterizado pelo número quântico total $\overrightarrow{\mathrm{J}}=\overrightarrow{\mathrm{L}}+\overrightarrow{\mathrm{S}}$, degenerado $(2 \mathrm{~J}+1)$ vezes pela seguinte interação de Zeeman:

$$
H=\beta(\overrightarrow{\mathrm{L}}+\mathrm{gS}) \cdot \overrightarrow{\mathrm{H}}
$$

Os autovalores correspondentes a (3.12) são expressos pela equação (3.13):

$$
E=g_{\mathrm{J}} \beta \mathrm{m}_{\mathrm{J}} \mathrm{H}_{0}
$$

sendo $\mathrm{m}_{\mathrm{J}}=+\mathrm{J},(+\mathrm{J}-1), \ldots(-\mathrm{J}+1),-\mathrm{J}$, as componentes do spin total $\mathrm{J}$, e $g_{\mathrm{J}}=\frac{3 \mathrm{~J}(\mathrm{~J}+1)+\mathrm{S}(\mathrm{S}+1)-\mathrm{L}(\mathrm{L}+1)}{2 \mathrm{~J}(\mathrm{~J}+1)}$ o fator de Landé.

\subsubsection{Interação Hiperfina}

O desdobramento hiperfino origina-se da interação do elétron desemparelhado com o momento magnético de núcleos de qualquer átomo $\left(\vec{\mu}_{\mathrm{r}}\right)$ com o qual sua órbita esteja associada (Ingram, 1969). Em íons metais de transição (tais como: cobre(II), ferro(III) e manganês(II)), o desdobramento hiperfino dominante é 
devido ao núcleo do próprio íon, além da possibilidade de ocorrer estruturas chamadas super-hiperfinas devido a interação com núcleos de ligantes.

A hamiltoniana da interação magnética em um campo magnético externo é:

$$
H=\mathrm{g} \beta S_{\mathrm{z}} \mathrm{H}_{\mathrm{z}}+\mathrm{A} S_{\mathrm{z}} I_{\mathrm{z}}
$$

sendo A uma constante, $I_{\mathrm{z}}$ a componente (na direção do campo) do momento angular do spin nuclear. Os autovalores do hamiltoniano da equação (3.14) são dados por:

$$
E=g \beta m_{s} H_{0}+A m_{s} m_{I}
$$

sendo $A$ a constante hiperfina, $m_{I}=+I,+I-1, \ldots,-I+1$, $-I$, as componentes do spin nuclear I, portanto existem $(2 \mathrm{I}+1)$ valores da componente $\mathrm{z}$ do momento angular $\left(I_{\mathrm{z}}\right)$, e o estado é desdobrado desse número de vezes. Sendo assim existem $(2 I+1)$ linhas hiperfinas, que podem ser utilizadas para identificar o núcleo responsável pelo desdobramento.

A figura 3.7 mostra o esquema do desdobramento hiperfino do hidrogênio que possui $\mathrm{I}=1 / 2$, suas possíveis componentes são $\mathrm{m}_{\mathrm{I}}=+1 / 2,-1 / 2$, e spin total $\mathrm{S}=1 / 2$, as transições permitidas são $\Delta \mathrm{m}_{\mathrm{S}}= \pm 1$ e $\Delta \mathrm{m}_{\mathrm{I}}=0$.

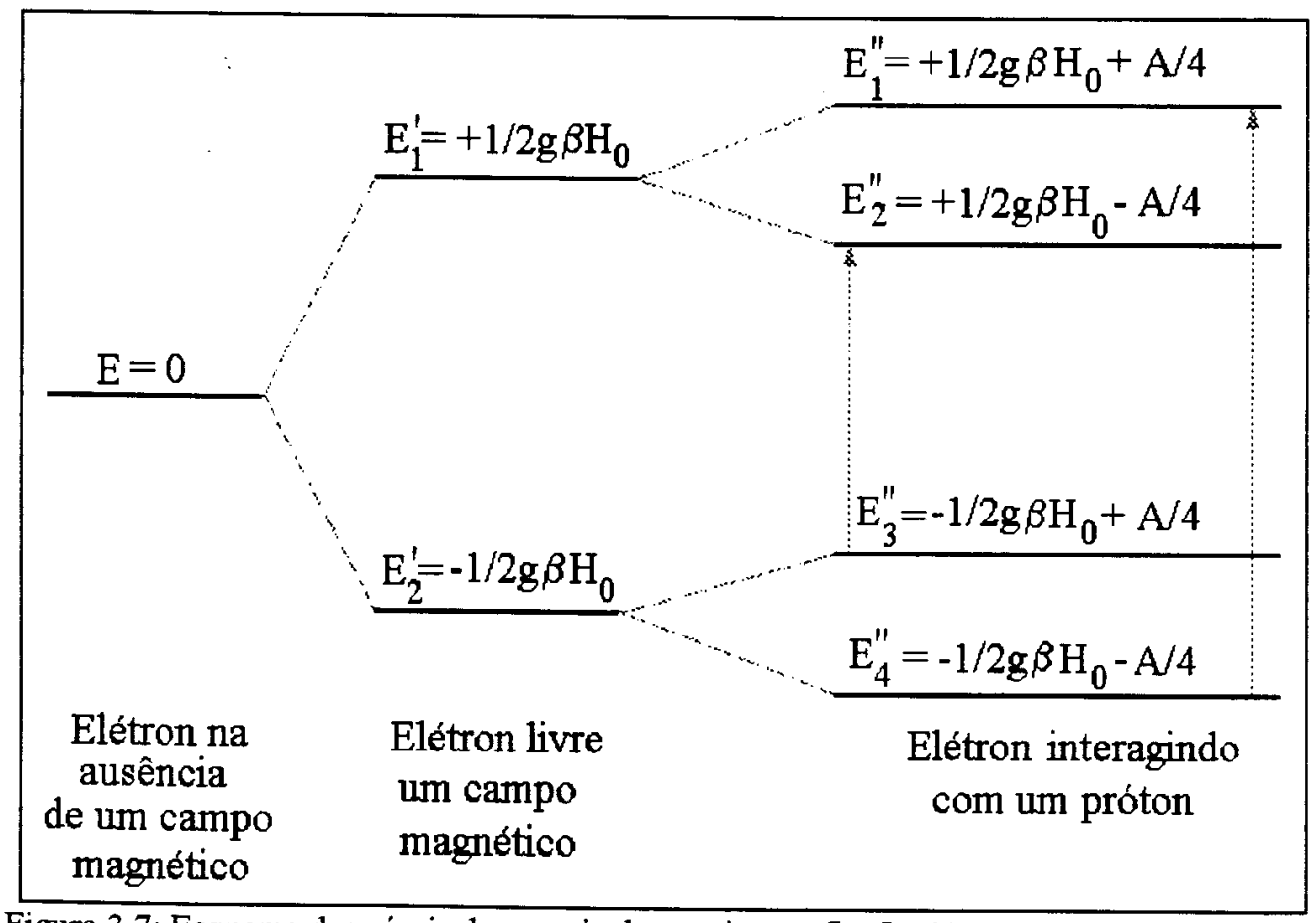

Figura 3.7: Esquema dos niveis de energia de um sistema $\mathrm{S}=\mathrm{I}=1 / 2 \mathrm{em}$ um campo magnético 
As múltiplas linhas de um único núcleo ou mútiplas linhas de diversos núcleos equivalentes podem ser diferenciadas. Estes últimos, embora igualmente espaçados, possuem intensidades diferentes, enquanto um único núcleo origina linhas de intensidades iguais. Em geral, os desdobramentos hiperfinos para $n$ núcleos equivalentes consistem de $(n+1)$ linhas que são igualmente espaçadas e têm intensidades dadas pelos coeficientes binomiais da expansão da expressão $(1+x)^{\mathbf{n}}$.

\subsubsection{Interações Dipolar (ou Anisotrópica) e de Contato (ou deFermi, ou Isotrópica)}

Considerando-se dois dipolos $\vec{\mu}_{\mathrm{s}}$ e $\vec{\mu}_{\mathrm{I}}$ (momentos magnéticos do spin do elétron e do spin do núcleo, respectivamente), separados de uma distância $\vec{r}$. : a hamiltoniana que representa estes dois tipos de interação dipolar pode ser representada pela mesma equação:

$$
H=\frac{\vec{\mu}_{\mathrm{s}} \cdot \vec{\mu}_{\mathrm{I}}}{\mathrm{r}^{3}}-3 \frac{\left(\vec{\mu}_{\mathrm{s}} \cdot \overrightarrow{\mathrm{r}}\right)\left(\vec{\mu}_{\mathrm{l}} \cdot \overrightarrow{\mathrm{r}}\right)}{\mathrm{r}^{5}},
$$

cuja energia é dada por:

$$
E=\operatorname{gg}_{N} \beta \beta_{N}\left[\frac{\left(3 \cos ^{2} \theta-1\right) S I}{r^{3}}-\frac{8 \pi}{3} \operatorname{SI} \delta(r)\right]
$$

onde $\beta_{\mathrm{N}}$ é o magnéton nuclear, $\mathrm{g}_{\mathrm{N}}$ é o valor giromagnético nuclear e $\delta(\mathrm{r})$ é a função delta, a qual é diferente de zero e unitária sómente para $\mathrm{r}=0$.

O primeiro termo entre colchetes da equação (3.17) representa a interação anisotrópica, e refere-se a estados quânticos diferentes de s. A interação direta dipolo-dipolo tem uma variação dada por $\left(3 \cos ^{2} \theta-1\right)$ que varia de um máximo de 2 para um mínimo de -1 quando o ângulo é variado de 0 a $\pi / 2$. Tanto pode ser aplicada para as interações hiperfinas do elétron com o próprio núcleo, como para as interações super-hiperfinas do elétron com núcleos de átomos vizinhos.

Em um líquido, todas as moléculas estão se movendo rapidamente, então a molécula próxima de algum específico elétron desemparelhado muda de posição rapidamente, e em geral em um tempo muito menor que a transição do spin 
do elétron. Com isso o campo magnético incrementado, experimentado pelo particular elétron desemparelhado, na verdade será uma média de todos produzidos pelas diferentes moléculas que estarão instantaneamente presentes durante a transição. Um valor médio de $\left(3 \cos ^{2} \theta-1\right)$, tomado sobre todos os possíveis ângulos é nulo. Portanto, desde que o movimento molecular desordenado é suficientemente rápido, todos os elétrons desemparelhados experimentam um campo magnético o qual tem um valor médio nulo por esse movimento.

O outro termo da equação (3.17) representa a interação de Fermi, a qual origina-se do fato da "função de onda" s do elétron ter um probabilidade finita de existir no sítio nuclear. É independente do ângulo entre o campo magnético aplicado e a orientação molecular, portanto é a mesma para cada molécula em um líquido.

\subsubsection{Efeito do Campo Cristalino}

A teoria eletrostática do campo cristalino, considera compostos tais como metal de transição ou um sal hidratado de um íon de transição como sendo um agregado de íons e moléculas que interatuam eletrostaticamente, mas que não trocam elétrons entre si, isto é, não considera a ligação covalente (Orgel, 1960).

Ao contrário do que ocorre com os íons livres, os elétrons desemparelhados, de íons metais de transição coordenados estão principalmente localizados em orbitais atômicos muito próximos de um particular átomo (os ligantes). Isto causa um forte acoplamente entre o spin e o movimento orbital do átomo, e como resultado, o valor de g associado com a ressonância do elétron difere largamente do encontrado para o spin livre.

A hamiltoniana dos elétrons em ambos os casos (íons livre e coordenado) na ausência de campo magnético externo é:

$$
H=\Sigma_{i} \frac{p_{i}^{2}}{2 m}+V
$$


onde o termo $\sum_{i} \frac{p_{i}^{2}}{2 m}$ é a energia cinética total do íon, e a somatória é sobre o índice $\mathrm{i}$ designando para cada elétron do íon, e V é o potencial experimentado, o qual é distinto para cada um dos dois casos.

Para o átomo livre o potêncial V é o da equação 3.19 (Pake, 1962). O primeiro termo é a atração coulombiana entre o núcleo e os elétrons, o segundo termo é a repulsão coulombiana entre os elétrons, o terceiro termo é o do acoplamento spinórbita, o quarto termo é a interação magnética (interação hiperfina) entre cada elétron e o núcleo.

$$
\mathrm{V}_{\text {livre }}=-\frac{\mathrm{Ze}^{2}}{\mathrm{r}_{\mathrm{i}}}+\frac{\mathrm{e}^{2}}{\mathrm{r}_{\mathrm{ij}}}+\lambda_{\mathrm{ij}} \overrightarrow{\mathrm{L}}_{\mathrm{ij}} \cdot \overrightarrow{\mathrm{S}}_{\mathrm{ij}}+a_{i} \overrightarrow{\mathrm{J}}_{i} \cdot \overrightarrow{\mathrm{I}}
$$

Para o íon metal ligado o potencial V é dado pela equação (3.20). O segundo termo é a interação do campo cristalino (potencial dos ligantes), no qual é suposto que a amostra cristalina externa dá origem ao campo eletrostático $\Phi_{\mathrm{c}}$ no íon com o qual cada elétron $-e_{i}$ interage.

$$
\mathrm{V}=\mathrm{V}_{\text {livre }}-\mathrm{e}_{\mathrm{i}} \Phi_{\mathrm{C}}\left(\overrightarrow{\mathrm{r}}_{\mathrm{i}}\right)
$$

Para o caso em que o potencial dos ligantes é maior que a interação spin-órbita, como é o caso dos íons dos metais de transição do grupo do ferro, o campo elétrico que atua sobre os elétrons perde a simetria do ín livre, e o estado fundamental a ser desdobrado por $H$ não é mais caracterizado por $\overrightarrow{\mathrm{J}}$ e o fator giro magnético medido não é mais descrito pela equação (3.12).

Os íons de metais de transição são caracterizados por ter a camada $3 \mathrm{~d}$ incompleta $(n=3$ e $1=2)$, a qual tem cinco funções angulares $\left(m_{1}=+1,+1-1, \ldots,-1+1\right.$, -1), a ilustração destes orbitais para um átomo livre está mostrado na figura 3.8. Uma vez que ao considerar os cinco orbitais como um conjunto, este tem simetria esférica, sendo assim na ausência de campos elétrico e magnético externos, não existe direção com a qual algum dos três eixos ( $\mathrm{x}, \mathrm{y}$ e $\mathrm{z}$ ) possa ser identificado, portanto todos os cinco estados são degenerados (possuem a mesma energia). 


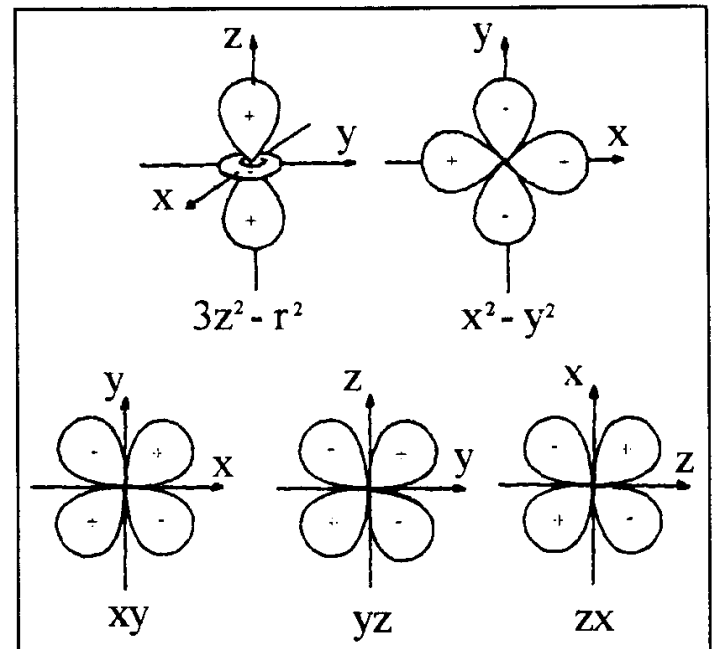

Figura 3.8: Distribuição angular da densidade eletrônica das cinco funções radiais $d$

O ín metálico coordenado terá seus orbitais modificados em relação aos do íon livre conforme a simetria do campo eletrostático criado pela coordenação com os ligantes.

Pelo método do campo cristalino, para um complexo de coordenação octaédrica regular (em geral a encontrada no centros paramagnéticos de ions metais de transição), os ligantes são substituídos por seis cargas pontuais negativas equivalentes nos vértices do octaedro, produzindo um campo eletrostático sobre o íon (de simetria cúbica) que está no centro (figura 3.9.a). Os elétrons nos orbitais $\mathrm{e}_{\mathrm{g}}\left(\left(3 \mathrm{z}^{2}\right.\right.$ $\left.-r^{2}\right)$ e $\left(x^{2}-y^{2}\right)$ ) sofrem uma repulsão maior do que os orbitais $t_{2 g}(x y, y z e z x)$, uma vez que os quatro lobos do orbital $\left(\mathrm{x}^{2}-\mathrm{y}^{2}\right)$ apontam na direção dos quatro átomos ao longo dos eixos x e y, e do mesmo modo, os dois lobos do orbital $\left(3 z^{2}-r^{2}\right)$ apontam na direção dos dois átomos ao longo do eixo z. Mais energia será exigida para locar os elétrons nestes dois orbitais do que no outros, removendo a degenerescência do íon livre.

Nos complexos de coordenação tetraédrica o íon localiza-se no centro, e quatro dos seis ligantes estão nas bissetrizes do plano xy (figura 3.9.b), portanto os orbitais $t_{2}(x y, y z$ e $z x)$ apontam na direção dos ligantes e os orbitais e $\left(\left(3 z^{2}-r^{2}\right)\right.$ e $\left(x^{2}\right.$ $\left.-y^{2}\right)$ ) na direção de densidade de spin zero.

A figura 3.9.c mostra o desdobramento dos níveis de energia do íon para as duas coordenações dos ligantes. 

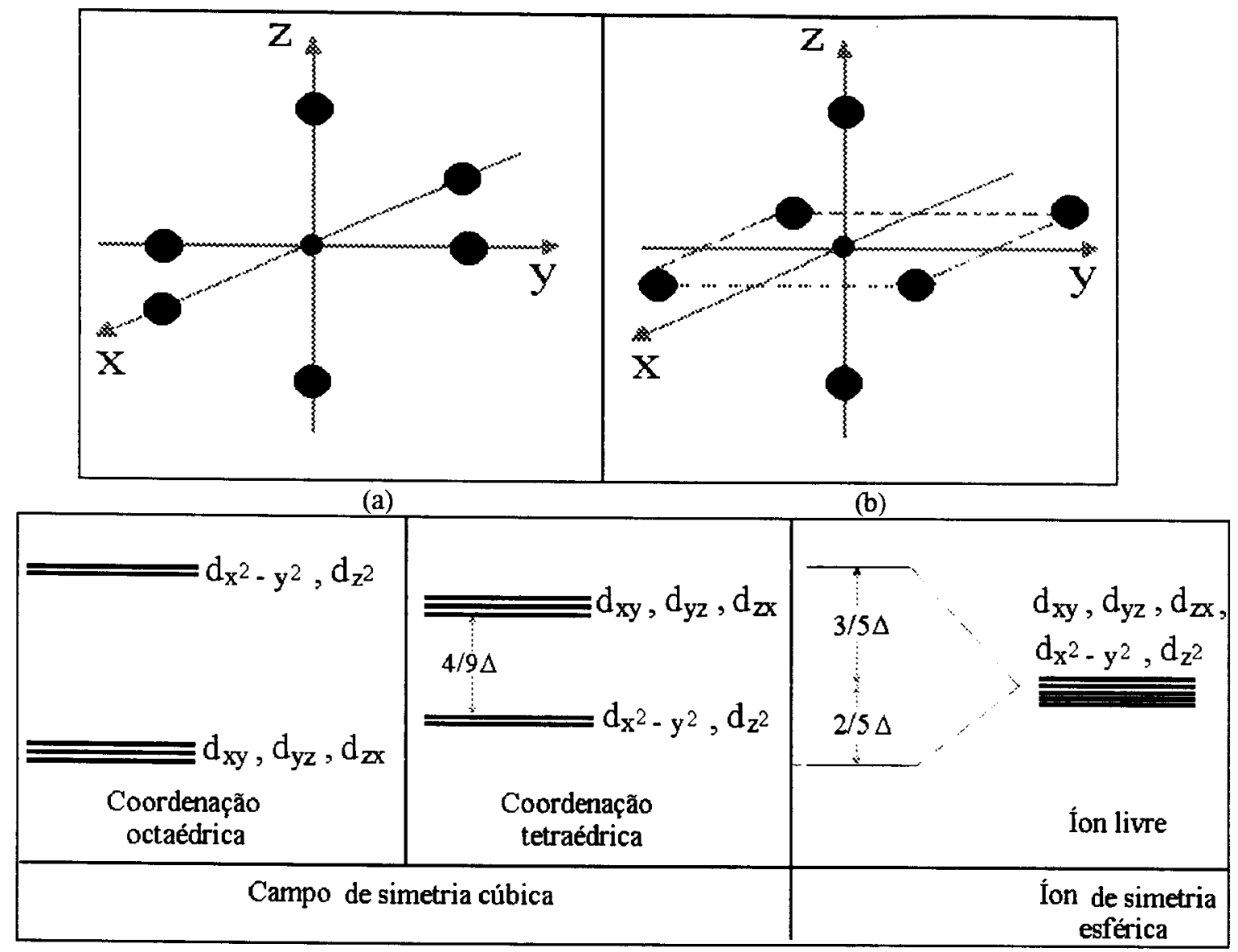

(c)

Figura 3.9: (a) Íon coordenado octaédricamente pelos ligantes, (b) Íon coordenado tetraédricamente pelos ligantes e (c) desdobramentos dos niveis de energia do íon livre para as duas coordenações dos ligantes

$\mathrm{Na}$ prática a tendência é encontrar íons em campos de simetrias distorcidas da produzida por coordenação octaédrica e tetraédrica puras dos ligantes. A origem das distorções da simetria do campos eletrostático deve-se ao fato de que: ou os ligantes são diferentes, ou apesar de serem iguais, as suas interações com os elétrons dos diferentes orbitais d não possui mesma intensidade, pois estes têm diferentes números de elétrons

A simetria octaédrica com distorção tetragonal ocorre por achatamento ou alongamento do octaédro, isto é, por aproximação ou distanciamento dos dois ligantes ao longo do eixo-z (figura 3.10.a), dando origem a um campo de simetria tetragonal. $\mathrm{O}$ nível octaédrico $\mathrm{e}_{\mathrm{g}}$ se subdivide em dois, e o $\mathrm{t}_{2 \mathrm{~g}} \mathrm{em}$ um nível não degenerado que contém somente o orbital $d_{x y}$ e um duplamente degenerado que contém os orbitais $d_{x z}$ e $d_{y z}$ (figura 3.10.a). A distorsão rômbica se forma pela deformação do octaédro tetragonal ao longo do eixo $x$ (figura 2.10.a), por 
compressão ou distensão, se elimina a equivalência de x e y. Os cinco orbitais tem diferentes energias (figura 3.10.b).

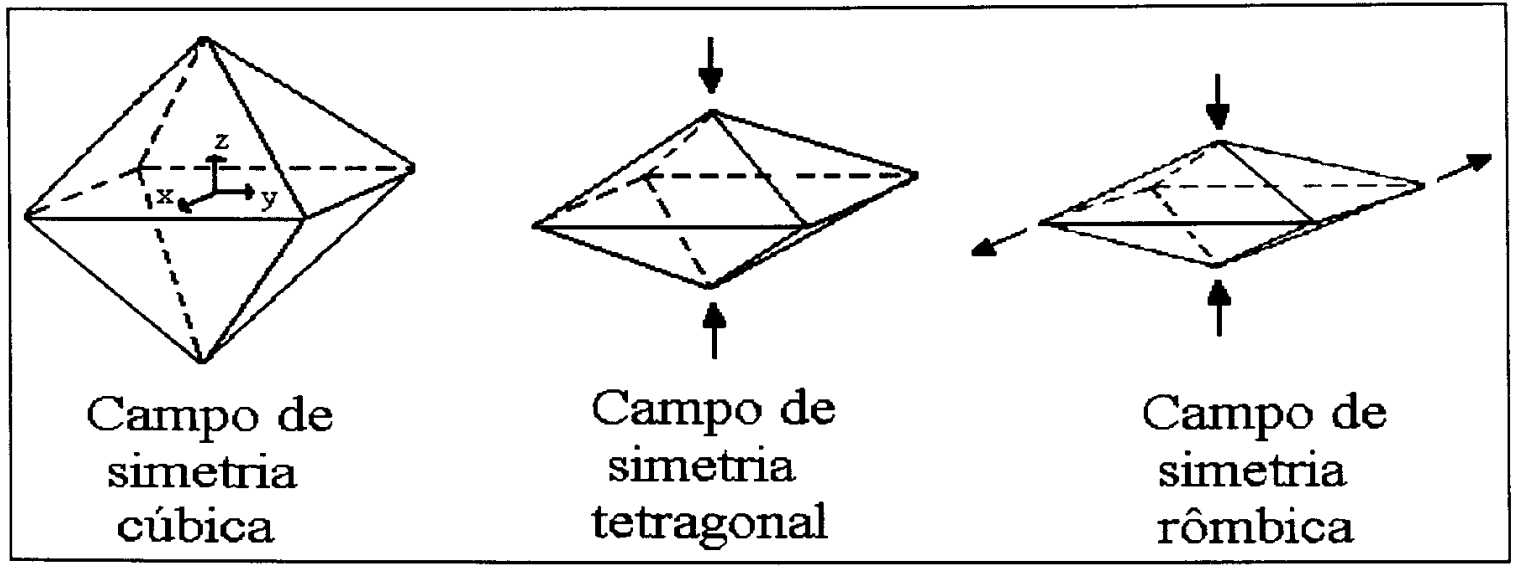

(a)

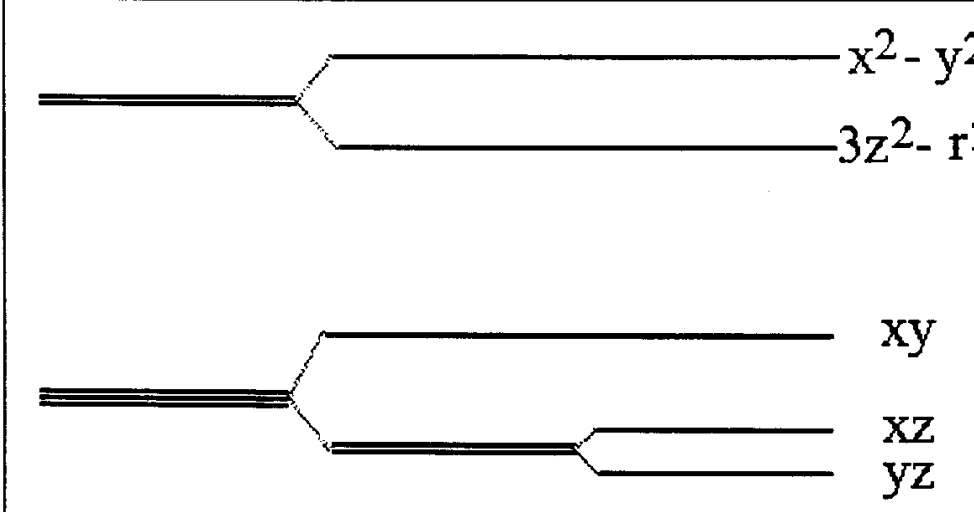

\section{Simetria Simetria Simetria Cúbica Tetragonal Rômbica}

(b)

Figura 3.10: (a) Distorções da simetria cúbica (ion coordenado octaédricamente): simetria tetragonal e simetria rômbica, e (b) níveis de energia dos orbitais d do íon paramagnético sob as diferentes distorsões do campo eletrostático de simetria cúbica

A distribuição eletrônica, baseada no princípio de exclusão de Pauli e na regra de Hund, definem a configuração de spin alta ou baixa, para uma dada simetria dos ligantes. $\mathrm{O}$ spin baixo ocorre quando o campo ligante é forte, pois a energia de desdobramento, $\Delta$, entre os orbitais $e_{g}$ e $t_{2 g}$ é grande o bastante, de modo que os elétrons seguem a regra de Rund e ocupam os orbitais de mais baixa energia, ao invés de distribuírem-se pelos cinco orbitais. $\mathrm{O}$ caso de spin baixo ocorre quando o desdobramento é pequeno e os elétrons distribuiem-se pelos dois conjuntos de orbitais ,$t_{2 g}$ e $e_{g}$, resultando assim uma configuração de spin alto. A figura 3.11 mostra as 
situações de spin baixo e spin alto para o íon metálico ferro(III) (orbital $3 d^{5}$ ) de coordenação octaédrica.

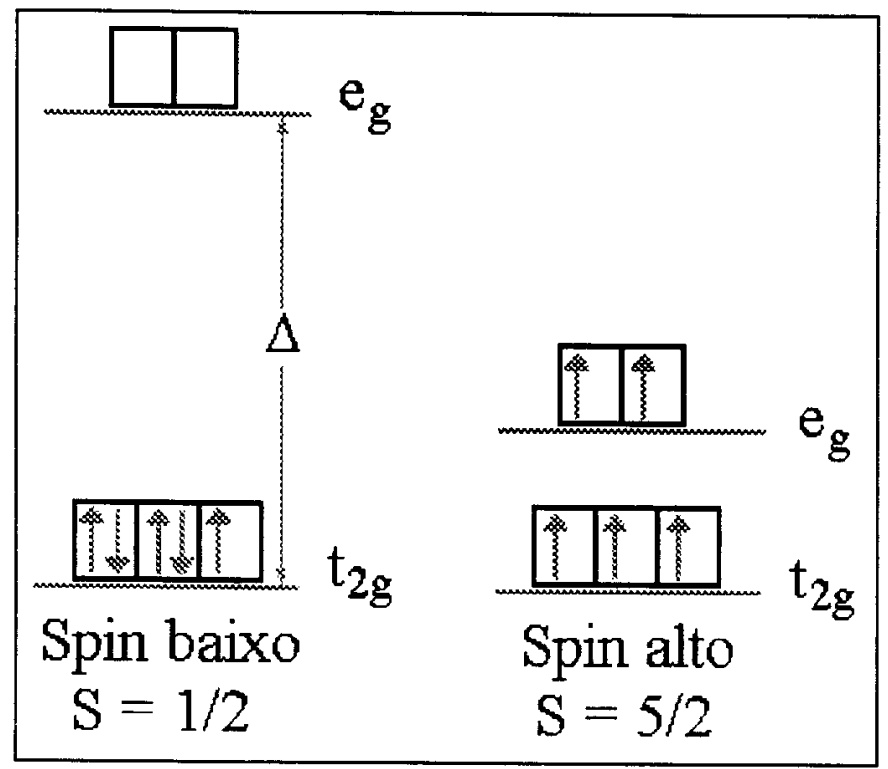

Figura 3.11: Configurações de spin baixo e spin alto para a coordenação octaédrica do íon metal ferro(III) (orbital $3 d^{5}$ )

\subsubsection{Interação de Intercâmbio (ou de Troca)}

A interação de troca é uma fenômeno quântico, sem analogia na fisica clássica, e ocorre entre centros paramagnéticos iguais quando estão suficientemente próximos para que haja superposição das funções de onda dos elétrons desemparelhados, a consequência é que os spins fazem intercâmbio entre as suas posições, como consequência desaparece a interação hiperfina e reduz a largura de linha ao redor do valor de $\mathrm{g}$.

\subsubsection{Anisotropia dos Espectros de EPR}

Uma das características do espectro de EPR é que em muitos casos as posições e as separações das linhas (especificadas pelos valores de g e constantes hiperfinas) dependem da direção do campo magnético relativa ao eixos moleculares Em outras palavras, os espectros podem ser anisotrópicos uma vez que existam diferentes simetrias do campo experimentado pelo elétron paramagnético.

Os termos da hamiltoniana do spin (devido ao efeito Zeeman eletrônico e devido a interação hiperfina) para algumas simetrias dos campos são dadas por: 
$\Rightarrow \quad$ Simetria cúbica:

$$
H=\mathrm{g} \beta \vec{S} \cdot \overrightarrow{\mathrm{H}}+\mathrm{A} \vec{S} \cdot \vec{I}
$$

$\mathrm{g}=\mathrm{g}_{\mathrm{x}}=\mathrm{g}_{\mathrm{y}}=\mathrm{g}_{\mathrm{z}}$,

$\mathrm{A}=\mathrm{A}_{\mathrm{x}}=\mathrm{A}_{\mathrm{y}}=\mathrm{A}_{\mathrm{z}}$.

$\Rightarrow$ Simetria axial (eixo $z$, sistemas teatragonal, trigonal e hexagonal):

$$
H=\mathrm{g}_{/ /} \beta S_{\mathrm{z}} \mathrm{H}_{z}+\mathrm{g}_{\perp} \beta\left(\mathrm{H}_{x} S_{\mathrm{x}}+\mathrm{H}_{y} S_{\mathrm{y}}\right)+\mathrm{A}_{/ /} S_{z} I_{z}+\mathrm{A}_{\iota}\left(S_{\mathrm{x}} I_{\mathrm{x}}+S_{\mathrm{y}} I_{y}\right)
$$

$\mathrm{g}_{\perp}=\mathrm{g}_{\mathrm{x}}=\mathrm{g}_{\mathrm{y}}$ e $\mathrm{g}_{/ /}=\mathrm{g}_{\mathrm{z}}$,

$\mathrm{A}_{\llcorner}=\mathrm{A}_{\mathrm{x}}=\mathrm{A}_{\mathrm{y}}$ e $\mathrm{g}_{/ /}=\mathrm{g}_{\mathrm{z}}$.

$\Rightarrow$ Simetria rômbica:

$$
H=\beta\left(\mathrm{g}_{\mathrm{x}} \mathrm{H}_{\mathrm{x}} S_{\mathrm{x}}+\mathrm{g}_{\mathrm{y}} \mathrm{H}_{y} S_{\mathrm{y}}+\mathrm{g}_{z} S_{2} \mathrm{H}_{z}\right)+\mathrm{A}_{x} S_{\mathrm{x}} I_{\mathrm{x}}+\mathrm{A}_{\mathrm{y}} S_{\mathrm{y}} I_{\mathrm{y}}+\mathrm{A}_{z} S_{z} I_{z},
$$

$\mathrm{g}_{\mathrm{x}} \neq \mathrm{g}_{\mathrm{y}} \neq \mathrm{g}_{\mathrm{z}}$

$A_{x} \neq A_{y} \neq A_{z}$.

\subsection{9. a Espectros de Amostras em Solução}

As moléculas em solução diluída e não viscosa possuem um movimento rápido e randômico, por isso os efeitos da anisotropia são anulados. Os valores de $\mathrm{g}$ e da constante hiperfina será uma média dos valores principais dos tensores $g\left(g_{x}, g_{y}\right.$ e $\left.g_{z}\right)$ e $A\left(A_{x}, A_{y}\right.$ e $\left.A_{z}\right)$. Esses valores são conhecidos como $g$ isotrópico $\left(\mathrm{g}_{0}\right)$ e constante isotrópica hiperfina $\left(\mathrm{A}_{0}\right)$ e são dados por:

$\Rightarrow$ Simetria axial:

$$
\begin{aligned}
\mathrm{A}_{0} & =1 / 3\left(\mathrm{~A}_{/ /}+2 \mathrm{~A}_{\perp}\right), \\
\mathrm{g}_{0} & =1 / 3\left(\mathrm{~g}_{/ /}+2 \mathrm{~g}_{\perp}\right),
\end{aligned}
$$


pois $g_{\perp}=g_{x}=g_{y}$ e $g_{/ /}=g_{z}$ e $A_{\perp}=A_{x}=A_{y}$ e $A_{/ /}=A_{z}$.

$\Rightarrow$ Simetria rômbica:

$$
\begin{gathered}
A_{0}=1 / 3\left(A_{x x}+A_{y y}+A_{z z}\right), \\
g_{0}=1 / 3\left(g_{x x}+g_{y y}+g_{z z}\right),
\end{gathered}
$$

pois $g_{x} \neq g_{y} \neq g_{z}$ e $A_{x} \neq A_{y} \neq A_{z}$.

A figura 3.12 mostra um espectro típico de complexo de cobre em solução a temperatura ambiente. $\mathrm{O}$ spin nuclear do cobre é $\mathrm{I}=3 / 2$, portanto as quatro linhas observadas são devidas a interação hiperfina do cobre com o próprio núcleo.

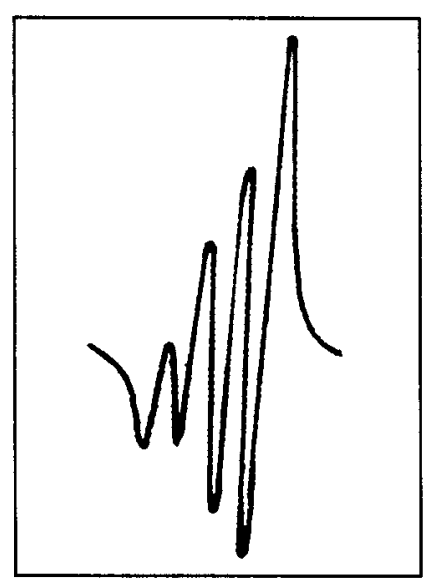

Figura 3.12: Espectro de um complexo de cobre em solução a temperatura ambiente

\subsection{9.b Espectros de Amostras em Estado Sólido}

Amostras em estado sólido compreende-se também amostras policristalinas e soluções congeladas.

Quando se abaixa a temperatura as moléculas já não possuem mais movimentos rápidos nem randômicos, então as contribuições de todas possíveis orientações poderão ser detectadas. As posições do campo magnético, $\mathrm{H}$, para obter transições de EPR são dadas pela equação (Knowles et al, 1976):

$$
h \nu=g_{\theta} \beta H+1 / 2 A_{\theta} m_{I}
$$


Para a simetria axial do campo experimentado pelo centro paramagnético, os valores de $\mathrm{g}$ e $\mathrm{A}$ em orientações intermediárias $\left(\mathrm{g}_{\theta}\right.$ e $\left.\mathrm{A}_{\theta}\right)$, o quais dependem do ângulo entre o campo e os eixos principais, são dados pelas equações:

$$
\begin{aligned}
g_{\theta}^{2} & =g_{/ /}^{2} \cos ^{2} \theta+g_{\perp}^{2} \operatorname{sen}^{2} \theta, \\
A_{\theta}^{2} & =A_{/ /}^{2} \cos ^{2} \theta+A_{\perp}^{2} \operatorname{sen}^{2} \theta .
\end{aligned}
$$

A figura 3.13 mostra a variação angular do valor de g com o campo magnético em uma simetria axial.

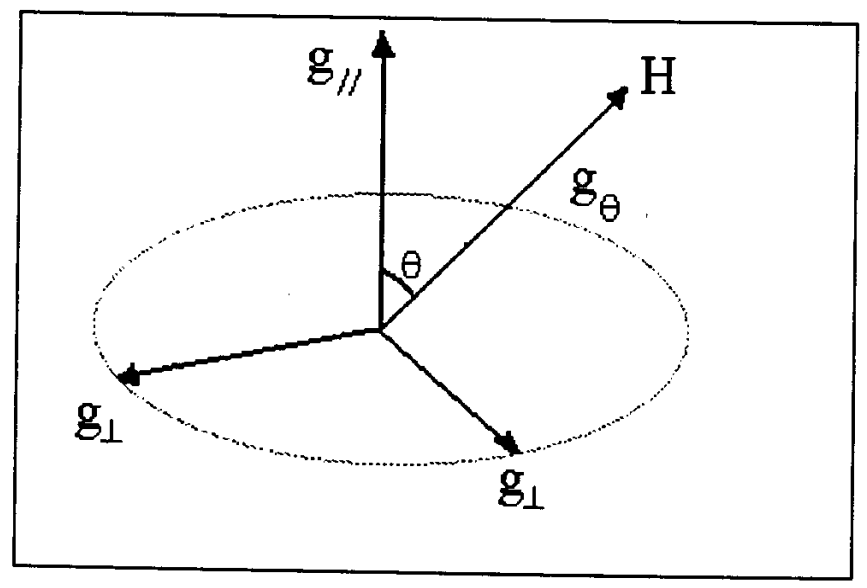

Figura 3.13: Variação angular do valor de g com o campo magnético em uma simetria axial

Ao invés de linhas finas encontradas nos espectros isotrópicos, devido a anisotropia as linhas são largas e distorcidas. A princípio todos os valores de A e g deveriam ser determinados nestes espectros. Mas devido a sobreposição dos espectros, nem sempre é possível.

A figura 3.14 mostra um espectro de solução congelada (ou espectro de pó) de uma proteína de cobre com simetria axial. 


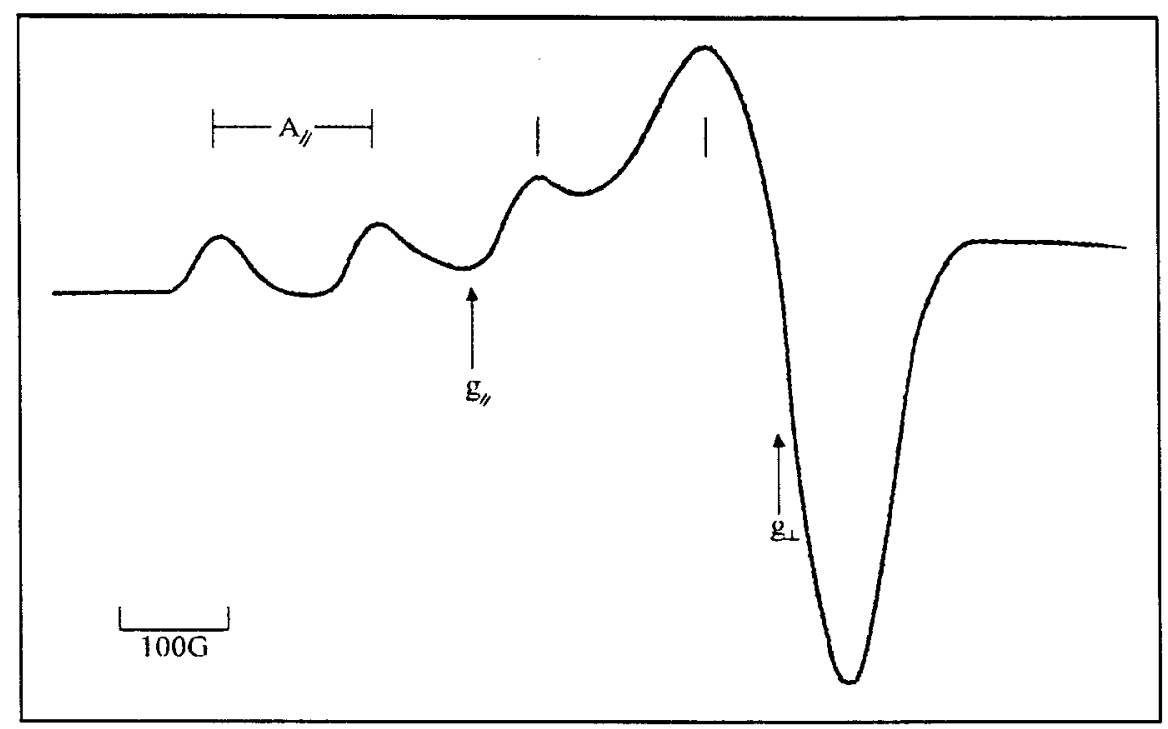

Figura 3.14: Espectro de EPR de amostra policristalina de uma proteina de cobre a $150^{\circ} \mathrm{C}$ (Knowles et al, 1976)

A contribuição de g $g_{\perp}$ para o espectro é a mais intensa porque há mais centros paramagnéticos nos quais o campo é perpendicular ao eixo $\mathrm{z}$, onde se mede $\mathrm{g}_{\perp}$ (McMillan, 1975).

\subsubsection{Método do Padrão Secundário para Deteç̧ão do Radical Livre Semiquinona}

Para a quantificação do radical livre semiquinona encontrado foi usado o método do padrão secundário (Singer, 1959), com um cristal de rubi $\left(\mathrm{Al}_{2} \mathrm{O}_{3}\right)$ contendo $0,5 \%$ de $\mathrm{Cr}^{+3}$ por peso, e seu fator $\mathrm{g}$ é 1,2629 , e portanto não interfere com o sinal do radical livre semiquinona, cujo valor de g é em torno de 2,03 .

A equação utilizada para determinação do número de radicais livres $\left(\mathrm{N}_{0}\right)$ foi (Poole, 1967):

$$
N_{0}=K\left|\frac{I_{A} \cdot\left(\Delta H_{\text {App }}\right)^{2} \cdot M_{R} \cdot G_{R}}{M_{A} \cdot G_{A} \cdot I_{R}}\right|,
$$

onde $\Delta H_{A p p}$ a largura de linha pico a pico da amostra, $I_{A}, I_{R}, M_{A}, M_{R}, G_{A}$ e $G_{R}$ são intensidade do sinal, modulação e ganho da amostra e do rubi, respectivamente. K é uma constante calculada da seguinte maneira: introduz-se um 'pitch' de $\mathrm{KCl}$ (padrão da Varian - 'strong pitch') que contém $3 \times 10^{15} \mathrm{spins} / \mathrm{cm}$, na cavidade, mede-se 
quantos cm estão na cavidade, e consequentemente o número de spins. Junto com o "pitch" de $\mathrm{KCl}$ coloca-se o padrão secundário (rubi). Após a aquisição dos parâmetros intensidade, ganho, amplitude de modulação do "pitch" e do rubi e da largura de linha do sinal do pitch, $\Delta \mathrm{H}_{\mathrm{Ppp}}$, monta-se a seguinte equação:

$$
N_{*}=K\left|\frac{I_{P} \cdot\left(\Delta H_{P}\right)^{2} \cdot M_{R} \cdot G_{R}}{M_{P} \cdot G_{P} \cdot I_{R}}\right|,
$$

onde $\mathrm{N}_{*}=3 \times 10^{15}$ spins para cada $\mathrm{cm}$ do pitch na cavidade, obtendo-se então a constante $\mathrm{K}$ :

$$
K=N_{*}\left|\frac{I_{R} \cdot M_{P} \cdot G_{P}}{M_{R} \cdot G_{R} \cdot I_{P} \cdot\left(\Delta H_{P}\right)^{2}}\right|
$$

\subsection{Espectroscopia de Absorção Eletrônica - UV-Visivel}

\subsubsection{Introdução}

Os espectros no UV-visível compreendem as seguintes regiões espectrais: $200-400 \mathrm{~nm}$ (ultravioleta) e 400-750 nm (visível).

A radiação cujo comprimento de onda está no intervalo citado acima causa transições eletrônicas e simultaneamente promove transições vibracionais e rotacionais.

Espectroscopia eletrônica trata com transições de moléculas entre diferentes potenciais eletrônicos (figura 3.15) (Harris \& Bertolucci, 1978). Em termos de teoria de orbital molecular, um elétron é promovido de um orbital de menor energia para um orbital de maior energia, ou o arranjo de elétrons dentro de um conjunto de estados degenerados é mudado tal que a energia total é aumentada. Essa transição, em geral leva, a uma diminuição da energia do estado vibracional do poço de potencial do estado excitado comparada com o poço do estado fundamental. A geometria da molécula pode também mudar no estado excitado. 


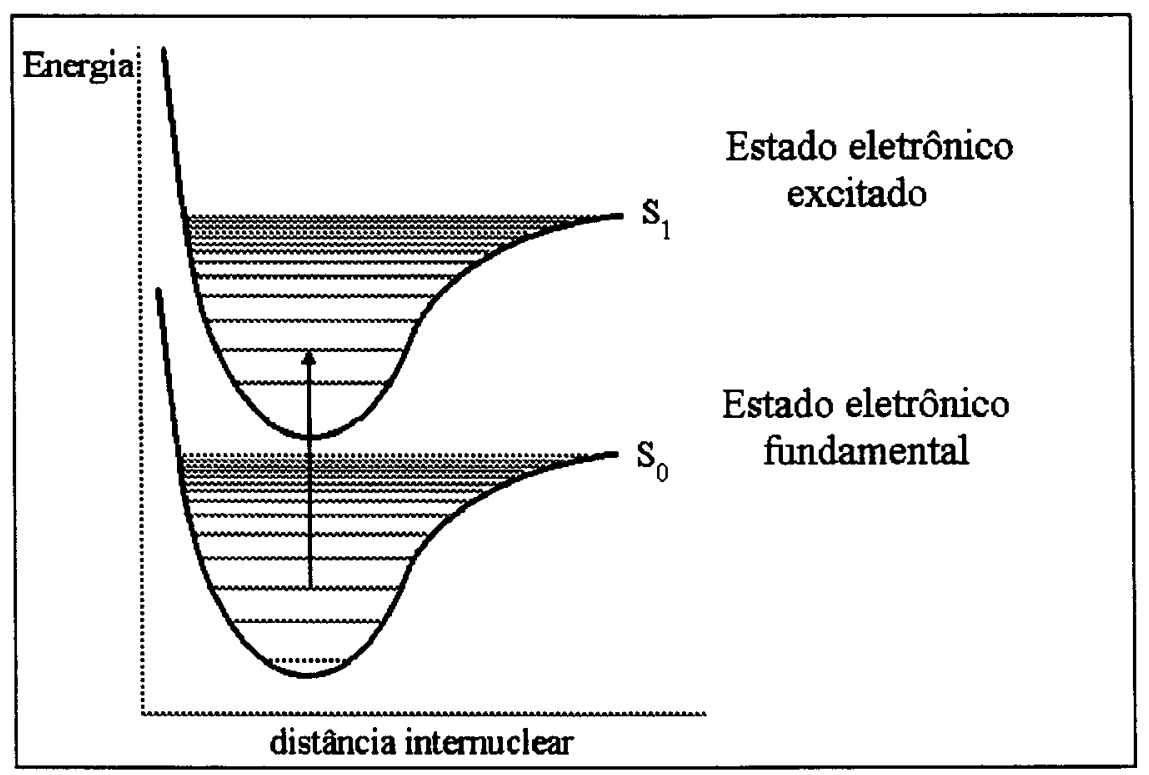

Figura 3.15: Transição eletrônica

\subsubsection{Lei de Beer-Lambert}

A lei de Beer-Lambert forma a base matemática-física das medidas de absorção de luz de gases e soluções na região uv-visível e infravermelho (Perkampus, 1992). A expressão informa quanta energia para um dado comprimento de onda $(\lambda)$ foi absorvida pelas moléculas da amostra em função de sua espessura (1), concentração molar (C) e do coeficiente de absorção molar ( $(\varepsilon)$ dessa amostra. Considerando que, $I_{0}$ é a intensidade da luz incidente e $I_{T}$ da luz transmitida na amostra, a intensidade absorvida $\mathrm{I}_{\mathrm{A}}$ é dada por: $\mathrm{I}_{\mathrm{A}}=\mathrm{I}_{0}-\mathrm{I}_{\mathrm{T}}$. A variação da intensidade da radiação ao passar pela espessura da amostra decai exponencialmente e é expressa por (Cantor \& Shimmel, 1969):

$$
\mathrm{I}_{\mathrm{T}}=\mathrm{I}_{0} \mathrm{e}^{-\alpha \mathrm{l}} \text {, }
$$

onde $\alpha=2,3003 \mathrm{C} \varepsilon$, e $\varepsilon$ o coeficiente de absorção molar (em $\left.\mathrm{M}^{-1} \mathrm{~cm}^{-1}\right)$ o qual é uma quantidade característica da substância dependente do comprimento de onda $(\lambda)$. Por definição a lei de Beer-Lambert é dada por:

$$
A(\lambda)=\log \left(\frac{I_{0}}{I_{T}}\right)=C \varepsilon(\lambda) 1,
$$

sendo A a absorbância ou densidade óptica. 


\subsubsection{Força do Oscilador}

Os estados eletrônicos moleculares dependem do número de elétrons assim como da estrutura ou geometria e da simetria da molécula. As funções de onda moleculares do estado fundamental e dos diferentes estados excitados determinam as regras de seleção e assim a intensidade das transições eletrônicas. A correlação entre teoria e experimento pode ser expressa pela força do oscilador, $f$, a qual pode ser estabelecida experimentalmente de $\varepsilon=f(\underline{v})$ usando a equação (3.36):

$$
\mathrm{f}_{\exp }=\frac{2303 \mathrm{mc}}{\pi \mathrm{e}^{2} \mathrm{~N}_{0}} \int_{\text {banda }} \varepsilon(\underline{v}) \mathrm{d} \underline{v}
$$

onde m é a massa do elétron,c a velocidade da luz, e a carga do elétron e $\mathrm{N}_{0}$ o número de Avogrado. Pode ser também representada aproximadamente pela expressão:

$$
\int_{\text {banda }} \varepsilon(\underline{v}) \mathrm{d} \underline{\underline{v}} \approx \varepsilon_{\max } \Delta \underline{v}_{1 / 2}
$$

onde $\Delta \underline{v}_{1 / 2}$ representa a largura de linha da banda. Para a transição de um estado 1 para o estado $k$ a equação (3.36) fica:

$$
f_{1, k}=\frac{8 \pi^{2} m c \underline{v}_{1, k}}{3 h e^{2}} G\left|\underline{\mu}_{1, k}\right|^{2},
$$

onde $\underline{v}_{1, \mathrm{k}}$ é o número de onda da transição $\mathrm{l} \rightarrow \mathrm{k}$, G é o peso estatístico o qual é igual a 1 para uma transição eletrônica pura e $\mu_{1, \mathrm{k}}$ o momento de dipolo de transição o qual pode ser calculado teoricamente. Sendo que a probabilidade de que a transição entre dois estados ocorra pela oscilação do campo elétrico da luz é proporcional ao quadrado da integral momento de dipolo de transição, portanto $\underline{\mu}_{1, \mathrm{k}}$ determina a intensidade da transição(Perkampus, 1992). 


\subsubsection{As Bandas do Ácido Húmico e do Herbicida 2,4-D}

A absorção de radiação por compostos orgânicos na região do ultravioleta e visível, envolve a transição de elétrons dos orbitais $\sigma, \pi$ e $n$ do estado normal para um estado excitado. Sistemas contendo duplas ligações $C=C$ experimentam transições $\pi \Rightarrow \pi^{*}$, e compostos com elétrons de átomos de $\mathrm{O}, \mathrm{N}, \mathrm{S}$ e halogênio não ligantes podem absorver devido as transições $n \Rightarrow \sigma^{*}$ (Poppi, 1988).

$\mathrm{O}$ ácido húmico geralmente possui uma absorção típica sem estrutura. É uma absorção larga, a qual extende-se com o decréscimo da absorção para a região do infravermelho distante (figura 3.16).
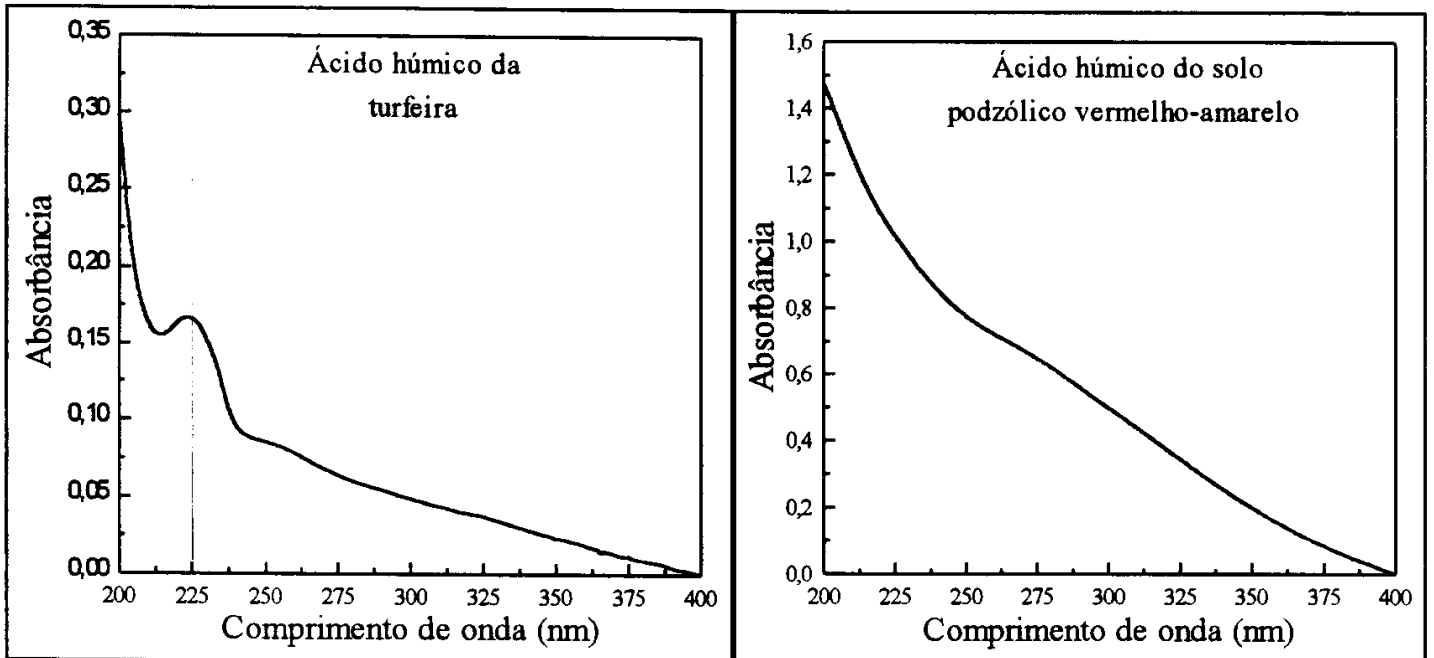

Figura 3.16: Espectro de absorção eletrônica de solução aquosa de ácidos húmicos utilizados neste trabalho

O espectro eletrônico de moléculas homocíclicas aromáticas têm várias características em comum (Struve, 1989). O benzeno tem um sistema de três bandas, as quais estão em $255 \mathrm{~nm}, 205 \mathrm{~nm}$ e $183 \mathrm{~nm}$. Este sistema de banda envolve excitações de elétrons do orbital $\pi$ para o orbital molecular $\pi^{*}$, e aparece repetidamente em espectros de outras moléculas aromáticas (Pesce et al, 1971). As bandas do 2,4-D estão em $291 \mathrm{~nm}, 282 \mathrm{~nm}$ e $228 \mathrm{~nm}$. O comprimento de onda de absorção igual a $228 \mathrm{~nm}$ foi o escolhido para ser monitorado neste trabalho assim como foi feito por Barriuso et al (1992). 


\subsection{Espectroscopia no Infravermelho por Transformada de Fourier - (do inglês, Fourier Transform Infrared - FTIR)}

Neste item foram utilizadas informações basicamente de três bibliografias: Griffiths et al, 1972, Cantor \& Schimmel, 1980 e Colthup et al, 1964

\subsubsection{Princípios da Espectroscopia no Infravermelho}

Os espectros no Infravermelho compreendem a seguinte região espectral: $400-4000 \mathrm{~cm}^{-1}$.

No infravermelho as transições se devem a vibração dos átomos da molécula. O modelo clássico para essa vibração é o de um sistema de átomos acoplados por molas e comporta-se como um simples oscilador harmônico, sendo o potencial $U_{\mathrm{r}}$ (figura 3.17.a) e a frequência da oscilação $\underline{v}\left(\mathrm{em} \mathrm{cm}^{-1}\right)$ expressos pelas seguintes equações, respectivamente:

$$
\mathrm{U}_{\mathrm{r}}=\frac{1}{2} \mathrm{k}(\Delta \mathrm{r})^{2} \quad \text { e } \quad \underline{v}=\frac{1}{2 \pi \mathrm{c}} \sqrt{\frac{\mathrm{k}}{\mathrm{u}}}
$$

onde $\Delta r$ é a diferença entre a distância internuclear, $r$, em qualquer tempo e a distância de equilíbrio, $\mathrm{r}_{0}, \mathrm{k}$ a constante de força, $\mathrm{u}$ a massa reduzida do sistema diatômico e $\mathrm{c}$ a velocidade da luz.

Um tratamento quântico do oscilador harmônico linear produz as seguintes energias vibracionais:

$$
\mathrm{E}_{\mathrm{vib}}=(\mathrm{v}+1 / 2) \mathrm{hc} \underline{\mathrm{v}}_{0}
$$

onde $\mathrm{E}_{\mathrm{vib}}$ é a energia vibracional, v é o número quântico vibracional, o qual assume números inteiros $0,1,2, . .$, e $\underline{v}_{0}$ o número de onda $\left(\mathrm{em} \mathrm{cm}^{-1}\right)$ do estado fundamental vibracional. O diagrama da energia potencial esta representado na figura 3.17.b. No caso real sempre existe anarmonicidade e a equação (3.39) deve ser modificada para: 


$$
E_{v i b}=h c\left[\underline{v}_{0}(v+1 / 2)-\chi \underline{v}_{0}(v+1 / 2)^{2}+\ldots\right]
$$

onde $\chi$ é a constante anarmônica. Devido a anarmonicidade vibracional o espaçamente entre os níveis vibracionais tornam-se menores com o aumento do número quântico vibracional e as transições que envolvem $\Delta v= \pm 2, \pm 3, \ldots$ passam a ser válidas além da regra de seleção $\Delta \mathrm{v}= \pm 1$ válida para o modelo de vibração harmônico.

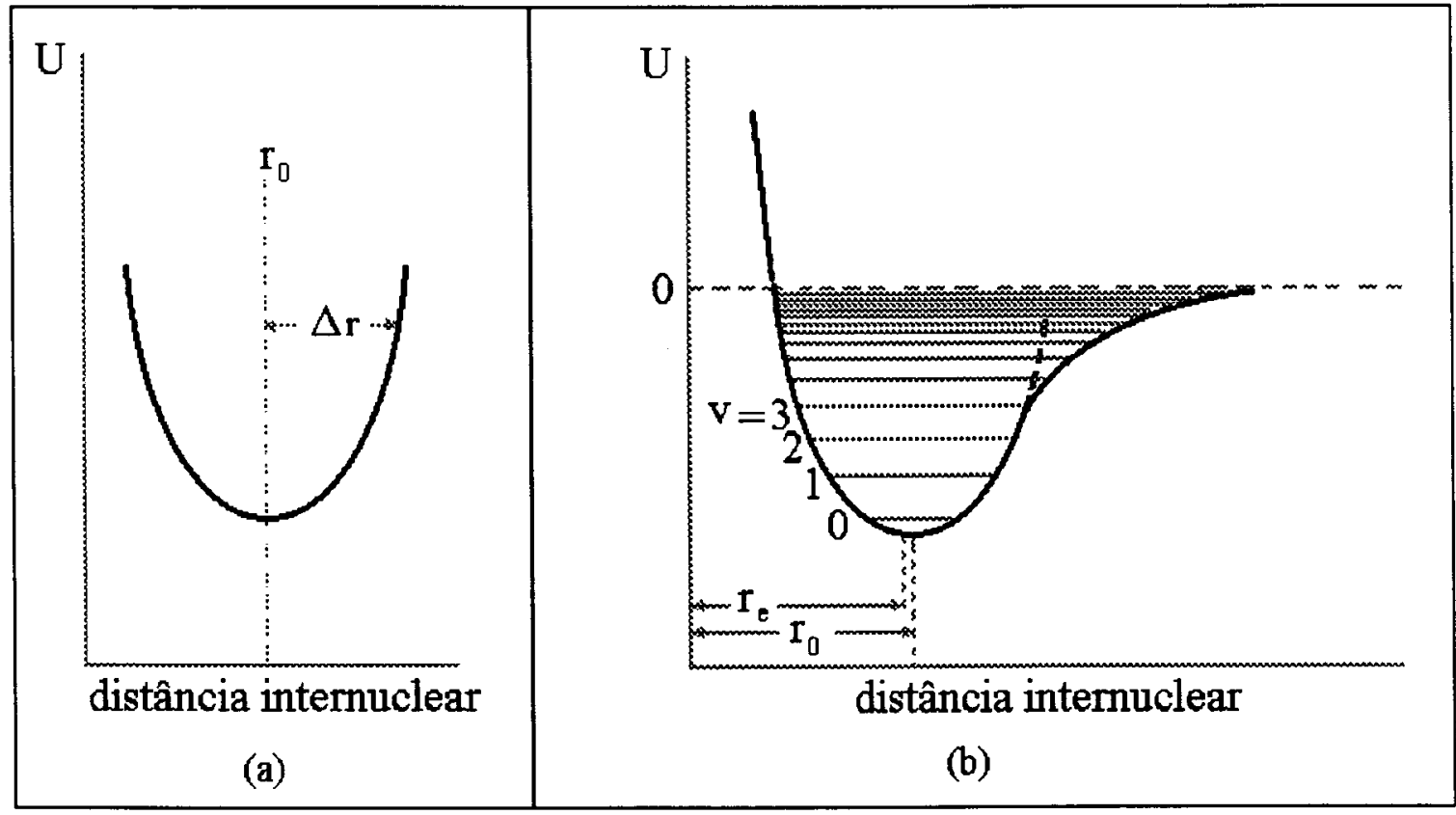

Figura 3.17: Diagrama da energia potencial de um oscilador diatômico harmônico (a) clássico e (b) quântico

A segunda condição para transição no infravermelho é que a vibração da molécula cause uma mudança no momento de dipolo. A variação senoidal do campo elétrico devida a vibração molecular pode interagir com a variação senoidal do campo elétrico devido a radiação. Se as frequências são iguais, a transferência máxima pode ocorrer por ressonância.

A intensidade da banda vibracional (ou magnitude da probabilidade de transição) depende da magnitude do dipolo elétrico induzido $\vec{\mu}$ pela luz na molécula. Uma transição vibracional de uma molécula pode ser descrita, segundo a aproximação de Born-Oppenheimer que separa o movimento eletrônico do nuclear, como:

$$
\psi_{0}(\mathrm{r}, \mathrm{R}) \phi_{\mathrm{v}}(\mathrm{R}) \longrightarrow \psi_{0}(\mathrm{r}, \mathrm{R}) \phi_{\mathrm{v}^{\prime}}(\mathrm{R})
$$


onde $\phi_{\mathrm{v}}$ e $\phi_{\mathrm{v}^{\prime}}$, referem-se a dois estados vibracionais diferentes do núcleo, r e R são as coordenadas do elétron e do núcleo, respectivamente, e $\psi_{0}$ é a função de onda do elétron do estado fundamental. Se os núcleos são estacionários, o operador dipolo elétrico $\underline{\mu}$ depende somente das coordenadas eletrônicas, $\mu=\mu(r)$, e o dipolo de transição é:

$$
\left\langle\psi_{0} \phi_{\mathrm{v}}|\underline{\mu}| \psi_{0} \phi_{\mathrm{v}{ }}\right\rangle=\left\langle\psi_{0}|\underline{\underline{\mu}}| \psi_{0}\right\rangle\left\langle\phi_{\mathrm{v}} \mid \phi_{\mathrm{v}}\right\rangle=0
$$

a integral em $\mathrm{r}\left\langle\psi_{0}|\underline{\mu}| \psi_{0}\right\rangle$ é nula uma vez que $\underline{\mu}$ é uma função ímpar e $\psi_{0}$ uma função par, e a integral $\left\langle\phi_{v} \mid \phi_{v}\right\rangle$ também é nula pois as autofunções $\phi_{v}$ e $\phi_{v}$ são ortogonais.

Se os núcleos não são estacionários, o operador dipolo depende implicitamente de $R$, pois a distribuição eletrônica muda com $R$, assim $\mu=\mu(r, R)$. Expandindo $\underline{\mu}$ em torno de uma posição de equilíbrio do núcleo, $\mathrm{R}_{0}$, por séries de Taylor obtemos:

$$
\begin{aligned}
& \underline{\mu}(\mathrm{r}, \mathrm{R})=\underline{\mu}\left(\mathrm{r}, \mathrm{R}_{0}\right)+\left(\frac{\partial \underline{\mu}(\mathrm{r}, \mathrm{R})}{\partial \mathrm{R}}\right)_{\mathrm{R}_{0}}\left(\mathrm{R}-\mathrm{R}_{0}\right)+\cdots, \\
& \left\langle\psi_{0} \phi_{\mathrm{v}}|\underline{\mu}| \psi_{0} \phi_{\mathrm{v}}\right\rangle=\left\langle\psi_{0}\left|[\partial \underline{\mu}(\mathrm{r}) / \partial \mathrm{R}]_{\mathrm{R}_{0}}\right| \psi_{0}\right\rangle\left\langle\phi_{\mathrm{v}}\left|\mathrm{R}-\mathrm{R}_{0}\right| \phi_{\mathrm{v}^{\prime}}\right\rangle .
\end{aligned}
$$

A equação (3.44) sintetiza a segunda regra de seleção, ela é o produto de dois termos, sendo que a integral eletrônica que muda o dipolo permanente do estado fundamental é companhada de uma mudança na posição molecular (integral vibracional).

\subsubsection{O Interferômetro de Michelson}

Os pricípios da absorção na região do infravermelho são os mesmos que para a absorção na região do uv-visível, assim seguindo a lei de Beer-Lamber.

$O$ espectrômetro dispersivo convensional utiliza um feixe de radiação policromático que passa através de um prisma ou de uma grade, então cada 
frequência é distinguida espacialmente, formando um espéctro de. Fendas finas são usadas afim de se obter um espectro de alta qualidade, elas fazem com que os intervalos de frequências sejam suficientemente finos, assegurando uma melhor resolução (Sanches, 1982). Na espectroscopia no infravermelho por transformada de Fourier, utiliza-se um interferômetro no lugar dos elementos dispersivos. A informação espectral de todas as frequências é obtida ao mesmo tempo, durante uma varredura do interferômetro.

A figura 3.18 mostra o esquema do interferômetro de Michelson, comumente usado. Ele consiste de dois espelhos perpendiculares, um deles, B, é fixo enquanto que o outro move-se com velocidade constante. Entre estes espelhos existe um separador de feixes, no qual o feixe em comum é dividido e posteriormente recombinado depois que a diferença de caminho entre os dois feixes foi introduzida.

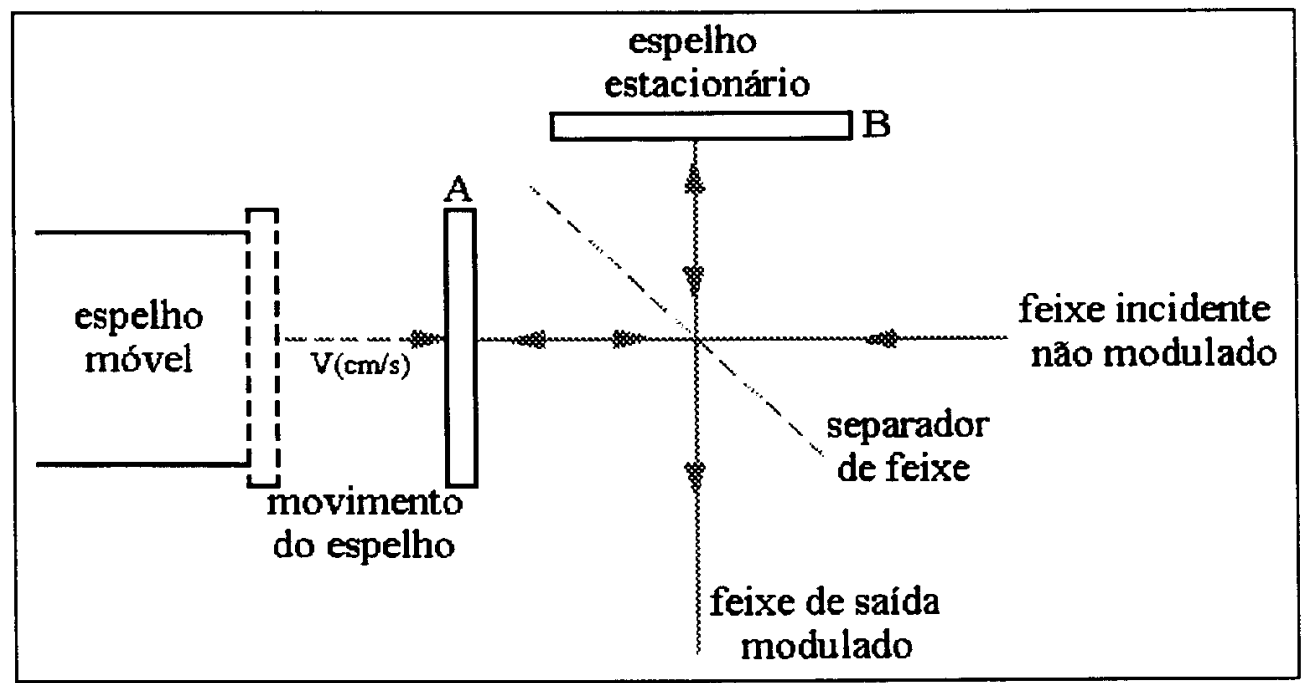

Figura 3.18: Esquema de um interferômetro de Michelson

Para uma radiação incidente monocromática, de frequência $\underline{v} \mathrm{~cm}^{-1}, o$ sinal do detector, ou interferograma, resulta numa série de máximos e mínimos, cuja intensidade é dada pela seguinte expressão:

$$
\mathrm{I}(\delta)=\mathrm{I}(\underline{v}) \cos (2 \pi v \delta)
$$

onde $\delta$ é a diferença de caminho ótico entre os dois feixes e $\mathrm{I}(\underline{v})$ é a intensidade da radiação incidente monocromática. 
Para uma fonte policromática, cada frequência deve ser tratada independentemente, e o interferograma é composto do sinal resultante de cada uma das frequências na equação (30) contidas no espectro, e é dado pela expressão:

$$
\mathrm{I}(\delta)=\int_{-\infty}^{\infty} \mathrm{I}(\underline{v}) \cos (2 \pi v \delta) \mathrm{d} \underline{\underline{v}}
$$

A transformada de Fourier do cosseno da equação (3.46), a qual pode ser feita por um microcomputador, é utilizada para que o interferograma contenha informações sobre a intensidade de cada frequência em função da diferença de caminho, a expressão (3.46) fica então dada por:

$$
I(\underline{v})=\int_{-\infty}^{\infty} I(\delta) \cos (2 \pi \underline{v} \delta) \mathrm{d} \delta .
$$

Como na prática não é possível a variação da diferença de caminho, $\delta$, de $-\infty$ a $\infty$, a integral é truncada em algum valor $\delta_{\max }$, o qual determina a resolução do espectro: $\Delta \underline{v}=1 / \delta_{\max }$

\subsubsection{As Bandas do Ácido Húmico e do Herbicida 2,4-D}

A espectroscopia no infravermelho tem sido largamente usada para caracterização de complexos de macromoléculas orgânicas tais como substâncias húmicas. $\mathrm{O}$ espectro no infravermelho de tais macromoléculas contém uma variedade de bandas assinaladas a grupos funcionais.

Orlov (1985) em seu livro reporta algumas dificuldades para se usar a técnica com amostras de ácido húmico, como a presença constante de uma certa quantidade de água, o que oculta as regiões espectrais mais importantes, mostrando oscilações nos grupos $-\mathrm{OH}$ próximo de $3400 \mathrm{~cm}^{-1}, 1600 \mathrm{~cm}^{-1}$ e $1400-1300 \mathrm{~cm}^{-1}$. O mesmo trabalho citado acima, menciona que ácidos húmico extraídos de diferentes tipos de solo são caracterizados por uma estrutura geral. Em alguns casos o efeito da vegetação afeta o espectro no infravermelho mais do que o tipo de solo, contudo muitos trabalhos reportam que a origem do ácido húmico pouco reflete no espectro. 
A tabela 3.1 que se segue mostra as principais bandas de absorbância e seus grupos responsáveis, para amostras de ácido húmico proveniente de uma turfeira adquiridas por Niemeyer et al (1992), da "International Humic Substances Society, U.S. Geological Survey, Denver, CO". Assim como a tabela 3.2, que mostra as principais bandas de absorbância do 2,4-D obtidas a partir do espectro de uma solução aquosa, $\mathrm{pH}=4$, que passou pelo processo de liofilização e posteriormente acrescida de $\mathrm{KBr}$. 
Tabela 3.1: As bandas no infravermelho do ácido húmico de uma turfeira Niemeyer et al (1992), da "International Humic Substances Society, U.S. Geological Survey, Denver, CO"

\begin{tabular}{|c|c|}
\hline Banda $\left(\mathrm{cm}^{-1}\right)$ & Atribuição aos grupos funcionais do ácido húmico \\
\hline 3380 & $\begin{array}{l}\text { Estiramento } \mathrm{OH} \text { do grupo fenólico (contribuição de } \mathrm{OH} \text { alifático, } \\
\qquad \mathrm{H}_{2} \mathrm{O} \text { e possivelmente } \mathrm{NH} \text { ) }\end{array}$ \\
\hline 3030 & Estiramento $\mathrm{OH}$ aromático \\
\hline 2930 & Estiramento $\mathrm{CH}$ assimétrico de $-\mathrm{CH}_{2}^{-}$ \\
\hline 2840 & Estiramento $\mathrm{CH}$ simétrico de $-\mathrm{CH}_{2}^{-}$ \\
\hline 2600 & Estiramento $\mathrm{OH}$ de $\mathrm{H}$-ligado a - $\mathrm{COOH}$ \\
\hline 1720 & Estiramento $-\mathrm{C}=\mathrm{O}$ de $-\mathrm{COOH}$ \\
\hline 1610 & Estiramento $\mathrm{C}=\mathrm{C}$ aromático e/ou estiramento $-\mathrm{COO}^{-}$assimétrico \\
\hline 1525 & Estiramento $\mathrm{C}=\mathrm{C}$ aromático \\
\hline 1450 & Deformação - $\mathrm{CH}$ de $-\mathrm{CH}_{3}$ e dobramento - $\mathrm{CH}$ de $\mathrm{CH}_{2}$ \\
\hline 1350 & Estiramento - $\mathrm{COO}^{-}$simétrico e/ou dobramento - $\mathrm{CH}$ de alifáticos \\
\hline 1270 & Estiramento $-\mathrm{C}-\mathrm{OH}$ de fenólico $\mathrm{OH}$ \\
\hline 1225 & Estiramento -C-O e deformação $\mathrm{OH}$ de - $\mathrm{COOH}$ \\
\hline 1170 & Estiramento -C-OH de alifáticos $\mathrm{OH}$ \\
\hline 830 & Dobramento $\mathrm{CH}$ aromático fora do plano \\
\hline$\overline{775}$ & Dobramento $\mathrm{CH}$ aromático fora do plano \\
\hline
\end{tabular}

Tabela 3.2: As bandas na região do infravermelho do herbicida 2,4-D

\begin{tabular}{|c|c|}
\hline Banda $\left(\mathrm{cm}^{-1}\right)$ & Atribuição aos grupos funcionais do 2,4-D \\
\hline 3440 & Estiramento $\mathrm{OH}$ \\
\hline 1715 & Estiramento $-\mathrm{C}=\mathrm{O}$ de $-\mathrm{COOH}$ \\
\hline 1620 & Estiramento $\mathrm{C}=\mathrm{C}$ aromático e/ou estiramento $-\mathrm{COO}^{-}$assimétrico \\
\hline 1420 & Estiramento $-\mathrm{COO}^{-}$simétrico \\
\hline 1430 & $\mathrm{Grupos}_{\mathrm{CO}, \mathrm{OH} \text { e } \mathrm{CH}_{2}}$ \\
\hline 1337 & Estiramento $-\mathrm{COO}$ simétrico e/ou deformação -CH \\
\hline 1244 & Estiramento $-\mathrm{C}-\mathrm{O}$ e deformação $\mathrm{OH}$ de - $\mathrm{COOH}$ \\
\hline 1162 & Deformação $\mathrm{CO}$ e OH \\
\hline 1064 & Deformação $\mathrm{C}-\mathrm{OH}$ de $-\mathrm{COOH}$ \\
\hline 878 & Dobramento $\mathrm{CH}$ aromático fora do plano \\
\hline
\end{tabular}




\section{Capítrelo 4. Materiais e Métados}

\subsection{Extração e Purificação do Ácido Húmico}

Foram extraidas amostras de ácido húmico provenientes de um solo podzólico vermelho-amarelo de uma profundidade de $0-20 \mathrm{~cm}$, representativo de $60 \%$ do solo do Estado de São Paulo, coletada na Estação Experimental de Pindorama/SP, do Instituto Agronômico de Campinas (IAC), e de uma turfeira na profundidade de 2,5-4,0m, coletada no Rio Mogi Guaçu na região próxima a Guatapará/SP.

A extração e a purificação das substâncias húmicas do solo, segundo características de solubilidade, foram realizados no laboratório de Radioquímica e Química Ambiental do IQSC-USP, em São Carlos/SP (Vieira, 1995). A figura que se segue, mostra simplificadamente o procedimento do fracionamento segundo características de solubilidade das frações da matéria orgânica.

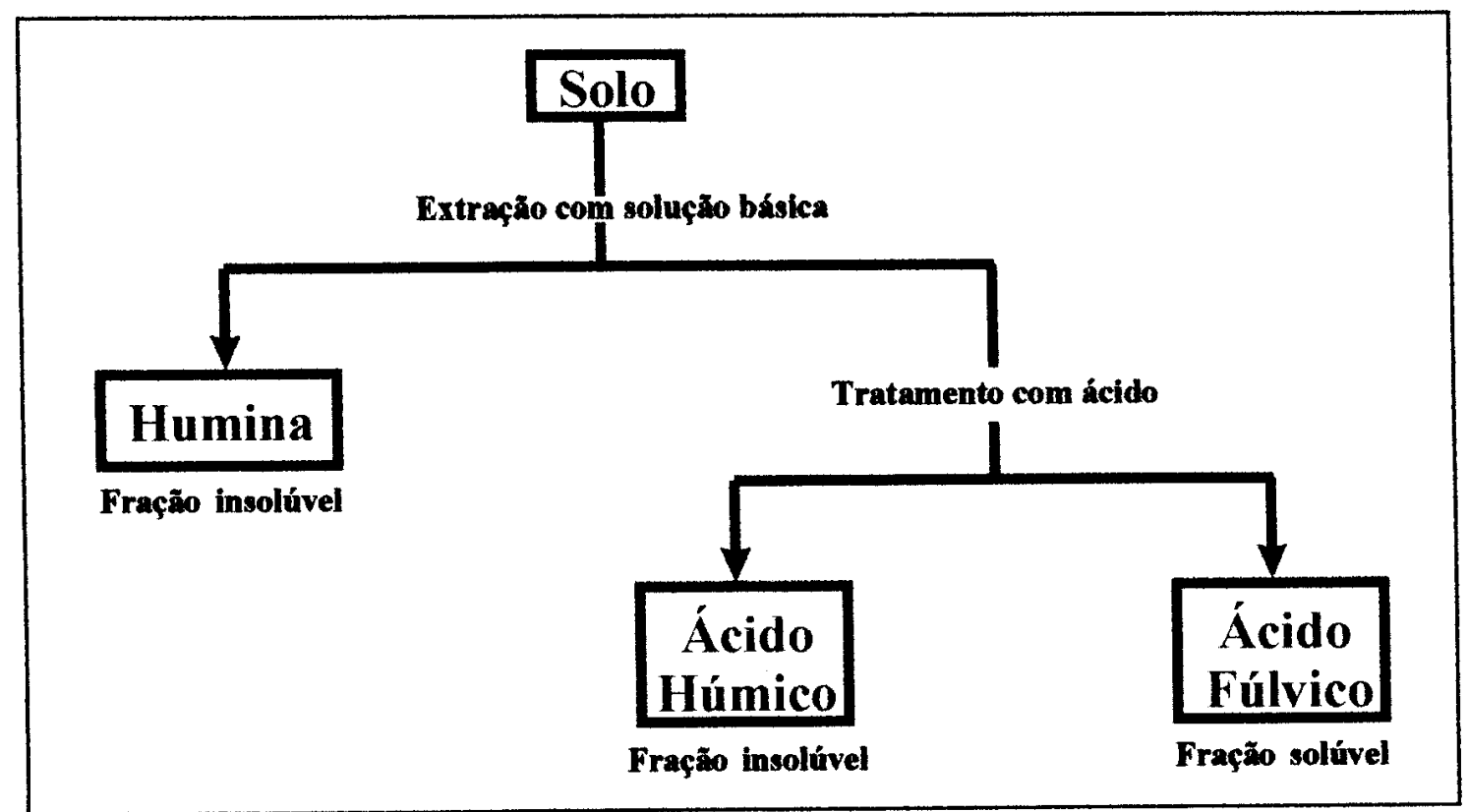

Figura 4.1: Procedimento simplificado do fracionamento da MO do solo (Shnitzer, M., 1978)

O mesmo laboratório acima citado fez as análises elementares e de grupos funcionais dos solos utilizados neste trabalho. E os resultados estão na tabela 4.1. 
Tabela 4.1: Análises elementar e dos grupos funcionais dos ácidos húmico dos solos podzólico vermelho-amarelo e da turfeira

\begin{tabular}{|c|c|c|}
\hline Grupos funcionais & $\begin{array}{c}\text { Ácido húmico do solo podzólico } \\
\text { vermelho-amarelo (meq/g) }\end{array}$ & $\begin{array}{c}\text { Ácido húmico da turfeira } \\
\text { (meq/g) }\end{array}$ \\
\hline Acidez total & 6,82 & 3,99 \\
\hline COOH & 3,69 & 2,88 \\
\hline OH fenólico & 3,13 & 1,11 \\
\hline OCH3 & 6,21 & 1,02 \\
\hline C=O & 1,80 & 0,96 \\
\hline Análise elementar & Teor de cinzas $=2,20 \%$ & Teor de cinzas $=2,13 \%$ \\
\hline Carbono & 44,00 & 52,85 \\
\hline Nitrogênio & 5,50 & 4,28 \\
\hline Hidrogênio & 5,10 & 5,21 \\
\hline Oxigênio & 43,20 & 37,66 \\
\hline
\end{tabular}

\section{2 .Preparação de Amostras}

$\mathrm{O}$ herbicida 2,4-diclorofenoxiacético (2,4-D) de massa molecular igual a $221,04, \mathrm{pKa}=2,6$ e estrutura química mostrada na figura 2.12 , foi adquirido comercialmente da Aldrich Chemical Co.

As soluções de cobre foram preparadas à partir de $\mathrm{CuSO}_{4} .5 \mathrm{H}_{2} \mathrm{O}$ obtidos comercialmente da Mallinckrodt.

$\Leftrightarrow$ Preparação das amostras contendo herbicida:

As soluções estoques do 2,4-D preparadas na concentração $1 \mathrm{mM}$ foram agitadas por 24 horas, de modo a obter uma completa diluição, sempre protegidas da luz solar para evitar possível fotodegradação e armazenadas em geladeira

$\Rightarrow$ Preparação das amostras de reação entre 2,4-D e ácido húmico:

Foram preparadas amostras com $20 \mathrm{mg}$ de ácido húmico dissolvidas em $25 \mathrm{ml}$ de solução 2,4-D na concentração de $1 \mathrm{mM}$ (amostras chamadas AH+2,4-D). 
Para as amostras referência foram utilizados $20 \mathrm{mg}$ de ácido húmico dissolvidas em 25 $\mathrm{ml}$ de água destilada (amostras chamadas $\mathrm{AH}$ ). Os valores de $\mathrm{pH}$ foram ajustados próximos de 2,0, 4,0 e 7,0, tanto para as amostras $\mathrm{AH}$, quanto para as $\mathrm{AH}+2,4-\mathrm{D}$.

O tempo de reação das amostras acima citadas foi de 4 dias, sob agitação e proteção da luz. Esse período foi utilizado para garantir a completa sorção do 2,4-D com o material húmico. Khan (1973), propôs cinéticas bifásicas para a interação do 2,4-D de amostras com ácido húmico (Figura 4.2), o 2,4-D após 24 horas era sorvido pelo ácido húmico a uma taxa significativa, mas não completa.

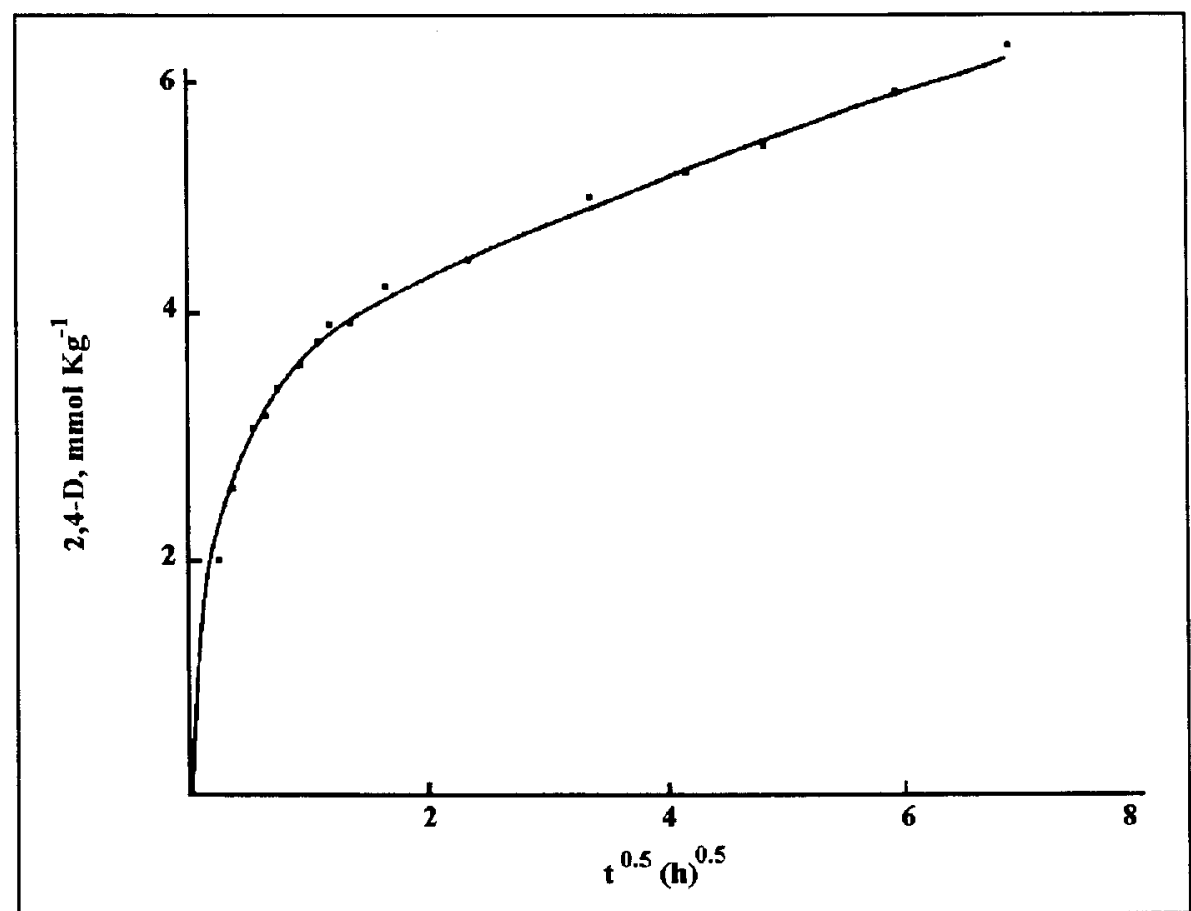

Figura 4.2: Massa de 2,4-D adsorvida pela Turfa em função de $t^{1 / 2}$ (Khan, 1973)

Afim de obter o sobrenadante das soluções $\mathrm{AH}+2,4-\mathrm{D}$ e $\mathrm{AH}$, estas foram, após os 4 dias de reação, acidificadas com solução $\mathrm{H}_{2} \mathrm{SO}_{4} 4 \mathrm{~N}$ a pH=2 (Senesi \& Testini, 1980), e centrifugadas na Centrífuga 215-Fanem, pertencente a EMBRAPA/CNPDIA-São Carlos/SP.

$\Rightarrow$ Preparação de amostras de reação entre 2,4-D e íon metálico:

Nas reações de complexação do herbicida com metais foram adicionadas soluções de $\mathrm{CuSO}_{4}$. a solucão de 2,4-D( $\left.1 \mathrm{mM}\right)$ de modo a obter a proporção ligante/metal de 1:1, são as amostras chamadas de $\mathrm{CuSO}_{4}+2,4-\mathrm{D}$ e $\mathrm{CuSO}_{4}$. 
As amostras eram agitadas por 24 horas, protegidas da luz. Os pHs foram ajustados em 2,0,3,5, 5,0 e 7,0.

Os pHs das soluções foram variados utilizando-se soluções estoque de $\mathrm{NaOH}$ e $\mathrm{HCl}$ em diferentes concentrações.

\subsection{Análises Espectroscópicas}

\subsubsection{Medidas de Absorção de Luz UV-Visível}

As medidas de absorção ótica foram realizadas em um espectrofotômetro Shimadzu modelo UV-1601-PC da EMBRAPA/CNPDIA-São Carlos/SP.

$\Rightarrow$ Amostras contendo herbicida mais ácido húmico:

Foram feitas medidas das soluções de $\mathrm{AH}+2,4-\mathrm{D}$, usando como amostra referência soluções de $\mathrm{AH}$, logo após a preparação (dia 0 ) e depois de 4 dias de reação (dia 4).

Foram feitas também medidas da absorção dos sobrenadantes obtidos de novas soluções $\mathrm{AH}+2,4-\mathrm{D}$ depois dos 4 dias de reação, após acidificação e posterior centrifugação, somente para as amostras contendo ácido húmico da turfeira. Para comparação, as medidas dessas soluções foram realizadas, no dia 0 e no dia 4 , ainda sem ter realizado o tratamento de acidificação e centrifugação. As soluções referência foram os sobrenadantes obtidos das soluções $\mathrm{AH}$.

Em geral, os espectros eram obtidos de a partir de $100 \mu \mathrm{l}, 200 \mu \mathrm{l}$ ou $300 \mu \mathrm{l}$ da solução diluídas em 3,5ml de água destilada, em cubetas de quartzo, de modo que a concentração do 2,4-D correspondia a intensidade de absorbância entre 0,1 e 2,0, adequada ao detector do espectrofotômetro, onde a Lei de Beer-Lambert é válida (Cantor \& Shimmel, 1980) Uma curva de calibração do 2,4-D (intensidade de absorbância versus concentração) foi feita verificando-se a região adequada (figura 4.3). 


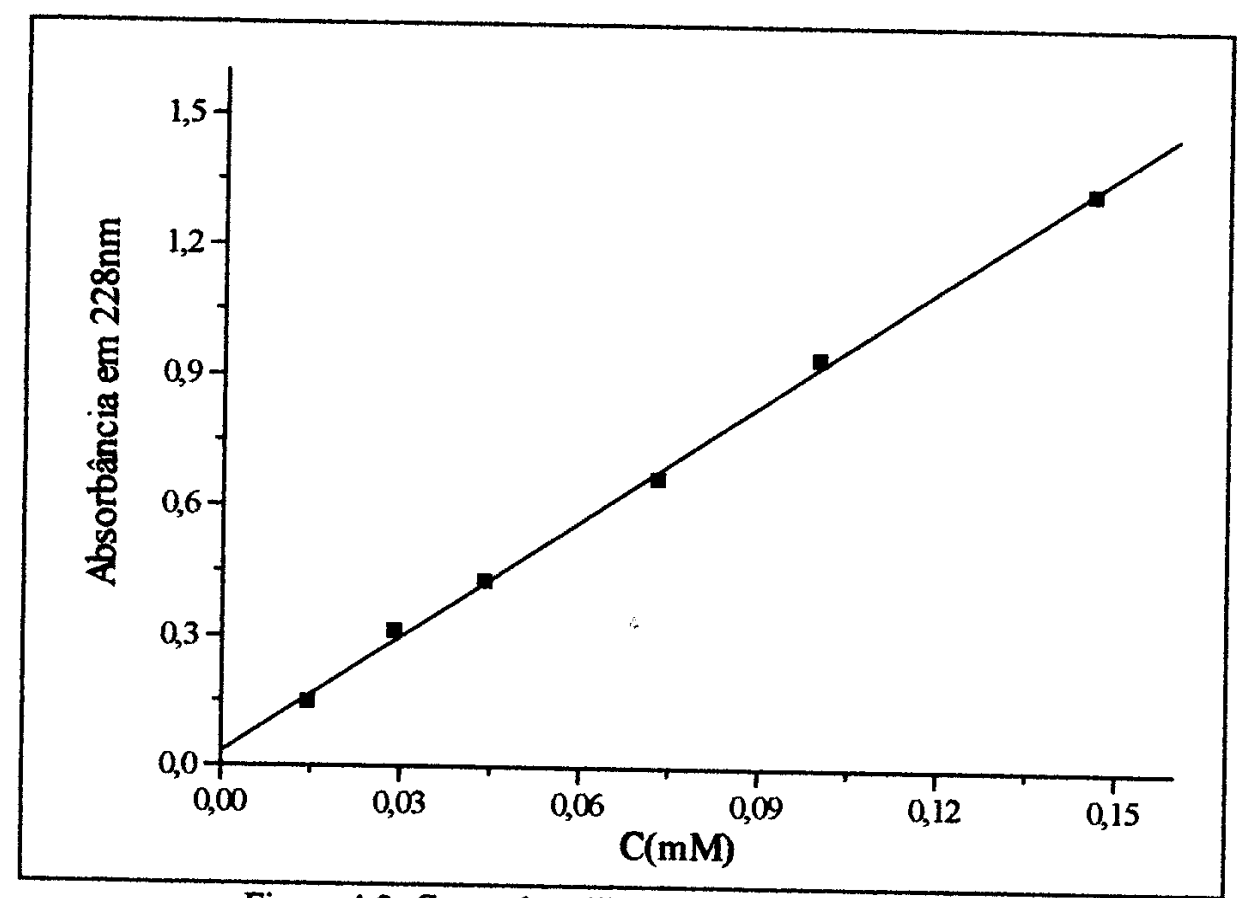

Figure 4.3: Curva de calibração da solução de 2,4-D

A região compreendida pelos espectros foi de $200-400 \mathrm{~nm}$. O comprimento de onda de absorção igual a $228 \mathrm{~nm}$ é característico do herbicida (Barriuso et al, 1992).

\subsubsection{Ressonância Paramagnética Eletrônica - EPR}

As medidas de EPR foram realizadas em um espectrômetro Varian da linha Century E-109, operando em banda-X $(9 \mathrm{GHz})$, cavidade retangular ('multipurpose cavity E-231'), à temperatura ambiente e próxima do nitrogênio liquido ($160^{\circ} \mathrm{C}$ ), utilizando-se o sistema de temperatura variável Varian que mantém o fluxo de gás nitrogênio resfriado, pertencente ao grupo de Biofisica do IFSC-USP-São Carlos/SP.

$\Leftrightarrow$ Amostras contendo herbicida mais ácido húmico:

As medidas de EPR eram realizadas em amostras sólidas obtidas das soluções de AH+2,4-D e de AH liofilizadas no liofilizador Savant modelo Speed Vac FC200, do Grupo de Biofisica do IFSC-USP-São Carlos/SP. 
À temperatura ambiente foram detectados e quantificados os radicais livres semiquinona do ácido húmico de ambos os solos. Para a quantificação foi usado o método do padrão secundário conforme citado no ítem 2.2.8.

O mesmo procedimento, citado nos dois parágrafos acima, foi tomado com relação as medidas dos precipitados coletados por acidificação e centrifugação das amostras $\mathrm{AH}$ e $\mathrm{AH}+2,4-\mathrm{D}$, mas somente para as amostras contendo ácido húmico da turfeira.

Os parâmetros geralmente utilizados para medidas de EPR foram:

- Modulação do sinal da microonda: $100 \mathrm{KHz}$;

- Tempo de varredura: 4 minutos;

- Para as amostras - radical livre semiquinona - : $\mathrm{H}_{0}=3400 \mathrm{G}, \Delta \mathrm{H}=100 \mathrm{G}$, amplitude da modulação $=2,0 \mathrm{G}$, constante de tempo $=0,128$ segundos, potência $=$ $0,2 \mathrm{~mW}$;

- Para o rubi: $\mathrm{H}_{0}=5400 \mathrm{G}, \Delta \mathrm{H}=200 \mathrm{G}$, amplitude da modulação $=5,0 \mathrm{G}$, constante de tempo $=0,128$ segundos, potência $=2,0 \mathrm{~mW}$;

- Para o 'strong pitch': $\mathrm{H}_{0}=3400 \mathrm{G}, \Delta \mathrm{H}=100 \mathrm{G}$, amplitude da modulação = 0,5G, constante de tempo $=0,128$ segundos, potência $=2,0 \mathrm{~mW}$.

Foram feitas curvas de saturação do sinal de EPR com a potência da microonda (em mW) para o 'strong pitch' e para a amostra contendo radicais livres (figuras 4.4 e 4.5), de onde foram escolhidas as potências adequadas, mencionadas acima. 


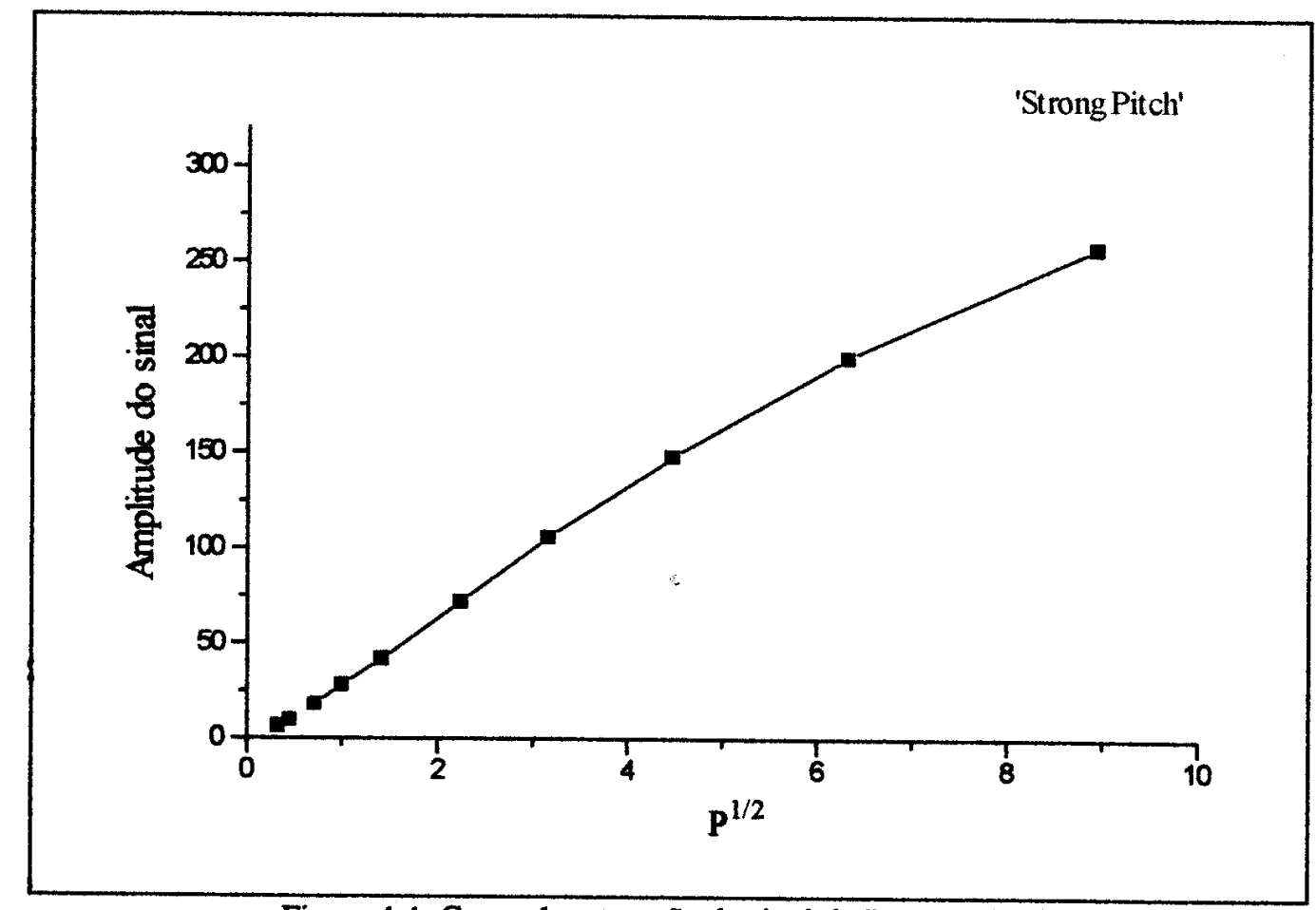

Figure 4.4: Curva de saturaçåo do sinal do "strong pitch"

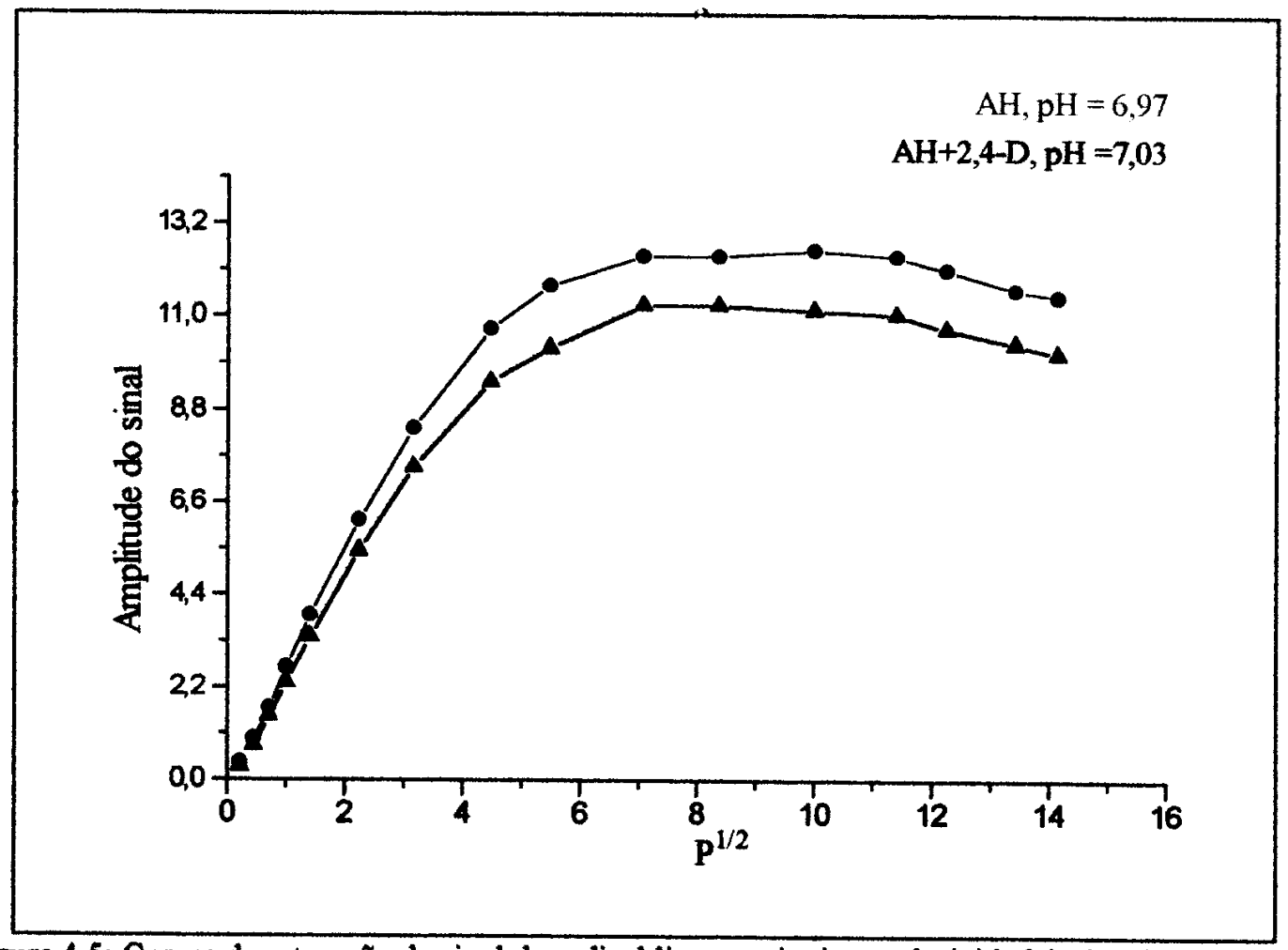

Figure 4.5: Curvas de saturaça do sinal do radical livre semiquinona do ácido húmico do solo podsolico vermelho- amarelo, amostra $\mathrm{AH}$ pH $=6,90$ e $\mathrm{AH}+2,4-\mathrm{D} \mathrm{pH}=6,70$

Foram obtidos à temperatura próxima de nitrogênio líquido $\left(-160^{\circ} \mathrm{C}\right)$ espectros de EPR dos íons de ferro(III) e de cobre(II) remanescente da purificação, e do radical livre das amostras $\mathrm{AH}+2,4-\mathrm{D}$ e $\mathrm{AH}$, com ácido húmico de ambos os solos. Os parâmetros experimentais foram: 
- $\mathrm{H}_{0}=2100 \mathrm{G}, \Delta \mathrm{H}=4000 \mathrm{G}$, amplitude da modulação $=5,0 \mathrm{G}$, constante de tempo $=0,128$ segundos, potência $=20 \mathrm{~mW}$.

$\Rightarrow$ Amostras contendo herbicida mais metal:

As medidas de EPR dos experimentos de complexação do 2,4$\mathrm{D}(\mathrm{lmM})$ com íons de cobre(II) foram feitas na temperatura do nitrogênio liquido. Os parâmetros empregados são os colocados abaixo.

- Para o $\mathrm{Cu}^{2+}: \mathrm{H}_{0}=2100 \mathrm{G}, \Delta \mathrm{H}=2000 \mathrm{G}$, amplitude da modulação = 5.0G, constante de tempo $=128$ segundos, potência $=20 \mathrm{~mW}$.

\subsubsection{Infravermelho com Transformada de Fourier - FTIR}

Os espectros de FTIR foram obtidos em um espectrômetro Bomem modelo MD-102, do IQSC-USP-São Carlos/SP.

As pastilhas foram obtidas adicionando-se a $100 \mathrm{mg}$ de $\mathrm{KBr} 1 \mathrm{mg}$ de 2,4-D puro e $2 \mathrm{mg}$ das amostras de AH+2,4-D e das amostras de $\mathrm{AH}$ liofilizadas. Optou-se em usar uma quantidade maior das amostras de AH+2,4-D e AH em relação a de 2,4-D pura, a fim de que a resolução do espectro fosse aumentada (Martin-Neto et al, 1994), uma vez que o $\mathrm{AH}$ tem peso molecular maior e consequentemente menos grupos funcionais por peso se comparado com o 2,4-D

Os precipitados obtidos por acidificação e centrifugação das amostras $\mathrm{AH}$ e $\mathrm{AH}+2,4-\mathrm{D}$, contendo ácido húmico da turfeira, passaram pelo procedimento acima, afim de se obter seus espectros de FTIR.

A região compreendida pelos espectros foi $400-4000 \mathrm{~cm}^{-1}$.

\subsection{Experiências de Fotodegradação}

Nas irradiações das amostras foi utilizada como fonte de luz uma lâmpada de xenônio de $150 \mathrm{~W}$, da marca Bausch-Lomb. Os espectros óticos 
foramobtidos antes e após as irradiações no espectrofotômetro ShimadzuUV-1601PC.

Foram feitas irradiações em três amostras diferentes:

$\Rightarrow \quad$ Amostra aquosa de 2,4-D(1mM), $\mathrm{pH}=6,95$, com um tempo total de exposição de 5 horas, sendo que foram realizadas medidas de absorção eletrônica antes da irradiação e a cada certo intervalo de tempo, totalizando 11 medidas. A referência foi água destilada, e os espectros medidos de $300 \mu$ da solução $2,4-\mathrm{D}(1 \mathrm{mM})$ diluídos em $3,5 \mathrm{ml}$ de água destilada.

$\Rightarrow \quad$ Amostras $\mathrm{AH}$ e $\mathrm{AH}+2,4-\mathrm{D}(1 \mathrm{mM})$, com ácido húmico da turfeira, em valor de $\mathrm{pH}$ igual a 7,00, foram obtidos 5 espectros eletrônica em 4 horas de irradiação, e os espectros eram resultantes de uma alíquota de $300 \mu$ das soluções dissolvida em $3,5 \mathrm{ml}$ de água destilada.

Todas as amostras foram irradiadas em cubetas de quartzo, e a uma distância de $20 \mathrm{~cm}$ da fonte de luz. 


\section{Capitula 5 - Resultados e Discussãa}

\subsection{Aduto 2,4-D-Ácido Húmico}

\subsubsection{Resultados}

\subsection{1.a Espectros de Absorção Eletrônica}

Neste ítem, o que se pretende é acompanhar o espectro de absorção eletrônica do herbicida 2,4-D, bandas de absorção nos comprimentos de onda $228 \mathrm{~nm}$, $284 \mathrm{~nm}$ e $291 \mathrm{~nm}$, contido em soluções aquosas acrescidas de ácido húmico (amostras $\mathrm{AH}+2,4-\mathrm{D}(1 \mathrm{mM})$ ), após a preparação (dia 0), e depois de 4 dias de reação (dia 4), em função do $\mathrm{pH}$. Também, soluções aquosas de ácido húmico ( $\mathrm{AH}$ ) foram preparadas como amostras de referência (ver capítulo 4, ítem 4.3.1).

Os valores médios da absorbância em $228 \mathrm{~nm}$ do 2,4-D $\left(\mathrm{A}_{228}\right)$ (e seus desvios médios absolutos) segundo o dia de aquisição do espectro e pH da solução, para amostras contendo ácido húmico do solo podzólico vermelho-amarelo, estão mostrados na tabela 5.1. E alguns desses espectros estão na figura 5.1.

Tabela 5.1: Intensidades da banda de absorção em 228nm do herbicida 2,4-D ( $\mathrm{A}_{228}$ ), obtidas a partir de soluções $\mathrm{AH}+2,4-\mathrm{D}(\mathrm{mm})$, com ácido húmico do solo podzólico vermelho-amarelo $\left({ }^{*} 200 \mu\right.$ l de solução AH+2,4-D diluídas em $3,5 \mathrm{ml}$ de água destilada, ${ }^{\star} 100 \mu$ l de solução $\mathrm{AH}+2,4-\mathrm{D}$ diluídas em 3,5ml de água destilada)

\begin{tabular}{|c|c|c|c|}
\hline $\mathrm{pH}$ & $\mathrm{A}_{228}$ (dia 0) & $\mathrm{A}_{228}$ (dia 4) & $\begin{array}{c}\text { Diferença (\%) de } \mathrm{A}_{228} \\
\text { entre o dia 0 e o dia 4 }\end{array}$ \\
\hline $2,03^{\star}$ & $(0,42 \pm 0,02)$ & $(0,448 \pm 0,003)$ & $-6 \%$ \\
\hline $4,00^{\star}$ & $(0,47 \pm 0,03)$ & $(0,46 \pm 0,02)$ & $+2 \%$ \\
\hline $6,70^{\star}$ & $(0,254 \pm 0,007)$ & $(0,25 \pm 0,03)$ & $+2 \%$ \\
\hline
\end{tabular}




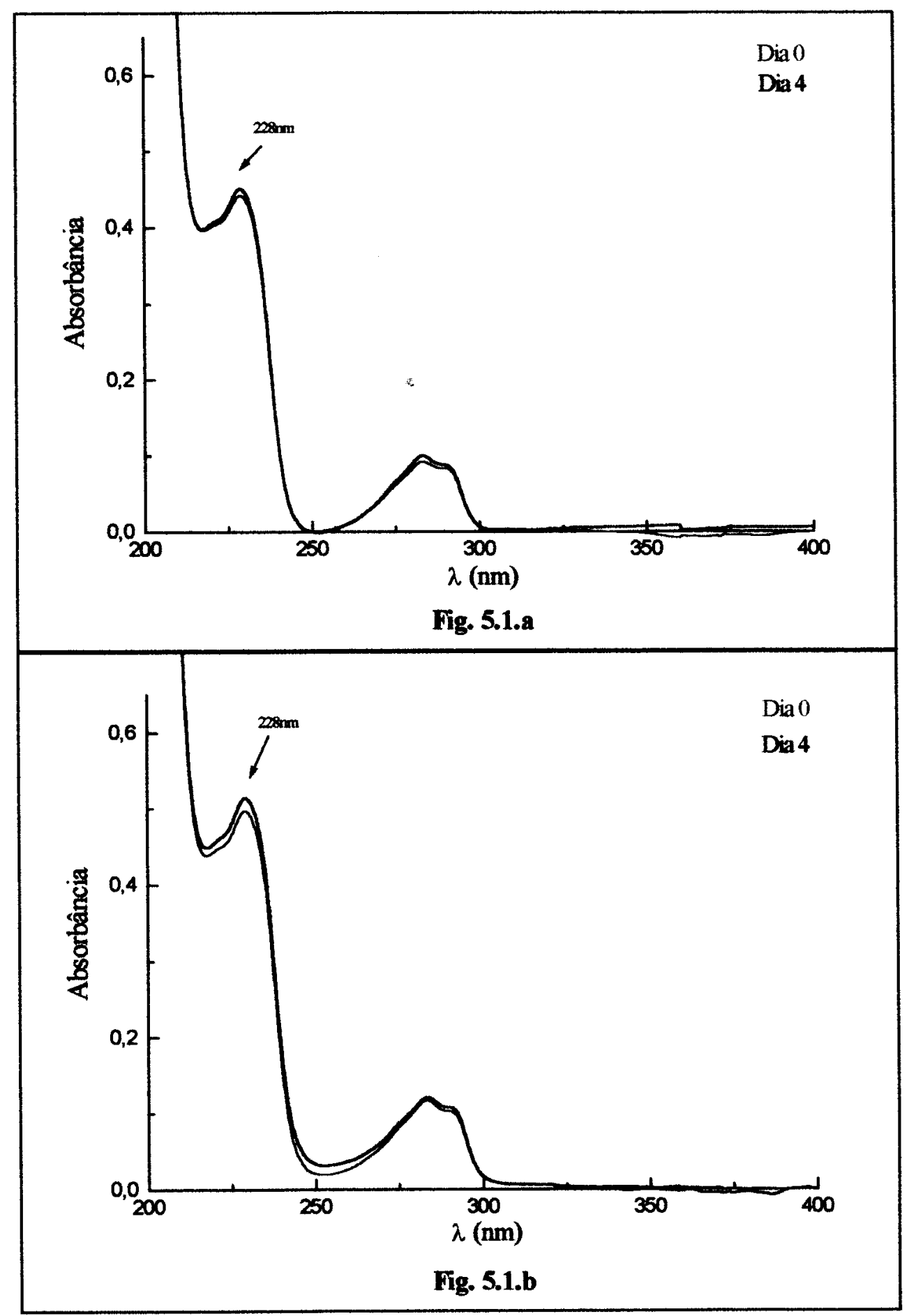




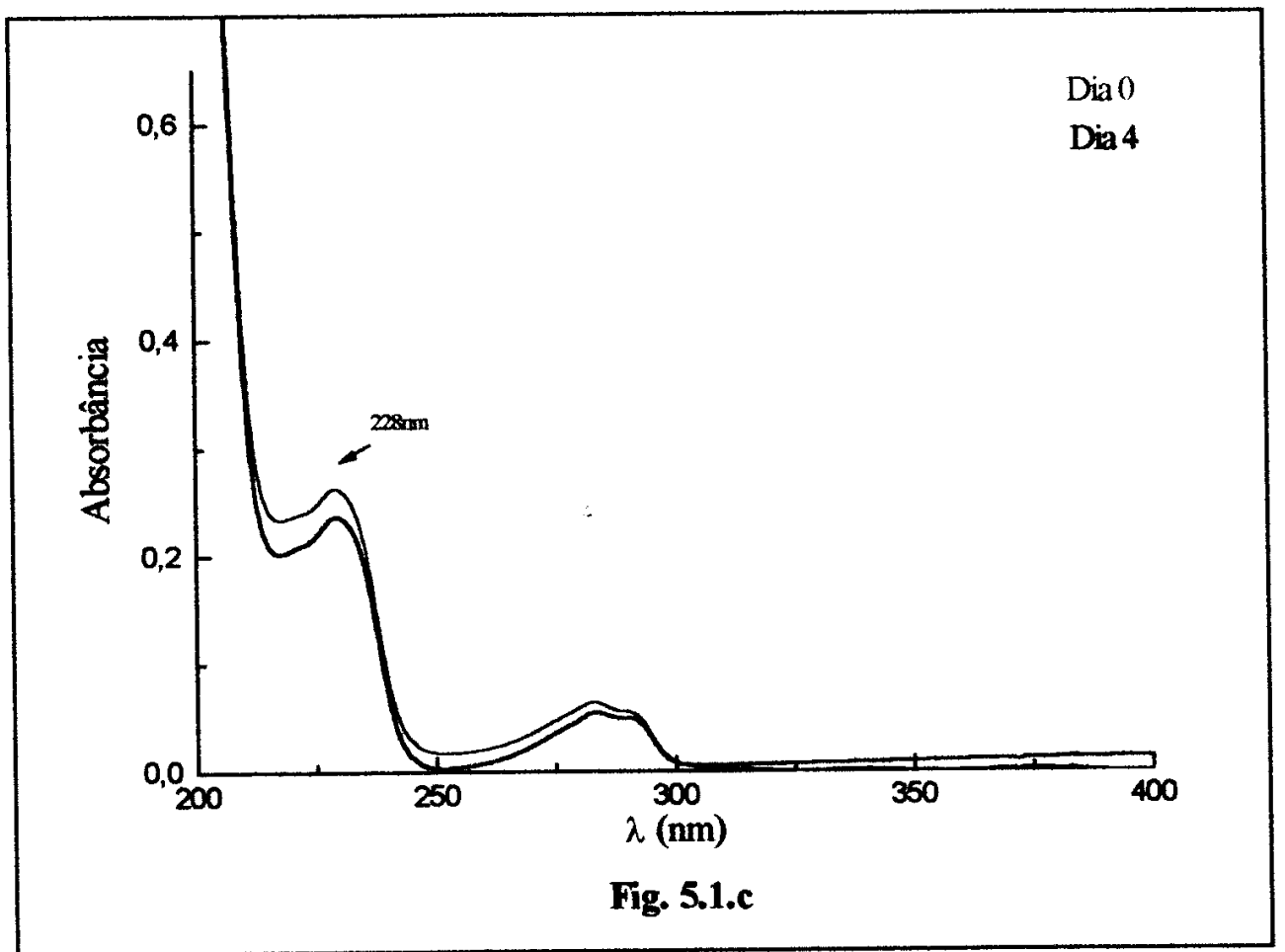

Figura 5.1: Espectros de absorção eletrônica das soluçōes $\mathrm{AH}+2,4-\mathrm{D}(1 \mathrm{mM})$, com ácido húmico do solo podzólico vermelho-amarelo, dia 0 e dia 4 , (a) $\mathrm{pH}=2.03^{\star}$, (b) $\mathrm{pH}=4.00^{*}$, e

(c) $\mathrm{pH}=6.70^{\star}(* 200 \mu \mathrm{l}$ de soluçäo $\mathrm{AH}+2,4-\mathrm{D}$ dissolvidos em 3,5ml de água destilada,

- $100 \mu$ de solução $\mathrm{AH}+2,4-\mathrm{D}$ dissolvidos em $3,5 \mathrm{ml}$ de água destilada)

Os dados da tabela 5.2 mostram valores médios da intensidade de absorção eletrônica do herbicida 2,4-D (A228) (e seus desvios médios absolutos), comprimento de onda $228 \mathrm{~nm}$, de soluções $A H+2,4-D(1 \mathrm{mM})$, com ácido húmico da turfeira, em função do dia da medida (dia 0 e dia4) e dos valores de $\mathrm{pH}$, tendo como referência as soluções AH. E os correspondentes espectros estão mostrados na figura 5.2.

Tabela 5.2: Intensidades da banda de absorção em 228nm do herbicida 2,4-D ( $\mathrm{A}_{228}$ ), obtidas a partir

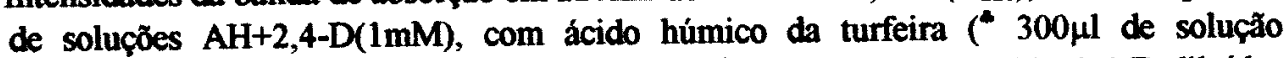
$\mathrm{AH}+2,4-\mathrm{D}$ diluídos em $3,5 \mathrm{ml}$ de água destilada, $200 \mu \mathrm{l}$ de solução $\mathrm{AH}+2,4-\mathrm{D}$ diluídos em $3,5 \mathrm{ml}$ de água destilada)

\begin{tabular}{|c|c|c|c|}
\hline $\mathrm{pH}$ & $\mathrm{A}_{228}-$ dia 0 & $\mathrm{A}_{228}-$ dia 4 & $\begin{array}{c}\text { Diferença (\%) de } \mathrm{A}_{228} \\
\text { entre o dia 0 e o dia 4 }\end{array}$ \\
\hline $2,04^{*}$ & $(0,65 \pm 0,02)$ & $(0,64 \pm 0,01)$ & $+2 \%$ \\
\hline $4,00^{\circ}$ & $(0,72 \pm 0,01)$ & $(0,70 \pm 0,04)$ & $+3 \%$ \\
\hline $6,99^{\circ}$ & $(0,471 \pm 0,008)$ & $(0,466 \pm 0,008)$ & $+1 \%$ \\
\hline
\end{tabular}




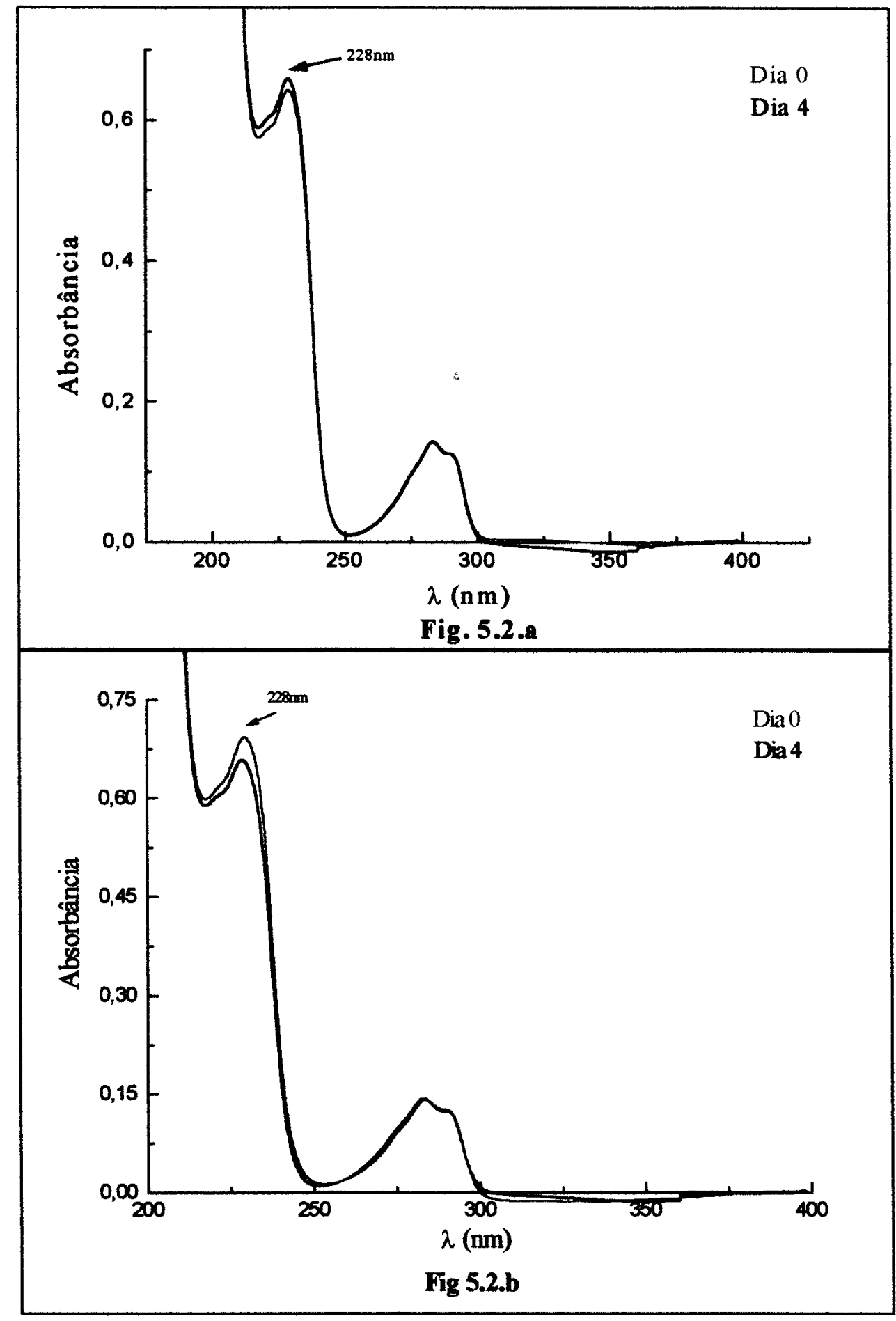




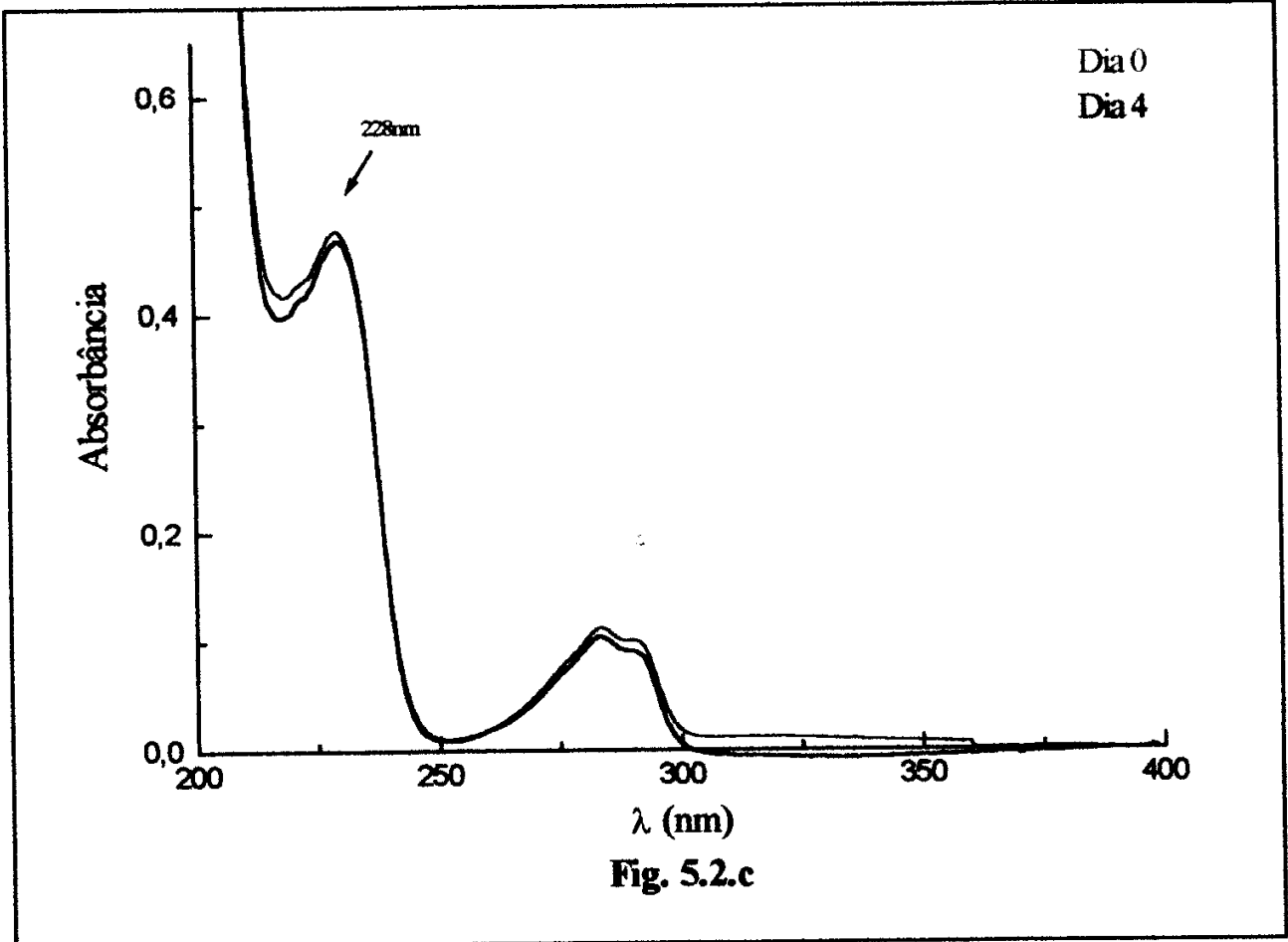

Figura 5.2: Espectros de absorção eletrônica das soluçð̧es $\mathrm{AH}+2,4-\mathrm{D}(1 \mathrm{mM})$, com ácido húmico da turfeira, dia 0 e dia 4 , (a) $\mathrm{pH}=2,04^{\star}$, (b) $\mathrm{pH}=4,00^{\circ}$, e (c) $\mathrm{pH}=6,99^{\star}$ (*300 $\mu \mathrm{l}$ de solução AH+2,4-D dissolvidos em 3,5ml de água destilada, ${ }^{\star 200 \mu l ~ d e ~ s o l u c ̧ a ̃ o ~}$ $\mathrm{AH}+2,4-\mathrm{D}$ dissolvidos em $3,5 \mathrm{ml}$ de água destilada)

Com os sobrenadantes coletados das soluções $\mathrm{AH}$ e $\mathrm{AH}+2,4-\mathrm{D}$, com ácido húmico da turfeira, após os 4 dias de agitação, acidificação a pH $=2$ e centrifugação, o que se pretende é quantificar a sorção do herbicida 2,4-D pelo ácido húmico. Para isso são necessárias as medidas absorbâncias do 2,4-D $\left(\mathrm{A}_{228}\right)$ a $228 \mathrm{~nm}$, dos sobrenadantes das soluções $A H+2,4-D(1 \mathrm{mM})$. A referência são os sobrenadantes das amostras $\mathrm{AH}$.

Os valores médios (e seus desvios médios absolutos) das intensidades

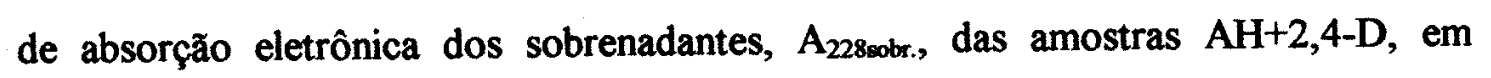
função dos valores de pH, estão mostrados na tabela 5.3 e alguns dos espectros estão

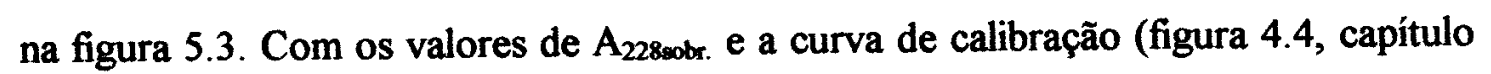
4, ítem 4.3.1) é possível calcular a massa do 2,4-D responsável pela intensidade da absorção do espectro eletrônico dos sobrenadantes, também apresentadas a seguir. 
Tabela 5.3: Intensidades da banda de absorção em 228nm do herbicida 2,4-D, obtidas a partir dos sobrenadantes das soluções $\mathrm{AH}+2,4-\mathrm{D}(1 \mathrm{mM})$, com ácido húmico da turfeira ( $300 \mu \mathrm{l}$ de

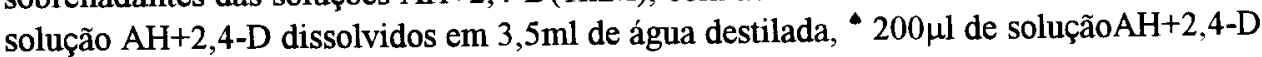
dissolvidos em $3,5 \mathrm{ml}$ de água destilada)

\begin{tabular}{|c|c|c|}
\hline $\mathrm{pH}$ & $\begin{array}{c}\text { A228sobr. }^{-} \\
\text {Sobrenadante }\end{array}$ & $\begin{array}{c}\text { Massa }_{\text {sobr. }}(\mathrm{mg}) \\
\text { do 2,4-D no } \\
\text { sobrenadante }\end{array}$ \\
\hline $2,04^{*}$ & $(0,600 \pm 0,002)$ & $(3,56 \pm 0,01)$ \\
\hline $4,02^{*}$ & $(0,644 \pm 0,001)$ & $(3,84 \pm 0,01)$ \\
\hline $7,01^{\star}$ & $(0,44 \pm 0,01)$ & $(3,8 \pm 0,2)$ \\
\hline
\end{tabular}

As soluções iniciais $\mathrm{AH}+2,4-\mathrm{D}$ têm concentração $1 \mathrm{mM}$ de 2,4-D, ou seja, 4,42mg do herbicida é a massa total inicial, o que corresponde a $1,2 \times 10^{19}$ moléculas de 2,4-D na solução inicial. Os resultados da tabela seguinte expõe o número de moléculas sorvidas de 2,4-D, que foram obtidos a partir da tabela 5.3 e a porcentagem de moléculas sorvidas em relação ao número total inicial.

Tabela 5.4 Massa(mg) e número de moléculas de 2,4-D sorvidas pelo ácido húmico da turfeira, calculados a partir da tabela 5.3

\begin{tabular}{|c|c|c|c|}
\hline $\mathrm{pH}$ & $\begin{array}{c}\text { Massa(mg) de 2,4D } \\
\text { sorvida pelo } \\
\text { ácido húmico }\end{array}$ & $\begin{array}{c}\text { Número de moléculas } \\
\left(\times 10^{+18}\right) \text { de } 2,4-\mathrm{D} \\
\text { sorvidas pelo ácido húmico }\end{array}$ & $\begin{array}{c}\text { Porcentagem de } \\
\text { moléculas sorvidas } \\
\text { em relação ao } \mathrm{n}^{\mathbf{0}} \\
\text { total inicial }\end{array}$ \\
\hline 2,04 & 0,86 & 2,33 & $19 \%$ \\
\hline 4,02 & 0,58 & 1,57 & $13 \%$ \\
\hline 7,01 & 0,6 & 1,7 & $14 \%$ \\
\hline
\end{tabular}




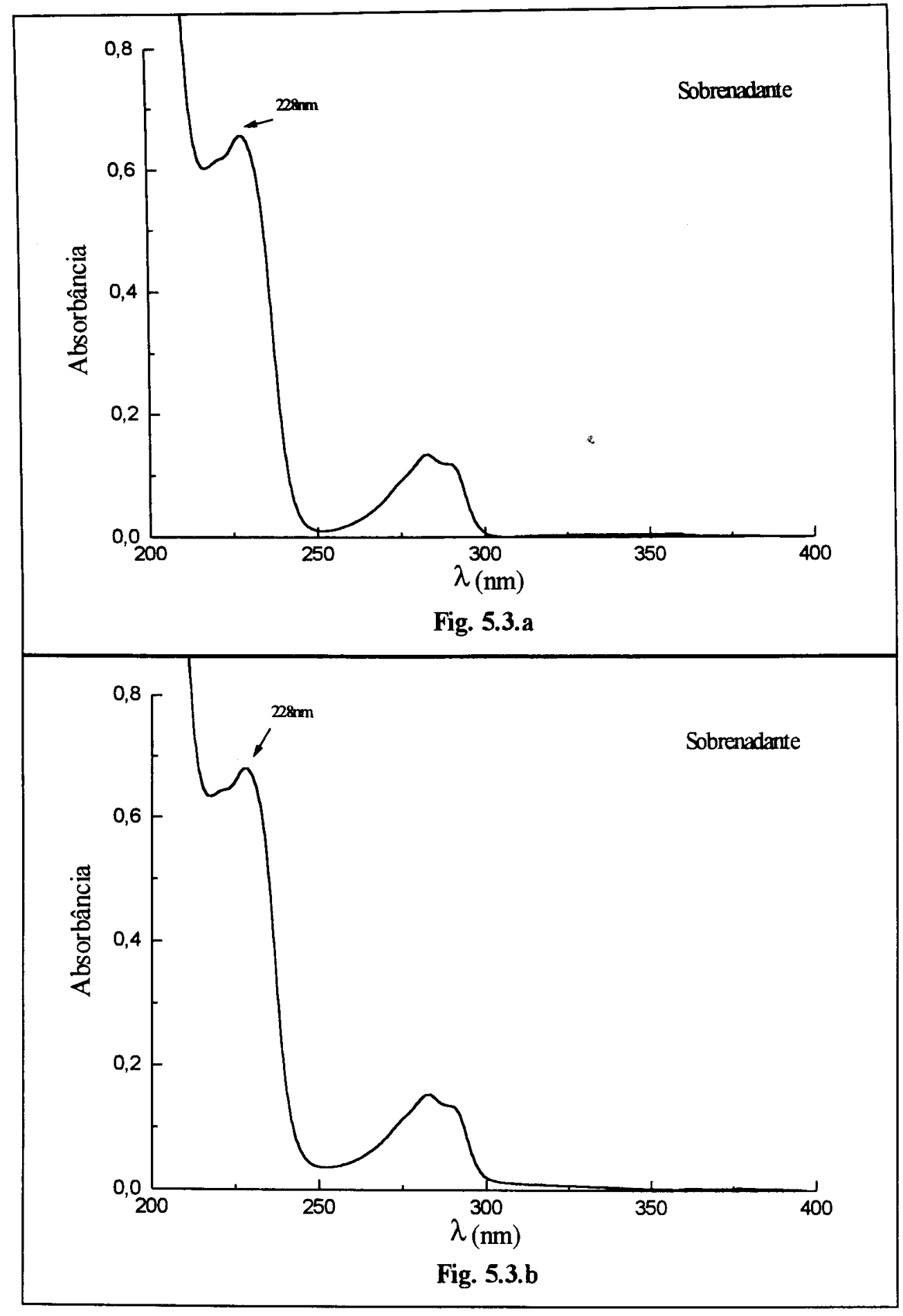

80 


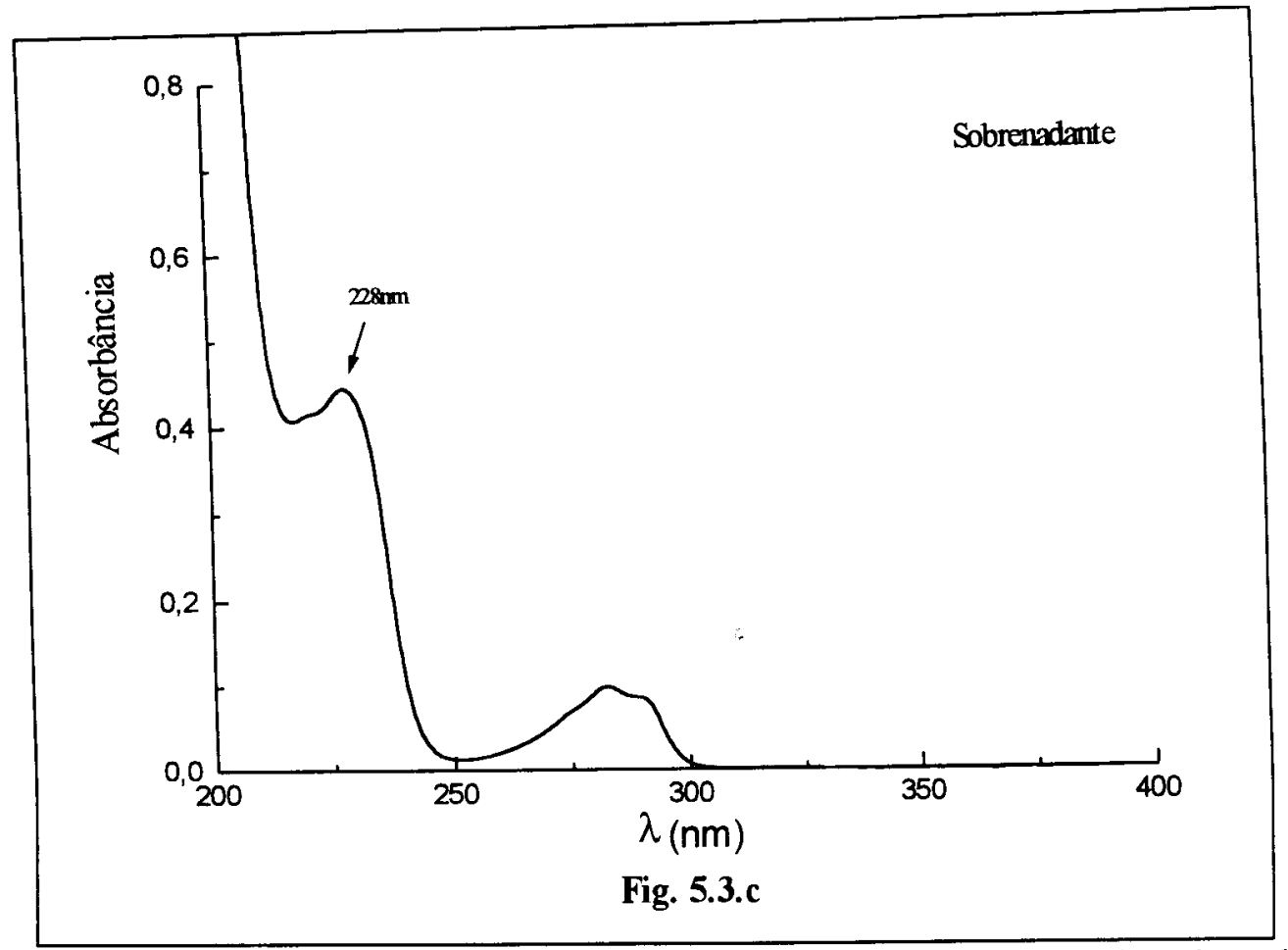

Figura 5.3: Os espectros de absorção eletrônica do herbicida 2,4-D obtidos a partir dos sobrenadantes das soluções $\mathrm{AH}+2,4 \mathrm{D}(1 \mathrm{mM})$, com ácido húmico da turfeira, (a) $\mathrm{pH}=2,04^{*}$, (b) $\mathrm{pH}=$ $4,01^{\star}$, e (c) $\mathrm{pH}=7,01^{\star}$ ( ${ }^{\star} 300 \mu \mathrm{l}$ de solução $\mathrm{AH}+2,4-\mathrm{D}$ dissolvidos em $3,5 \mathrm{ml}$ de água destilada, ${ }^{\star} 200 \mu 1$ de solução $\mathrm{AH}+2,4-\mathrm{D}$ dissolvidos em 3,5ml de água destilada)

\subsection{1.b Espectros de EPR}

A técnica de EPR foi a ferramenta usada para calcular os níveis de radicais livres semiquinona (número de spins por grama da amostra) do solo podzólico vermelho-amarelo das amostras $A H+2,4-\mathrm{D}(1 \mathrm{mM})$ e $\mathrm{AH}$, obtidos após a liofilização depois de 4 dias de agitação das soluções. Na quantificação de semiquinona usou-se o método do padrão secundário (ver capítulo 3 , ítem 3.2.8), para os diferentes valores de $\mathrm{pH}$.

A tabela 5.5 diz respeito a média da densidade de radicais livres $\left(\mathrm{N}_{0}\right)$, do solo podzólico vermelho-amarelo, das amostras AH+2,4-D e AH, e a diferença dos valores encontrados entre as amostras (em \%) em função do $\mathrm{pH}$. E na figura 5.4 pode se ver alguns dos espectros referentes a essa tabela. Os parâmetros utilizados para se obter os espectros do semiquinona encontram-se no capítulo 4, ítem 4.3.2. 
Tabela 5.5: Média da densidade de radicais livres semiquinona $\left(\mathrm{N}_{0}\right)$, do ácido húmico do solo poctzólico vermelho-amarelo, das amostras $\mathrm{AH}+2,4-\mathrm{D}(1 \mathrm{mM})$ e AH liofilizadas

\begin{tabular}{|c|c|c|c|c|}
\hline Amostra & $\mathrm{pH}$ & $\begin{array}{c}N_{0}(\operatorname{spin} / g) \times \\
10^{+17}\end{array}$ & $\begin{array}{c}\text { Diferença (\%) de } \\
\mathrm{N}_{0} \text { entre } \mathrm{AH} \text { e } \\
\mathrm{AH}+2,4-\mathrm{D}\end{array}$ & $\begin{array}{l}\text { Largura de linha } \\
\text { do sinal de EPR } \\
-\Delta H(G)\end{array}$ \\
\hline AH & 2,02 & $(9 \pm 1)$ & \multirow[b]{2}{*}{$+11 \%$} & $(4,91 \pm 0,08)$ \\
\hline $\mathrm{A} \mathrm{H}+2,4-\mathrm{D}$ & $2, \overline{0}$ & $(8 \pm 1)$ & & $(4,94 \pm 0,08)$ \\
\hline$\overline{\mathrm{AH}}$ & 4,03 & $(3,2 \pm 0,3)$ & \multirow[b]{2}{*}{$+9 \%$} & $(5,1 \pm 0,2)$ \\
\hline$\overline{\mathrm{A}}+\overline{\mathrm{H}}, \overline{4-\mathrm{D}}$ & 4,00 & $(2,9 \pm 0,4)$ & & $(5,2 \pm 0,2)$ \\
\hline$\overline{\mathrm{AH}}$ & 6,90 & $(2,9 \pm 0,3)$ & \multirow[b]{2}{*}{$+24 \%$} & $(5,28 \pm 0,04)$ \\
\hline $\mathrm{A} H+2,4-\mathrm{D}$ & $\overline{6}, \overline{70}$ & $(2,2 \pm 0,2)$ & & $(5,3 \pm 0,2)$ \\
\hline
\end{tabular}

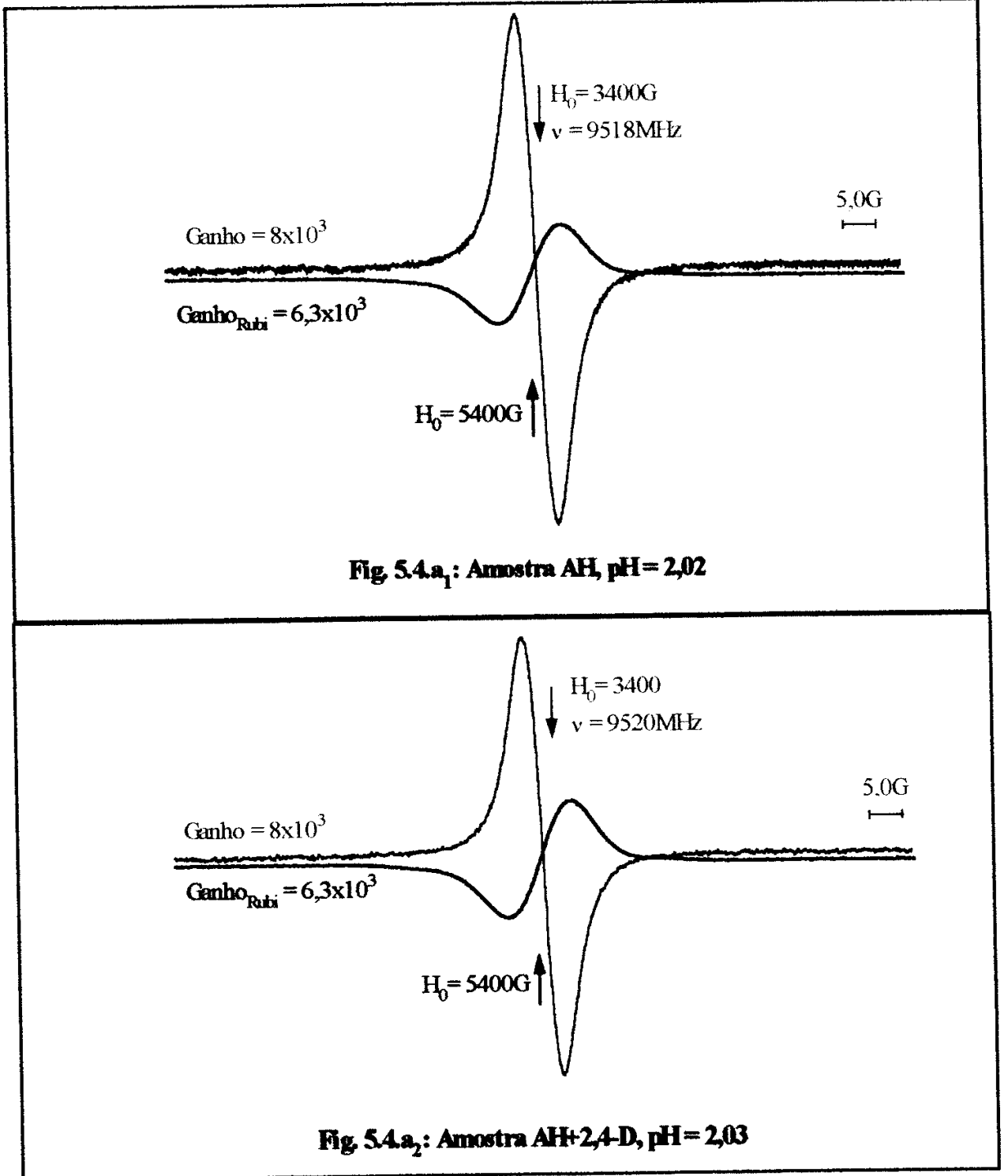

Figura 5.4: Espectro de EPR do radical livre semiquinona do solo podzólico vermelho-amarelo e do padrão rubi, das seguintes amostras liofilizadas: $\left(a_{1}\right) \mathrm{AH}, \mathrm{pH}=2,02,\left(\mathrm{a}_{2}\right) \mathrm{AH}+2,4-\mathrm{D}$, $\mathrm{pH}=2,03$ 
$\mathrm{Na}$ tabela 5.6 estão apresentados as médias dos resultados da quantificação dos radicais livres do ácido húmico da turfeira, $\mathrm{N}_{0}$, para as amostras $\mathrm{AH}+2,4-\mathrm{D}(1 \mathrm{mM})$ e $\mathrm{AH}$, liofilizadas após 4 dias de agitação das soluções, em função dos valores de $\mathrm{pH}$. A figura 5.5 têm alguns dos correspondentes espectros de EPR. Os parâmetros utilizados experimentais para se obter os espectros do semiquinona encontram-se no capítulo 4, ítem 4.3.3.

Tabela 5.6: Média da densidade de radicais livres semiquinona $\left(\mathrm{N}_{0}\right)$, do ácido húmico da turfeira, das amostras $\mathrm{AH}+2,4-\mathrm{D}(1 \mathrm{mM})$ e $\mathrm{AH}$ liofilizadas

\begin{tabular}{|c|c|c|c|c|}
\hline Amostra & $\mathrm{pH}$ & $\mathrm{N}_{0}(\mathrm{spin} / \mathrm{g}) \times 10^{+18}$ & $\begin{array}{c}\text { Diferença (\%) de } \\
\mathrm{N}_{0} \text { entre } \mathrm{AH} \mathrm{e} \\
\mathrm{AH}+2,4-\mathrm{D} \\
\end{array}$ & $\begin{array}{c}\text { Largura de linha } \\
\text { de sinal de EPR } \\
-\Delta H(G)\end{array}$ \\
\hline$\overline{\mathrm{AH}}$ & 2,02 & $\overline{(3,7 \pm 0,4)}$ & \multirow[b]{2}{*}{$+22 \%$} & $(4,2 \pm 0,2)$ \\
\hline $\mathrm{AH}+2,4-\mathrm{D}$ & 2,04 & $(2,8 \pm 0,3)$ & & $(4,2 \pm 0,2)$ \\
\hline$\overline{\mathrm{AH}}$ & 4,00 & $(2,0 \pm 0,2)$ & \multirow[b]{2}{*}{$+20 \%$} & $(4,3 \pm 0,3)$ \\
\hline $\mathrm{AH}+2,4-\mathrm{D}$ & 4,00 & $(1,6 \pm 0,2)$ & & $(4,3 \pm 0,1)$ \\
\hline $\mathrm{AH}$ & 7,00 & $(2,1 \pm 0,2)$ & \multirow[b]{2}{*}{$+29 \%$} & $\overline{(4,4 \pm 0,2)}$ \\
\hline $\mathrm{AH}+2,4-\mathrm{D}$ & 6,99 & $(1,5 \pm 0,2)$ & & $(4,4 \pm 0,2)$ \\
\hline
\end{tabular}




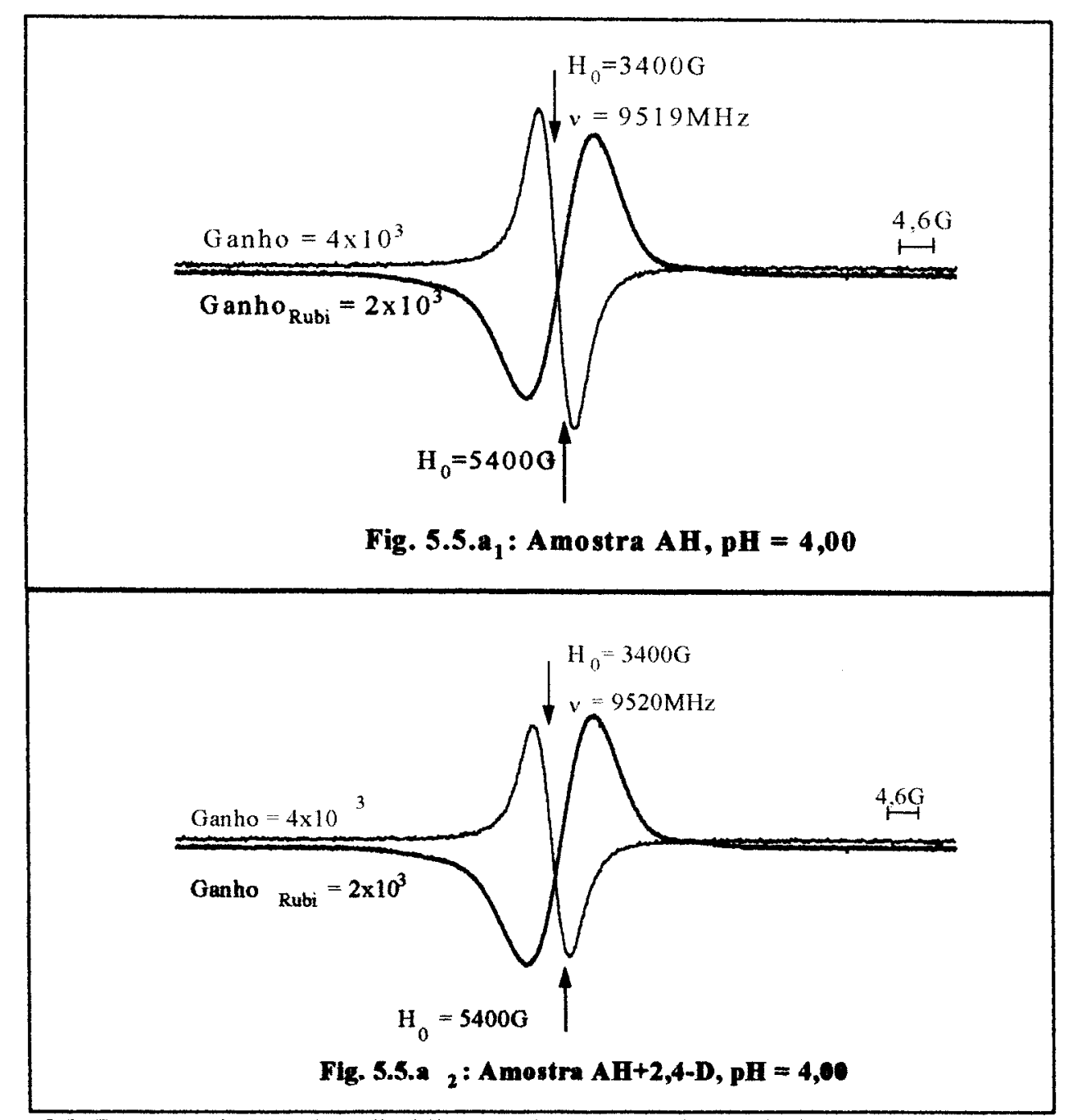

Figura 5.5: Espectros de EPR do radical livre semiquinona do ácido húmico de tufa e do padrão rubi das seguintes amostras liofilizadas: $\left(a_{1}\right) \mathrm{AH}, \mathrm{pH}=4,00,\left(\mathrm{a}_{2}\right) \mathrm{AH}+2,4-\mathrm{D}, \mathrm{pH}=4,00$

Os precipitados das soluções $\mathrm{AH}$ e $\mathrm{AH}+2,4-\mathrm{D}(1 \mathrm{mM})$, com ácido húmico da turfeira, obtidos após acidificação a $\mathrm{pH}=2$ e centrifugação do material que reagiu durante quatro dias, foram liofilizados e tiveram seus radicais semiquinonas quantificados por EPR. A tabela 5.7 tem as médias dos resultados da quantificação (e seus desvios médios absolutos), $\mathrm{N}_{\text {oprec., já corrigidos pelos valores }}$ corretos de massa do ácido húmico, através da tabela 5.3, isto é, massa precipitado(2,4-D) $=$ massa $_{\text {Total(2,-D) - massa }}$ obr.(2,4-D), uma vez que a massa das amostras AH+2,4-D no tubos de quartzo incluem além da massa do ácido, a massa do herbicida, que não contribui para o sinal. A figura que segue têm os espectros de EPR do precipitado, com as intensidades do sinal de EPR também corrigidas pelo valor da massa. 
Tabela 5.7: Média da densidade de radicais livres semiquinona $\left(\mathrm{N}_{(\mathrm{prec}}\right)$ do ácido húmico precipitado da turfeira, das amostras $\mathrm{AH}+2,4-\mathrm{D}(1 \mathrm{mM})$ e AH liofilizadas

\begin{tabular}{|c|c|c|c|c|}
\hline Amostra & $\mathrm{pH}$ & $\begin{array}{c}\mathrm{N}_{\text {oprec. }}(\mathrm{spin} / \mathrm{g}) \times \\
10^{+18}\end{array}$ & $\begin{array}{c}\text { Diferença (\%) de } \\
\mathrm{N}_{\text {oprec. }} \text { entre AH e } \\
\text { AH+2,4-D }\end{array}$ & $\begin{array}{c}\text { Largura de linha } \\
\text { de sinal de EPR } \\
-\Delta H(G)\end{array}$ \\
\hline$\overline{\mathrm{AH}}$ & 2,03 & 2,04 & \multirow[b]{2}{*}{$-3 \%$} & 4,38 \\
\hline $\mathrm{A} \overline{\mathrm{H}}+2,4-\mathrm{D}$ & $2, \overline{04}$ & $(2,10 \pm 0,06)$ & & $(4,38 \pm 0,05)$ \\
\hline$\overline{\mathrm{AH}}$ & 4,01 & 2,0 & \multirow[b]{2}{*}{$0 \%$} & 4,25 \\
\hline$\overline{\mathrm{A}} \overline{\mathrm{H}}+\overline{2}, \overline{4-\mathrm{D}}$ & 4,02 & $(2,0 \pm 0,1)$ & & $(4,25 \pm 0,05)$ \\
\hline$\overline{\mathrm{AH}}$ & 6,97 & 1,82 & \multirow[b]{2}{*}{$-7 \%$} & 4,38 \\
\hline$\overline{\mathrm{A}}+2, \overline{4}-\mathrm{D}$ & 7,01 & $(1,96 \pm 0,07)$ & & $(4,44 \pm 0,06)$ \\
\hline
\end{tabular}

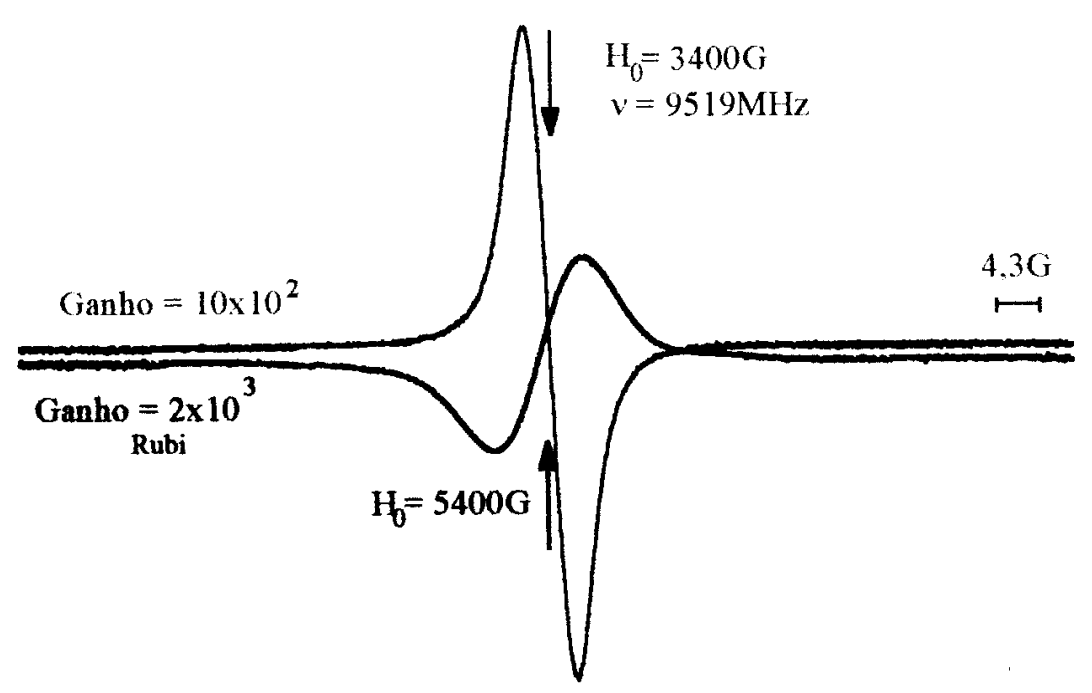

Fig. 5.6.a 1 : Precipitado da amostra $\mathrm{AH}, \mathrm{pH}=2,03$

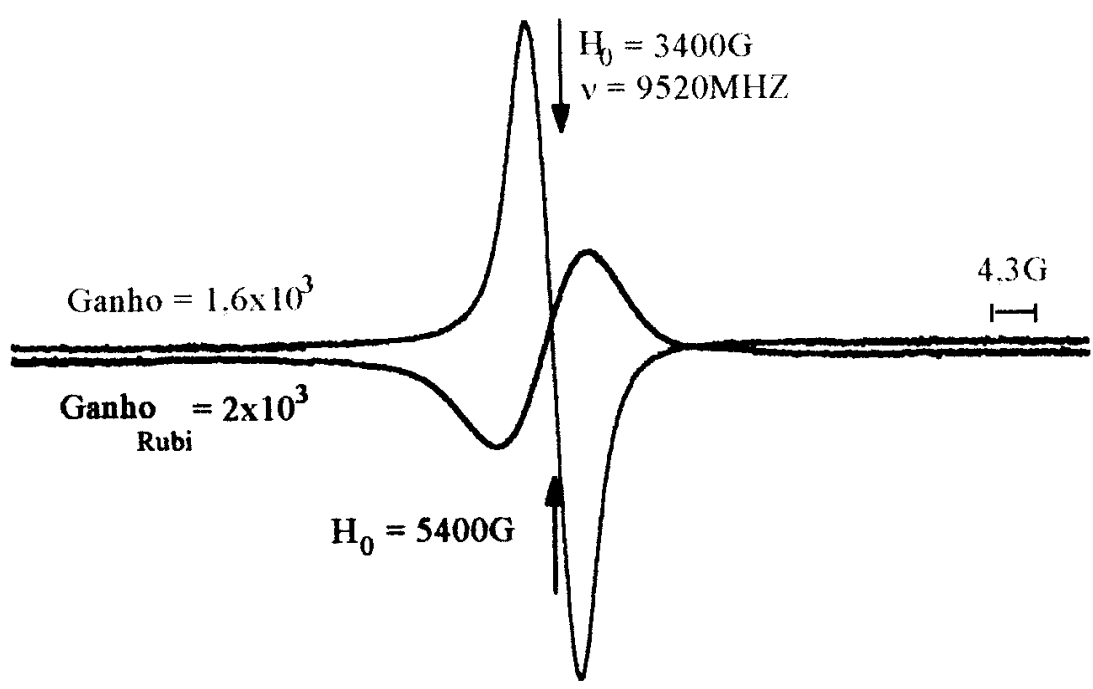

Fig. 5.6.a 2 Precipitado da amostra $A H+2,4-D, p H=2,04$ 


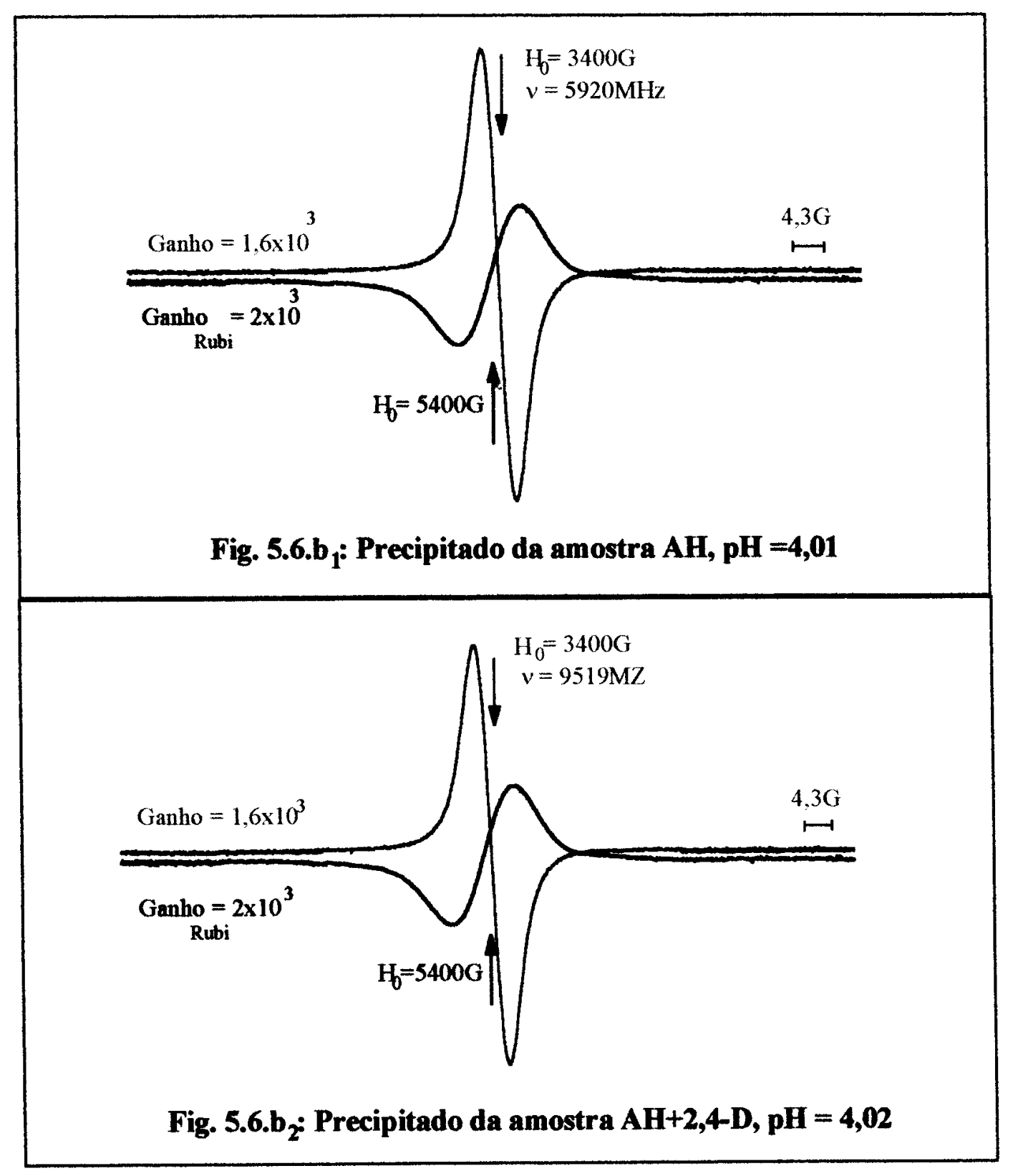




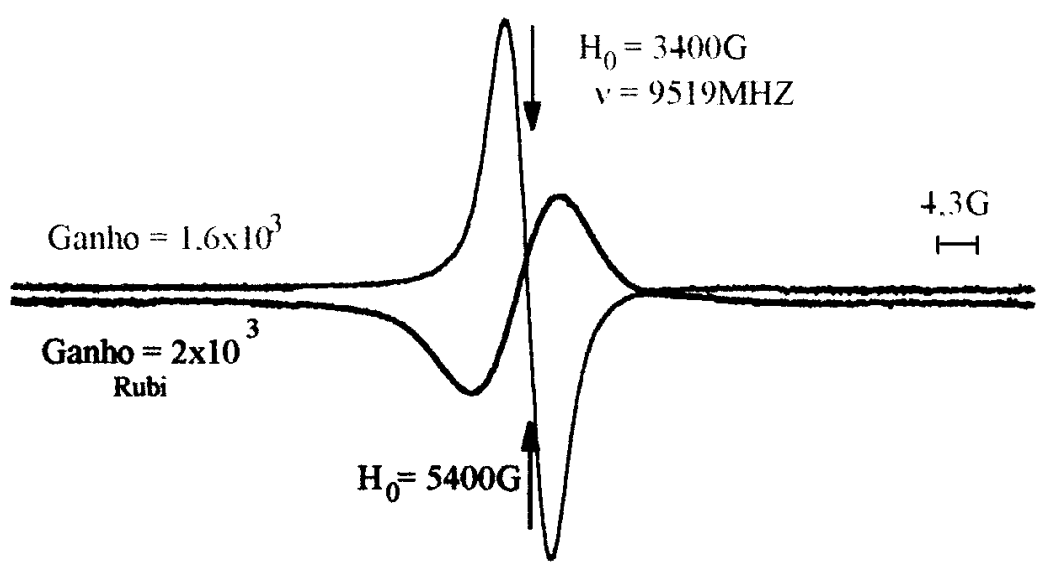

Fig. 5.6.c : $_{\text {: Amostra AH+2,4-D, pH }=6,97}$

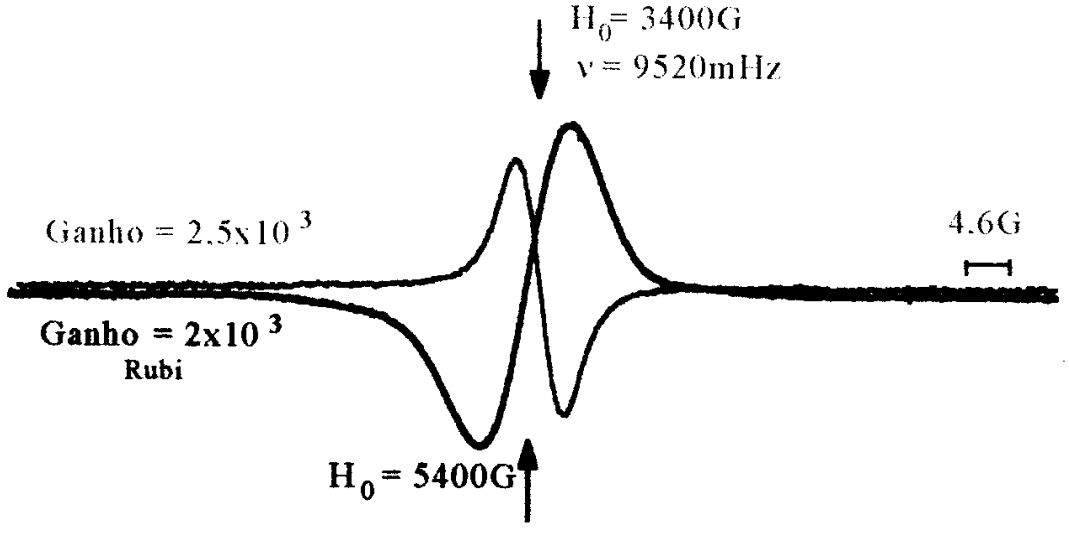

Fig. 5.6. $c_{2}$ : Amostra AH+2,4-D, $\mathrm{pH}=6,99$

Figura 5.6: Espectro de EPR do radical livre semiquinona da turfeira e do padrão rubi, dos precipitados das seguintes amostras liofilizadas: $\left(a_{1}\right) \mathrm{AH}, \mathrm{pH}=2,03,\left(\mathrm{a}_{2}\right) \mathrm{AH}+2,4-\mathrm{D}$, $\mathrm{pH}=2,04,\left(\mathrm{~b}_{1}\right) \mathrm{AH}, \mathrm{pH}=4,01,\left(\mathrm{~b}_{2}\right) \mathrm{AH}+2,4-\mathrm{D}, \mathrm{pH}=4,02,\left(\mathrm{c}_{1}\right) \mathrm{AH}, \mathrm{pH}=6,97, \mathrm{e}$ $\left(\mathrm{c}_{2}\right) \mathrm{AH}+2,4-\mathrm{D}, \mathrm{pH}=7,01$

Foram obtidos espectros de EPR contendo os sinal dos ions ferro(III), do cobre(II) e do radical livre semiquinona, próxima a temperatura de nitrogênio líquido $\left(-160^{\circ} \mathrm{C}\right)$, das amostras $\mathrm{AH}$ e $\mathrm{AH}+2,4-\mathrm{D}$ com ácido húmico de ambos os solos, e estão apresentados dois deles na figura 5.7. Os parâmetros experimentais utilizados para obtenção dos espectros estão no capítulo 4, ítem 4.3.2. 


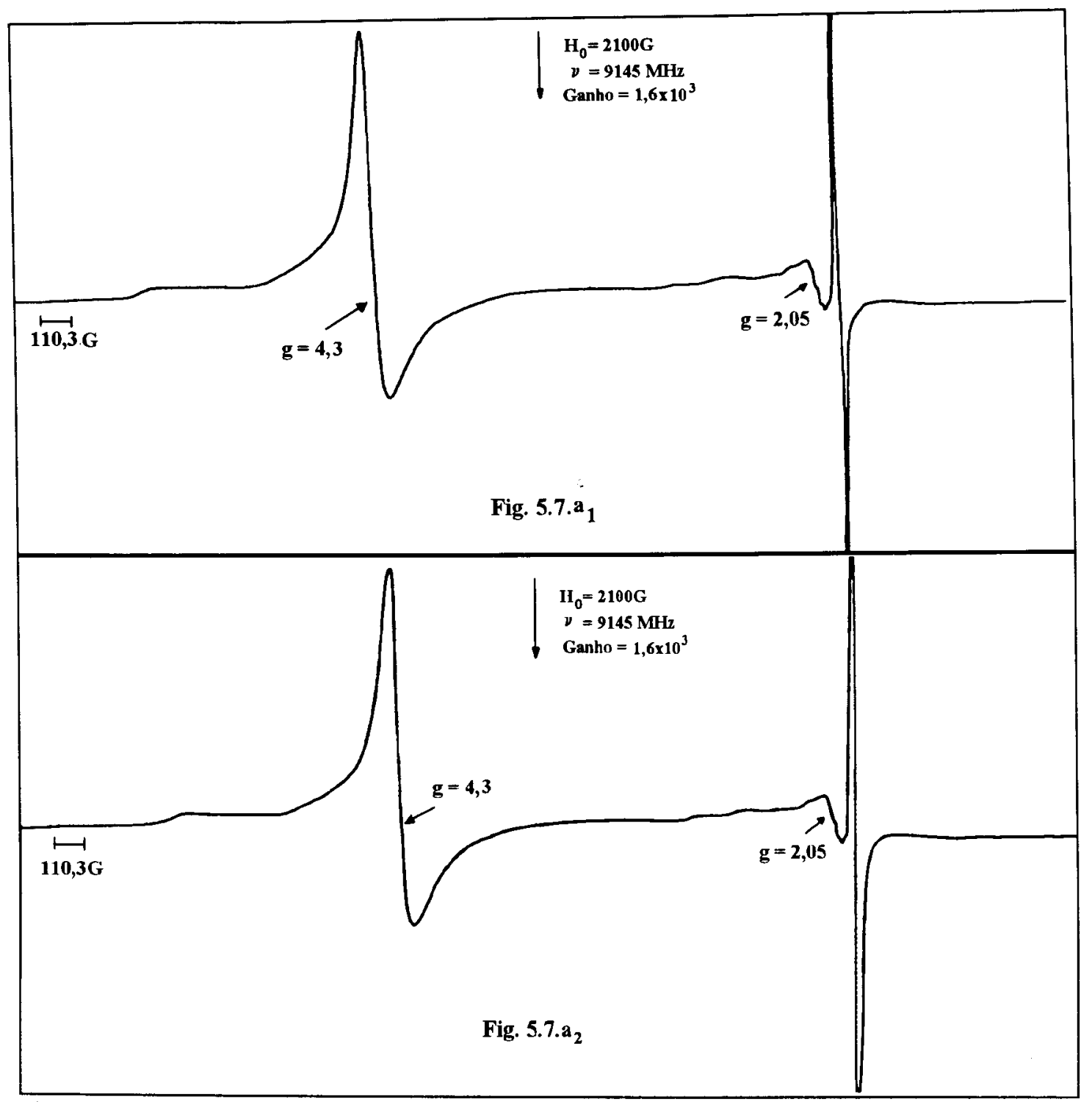

Figura 5.7: Espectro de EPR a temperatura de nitrogênio líquido das seguintes amostras $\left(\mathrm{a}_{1}\right) \mathrm{AH}$, $\mathrm{pH}=6,99$ e $\left(\mathrm{a}_{2}\right) \mathrm{AH}+2,4-\mathrm{D}, \mathrm{pH}=6,97$, com ácido húmico da turfeira

\subsubsection{1.c Espectros de FTIR}

O objetivo de utilizar a técnica de FTIR é de identificar possíveis alterações nos grupos funcionais do ácido húmico devidas a interações com o herbicida. Para isso é necessário obter os espectros tanto do ácido húmico e ácido húmico mais herbicida, e também do herbicida puro, para valores de $\mathrm{pH}$ correspondentes, para comparação.

Os espectros de absorção no infravermelho de amostras liofilizadas depois de 4 dias de agitação das soluções do 2,4-D, em diferentes valores de $\mathrm{pH}$, 
estão na figura 5.8, e as atribuições das bandas aos grupos funcionais encontram-se no capítulo 3, ítem 3.4.4.

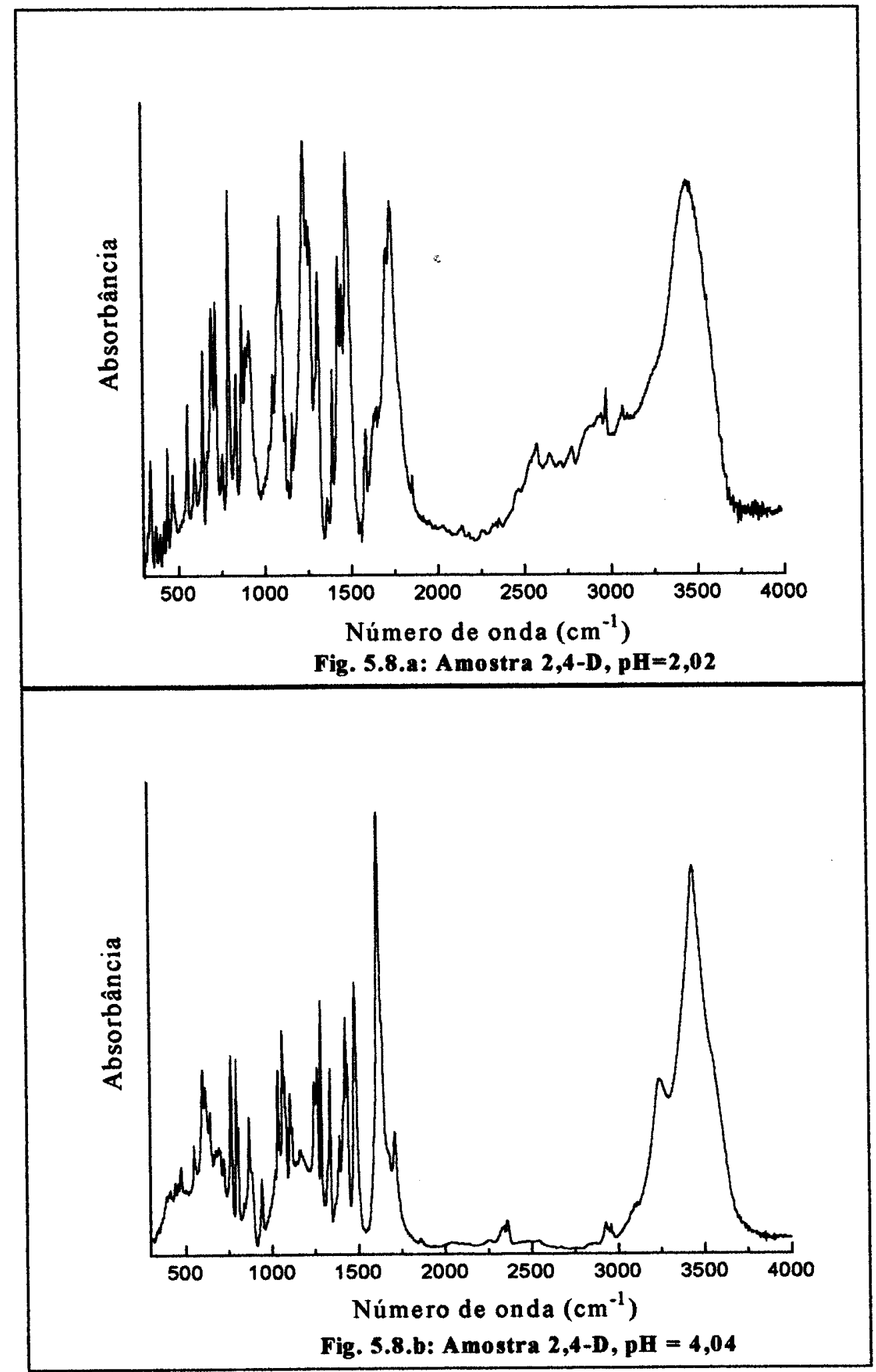




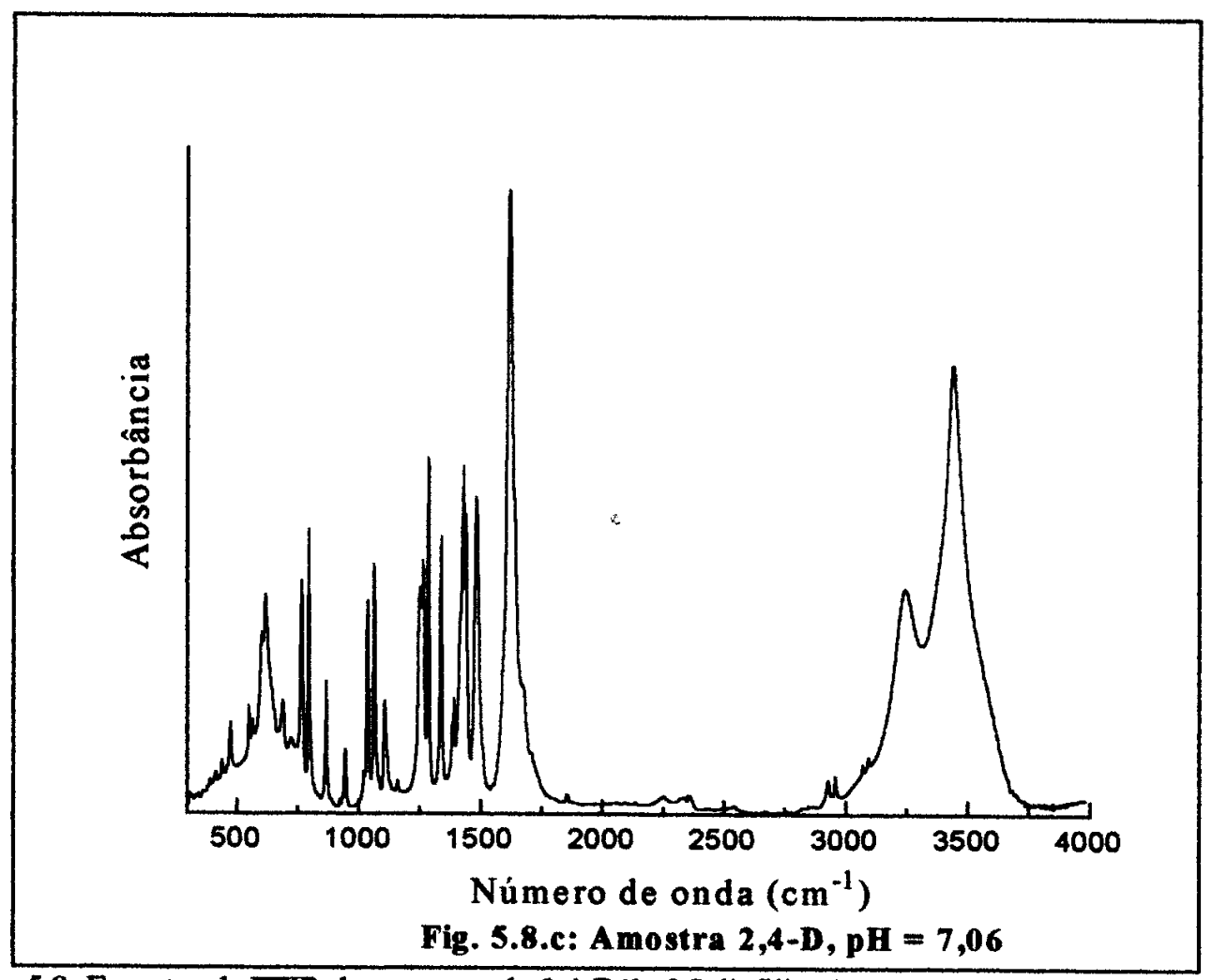

Figura 5.8: Espectro de FTIR de amostras do 2,4-D(1mM) liofilizadas, (a) $\mathrm{pH}=2,02$, (b) $\mathrm{pH}=4,04$, e (c) $\mathrm{pH}=7,06$

A figura 5.9 mostra os espectros das amostras $\mathrm{AH}$ e $\mathrm{AH}+2,4-$ $\mathrm{D}(1 \mathrm{mM})$, com ácido húmico do solo podzólico vermelho-amarelo, liofilizadas depois de 4 dias de agitação das soluções, segundo valores de $\mathrm{pH}$. Os grupos funcionais do ácido húmico estão identificados no capítulo 3, ítem 3.4.4. 


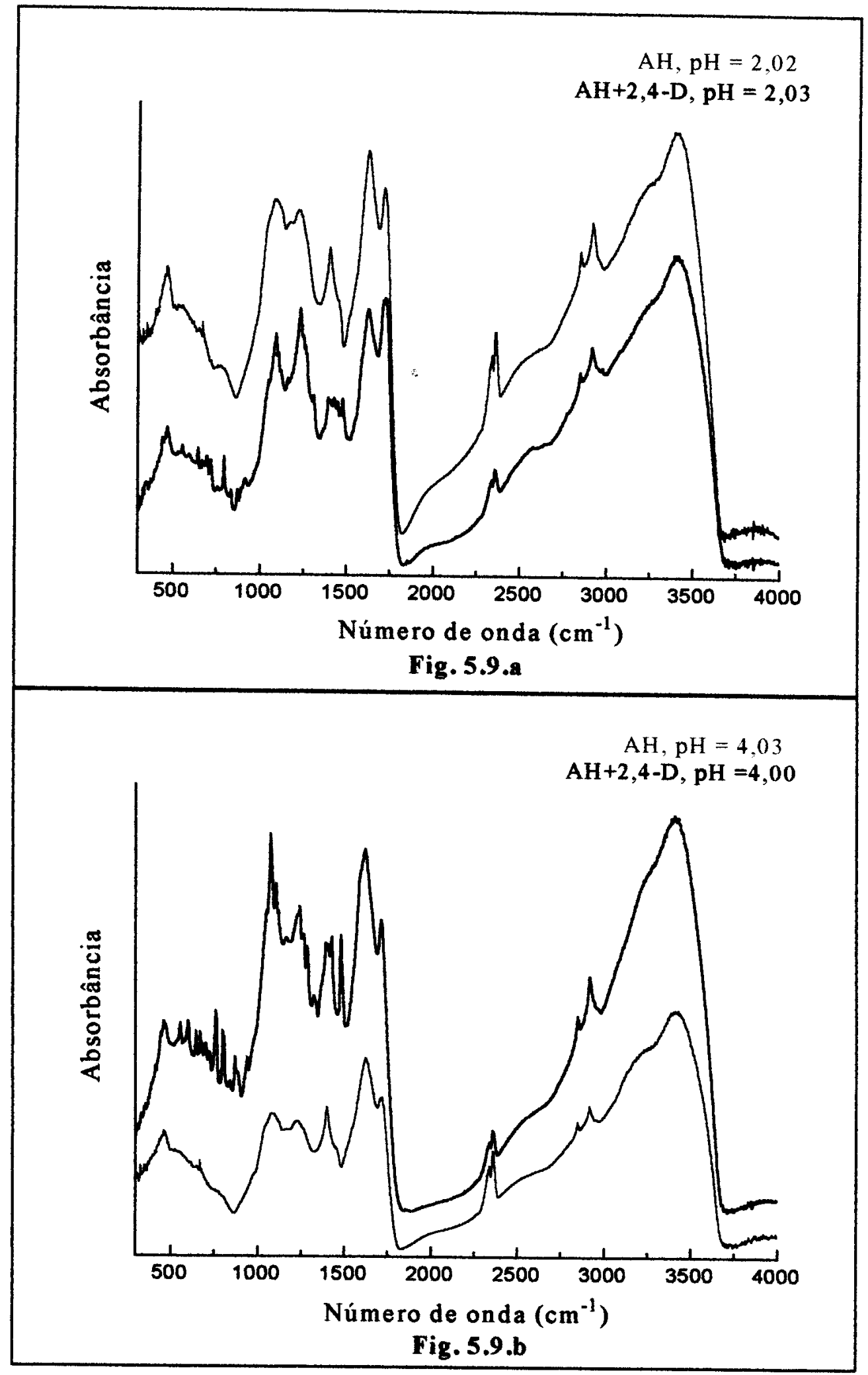




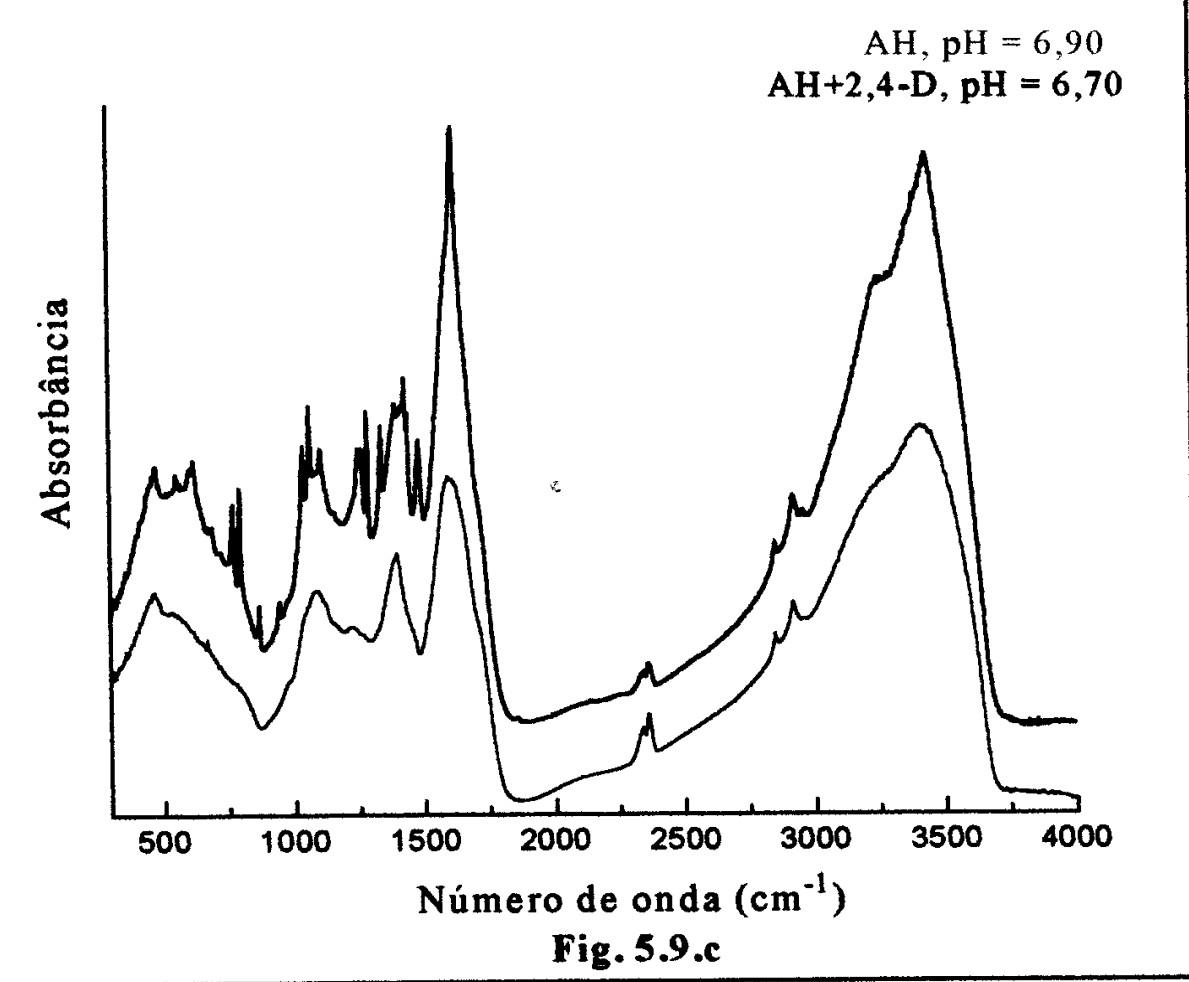

Figura 5.9: Espectros de FTIR de amostras liofilizadas contendo ácido húmico do solo podzólico vermelho-amarelo, (a) $\mathrm{AH} \mathrm{pH}=2,02$ e $\mathrm{AH}+2,4-\mathrm{D} \mathrm{pH}=2,03$, (b) $\mathrm{AH} \mathrm{pH}=4,03 \mathrm{e}$ $\mathrm{AH}+2,4-\mathrm{D} \mathrm{pH}=4,00, \mathrm{e}$ (c) $\mathrm{AH}$ pH $=6,90$ e $\mathrm{AH}+2,4-\mathrm{D} \mathrm{pH}=6,70$

Os espectros de FTIR para as amostras AH e AH+2,4-D em função do $\mathrm{pH}$, para ácido húmico da turfeira, estão mostrados na figura 5.10 . 


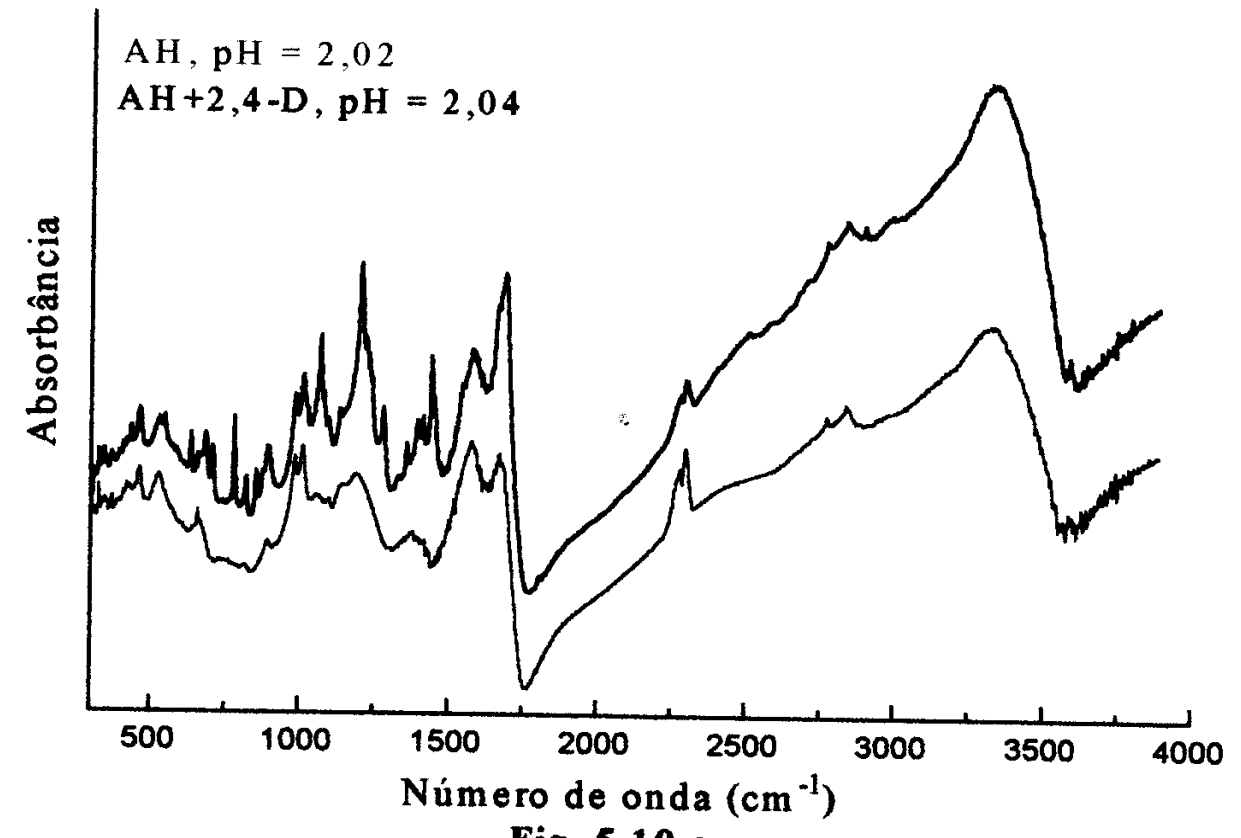

Fig. 5.10.2

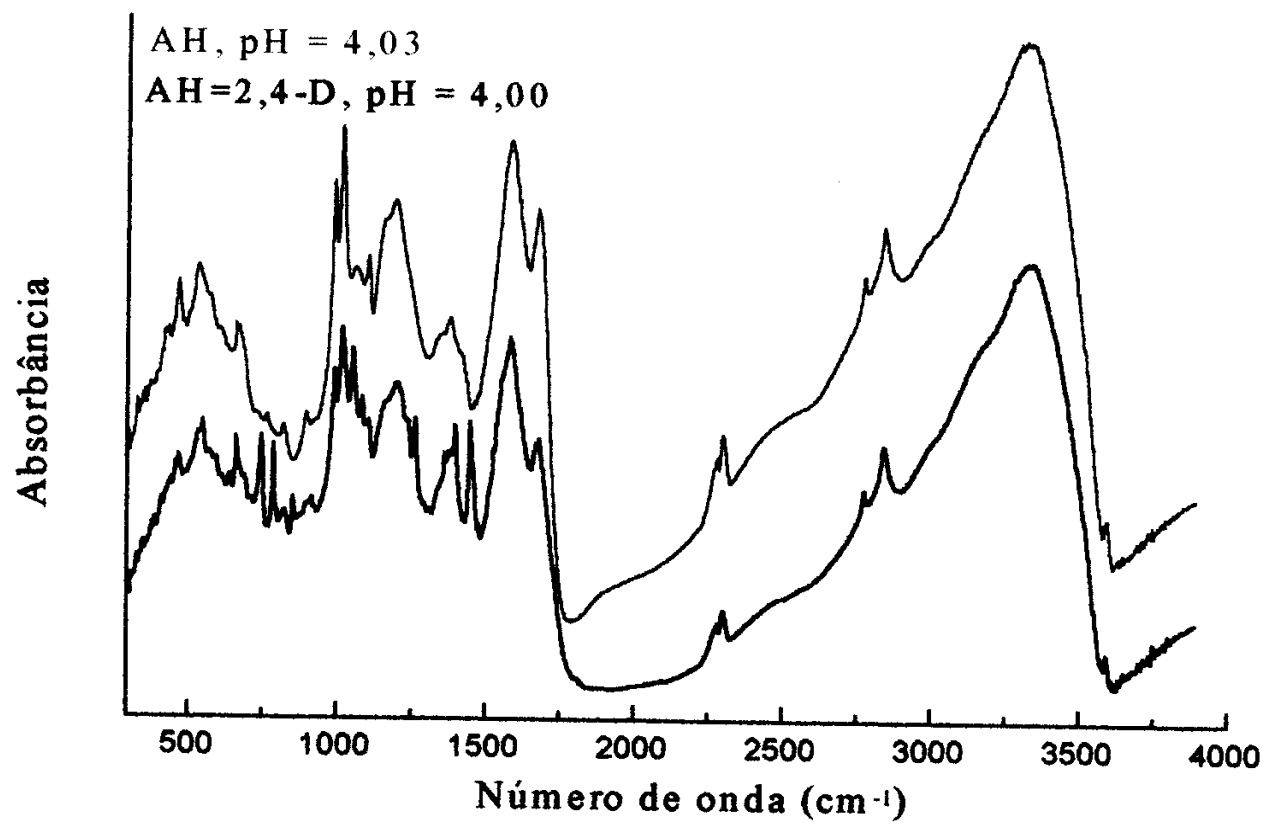

Fig. 5.10.b 


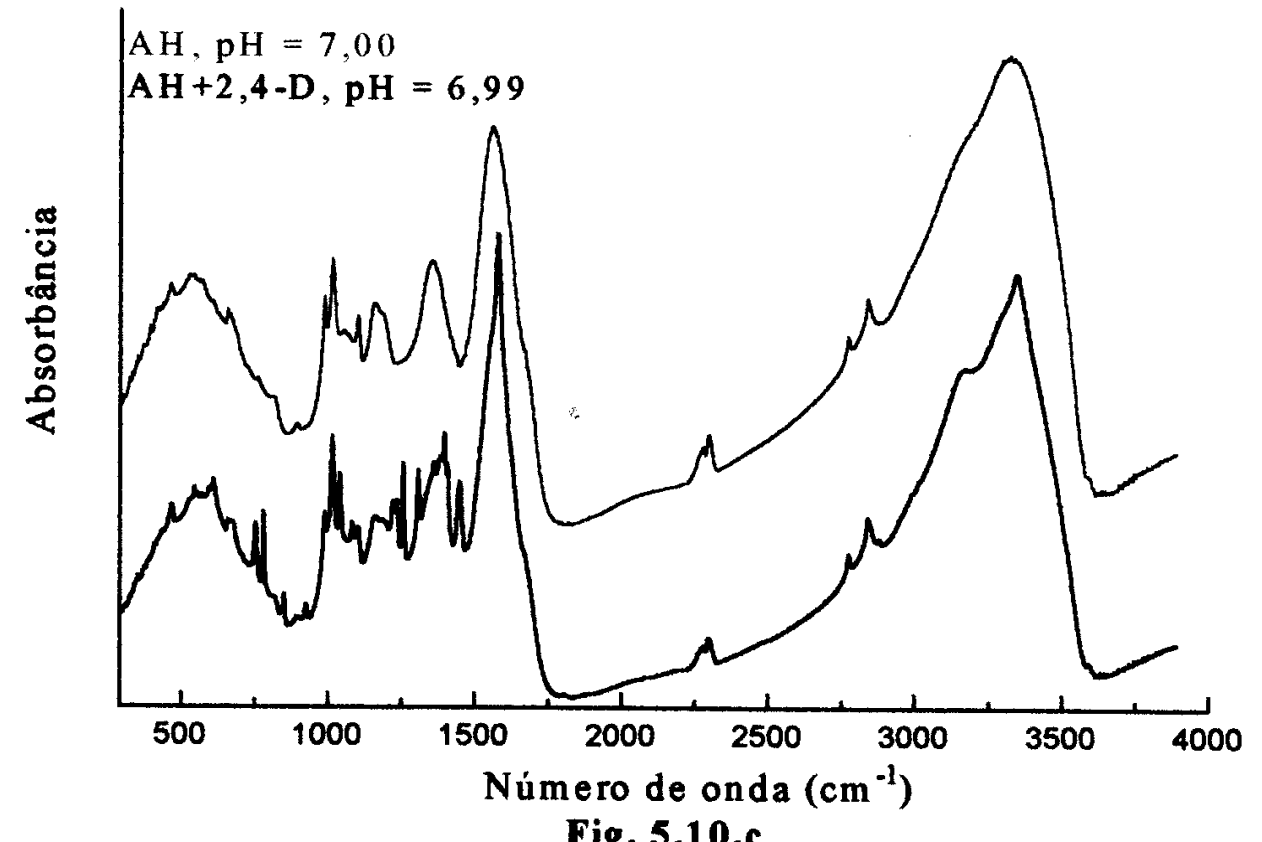

Fig. 5.10.c

Figura 5.10: Espectros de FTIR de amostras liofilizadas contendo ácido húmico da turfeira, (a) $\mathrm{AH}$ pH $=2,02$ e AH+2,4-D pH=2,04, (b) $\mathrm{AH} \mathrm{pH}=4,00$ e AH+2,4-D $\mathrm{pH}=4,00$, e (c) $\mathrm{AH} \mathrm{pH}=7,00$ e $\mathrm{AH}+2,4-\mathrm{D} \mathrm{pH}=6,99$

Os espectros de FTIR dos precipitados das amostras AH e AH+2,4-D também foram obtidos, das amostras contendo ácido húmico da turfeira, e podem ser observados na figura 5.11 . 


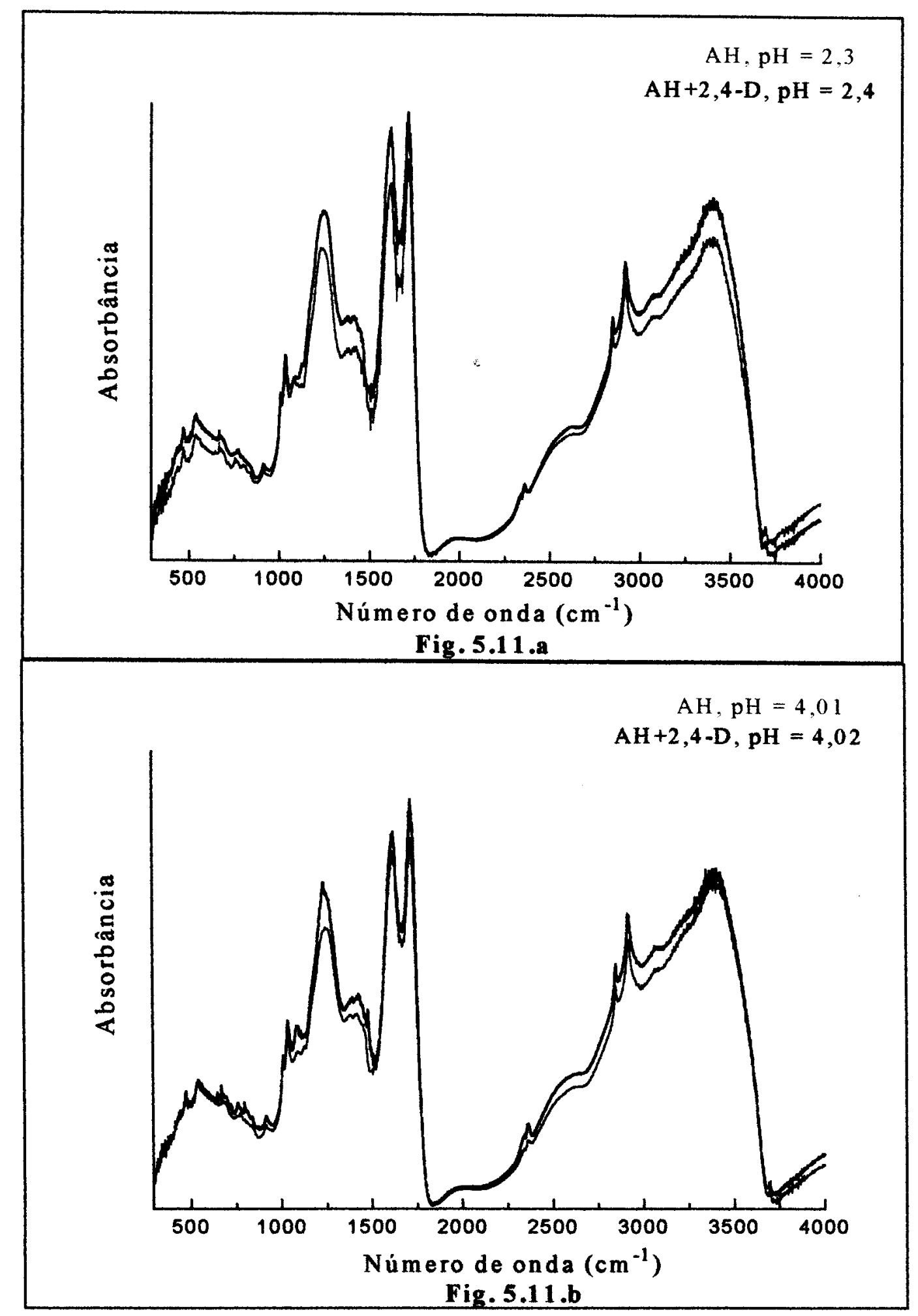




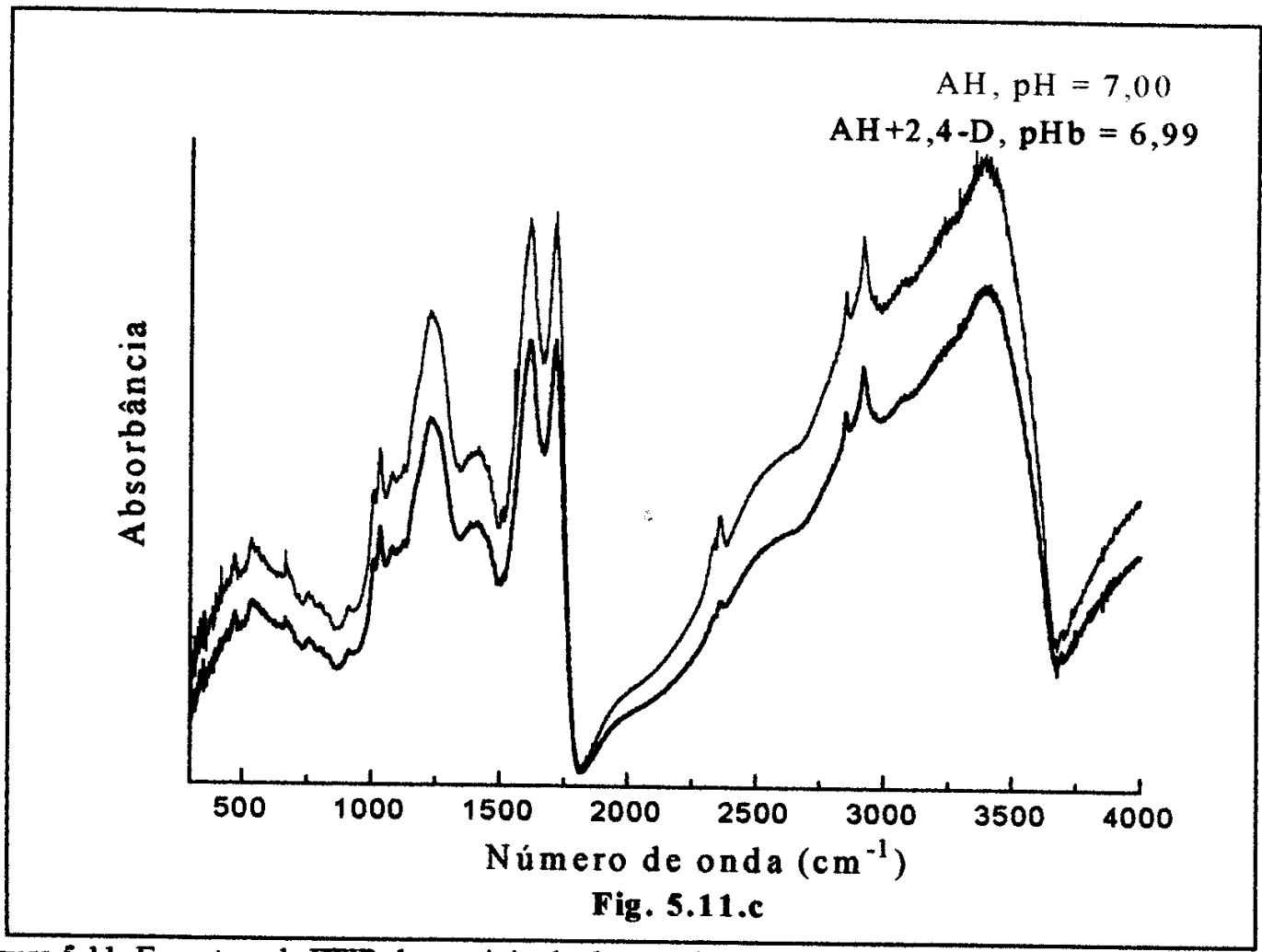

Figura 5.11: Espectros de FTIR do precipitado das seguintes amostras liofilizadas contendo ácido húmico da turfeira, (a) $\mathrm{AH} \mathrm{pH}=2,03 \mathrm{e} \mathrm{AH}+2,4-\mathrm{D} \mathrm{pH}=2,04$, (b) $\mathrm{AH} \mathrm{pH}=4,01 \mathrm{e}$ $\mathrm{AH}+2,4-\mathrm{D} \mathrm{pH}=4,02$, e (c) $\mathrm{AH}$ pH $=6,97$ e $\mathrm{AH}+2,4-\mathrm{D} \mathrm{pH}=7,01$

\subsubsection{Discussð̃es}

$\Rightarrow$ Espectros de Absorção Eletrônica:

Acompanhando as absorbâncias do herbicida 2,4-D $\left(\mathrm{A}_{228}\right)$, a $228 \mathrm{~nm}$, nas tabelas 5.1 e 5.2, com ácidos húmicos dos solos podzólico vermelho-amarelo e da turfeira, para o dia 0 e 0 dia 4, pode-se observar que não ocorreram mudanças significativas da banda de absorção eletrônica. As taxas de crescimento ou decréscimo calculadas para os três valores de $\mathrm{pH}$, após os 4 dias de reação da solução $\mathrm{AH}+2,4-\mathrm{D}$, da banda são praticamente da ordem do erro da medida (os valores médios do erro das medidas são: $5 \%$ para o solo podzólico vermelho-amarelo e $3 \%$ para a turfeira). Portanto não foi observada a degradação ou evidenciado reações que alterassem a intensidade e forma da banda de absorção do herbicida devido a presença de ácido húmico, isso para ambos os solos utilizados neste projeto e para valores diferentes de $\mathrm{pH}$. 
Ao se coletar e obter espectros eletrônicos dos sobrenadantes das amostras $A H+2,4-D$, com ácido húmico da turfeira, a proposta é de se quantificar a massa (e concentração) de 2,4-D sorvida pelo ácido húmico, conforme exposta na tabela 5.4. A maior sorção ocorreu em $\mathrm{pH}=2,04,19 \%$ do total inicial de moléculas de 2,4-D $\left(1,2 \times 10^{19}\right)$ foram sorvidas, ou seja, $2,33 \times 10^{18}$ moléculas de 2,4-D ficaram retidas no ácido húmico devido a algum processo de sorção (adsorção, absorção e/ou partição), nos valores de $\mathrm{pH} \mathrm{4,02} \mathrm{e} \mathrm{7,01,} \mathrm{as} \mathrm{sorções} \mathrm{foram} \mathrm{praticamente} \mathrm{idênticas,}$ $13 \%$ e $14 \%$ em relação as iniciais, respectivamente.

O estudo da quantificação da sorção para melhor ser analisado, deve levar em conta a massa de ácido húmico "disponível" ao herbicida. Por exemplo, Martin-Neto (1994), reporta que a capacidade máxima de adsorção do ácido húmico pela atrazina é igual a $\mathrm{r}_{\mathrm{AT}}=(0,23 \mu \mathrm{mol}$ de atrazina $) /(\mathrm{mg}$ de ácido húmico $)$. No presente trabalho, em $\mathrm{pH}=2,04$, foi observado que a mesma razão para o herbicida 2,4-D é $\mathrm{r}_{2,4-\mathrm{D}}=(12,1 \mu \mathrm{mol}$ de 2,4-D)/(mg de ácido húmico), e nos valores de $\mathrm{pH} 4,02$ e 7,01, têm-se $\mathrm{r}_{2,4-\mathrm{D}}=8,1 \mu \mathrm{mol} /(\mathrm{mg}$ de ácido húmico $)$ e $\mathrm{r}_{2,4-\mathrm{D}}=8,4 \mu \mathrm{mol} /(\mathrm{mg}$ de ácido húmico), respectivamente. Todas as razões observados para o 2,4-D nos diferentes valores de $\mathrm{pH}$ são bem maiores que os apresentados para a atrazina.

\section{$\Rightarrow$ Espectros de EPR:}

Senesi (1988) coloca que amostras de diferentes origens de ácido húmico, mostram reatividades diferentes com herbicida clorofenóxi, a qual decresce de acordo com a origem do ácido húmico: sintéticos $>$ turfa $>$ solos $>$ carvão vegetal. Esse resultado foi interpretado considerando-se as características dos ácidos húmicos, tais como grupos funcionais, análise elementar e número de semiquinona. Neste trabalho, os dois ácido húmicos escolhidos possuem diferenças nas características acima citadas, conforme mostradas na tabela 4.1 e nas tabelas 5.5 e 5.6. Nestas últimas pode-se salientar o fato de que o ácido húmico da turfeira tem uma ordem de grandeza a mais de radicais livres semiquinona em relação ao outro utilizado, o que facilitaria possíveis reações envolvendo o radical livre deste ácido húmico.

Os espectros obtidos das amostras $\mathrm{AH}$ e $\mathrm{AH}+2,4-\mathrm{D}$ próximo a temperaturado nitrogênio líquido $\left(-160^{\circ} \mathrm{C}\right)$, com sinais dos íons ferro(III), cobre(II), remanescentes da purificação de ambos os ácidos húmicos utilizados, nos diferentes 
valores de $\mathrm{pH}$ (figura 5.7), mostraram-se bastante semelhantes: o valor de $\mathrm{g}=4,27$ é devido ao espectro rômbico do íon metálico $\mathrm{Fe}(\mathrm{III})$ na configuração "spin alto" ( $\mathrm{S}$ = $5 / 2$ ), o sinal $\mathrm{g}=2,05$ é do complexo de $\mathrm{Cu}(\mathrm{II})$. Em alguns valores de $\mathrm{pH}$ as linhas super-hiperfinas são bem pronunciadas, devido a $\mathrm{n}$ átomos de nitrogênio (MartinNeto et al, 1991). Os sinais de EPR dos íons metálicos remanescentes da purificação não tiveram alterações de suas intensidades e nem dos seus valores g-, mostrando que não interagem na presença do $2,4-\mathrm{D}$, e portanto nas medidas em geral.

A quantificação dos radicais livres semiquinona do ácido húmico de ambos os solos das amostras sólidas $\mathrm{AH}+2,4-\mathrm{D}$, tabelas 5.5 e 5.6, indicam um decréscimo no número dos radicais ao serem comparados com as amostras sólidas $\mathrm{AH}$, sendo mais acentuado no $\mathrm{pH}=7,24 \%$ para o solos podzólico vermelho-amarelo e $29 \%$ para a turfeira. A menor diferença foi para $\mathrm{pH}=4$, que tiveram $9 \%$ e $20 \%$ para os ácidos húmicos anteriormente citados. $\mathrm{O}$ valor médio do erro das medidas da concentração de radicais, de ambos os solos, foi $11 \%$. Para todos os valores de $\mathrm{pH}$, a turfeira mostrou sempre uma maior diferença.

De acordo com Senesi (1988 e 1992), os espectros de amostras de ácidos clorofenoxialcanóicos (da família do 2,4-D) que interagem com ácido húmico, mostram um considerável decréscimo do sinal de radicais livres e alargamento do sinal de EPR, com respeito as amostras AH não reagidas. O mesmo autor cita três outros trabalhos que não utilizaram espectroscopia de EPR, mas sugerem a incorporação de compostos clorofenóxi em ácido húmico através da formação de ligações covalentes (como já foi colocado no capítulo 3, ítem 2.2.3), mas por meio de um radical fenóxi produto de degradação, gerado biologicamente, quimicamente e/ou fotoquimicamente, do herbicida em água e sob o efeito da luz e do ar. Neste trabalho, optou-se em realizar os experimentos na ausência da luz solar uma vez que no solo a radiação solar atua somente na superficie.

Os resultados inicialmente obtidos neste trabalho aparentemente estavam em concordância com os acima citados em dois pontos: diminuição dos radicais livres em amostras $\mathrm{AH}+2,4-\mathrm{D}$ comparadas com as $\mathrm{AH}$, e a turfa apresenta maior diferença em relação ao solo podzólico vermelho-amarelo (uma vez que possui mais semiquinona). Mas os valores das larguras de linhas do sinal de EPR aqui 
obtidos não sofreram alterações significativas, as variações desses valores estão dentro do erro das medidas, como podem ser conferidas nas tabelas 5.5 e 5.6 .

Avaliando mais cuidadosamente os dados para os cálculos dos valores de $\mathrm{N}_{0}$ (spin/g) observou-se que não foi levado em conta o fato de que nas amostras $\mathrm{AH}+2,4-\mathrm{D}$ não existiam somente massa de ácido húmico mas também de herbicida, $\mathrm{e}$ que deveria ser subtraída da massa total para se obter o real valor de $\mathrm{N}_{0}(\mathrm{spin} / \mathrm{g}$ ), onde "g" é gramas de ácido húmico. Caso o valor de correção fosse relevante, excluir a possível quantidade de 2,4-D que não estava ligada ao ácido húmico através da precipitação do ácido húmico com o 2,4-D ligado. Em seguida o 2,4-D presente no sobrenadante foi quantificado por Uv-visível e também calculada a massa de herbicida ligado (tabela 5.4) que foi excluída no cálculo da concentração de spin do ácido húmico que reagiu com o 2,4-D.

Com a "correção" do número de radicais livres húmicos feita (somente para a turfeira uma vez que apresenta maiores diferenças nas intensidades dos espectros), a tabela 5.7 foi preenchida, e como resultado pode-se observar que a variação no número de radicais entre as amostras $\mathrm{AH}$ e $\mathrm{AH}+2,4-\mathrm{D}$ é praticamente inexistente para todos os valores de $\mathrm{pH}$. Logo, o mecanismo de ligação covalente proposto entre o 2,4-D e as substâncias húmicas não se aplica aos ácidos húmicos utilizados neste trabalho. Portanto somente mecanismos de fraca sorção podem estar envolvidos na interação do ácido húmico com o 2,4-D. Esse resultado está coerente com as observações de Khan (1973), e sugere possível reversibilidade da ligação.

\section{Espectros de FTIR:}

Acompanhando os espectros do 2,4-D puro em função dos valores de $\mathrm{pH}$ na figura 5.8, pode-se observar a evolução das bandas referentes ao grupo carboxílico e ao carboxilato, próximas a $1710 \mathrm{~cm}^{-1}$ e $1625 \mathrm{~cm}^{-1}$,respectivamente. Em $\mathrm{pH}=2,02$ somente a banda em $1710 \mathrm{~cm}^{-1}$ foi observada, neste valor de $\mathrm{pH}$ todas as moléculas de 2,4-D tiveram seus grupos protonados, portanto a banda de carboxilato não apareceu. Com o aumento do $\mathrm{pH}$ para 4,04 , a banda de maior intensidade (relativa) foi a de $1625 \mathrm{~cm}^{-1}$, somente $2 \%$ dos grupos carboxílicos do 2,4-D estavam protonados neste $\mathrm{pH}$, por esse motivo a intensidade da banda em $1710 \mathrm{~cm}^{-1}$ praticamente não aparece, e desapareceu em $\mathrm{pH}=7,06$, no qual todas as moléculas 
de 2,4-D estavam na forma de sal, e a banda em $1625 \mathrm{~cm}^{-1}$ tem seu valor máximo. Essas medidas foram muito importante para a adequada interpretação dos espectros do produto de interação ácido húmico e 2,4-D.

Os espectros apresentados nas figuras 5.9 e 5.10 mostram claramente a sobreposição das bandas de absorção do 2,4-D no infravermelho (figuras 5.8), provavelmente devido a deposição do herbicida sobre o ácido húmico, uma vez que a massa de 2,4-D que não foi adsorvida pelo material húmico (da turfa) é grande se comparada com a que foi sorvida (tabelas 5.3 e 5.4). Subtrações de espectro foram realizadas, do tipo: espectro(AH+2,4-D) - k.espectro(2,4-D), para cada valor de $\mathrm{pH}$, mas o valor de $\mathrm{k}$ era de dificil ajuste uma vez que tanto o material húmico quanto $\mathrm{o}$ herbicida praticamente absorve em toda a região do espectro observado.

De acordo com Khan (1973a), a adsorção de pesticidas ácidos e aniônicos, tais como ácidos clorofenoxialcanóicos, esters, asulam e dicamba pode ocorrer através de pontes de hidrogênio por meio de seus grupos carboxilicos, abaixo de seus valores de $\mathrm{pKa}$, como exemplificado na figura 5.12, o que ocasionaria sensiveis mudanças nas bandas referêntes aos grupo carboxílico e carboxilatos do ácido húmico (bandas em $1210 \mathrm{~cm}^{-1}, 1625 \mathrm{~cm}^{-1} \mathrm{e} 1710 \mathrm{~cm}^{-1}$, atribuídas a estiramento $-\mathrm{C}-\mathrm{O}$, estiramento $-\mathrm{COO}^{-}$assimétrico e estiramento $-\mathrm{C}=\mathrm{O}$ de $-\mathrm{COOH}$, respectivamente). Nos espectros de FTIR das amostras em que optou-se pela precipitação (figura 5.10), as bandas do ácido húmico citadas acima são distinguiveis, mas não mostraram evidências de uma mudança efetiva das bandas dos precipitados $\mathrm{AH}+2,4-\mathrm{D}$. Logo, pontes de hidrogênio provavelmente não é o mecanismo de ligação entre o 2,4-D e o ácido húmico da turfeira utilizado neste trabalho.

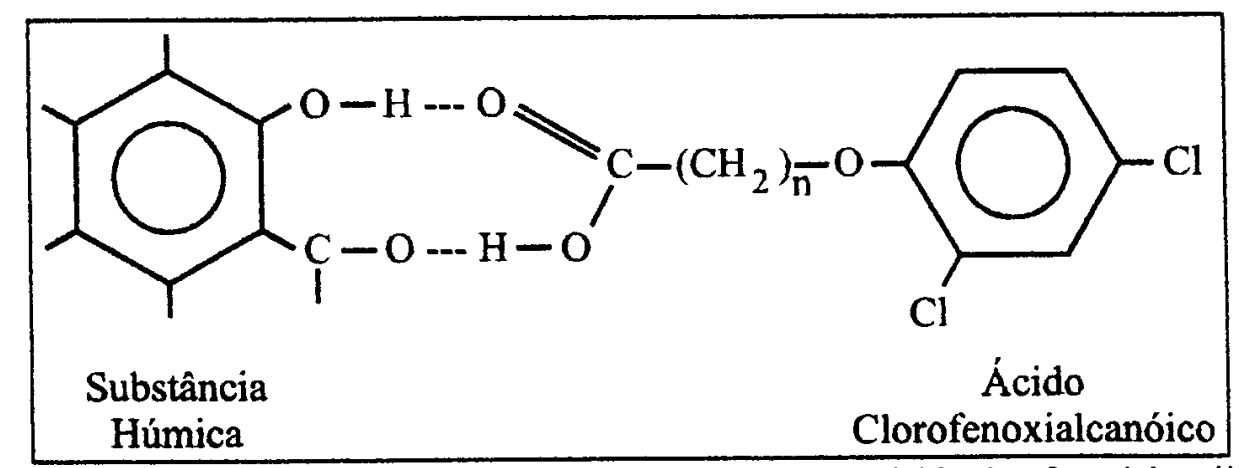

Figura 5.12: Ligação de hidrogênio entre substância húmica e ácido clorofenoxialcanóico 


\subsection{Complexação 2,4-D com Cu(II)}

\subsubsection{Resultados}

A retenção de herbicidas no solo por ions metálicos pode constituir um mecanismo de adsorção no solo e eventualmente um risco de contaminação, uma vez que a complexação assumida pode se tratar de um produto instável e que a qualquer momento o herbicida pode estar novamente disponível ao meio, isto é, o herbicida em questão pode se tratar de um ligante reversivel. Assim utilizou-se ion de cobre (II), que é um micronutriente das plantas e está presente no solo para avaliar a possível complexação com o 2,4-D, a técnica escolhida para o estudo foi a de EPR.

As soluções de metal foram obtidas a partir dos sais $\mathrm{CuSO}_{4} .5 \mathrm{H}_{2} \mathrm{O}$, e adicionadas as soluções de 2,4-D(1mM), na proporção ligante/metal de 1:1. Foram adquiridos espectros tanto das soluç̋̃es com herbicidas quanto de soluções aquosas dos sais (amostras chamadas de $\mathrm{CuSO}_{4}+2,4-\mathrm{D}$ e $\mathrm{CuSO}_{4}$, respectivamente), para comparação, em função dos valores de $\mathrm{pH}$, e a temperatura de nitrogênio líquido. $\mathrm{Os}$ parâmetros espectroscópicos foram citados no capitulo 4 , ítem 4.3.2.

Os espectros relativos a complexação com $\mathrm{Cu}(\mathrm{II})$ estão apresentados na figura 5.13 .

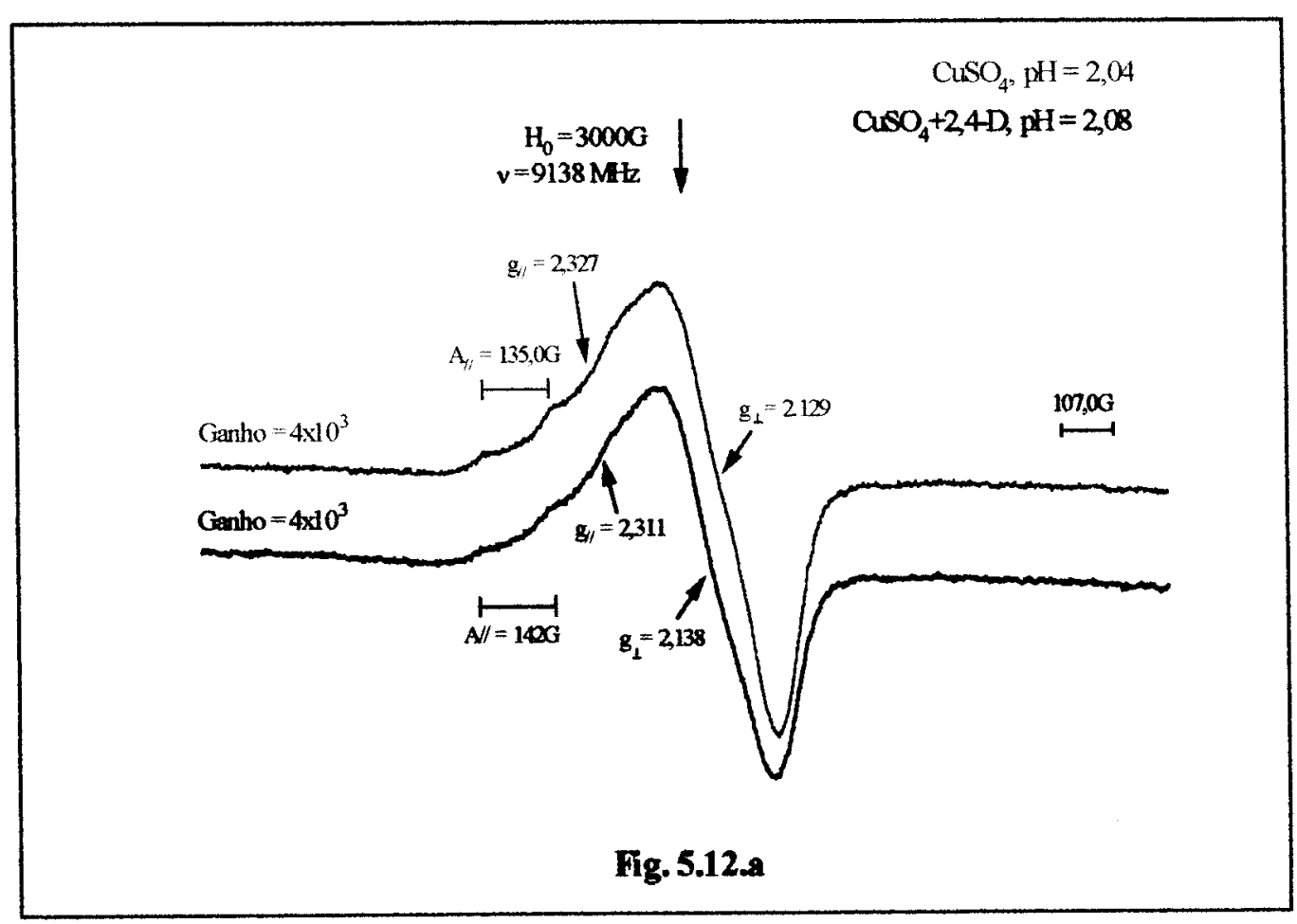




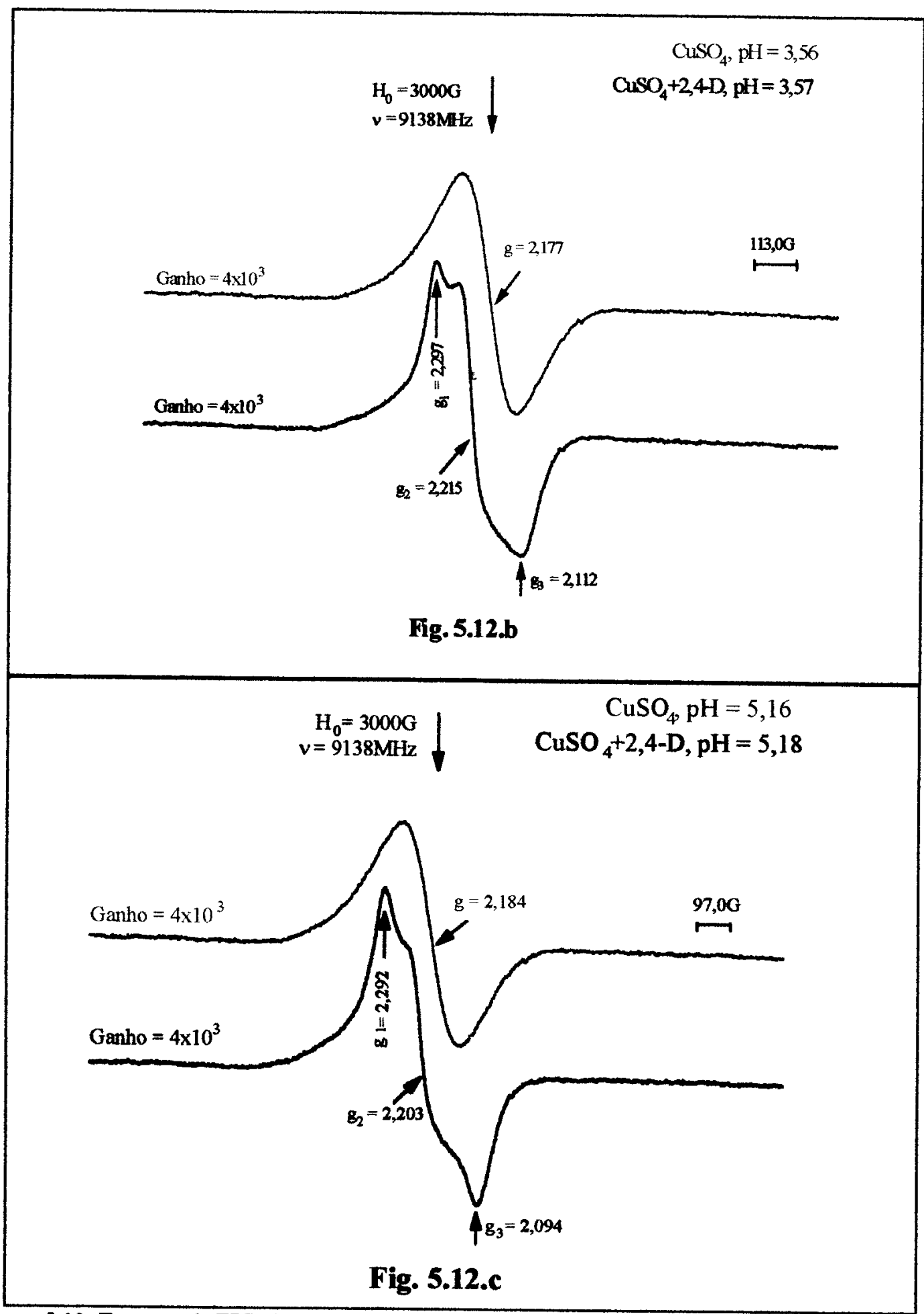

Figura 5.13: Espectro de EPR das soluçes aquosas: (a) $\mathrm{CuSO}_{4} \mathrm{pH}=2,04$ e $\mathrm{CuSO}_{4}+2,4-\mathrm{D} \mathrm{pH}=2,08$, (b) $\mathrm{CuSO}_{4} \mathrm{pH}=3,56$ e $\mathrm{CuSO}_{4}+2,4-\mathrm{D} \mathrm{pH}=3,57, \mathrm{e}$

(c) $\mathrm{CuSO}_{4} \mathrm{pH}=5,16$ e $\mathrm{CuSO}_{4}+2,4-\mathrm{D} \mathrm{pH}=5,18$ 


\subsubsection{Discussã̃o}

Nos espectros de EPR do $\mathrm{Cu}(\mathrm{II})$ (figura 5.13) tanto em solução aquosa quanto em solução contendo herbicida, para diferentes valores de $\mathrm{pH}$, é possível investigar as coordenações do $\mathrm{Cu}(\mathrm{II})$ na presença do herbicida 2,4-D

A solução aquosa de $\mathrm{Cu}$ (II) era preparada primeiramente, e depois a solução contendo herbicida era adicionada. Assim inicialmente o que ocorreu foi uma hidratação do $\mathrm{Cu}(\mathrm{II})$.

A figura 5.13.a mostra os espectro do $\mathrm{Cu}(\mathrm{II})$ em solução aquosa e em solução aquosa contendo herbicida $(\mathrm{pH}=2)$, e em ambos os espectros foi possível identificar a simetria axial, assim como valores de $\mathrm{g}_{/ /}$e $\mathrm{g}_{\perp}$, os quais são bem próximos provavelmente porque correspondem a complexos de $\mathrm{Cu}(\mathrm{II})$ coordenados com seis moléculas de água, uma vez que nesse valor de $\mathrm{pH}$ as moléculas do 2,4-D estavam todas protonadas $(\mathrm{pKa}=2,6)$. Mas as separações hiperfinas $\left(\mathrm{A}_{/ /}\right)$não são bem definidas, possivelmente devido a interação de troca experimentada pelo $\mathrm{Cu}(\mathrm{II})$. $\mathrm{Na}$ figura 5.14 apresenta-se a subtração entre os espectros das amostras $\mathrm{CuSO}_{4}+2,4-\mathrm{D}$ e $\mathrm{CuSO}_{4}$ (isto é, $\left(\mathrm{CuSO}_{4}+2,4-\mathrm{D}\right)-\left(\mathrm{CuSO}_{4}\right)$ ), onde pode ser observada uma melhor resolução das linhas hiperfinas do $\mathrm{Cu}(\mathrm{II})$ hidratado da amostra contendo 2,4-D, muito provavelmente porque a interação de troca é menos intensa devido a presença de mais moléculas (no caso do herbicida), afastando as de $\mathrm{Cu}(\mathrm{II})$.

A coordenação mais estável para o $\mathrm{Cu}(\mathrm{II})$ hidratado é a octaédrica distorcida. A configuração eletrônica $\left(\mathrm{t}_{2 \mathrm{~g}}\right)^{6}\left(\mathrm{e}_{\mathrm{g}}\right)^{3}$ correspondente dá origem a um estado fundamental duplamente degenerado, existem duas possibilidades para a configuração eletrônica: $\left(d_{z^{2}}\right)^{2}\left(d_{x^{2}-y^{2}}\right)^{1}$ e $\left(d_{z^{2}}\right)^{1}\left(d_{x^{2}-y^{2}}\right)^{2}$ (Orgel, 1960). No caso da primeira ocorrer, as quatro ligações no plano xy são mais curtas do que as duas no eixo $z$. No outro caso, se o elétron desemparelhado está no orbital $\mathrm{d}_{z^{2}}$, ocorrem duas ligações curtas no eixo $\mathrm{z}$ e quatro ligações mais extensas no plano perpendicular. Experimentalmente a configuração $\left(d_{z^{2}}\right)^{2}\left(d_{x^{2}-y^{2}}\right)^{1}$ é a encontrada, mas a teoria molecular orbital não distingue a distorção mais estável. 
Os espectros das amostras $\mathrm{CuSO}_{4}+2,4-\mathrm{D}$ e $\mathrm{CuSO}_{4}$ no valor de $\mathrm{pH} 7$ não mostram absorção de microonda, devido a provável precipitação do cobre como hidróxido de cobre (Traghetta, 1992).

\subsection{Fotodegradação do 2,4-D}

\subsubsection{Resultados}

O herbicida 2,4-D possui bandas de absorção eletrônica somente em comprimentos de onda abaixo de $300 \mathrm{~nm}$, sendo assim a decomposição por meio da luz solar torna o processo de remediação do herbicida algo demorado ou improvável de ocorrer, uma vez que a camada de ozônio bloqueia as radiações solares abaixo de $290 \mathrm{~nm}$ (veja capítulo 2, ítem 2.1.2). Portanto fotodecomposição como meio de descontaminação pelo 2,4-D somente deverá ser efetiva em soluções aquosas através de irradiação com luz ultravioleta. Assim utilizou-se uma lâmpada de xenônio, que emite no ultravioleta para irradiar soluções aquosas de 2,4-D com potência de $150 \mathrm{~W}$ (veja método no capítulo4, ítem 4.3.2)

Foram feitas cinéticas da decomposição do 2,4-D em solução aquosa e em solução contendo ácido húmico da turfeira, para os valores de $\mathrm{pH} 6,95$ e 7,00, respectivamente. A figura 5.15 apresenta os espectros eletrônicos do 2,4-D em solução aquosa em função do tempo de irradiação. Já na figura 5.16 os espectros eletrônicos são da solução com ácido húmico em função do tempo de irradiação. 


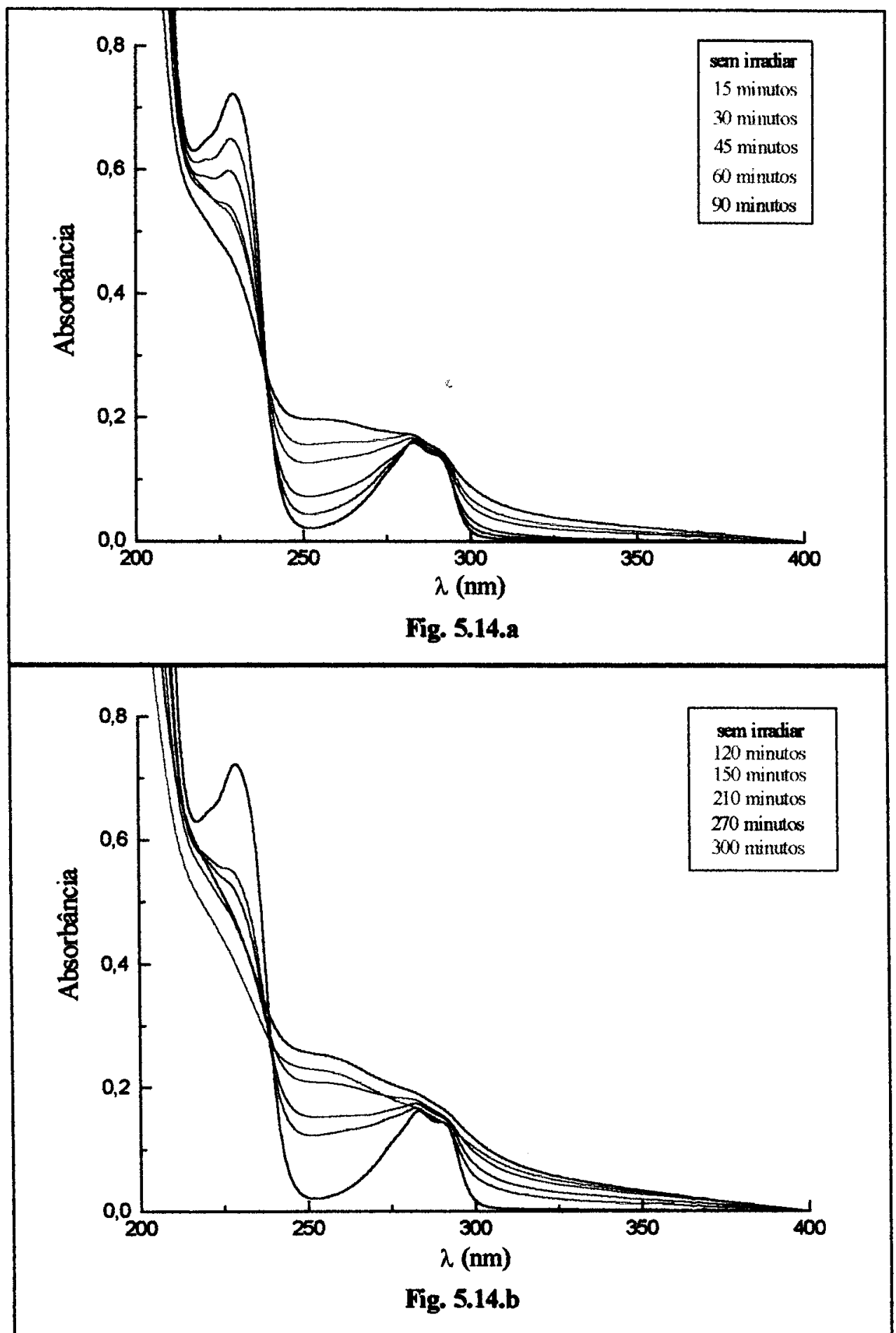

Figura 5.15: Espectro de absorção eletrônico do 2,4-D em solução aquosa para diferentes tempos de exposição a irradiação, (a) de 0, 15, 30, 45, 60 e 90 minutos, (b) 0, 120, 150, 210, 270 e 300 minutos, $300 \mu \mathrm{l}$ de solução AH+2,4-D diluídos em $3,5 \mathrm{ml}$ de água destilada 


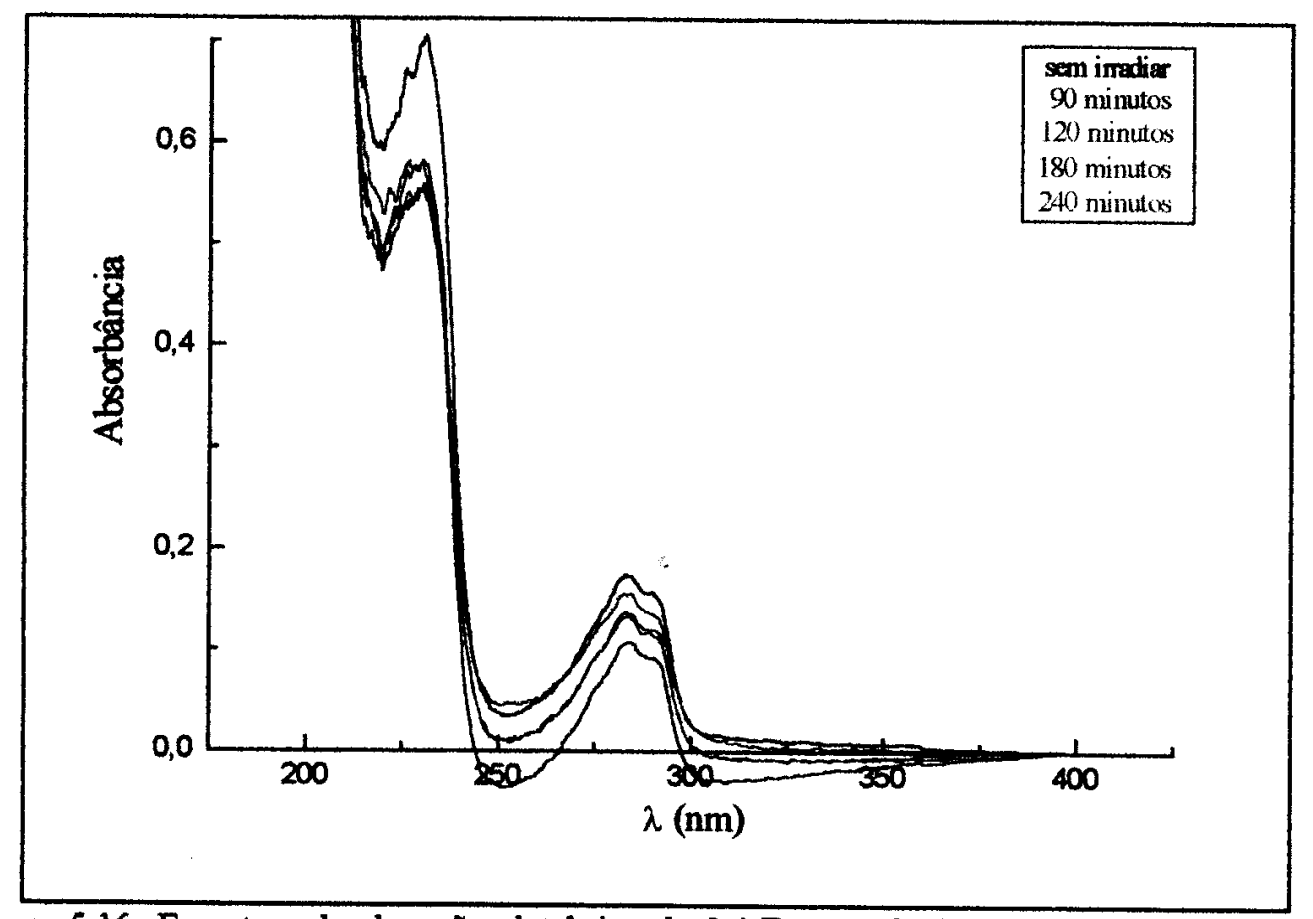

Figura 5.16: Espectros de absorção eletrônica do 2,4-D em solução contendo ácido húmico da turfeira para diferentes tempos de exposiçăo a irradiação de $0,90,120,180,150,240$ minutos, (300 $\mu \mathrm{l}$ de solução $\mathrm{AH}+2,4-\mathrm{D}$ dissolvidos em 3,5ml de água destilada)

\subsubsection{Discussão}

$\Rightarrow$ Amostra aquosa de 2,4-D(1mM):

A figura 5.16 mostra espectros da solução de 2,4-D, na qual a irradiação de luz causou a fotólise direta do herbicida, resultando em uma transformação química cujo mecanismo simplificado pode ser esquematizado através de três passos:

$$
\begin{gathered}
2,4-D \stackrel{\mathrm{bv}}{\longrightarrow} 2,4-\mathrm{D}^{*}, \mathrm{r}_{0}=\mu \mathrm{q} \\
2,4-\mathrm{D}^{*} \stackrel{\mathrm{K}_{1}}{\longrightarrow} 2,4-\mathrm{D}, \mathrm{r}_{1}=\mathrm{K}_{1} \mathrm{C}_{2,4-\mathrm{D}}^{*} \\
2,4-\mathrm{D}^{*} \stackrel{\mathrm{K}_{2}}{\longrightarrow} \text { sub - produtos, } \mathrm{r}_{2}=\mathrm{K}_{2} \mathrm{C}_{2,4-\mathrm{D}}^{*} .
\end{gathered}
$$

O primeiro passo corresponde a ativação do 2,4-D por absorção da irradiação. $O$ segundo é a desativação do pesticida ativado para o seu estado fundamental. $O$ terceiro é a real fotodecomposição do 2,4-D, levando a formação de sub-produtos. 
A taxa de produção do $2,4-\mathrm{D}^{*}$ é:

$$
\mathrm{r}_{2,4-\mathrm{D}}=-\frac{\mathrm{K}_{2}}{\mathrm{~K}_{1}+\mathrm{K}_{2}} \mu \mathrm{q}=-\phi \mu \mathrm{q}
$$

onde $\phi$ é o rendimento quântico, o qual indica as moléculas decompostas do 2,4-D por absorção de um fóton, o produto $\mu \mathrm{q}$ é a taxa volumétrica local de energia de absorção.

Este resultado está de acordo com resultados obtidos por Chamarro \& Esplugas (1993), que não só observaram a fotólise direta do herbicida como também fizeram estudos da influência do $\mathrm{pH}$ da solução. E constataram a influência do $\mathrm{pH}$ somente para tempos maiores de irradiação (a partir de 40 minutos), devido possivelmente a formação de um produto com características similares as do ácido húmico em pH neutro e básico, o que significa que em pH ácido as moléculas de 2,4D têm menos "competição" ao serem irradiadas.

\footnotetext{
$\Rightarrow$ Amostras $\mathrm{AH}$ e $\mathrm{AH}+2,4-\mathrm{D}(1 \mathrm{mM})$ :

As substâncias húmicas são conhecidas por serem fotosintetizantes, isto é, elas podem participar da fotólise indireta de outras substâncias, tais como herbicidas, absorvendo a energia da irradiação que resultará na transformação do herbicida. Por outro lado, as substâncias húmicas podem retardar a fotólise de alguns herbicidas, agindo como um inibidor da fotodegradação do herbicida. Esta segunda alternativa é a que se encaixa em nossos resultados (mostrados na figura 5.18), após 240 minutos de irradiação da amostra, o pico em 228nm do 2,4-D permanece inalterado, o que não ocorre na solução aquosa de 2,4-D, na qual após 60 minutos de irradiação o pico em $228 \mathrm{~nm}$ decresce consideravelmente. As medidas deste trabalho foram feitas para uma proporção de concentração de herbicida em relação a massa de ácido húmico (20mg de ácido húmico dissolvidas/25ml de solução 2,4-D(1mM)) Como foi observado o 2,4-D é fotodegradável diretamente, e é inibido na presença de ácido húmico nessa concentração.
} 


\section{Capitula 6 - Conclusões}

\subsection{Aduto 2,4-D - Ácido Húmico}

Com a revisão de literatura, pode-se destacar duas tendências principais de mecanismos para explicar a sorção do herbicida 2,4-D pelo ácido húmico do solo, que são as ligações do tipo covalente, proposta por Senesi (1988) a partir de dados espectroscópicos, principalmente, que são ligações fortes provavelmente irreversíveis, e por outro lado Khan (1973 e 1973a), a partir de cálculos de energia e calor de ativação de dados obtidos por cromatografia gasosa, que propôs as forças de Van der Walls e ligação hidrofóbica, e pontes de hidrogênio como os responsáveis pela interação, estas são de carácter fraco.

Através da técnica de UV-visível foi observado que o 2,4-D na presença de ácidos húmicos, após quatro dias de reação, não se degrada, e a capacidade de sorção do 2,4-D por miligrama de ácido húmico da turfeira é maior que a calculada para o herbicida atrazina, o qual teve seus mecanismos de interação evidenciados pelas mesmas técnicas espectroscópicas utilizadas neste trabalho.

Com o recurso de acidificação e centrifugação (que é o método sugerido na literatura, e que já foi aqui mencionado) foi possível pela técnica de EPR constatar a não variação da concentração de radicais livres do ácido húmico da turfeira devido a reação com 2,4-D, resultado este que vai contra a proposta de ligação covalente. $O$ mesmo recurso citado acima também possibilitou a exclusão do provável 2,4-D excedente (que não sofreu sorção) nas amostras, e a obtenção dos espectros de FTIR, nos quais as bandas do ácido húmico da turfeira que estão relacionadas com pontes de hidrogênio (as bandas do grupo carboxílico) não se alteram na presença do $2,4-\mathrm{D}$.

A escolha de mais de uma técnica de espectroscopia, ou qualquer técnica que contribua para o objetivo de entender a sorção, faz-se necessário no sentido de uma ser complementar da outra e/ou no sentido de que o que uma não detecta é possível que a outra o faça. Assim neste trabalho foram empregadas três técnicas espectroscópicas: UV-Visível, FTIR e EPR, a primeira indicou que a sorção 
ocorre, e através das duas últimas verificou-se que mecanismos de interação entre o ácido húmico e o 2,4-D propostos pela literatura internacional, que são ligação covalente e pontes de hidrogênio, não se aplicam aos ácidos húmicos de solos brasileiros utilizados neste trabalho. Muito provavelmente devido a somente mecanismos de fraca sorção, tais como ligação hidrofóbica e forças de van der Walls, estarem envolvidos na interação desses ácidos húmicos e 2,4-D, conforme dados de Khan (1973).

O fato dos ácidos húmicos possuírem regiões hidrofóbicas, isto é, regiões formadas por grupos moleculares apolares, tais como cadeias alifáticas ou porções lipídicas, que tendem a reter herbicidas apolares que interagem fracamente com a água, talvéz explique a maior sorção do $2,4-\mathrm{D}$ em $\mathrm{pH}=2,00$, no qual suas moléculas estão na forma molecular.

A sorção, como já foi mencionado, é um termo que engloba três processos adsorção, absorção e difusão interna do herbicida no ácido húmico, esta última é outra possibilidade de ocorrer, e estudos feitos por Khan (1973), já citado neste trabalho, informam que a adsorção do 2,4-D ocorre nos primeiros minutos de contato com a superficie do ácido húmico, e a fase mais demorada possivelmente ocorra por difusão interna pelo poros do ácido húmico.

As conclusões obtidas para o ácido húmico da turfeira podem ser extendidas ao ácido húmico do solo podzólico vermelho-amarelo ao serem feitas as seguintes observações a seu respeito: não degradou o herbicida após quatro dias de reação, as larguras de linha dos espectros de EPR dos seus radicais livres não se alteraram com o acréscimo do herbicida, seus espectros de FTIR também apresentam a sobreposição das bandas do 2,4-D, o que mostra também o provável excesso de 2,4-D, cuja massa mais a sorvida ao serem subtraidas dos espectros de EPR das amostras $\mathrm{AH}+2,4-\mathrm{D}$, tornariam as intensidades do sinal próximas as das amostras $\mathrm{AH}$.

Portanto nos solos podzólicos vermelho-amarelo e de turfeira que contém ácidos húmicos com características semelhantes aos que foram utilizados neste trabalho, o 2,4-D pode constiuir um potencial de risco de contaminação, uma vez que a ligação hidrofóbica e principalmente as forças de Van der Walls são um tipo de interação temporária com o herbicida, qualquer mudança do ambiente em que se encontram pode levar a reversibilidade. Além do caráter de toxidade encerrada pelo 
herbicida excedente no ambiente, outro fato a se levar em conta no caso da reversibilidade, é a rotatividade de culturas, muitas vezes a cultura posteriormente plantada não utiliza o mesmo herbicida para afetar as suas pragas dominantes pois pode ser fitotóxica para esta nova cultura, e no entanto o 2,4-D está lá operante.

\subsection{Complexação 2,4-D com Íons Metálicos Cu(II)}

Ficou constatado que em $\mathrm{pH}=2,0$ a hidratação é o complexo mais estável do $\mathrm{Cu}(\mathrm{II})$, não havendo complexação com o herbicida muito provavelmente devido aos grupos carboxílicos do 2,4-D estarem protonados $(\mathrm{pKa}=2,6)$.

$\mathrm{Na}$ faixa de $\mathrm{pH} 3,5$ - 5,0, o $\mathrm{Cu}(\mathrm{II})$ forma um complexo com o 2,4-D com simetria rômbica, para maiores especificações, tais como o número de moléculas de herbicida que compõe a coordenação e o tipo de coordenação, é necessário que a interação de troca observada, nesta proporção de 1 ligante: 1 metal, seja eliminada, o que deve ocorrer para concentrações maiores de ligantes em relação a do $\mathrm{Cu}(\mathrm{II})$.

\subsection{Fotodegradação do 2,4-D}

A fotólise direta do 2,4-D em solução aquosa utilizando fonte artificial de luz foi observada e pode vir a constituir um método de remediação de ambientes aquáticos contaminados por esse herbicida. Mas antes de ser um meio efetivo de descontaminação, é necessário saber se o sub-produto do 2,4-D obtido é menos tóxico que o original, somente a completa mineralização é certa ser atóxica.

A maioria dos herbicidas precisam de moléculas fotosintetizantes tais como substâncias húmicas e argilas minerais, mas segundo resultados deste trabalho, este não é o caso do 2,4-D para as substâncias húmicas, ou mais especificamente para o ácido húmico de turfeira na concentração de $600 \mathrm{mg} / \mathrm{l}$, que atua no herbicida como um inibidor de sua fotodegradação. 


\subsection{Sugestões de Trabalhos Futuros}

- Aplicar procedimento de acidificação a pH $=2$ e centrifugação do ácido húmico do solo podzólico vermelho-amarelo para quantificação da sorção do herbicida através da técnica de UV-visível, posterior quantificação dos semiquinonas por EPR e obtenção de espectros de FTIR.

- Nos experimentos de complexação $\mathrm{Cu}(\mathrm{II})$-herbicida, aumentar o número de ligantes em relação ao de metal, para eliminar a interação de troca do cobre e propor o tipo de coordenação assumida pelo complexo.

- Fazer a fotodegradação do 2,4-D em diferentes concentrações do ácido húmico. 


\section{Referências Bibliagráficas}

- "Atlas do Meio Ambiente do Brasil", EMBRAPA/Fundação Banco do Brasil, ed. Terra Viva, 1994.

- Audreux, F. G.; Cerri, C. C.; Eduardo, B. de P.; Choné, T., The Sci. of the Total Environ., 90, 249-265, 1990.

- Barriuso, E.; Feller, C.; Calvet, R.; Cerri, C., Geoderma, 53, 155-167, 1992.

- Bersohn, M.; Baird, J., "An Introduction to Electron Paramagnetic Resonance”, W. A. Benjamin, Inc., 1966.

- Calvo, R.; Passeggi, M. C. G.; Isaacson, R. A.; Okamura, M. Y.; Feher, G., J. Biophysical Society, 표, 149-165, 1990.

- Cantor, C. R.; Schimel, P. R., "Biophysical Chemistry Part II: Techniques for the Study of Biological Struture and Funtion", ed. W. H. Freeman and Company, 1980.

- Chamarro, E.; Esplugas, S., J. Chem. Tech. Biotechnol., 57, 273-279, 1993.

- Cheng, H. H., "Pesticides in the Soil Environment Processes: Impacts, and Modeling", SSSA Book Series:2, 1990.

- Cloutier, J.-N.; Leduy, A.; Ramalho, R. S., The Can. J. of Chem. Engineering, $\underline{63}$, 1985.

- Colthup, N. B.; Daly, L.H.; Wiberley, S. E., "Introduction to Infrared and Raman Spectroscopy", New York, Academic Press, 1964. 
- Cordeiro, J. M. M., “Contribuição ao estudo do comportamento macromolecular de ácido húmico em solução aquosa e da influência da idade do material em suas propriedades", dissertação, IQSC, USP, 1987.

- Donnelly, P. K.; Entry, J. A.; Crawford, D. L., Applied and Environ. Microbiology, $\underline{59}(8), 1993$.

- Futino, A. M.; Silveira, J. M. J. F., “A indústria de defensivos agrícolas no Brasil”, Agricultura em São Paulo", $\underline{38}, 1-43$, tomo especial.

- Griffiths, P. R.; Haseth, J. A., "Fourier Transform Infrared Spectrometry", New York, John Willey, 1986.

- Grover, R.; Smith, A. E., Can. J. Soil Sci., 54(2), 179-86, 1974.

- Harris, D, C.; Bertolucci, M.D., "Symetry and Spectroscopy: an Introduction to Vibracional and Electronic Spectroscopy", New York, Dover, 1978.

- Hathaway, B. J.; Billing, D. E., Coordin. Chem. Rev., 5, 143-207, 1970.

- Heeling, C. S., Soil Sci. Soc. Amer. Proc., Ann Arbor, 포, 732-737, 1971.

- Hermosin, H. C.; Cornejo, J., J. Environ. Qual., 22 , 325-331, 1993.

- Ingram, D. J. E., "Biological and Biochemical Applications of Electron Spin Resonance", Adam Hilger ltd, 1969.

- Khan, S. V., Can. J. Soil Sci., 53, 429-434, 1973. 
- Khan, S. U., Environ. Lett., 4, 141-148, 1973a

- Knowles, F.; Marsh, D.; Rattle, H. W. E., "Magnetic Resonance of Biomolecules: an Introduction to the Theory and Practice of NMR and ESR in Biological Systems", London, John Wiley, 1976.

- Luchini, L. C., “Adsorção-dessorção dos herbicidas paraquat, diuron e 2,4-D em seis solos brasileiros", ESALQ, USP, dissertação, 1987.

- McMillan, J. A., "Paramagnetismo Eletrônico", The General Scretariat of the Organization of American States Washington, DC.

- Martin-Neto, L.; Nascimento, O. R.; Talamoni, J.; Poppi, N. R., Soil Science, 51, 369$376,1991$.

- Martin-Neto, L.; Vieira, E. M.; Sposito, G., Environ. Sci. Technol., 20(20), 1994.

- Moreale, A.; Van Bladel, R., J. Environ. Qual., 9(4), 627-633, 1980.

- Orgel, L., "Introdução a Química dos Metais de Transição", Ed. Edgard Blucher, 1960.

- Niemeyer, J.; Chen, Y.; Bollag, J. -M., Soil Sci. Soc. Am. J., 56, 135-140, 1992.

- Orlov, D. S., "Humus Acids of Soils: Infrared Spectra of Humus Acids", A. A. Balkema/Rotterdam, 1985.

- Pake, G. E., "Paramagnetic Resonance: an Introductory Monograph", W. A. Benjamin, Inc., 1962. 
- Perdue, E. M.; Wolfe, N. L., Environ. Sci. Technol., 16, 847-857, 1982.

- Pesce, A. J.; Rosen, C G.; Pasby, T. L., "Fluorescence Spectroscopy: an Introduction for Biology and Medicine", Ad. Marcel Dekker, Inc., 1971.

- Pinheiro, A. C.; Monteiro, A. L., "Ciências do Ambiente: Ecologia, Poluição e Impacto Ambiental", ed. Mc Graw Hill, 1ํe ed., 1992.

- Pivetz, B. E.; Steenhuis, T. S., J. Environ. Qual., 24, 564-570, 1995.

- Primavesi, A., “A Agricultura em Regiões Tropicais: Manejo Ecológico do Solo”, ed. Nobel, $9^{\mathrm{a}}$ ed., 1990.

- Poole, C. P., "Electron Spin Ressonance: a Comprehensive Treatise on Experimental Techniques", New York, Interscience, 1967.

- Poppi, N. P., "Estudos dos ácidos húmicos e fúlvicos, extraídos de solos por métodos químicos e espectroscópicos - separação e identificação de seus produtos de oxidação por CG/EM", IQSC, USP, dissertação, 1988.

- Ranzani, G., “Manual do Levantamento de Solos”, ed. Edgard Blücher ltda, 1969.

- Rifaldi, R.; Schinitzer, M., Soil Sci. Sco. Am. Proc., 트, 1972.

- Russel, E. W., "Soil Condition and Plant Growth", ed. Longmans Green, New York, $10^{\mathrm{a}}$ ed., 1973.

- Sanches, R., "Fourier transform infrared spectroscopy of photoreceptor membrane films", Boston University Graduate School, tese, 1982. 
- Sawhney, B. L.; Brown, K., "Reactions and Movement of Organic Chemicals in Soils", SSSA Special Publication Number 22, 1989.

- Schnitzer,H. -R.; Khan, S. U., Soil Organic Matter, Amsterdan, Elsevier, 1978.

- Schulten, H.-R.; Plage, B.; Schnitzer, M., Naturwissenschaften, 78, 1991.

- Schulten, H.-R., Fresenius J. Anal. Chem., 73, 351-361, 1995.

- Schulten, H.-R.; Schnitzer, M., Naturwissenschaften, 2, 487-498, 1995.

- Senesi, N., "Methodological Aspects of the Study of Pesticide in soil", cap. "The Role of Humic Substance in the behaviour of Pesticides in Soil: Interactions Involving Free Radical Species”, INRA Versailles, 1988.

- Senesi, N., The Sci. of the Total Environ., Elsevier Science Publishers B. V., 123-124, 1992.

- Senesi, N.; Testini, C., Soil Sci., 130(6), 314-320, 1980.

- Singer, R. H., Physical Review, 99(4), 222-226, 1955.

- Spadotto, C. A.; Gomes, M. A. F.; Neves, M. C.; Barreto-Luis, A. J., "Caracterização do uso de agrotóxicos no Brasil: subsídio para o gerenciamento dos riscos ambientais", Congresso Latino Americano de Ciências do Solo, 1996.

- Sposito, G.; Reginato, R. J., "Opportunities in Basic Soil Science Research", Soil Science of America, Inc., Madison, Wisconsin, USA, 1992. 
- Stevenson, F. J., J. Environ. Qual., 1(4), 333-343, 1972.

- Stevenson, F. J., ACS Symp. Ser., 29, 180-207, 1976.

- Struif, B. L.; Weil, L.; Quentin K. E., Wom. Wasser, 45, 53-73, 1975.

- Struve, W. S., "Fundamentals of Molecular Spectroscopy", A. Wiley - Interscience Publication, John Wiley \& Sons, 1989.

- Sun, J.; Pignatello, J. J., J. Agric. Food Chem., 41(2), 1993.

- Takamatsu, T.; Yoshida, T., Soil Sci., 125, 1978.

- Traghetta, D. G., "Estudos espectroscópicos do herbicida picloram em interações com íons metálicos e sob efeito da luz UV-visível”, IFSC, USP, dissertação, 1992.

- Vieira, E. M. , "Estudos da adsorção/desorção do herbicida 2,4-D no solo e nas substâncias húmicas", IQSC, USP, tese, 1996.

- Wang, Z.-D.; Pant, B. C.; Langford, C., Analytica Chimica Acta, 232, 43-49, 1990.

- Warnock, J. W.; Lewis, J., Alternatives, 10(2-3), 1982.

- Wilson, R. G.; Cheng, H. H., J. Environ Qual., 7(2), 281-286, 1978. 